\title{
Insights into the biofilm formation of Bacillus subtilis
}

\author{
Dissertation \\ for the award of the degree \\ "Doctor rerum naturalium"
}

\author{
of the Georg-August-University Göttingen \\ within the doctoral program "Microbiology and Biochemistry" \\ of the Graduate School for Neurosciences, Biophysics, and Molecular Biosciences \\ (GGNB) \\ submitted by
}

Jan Kampf

from Lübbecke

Göttingen, 2018

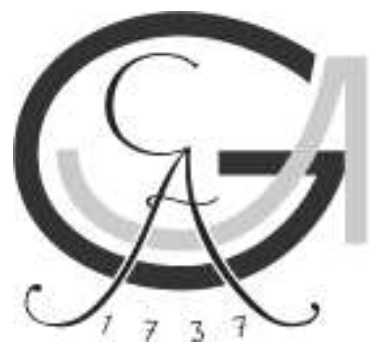





\title{
Thesis Committee
}

Prof. Dr. Jörg Stülke (Supervisor and $1^{\text {st }}$ Reviewer)

Institute for Microbiology and Genetics, Department of General Microbiology, Georg-August-University Göttingen

Prof. Dr. Christiane Gatz ( $2^{\text {nd }}$ Reviewer)

Schwann-Schleiden-Research-Center for Molecular Cell Biology, Department Plant Molecular Biology and Physiology, Georg-August-University Göttingen

PD Dr. Fabian M. Commichau

Institute for Microbiology and Genetics, Department of General Microbiology, Georg-August-University Göttingen

\author{
Additional members of the Examination Board \\ Prof. Dr. Rolf Daniel \\ Institute for Microbiology and Genetics, Department of Genomic and Applied Microbiology, \\ Georg-August-University Göttingen
}

Prof. Dr. Stefan Klumpp

Institute for nonlinear Dynamics, Department of Theoretical Biophysics, Georg-August-University Göttingen

Prof. Dr. Stefanie Pöggeler

Institute for Microbiology and Genetics, Department of Genetics of Eukaryotic Microorganisms, Georg-August-University Göttingen

Date of oral examination: April $5^{\text {th }}, 2018$ 

I hereby declare that this doctoral thesis entitled "Insights into the biofilm formation of Bacillus subtilis" has been written independently and with no other sources and aids than quoted.

Jan Kampf 

"Man sollte immer ein gewisses Understatement wahren!"

Lammbock 



\section{Danksagung}

Zunächst möchte ich mich bei Prof. Jörg Stülke bedanken. Mit seinem Vertrauen, seiner positiven Einstellung, und fachlichen Kompetenz hat er diese Arbeit in diesem Umfang erst möglich gemacht. Vielen Dank geht an Dr. Fabian M. Commichau. Die stets offene Tür, seine ruhige Art, das gute Auge beim Betrachten meiner Ergebnisse und viele gute Ideen, haben maßgeblich zur Arbeit beigetragen. Ein großer Dank geht auch an Frau Prof. Gatz. Ihr kritischer, aber stets konstruktiver Blick und das Interesse an meinen Beobachtungen haben sich ausgezahlt, und zu einer immer besser werdenden Arbeit geführt.

Danke, oder besser: „thank you“ and "merci beaucoup" for the great time in Newcastle upon Tyne in the north of England. Proteins are my friend today. Prof. Rick Lewis, Dr. Robert Cleverley, Dr. Lorraine Hewitt, Dr. Arnaud Basle and Dr. Vincent Rao were great hosts and teachers for me, cheers!

Des Weiteren geht ein großer Dank an Dr. Miriam Dormeyer, Prof. Alexander Grünberger und Prof. Dietrich Kohlheyer für die Arbeit mit den Microfluidic Chambers am Forschungszentrum Jülich. Ebenso möchte ich mich beim G2L Göttingen, und besonders bei Dr. Andrea Thürmer und Dr. Anja Poehlein bedanken, für viele Sequenzen und Troubleshootings. Ebenfalls ein großer Dank an Fan Chen und Prof. Wolfgang Eisenreich für die schnelle und unkomplizierte Zusammenarbeit bei der Metabolomanalyse.

Ohne Unterstützung im Labor geht nichts. Danke an die Laborfeen Christina Herzberg, Julia Busse, Sabine Lentes, sowie Silvia Carrillo-Castellón, die alle durch Know-How, Ideen und Zuarbeit mich unglaublich unterstützt haben. Des Weiteren möchte ich mich bei meinen Masterstudenten und HiWis bedanken. Laura Griese, Verena Siebert, Simon Wölfel und Philipp Mroch. Ihr wart eine tolle Unterstützung. Weiterer Dank für tolle Ideen und ein offenes Ohr geht an Anika Klewing, Dr. Nora Cascante-Estepa und Dr. Katrin Gunka, als tolle Laborkolleginnen mit Rat und Tat. Tausend Dank auch an den Rest der ganzen AG Stülke und HIF. Es war eine manchmal anstrengende, aber tolle Zeit. Ich freue mich die letzten Jahre hier in Göttingen am Nerd-Campus mit euch verbracht, und das ein oder andere Kaltgetränk mit euch genossen zu haben.

Danke an meine WG die G10 und meine zweite Heimat die L5, die Kazzen Kru, sowie alle anderen Freunde für die Unterstützung, den Ausgleich neben der Arbeit und die Zeit beim Grillen, Feiern und Chillen. Ebenso ein dicker Dank an das Rugbyteam vom SC Weende für die Möglichkeit meinen Laborfrust bei euch zu kompensieren und diesen wunderbaren Sport auszuüben. Früher wart Ihr mal cooler! Das Studium ist die beste Zeit des Lebens, und ihr alle habt sie mir unglaublich versüßt.

Zu guter Letzt, danke Mama, danke Ines, danke Anita und danke an den ganzen Rest der „buckeligen“ Verwandtschaft. Ihr seid toll und immer für mich da. Ohne euch wäre es nicht gegangen. 

Content

List of publications................................................................................................................ III

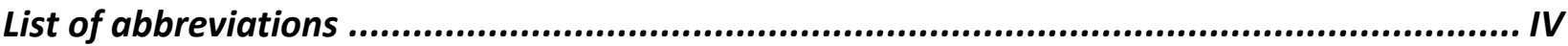

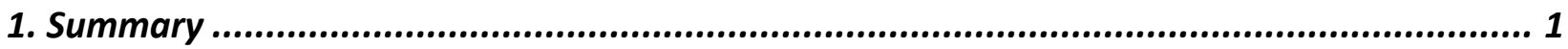

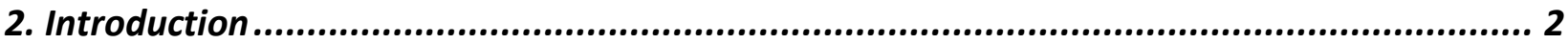

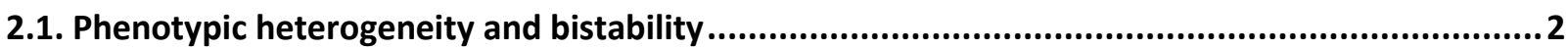

2.2. Phenotypic heterogeneity in B. subtilis with focus on motility and biofilm formation................6

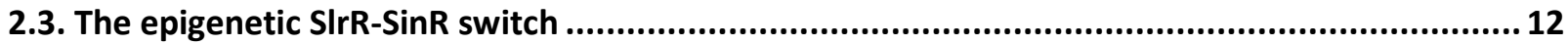

2.4. The $y m d B$ mutant and the role of the phosphodiesterase YmdB in biofilm formation ..............14

2.5. The potential role of RNA-binding protein SpoVG in biofilm formation ...............................17

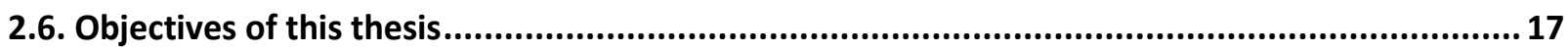

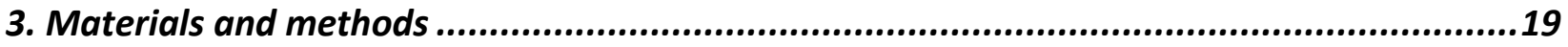

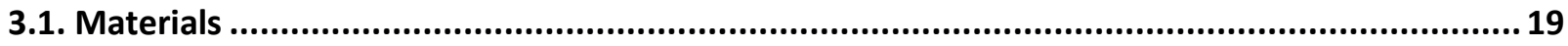

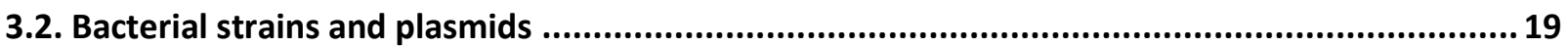

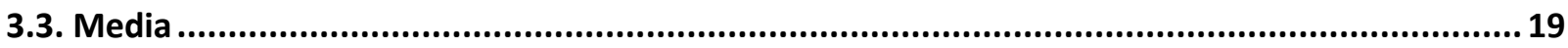

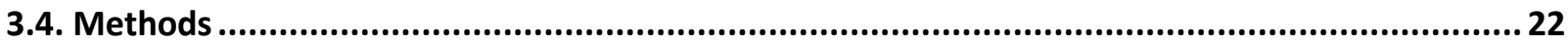

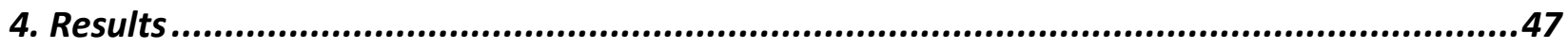

4.1. Elevated SinR levels are responsible for the biofilm defect in the $y m d B$ mutant .....................47

4.2. Analysis of translational activity and protein stability of $\operatorname{Sin} R$ in the $y m d B$ mutant..................49

4.3. Influence of the $5^{\prime}$ UTR of $\sin R$ on biofilm formation in the wild type and the $y m d B$ mutant.....51

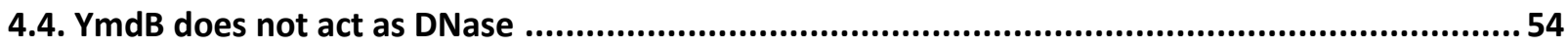

4.5. Identification of potential RNA interaction partners of YmdB and its influence on biofilm

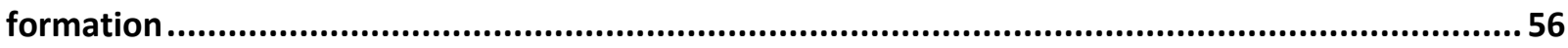

4.6. Influence of SpoVG on biofilm formation and fishing for potential RNA binding partners of the

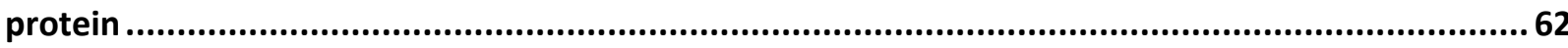


4.7. Analysis of lifestyle decisions from $B$. subtilis on single cell level in real-time

4.8. Characterization of the influence of $\operatorname{Sin} R$ mutations found in $y m d B$ suppressors on DNA binding, oligomerization and binding to its antagonist Sinl.

4.9. Sample preparation for metabolome flux analysis of wild type, biofilm producers and non-biofilm producers

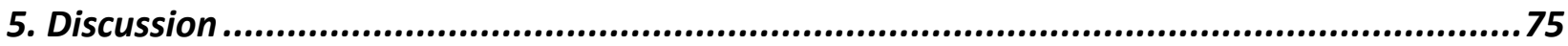

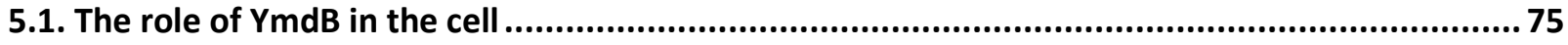

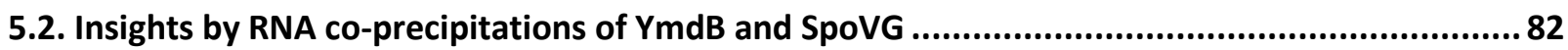

5.3. Selective pressure in the $y m d B$ mutant and the dynamic decision-making in real-time............ 84

5.4. The impact on protein functions of mutations in $\operatorname{Sin} R$ mutants found in $y m d B$ suppressors...... 85

5.5. Outlook .88

6. References. .90

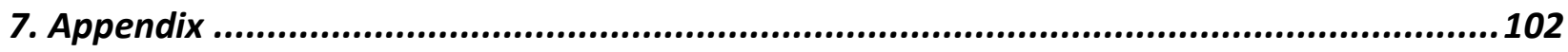

7.1. Conservations of SpoVG and location of mutations during cloning..................................... 102

7.2. Bacterial strains 103

7.3. Oligonucleotides 106

7.4. Plasmids 112

7.5. Chemicals, utilities, equipment, antibodies, enzymes, software, and webpages. 114

7.6. Curriculum vitae. 121 


\section{List of publications}

During this thesis

Kampf, J., Gerwig, J., Kruse, K., Cleverley, R., Dormeyer M., Grünberger, A., Kohlheyer, D., Commichau, F. M., Lewis, R. J., and Stülke, J. (2018) Selective pressure for biofilm formation in Bacillus subtilis: differential effect of mutations in the master regulator SinR on bistability. Submitted.

Kampf, J., Gundlach, J., Herzberg, C., Treffon, K., and Stülke, J. (2017) Identification of c-di-AMP-binding proteins using magnetic beads. Methods Mol Biol 1657: 347-359.

Kampf, J., and Stülke, J. (2017) Cyclic-di-GMP signalling meets extracellular polysaccharide synthesis in Bacillus subtilis. Environ Microbiol Rep 9: 182-185.

Gundlach, J., Mehne, F.M.P., Herzberg, C., Kampf, J., Valerius, O., Kaever, V., and Stülke, J. (2015) An Essential poison: synthesis and degradation of cyclic di-AMP in Bacillus subtilis. J Bacteriol 197: 3265-3274.

Kampf, J., and Stülke, J. (2015) Minor cause--major effect: a novel mode of control of bistable gene expression. PLoS Genet 11: e1005229

Gundlach, J., Dickmanns, A., Schröder-Tittmann, K., Neumann, P., Kaesler, J., Kampf, J., Herzberg, C., Hammer, E., Schwede, F., Kaever, V., Tittmann, K., Stülke, J., and Ficner, R. (2015) Identification, characterization, and structure analysis of the cyclic di-AMP-binding PII-like signal transduction protein DarA. J Biol Chem 290: 3069-3080.

Before this thesis

Jedrusik-Bode, M., Studencka, M., Smolka, C., Baumann, T., Schmidt, H., Kampf, J., Paap, F., Martin, S., Tazi, J., Müller, K.M., Krüger, M., Braun, T., and Bober, E. (2013) The sirtuin SIRT6 regulates stress granule formation in C. elegans and mammals. J Cell Sci 126: 5166-5177. 


\section{List of abbreviations}

\begin{tabular}{|c|c|}
\hline$\%(v / v)$ & $\%$ (volume/volume) \\
\hline$\%(w / v)$ & $\%$ (weight/volume) \\
\hline A/Ala & alanine \\
\hline AA & amino acid \\
\hline Amp & ampicillin \\
\hline AMP & adenosine monophosphate \\
\hline AP & alkaline phosphatase \\
\hline APS & ammonium persulfate \\
\hline B. & Bacillus \\
\hline bis- $p N P P$ & bis-para-nitrophenylphosphate \\
\hline C/Cys & cysteine \\
\hline CAA & casamino acid \\
\hline cAMP & cyclic adenosine monophosphate \\
\hline cat & chloramphenicol resistance cassette \\
\hline CCR & combined-chain reaction \\
\hline c-di-AMP & cyclic diadenylate monophosphate \\
\hline c-di-GMP & cyclic diguanosine monophosphate \\
\hline CFP & cyan fluorescent protein \\
\hline cGAMP & cyclic guanosine monophosphate-adenosine monophosphate \\
\hline cGMP & cyclic guanosine monophosphate \\
\hline chromDNA & chromosomal DNA \\
\hline deion & deionized \\
\hline DMSO & dimethyl sulfoxide \\
\hline DNA & deoxyribonucleic acid \\
\hline DNAse & deoxyribonuclease \\
\hline dNTPs & deoxyribose nucleoside triphosphates \\
\hline DTT & dithiothreitol \\
\hline E. & Escherichia \\
\hline e.g. & lat. for example \\
\hline E/Glu & glutamic acid \\
\hline EDTA & ethylenediaminetetraacetic acid \\
\hline EMSA & electrophoretic mobility shift assay \\
\hline EPS & exopolysaccharides \\
\hline
\end{tabular}




\begin{tabular}{|c|c|}
\hline et al. & lat. and others \\
\hline F/Phe & phenylalanine \\
\hline FACS & fluorescence-activated cell sorting \\
\hline Fig. & figure \\
\hline fwd & forward \\
\hline GFP & green fluorescent protein \\
\hline Glc & glucose \\
\hline GTP & guanosine triphosphate \\
\hline $\mathrm{H}$ & hydrogen \\
\hline $\mathrm{H}_{2} \mathrm{O}$ & water \\
\hline HTH & helix-turn-helix \\
\hline IPTG & isopropyl $\beta$-D-1-thiogalactopyranoside \\
\hline K/Lys & lysine \\
\hline Kan & Kanamycin \\
\hline $\mathrm{kb}$ & kilo base pairs \\
\hline L/Leu & leucine \\
\hline lat. & latin \\
\hline LB & lysogeny broth (medium) \\
\hline LFH & long flanking homology \\
\hline$L$. & Listeria \\
\hline mRNA & messenger RNA \\
\hline mut & mutated \\
\hline $\mathrm{N}$ & nucleotide \\
\hline NPKM & $\begin{array}{l}\text { normalized reads for nucleotide activities per } \\
\text { kilobase of exon model per million mapped reads }\end{array}$ \\
\hline NTP & nucleotide triphosphates \\
\hline$O D_{x}$ & optical density, $\lambda=x \mathrm{~nm}$ \\
\hline ORF & open reading frame \\
\hline$P$ & phosphoryl group \\
\hline P/Pro & Proline \\
\hline PAGE & polyacrylamide gel electrophoresis \\
\hline PBS & phosphate buffered saline \\
\hline $\mathrm{PCl}$ & phenol:chloroform:isoamylalcohol \\
\hline PCR & polymerase chain reaction \\
\hline $\mathrm{pH}$ & power of hydrogen \\
\hline PNAG & poly- $N$-acetylglucosamine \\
\hline
\end{tabular}




\begin{tabular}{|c|c|}
\hline (p)ppGpp & $\begin{array}{l}\text { guanosine 3'-pyrophosphate } 5^{\prime} \text {-triphosphate; } \\
\text { guanosine } 3^{\prime}, 5^{\prime} \text {-bispyrophosphate }\end{array}$ \\
\hline PVDF & polyvinylidene difluoride \\
\hline$P_{x x x}$ & promoter from gene $x x x$ \\
\hline $\mathrm{Q} / \mathrm{G} \ln$ & glutamine \\
\hline qRT-PCR & quantitative reverse transcription PCR \\
\hline $\mathrm{R} / \operatorname{Arg}$ & arginine \\
\hline RBS & ribosomal binding site \\
\hline rev & reverse \\
\hline RNA & ribonucleic acid \\
\hline RNase & ribonuclease \\
\hline RNAseq & RNA sequencing \\
\hline rpm & rounds per minute \\
\hline rRNA & ribosomal ribonucleic acid \\
\hline RT & room temperature \\
\hline S/Ser & serine \\
\hline SDS & sodium dodecyl sulfate \\
\hline SEC-MALS & size exclusion chromatography multi-angle light scattering \\
\hline sRNA & small regulatory RNA \\
\hline T/Tyr & tyrosine \\
\hline Tab. & table \\
\hline Tet & tetracycline resistance cassette \\
\hline tRNA & transfer-RNA \\
\hline$U$ & units \\
\hline $\mathrm{W} / \operatorname{Trp}$ & tryptophan \\
\hline wt & wild type \\
\hline YFP & yellow fluorescent protein \\
\hline ZAP & Zellaufschluss-Puffer \\
\hline$\sigma$ & sigma factor \\
\hline
\end{tabular}

\section{Prefixes}

UTR

untranslated region

M

Mega

K

Kilo

m

milli

$\mu$

micro 
$\mathrm{p}$

Nucleotides

A

C

G

$\mathrm{T}$

U

R

Y

\section{Units}

$\%$

${ }^{\circ} \mathrm{C}$

$\lambda$

bp

D

g

g

h

I

m

$\min$

mol

M

psi

$\mathrm{S}$

U

V nano

pico

adenosine

cytosine

guanosine

thymine

uracil

purine base (adenosine or guanosine)

pyrimidine base (cytosine or thymine) 



\section{Summary}

Bacillus subtilis forms highly structured biofilms to protect itself against harmful environments, and to have an advantage in the competition with other species. The cells of $B$. subtilis that secrete the biofilm matrix, express genes involved in synthesis of exopolysaccharides (EPS) and the protein components of the matrix. The regulation of the transition from matrix production to motility is governed by the epigenetic SIrR-SinR switch. The deletion of the phosphodiesterase YmdB leads to total lack of biofilm formation, the repression of the SinR regulon, and to enhanced expression of the $\sigma^{\mathrm{D}}$ regulon. However, the molecular mechanisms by which $\mathrm{YmdB}$ is involved in the regulation of these developmental states still need to be elucidated, which was the aim of this thesis. We used different approaches to characterize the function of YmdB. We could show that the deletion of $y m d B$ results in increased amounts of the master regulator $\operatorname{Sin} R$ in the cell, leading to permanent repression of matrix genes. In addition, we investigated possible mechanisms by which $Y m d B$ could regulate SinR amounts in the cell. YmdB might function via impeding the access of the ribosome to its initiation site of the $\sin R$ transcript. Another approach to characterize the function of $Y m d B$, was the identification of RNA interaction partners of the potential RNAbinding protein. Genes encoding for the potential interacting RNAs were tested for their impact on biofilm formation. The selected targets differently affected the biofilm formation but did not restore biofilm formation in the $y m d B$ mutant nor did they result in loss of biofilm formation in the wild type. YmdB probably does not act via interaction with one specific RNA. Furthermore, the $y m d B$ mutant forms quickly suppressor mutants, which harbor mainly mutations in SinR. We biochemically characterized several mutations for their impact on DNA- and protein interaction as well as on oligomerization state of SinR. Hereby, we could underline the importance of different residues of the protein for DNA binding, interaction with its antagonist $\operatorname{Sinl}$ and the formation of the SinR tetramer. Aside from that, we documented the dynamics of gene expression patterns in wild type and ymdB mutant cells by microfluidic analysis coupled to time-lapse fluorescence microscopy. Our results confirm the bistable character for motility and matrix genes expression, as well as the quick introduction of suppressor mutations in the $y m d B$ mutant, restoring matrix gene expression. Additionally, we analyzed the effect of the deletion of the RNA-binding protein SpoVG on biofilm formation and could detect an extended spreading of the macrocolony especially in combination with the deletion of the master regulator of biofilm formation, SinR. Additionally, SpoVG interacts with many RNAs, which indicates that SpoVG might has a global function as RNA-binding protein in B. subtilis. This work focused on the regulation and characterization of biofilm formation. We could specify the effect of YmdB on the homeostasis of the epigenetic SIrR-SinR switch for motility and biofilm formation, as well as the role of SpoVG as RNA-binding protein in B. subtilis. 
Introduction

\section{Introduction}

Bacteria express different sets of genes to deal with various situations. The expression of different gene sets allows bacteria to enter different developmental programs, which are advantageous in various circumstances. Microorganisms evolved a tightly regulated lifestyle, which is the predominant lifestyle of most microorganisms on earth, and is called a biofilm (Davey and O'toole, 2000; Mielich-Süss and Lopez, 2014). This pellicle-like or sessile lifestyle allows microorganisms to live on nearly all surfaces and liquids. They adhere to natural surfaces such as rocks, or the roots of plants, live as sediments in harmful, acidic lakes, or just as plaque on the teeth of every one of us (Kolenbrander and London, 1993; Amellal et al., 1998; Lünsdorf et al., 2002). They also inhabit artificial surfaces such as the inner surface in water pipes (Yu et al., 2010). Biofilm are cells embedded in a self-produced matrix made of majorly extracellular polysaccharides and proteins. Only a subpopulation of the cells embedded in a biofilm, called matrix producers, secretes these components that stick the cells to each other (Vlamakis et al., 2013). Living in a spatially structured environment such as a biofilm is advantageous for bacteria. The biofilm gives the opportunity to share common goods such as toxins against other bacteria or further collectively used proteins, to acquire transmissible, genetic elements by horizontal gene transfer, and to develop a higher resistance against toxic or harmful substances such as detergents or antibiotics by the physical barrier of the secreted matrix (Watnick and Kolter, 2000). The decision of a cell to become a matrix producer, is a decision for the induction of a specific genetic and metabolic program of the cell, while other cells in the community express another genetic program to fulfill further important functions such as becoming resistant persister cells, to guarantee the survival of the population (Ackermann, 2015). The occurrence of "nonconformist" cells within an isogenic population is phenotypic heterogeneity (Grote et al., 2015).

\subsection{Phenotypic heterogeneity and bistability}

Phenotypic heterogeneity defines the occurrence of "nonconformist" individuals within an isogenic population. The individual cells show an expression profile partially different from that of the rest of the population (Grote et al., 2015). Bacterial cells integrate signals through the environment; communicate these signals among each other leading to a collective decision-making for every cell in the view of growth, movement and metabolic activities. Isogenic cells can choose between different lifestyles to answer in a proper manner to various situations. 
The term bistability is often used to describe the developmental state of a cell. Bistable is the status of a network with two steady states or in biological systems, two distinguishable phenotypes within a clonal population (Veening et al., 2008b). On the level of a bacterial community, a switch-like behavior can lead to bimodal distributions in gene expression because some cells enter a genetic program, whereas others do not (Dubnau and Losick, 2006; Smits et al., 2006). Bistability depends on unimodal noise in the expression of a master regulatory gene. A cell passes a threshold in expression of this master regulator gene, the quantitative change converts to a qualitative change and a new expression pattern emerges: the cell community diverges into coexisting lifestyles. Bistability describes, that a regulatory system can switch between two alternative states but does not stay at intermediate states.

\section{Causes for phenotypic heterogeneity}

Causes that trigger phenotypic heterogeneity (see Fig. 1), molecular mechanisms, and different examples and the benefits for phenotypic heterogeneity in bacteria, shall be elucidated in the following part of this work.

Availability of nutrients, presence of molecules such as antibiotics, temperature and far more signals are sensed by a bacterial cell. A bacterial culture or a macrocolony is affected by environmental factors, which do not homogeneously reach each cell and trigger equally the expression of genes in the cells of a community. Environmental gradients or fluctuations of molecules can be seen as different signals in a culture (Elowitz et al., 2002; Blake et al., 2006; Süel et al., 2007). For example, biofilms form an environment, which shows differences in the access of oxygen (Beer et al., 1994).

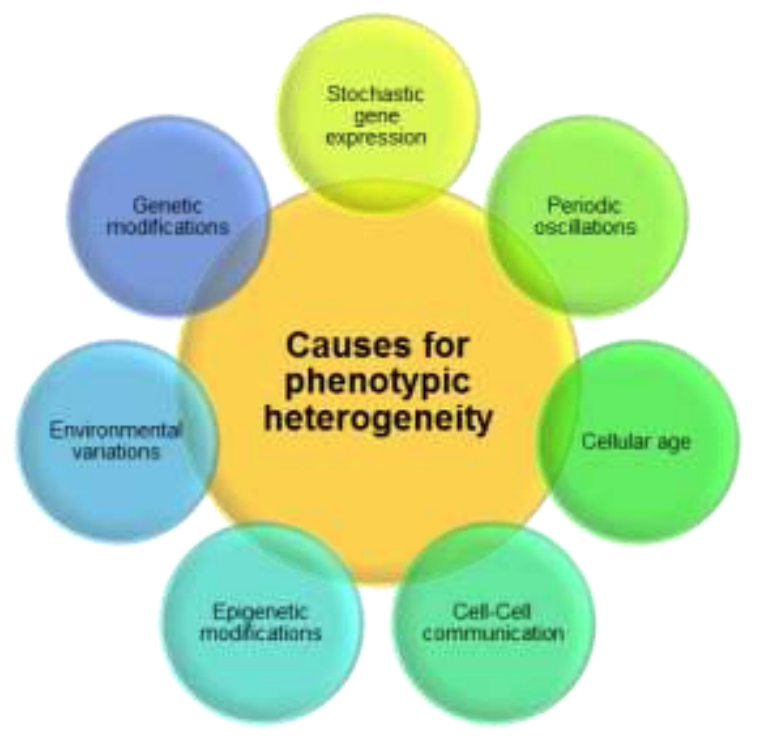

Figure 1 Overview of causes for phenotypic heterogeneity. 
Introduction

Another factor for different gene expression patterns are genetic modifications such as gene amplifications, loss of function or gain of function mutations. These events can lead to varying gene expressions of an individual cell or subpopulation in a culture (Hallet, 2001; Darmon and Leach, 2014).

Stochasticity in molecular mechanisms is triggered by stochastic gene expression (Elowitz et al., 2002; Blake et al., 2006; Süel et al., 2007), as well as by stochastic partitioning of molecules during cell division (Schwabe and Bruggeman, 2014). The consequence for the molecular composition of the cell and its phenotype is a variation over time and between individual cells in a culture. An example for stochastic gene expression was given by experiments with $E$. coli. A cyan fluorescent and a yellow fluorescent protein was fused to lactose promoters and integrated into the genome of the bacterium. Since both reporter fusions were controlled by the same promoter, the expectation was an equal expression of both constructs. It was observed that the fluorescence differed in absolute fluorescence levels and the ratio of the fluorescence signals in the cells (Schwabe and Bruggeman, 2014).

Periodic oscillation is another mechanism, which leads to different phenotypic states in a microbial culture. Examples for periodic oscillation is the cell cycle (Levine et al., 2013) or the switch between the two incompatible metabolic processes in cyanobacteria: nitrogen fixation and photosynthesis, since the nitrogenase is inhibited by molecular oxygen that is produced by photosynthesis (Misra and Tuli, 2000; Berman-Frank et al., 2003).

Age-dependent phenotypic heterogeneity is described for bacteria such as Methylobacterium extorquens (Bergmiller and Ackermann, 2011). In an experiment were individuals of $M$. extorquens monitored in clonally growing population over time. The pole age, cell size and interdivision intervals of individual cells were observed. Cell size and timing of cell division varied between different individuals. It was found, that increasing pole age correlated with increased cell size and decreasing of the intervals between cell divisions (Bergmiller and Ackermann, 2011).

Phenotypic heterogeneity is also achieved by cell-cell interactions by diffusible molecules (Snijder et al., 2009; Reuven and Eldar, 2011). It is most likely that "decisions" for the individual cell fate are influenced by the phenotypes of other cells in the environment. Signals from one subpopulation of cells can influence the expression of many genes in another subpopulation. Quorum sensing is one of the most studied mechanisms for intercellular adaptation of gene expression inter and intra species (Waters and Bassler, 2005). For example, $B$. subtilis uses quorum sensing to regulate the initiation of competence using the ComX pheromone (Magnuson et al., 1994; Solomon et al., 1995).

Epigenetic modifications such as DNA methylation and variations of histone composition and can be responsible for different expression patterns of genes leading to various cell differentiations. Epigenetic modifications are an important source of phenotypic variations especially in eukaryotes (Avery, 2006). 


\section{Benefits of phenotypic heterogeneity}

Why did bacteria evolve so many mechanisms, which lead to different genetic expression patterns in a clonal culture? There are many benefits of phenotypic heterogeneity (see Fig. 2). i) Bacteria can adapt to dynamic environments by phenotypic heterogeneity. Protective features can be expressed randomly by bacteria to face rapid changes in the environment (Thattai and van Oudenaarden, 2004; Kussell and Leibler, 2005; Wolf et al., 2005; Acar et al., 2008). This bacterial behavior is connected to so called bethedging (Veening et al., 2008b). One prominent example is the development of persister cells in E. coli. E. coli shows different phenotypes with varying resistance against antibiotics. There are normally growing cells and slowly growing persister cells, which have an increased resistance against antibiotics. When this culture is exposed to a strong antibiotic, the majority of the population is killed. When the antibiotic is removed, a small fraction of the cells starts to grow again. These regrown bacteria are as sensitive as before against antibiotic stress and have not evolved an antibiotic resistance (Balaban et al., 2004). The formation of persisters in E. coli has been connected to fluctuations in the expression of an intracellular toxin HipA. Bacteria, which exceed a threshold of HipA become dormant and tolerant to antibiotics (Rotem et al., 2010).

Another benefit is the ii) division of labor for common goods, bacterial communities have an advantage for proliferation, colonizing niches, which need specialized metabolic activities for the access to nutrients or to protect each other against harmful environmental conditions (Shapiro, 1998). For example, starving B. subtilis cells secret subtilisin E. Subtilisin E degrades proteins in the environment and is freely diffusible and all bacteria in a culture profit.

iii) The division of labor overcomes incompatibilities. Another situation, in which phenotypic heterogeneity confers a benefit through division of labor is an environment, in which incompatible cellular processes are required for functional metabolic activity (Ozbudak et al., 2002; Johnson et al., 2012; Lorenzo et al., 2015). Parallel activity of specific processes in individuals is either not possible or not efficient. A prominent example are the incompatible metabolic processes of nitrogen fixation and photosynthesis in cyanobacteria (Misra and Tuli, 2000; Berman-Frank et al., 2003). 


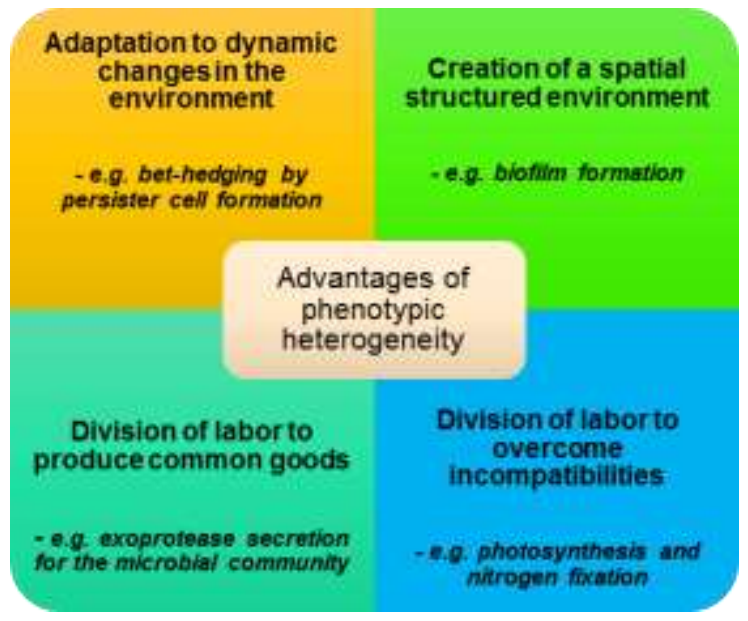

Figure 2 Overview of advantages of phenotypic heterogeneity for a clonal population.

Another advantage of phenotypic heterogeneity is iv) the creation of a spatially structured environment such as a biofilm (Chai et al., 2008; Stewart and Franklin, 2008). The matrix increases the resistance against toxic substances, facilitates the share of genetic information or common goods (Watnick and Kolter, 2000), but also helps to protect a colony against "cheaters". A structured environment can play an important role in protecting clonal cultures from individuals, so-called "cheaters" that only benefit from the division of labor of the community without supporting the population. Such structures as biofilms confines these cheaters, and limit these individuals from becoming the majority of a microbial population. (Nowak and May, 1992; Velicer, 2003).

\subsection{Phenotypic heterogeneity in B. subtilis with focus on motility and biofilm formation}

The Gram-positive bacterium B. subtilis inhabits various environments with varying conditions such as soil, plants and their roots, or intestines of animals (Bais et al., 2004; Barbosa et al., 2005). The bacteria face many different environmental conditions, dynamic changes, and need to sense the respective signals to respond in a proper way. For example, the signal transductions that trigger different lifestyles of $B$. subtilis is achieved majorly via phosphorylation of at least three master regulators for different genetic programs, SpoOA, DegU and ComA and additional by expression of the sigma factor D $\left(\sigma^{D}\right)$ leading to different cell types (see Fig. 3) (López and Kolter, 2010). The three master regulators are activated via phosphorylation. The phosphorylation of a master regulator and the portion of phosphorylated master regulator per cell can lead on the one hand, to the activation of specific differentiation of a cell, while on the other hand, specific cell fates are repressed, leading to a bistable status like "All-or-Nothing" (López and Kolter, 2010). The master regulators are phosphorylated by specific sensor kinases in the presence of different signals (e.g. starvation, or temperature changes). The master 
regulator SpoOA is phosphorylated by at least five sensor kinases (LeDeaux et al., 1995; Jiang et al., 2000a; Jiang et al., 2000b). DegU is phosphorylated by DegS (Msadek et al., 1990; Dahl et al., 1991), and the membrane bound sensor kinase ComP phosphorylates ComA (Weinrauch et al., 1990). Deactivation of the master regulators is achieved by dephosphorylation. The dephosphorylation reaction is performed by in total eleven enzymes called Rap (response-regulator aspartyl-phosphate phosphatases). These enzymes lead to direct or indirect dephosphorylation of the master regulators or bind to a master regulator to inhibit the DNA binding (e.g. RapC, F and G) (Lazazzera, 2001; McQuade et al., 2001; Auchtung et al., 2006).

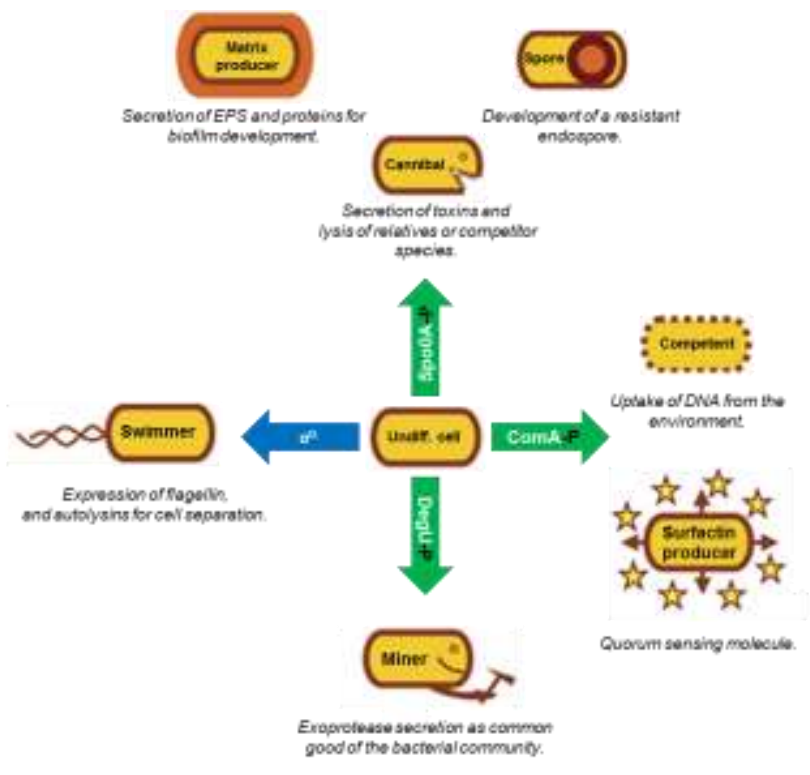

Figure 3 Schematic overview of the distinct cell types that differentiate in $B$. subtilis population. The different cell types are classified into groups, dependent to the master regulator that triggers their development. Arrows indicate the major regulators and the process of differentiation. The black " $P$ " indicates the activation of the regulator by phosphorylation (adapted from López and Kolter, 2010)

The first distinct cell status described for $B$. subtilis was the formation of endospores. Starving B. subtilis cells form dormant endospores only in a subpopulation of cells, while other cells exposed to the same limiting environment do not become spore formers (Freese, 1972; Chung et al., 1994). Spores are resistant structures with no metabolic activities. They store essential proteins and the bacterial DNA for germination when the conditions are improved (Piggot and Hilbert, 2004). A drop of key metabolites like ATP, GTP and charged tRNAs stimulates the phosphorylation of the master regulator SpoOA. High levels of Spo0A-P leads to expression of genes for the formation of endospores, while low to medium levels force matrix production and cannibalism (Kudoh et al., 1984; Fujita et al., 2005). Especially the major sensor kinase KinA senses the metabolic status of the cell and phosphorylates SpoOA to induce sporulation during starvation (Taylor and Zhulin, 1999).

Competence is a developmental program of a cell, in which bacteria can take up external DNA (Dubnau, 1991, 1999). Surfactin producers synthesize the lipopeptide surfactin, which functions as a 
Introduction

quorum sensing molecule. Surfactin triggers matrix production via KinC. Surfactin is sensed as an autoinducer signal to trigger further cells in a community, which do not produce surfactin, to become matrix producers (López and Kolter, 2010). The same genetic cascade initiates competence and surfactin production. Only a small subpopulation of $B$. subtilis cells do express genes for competence development and surfactin by a overcoming a specific ComK concentration threshold in the cell, which is normally permanently degraded (Avery, 2005). Competence is activated via a quorum sensing mechanism by the pheromone ComX, which is sensed by ComP of other cells in the community. ComP activates ComA by phosphorylation. ComA-P leads to the expression of surfactin genes (Nakano et al., 1991a; Nakano et al., 1991b). The surfactin operon harbors also a small sequence encoding the coms peptide. Coms indirectly activates the regulator ComK, which leads finally to competence in B. subtilis (Nakano et al., 1991a; Nakano et al., 1991b; D'Souza et al., 1994; Magnuson et al., 1994; van Sinderen et al., 1995). Surfactin producers can then develop competence. ComK activation is obtained by a bimodal regulation (Smits et al., 2005), that forces a small subpopulation of surfactin producers to develop competence. The trigger for competence is the CSF (derived from the $\mathrm{C}$ terminus of $\mathrm{PhrC}$ ) peptide via quorum sensing. When the concentration of CSF is high enough in the environment, CSF is imported into another cell and binds to RapC. CSF inhibits RapC from dephosphorylation of ComA-P (Lazazzera et al., 1997; Lazazzera et al., 1999).

Cannibalism is next to sporulation a developmental status to face nutrient depletion. A subpopulation of cannibal cells secretes two toxic peptides, Skf and Sdp. Cells, which express these toxins develop an immunity against them. While other cells in the culture are killed and lyse, the cannibal cells can feed on the dead cells, survive the nutritional limitation and postpone the entrance into sporulation (González-Pastor et al., 2003; Ellermeier et al., 2006; Claverys and Håvarstein, 2007). Low levels of Spo0A-P activate the expression of the skfA-H operon, responsible for Skf production. The expression of Sdp toxin is indirectly regulated. The repressor AbrB is repressed by low levels of Spo0A-P, which allows the expression of the $s d p A B C$ operon (Fujita et al., 2005). Interestingly, cannibalism and matrix production are triggered by low levels of Spo0A-P and appear in one subpopulation (López and Kolter, 2010).

Miners are exoprotease producers, which are able to secrete degradative enzymes such as subtilisin, bacillopeptidase or levansucrase into their environment. These enzymes help to degrade proteins and polysaccharides in the extracellular milieu, which can then feed the bacterial community (Msadek et al., 1990; Msadek, 1999). These cells, which secrete degradative enzymes are called "miners", since they produce common goods for the bacterial community (Veening et al., 2008b; Veening et al., 2008a). The sensor kinase DegS phosphorylates DegU (Dahl et al., 1991). DegU-P leads to expression of exoproteases and inhibits motility (Kunst et al., 1994; Amati et al., 2004; Kobayashi, 2007; Verhamme et al., 2007). Another mechanism, which regulates the development of miners, is the quorum sensing 
mechanism forced by the pentapeptide PhrG. High levels of PhrG in the cell surrounding lead to import of the peptide into other cells, where it binds RapG. The interaction of PhrG and RapG leads to inhibition of the phosphatase activity of RapG and subsequently to DegU-P accumulation in the cell, finally leading to the exoprotease synthesis (Ogura et al., 2003).

\section{Formation of motile cells (swimmers)}

Motility is important for cells to leave nutrient depleted environments and to find new nutrient rich niches (Dubnau and Losick, 2006). The flagellum of B. subtilis is necessary for the self-enforced mobility of the bacterium. The formation of motile cells is not dependent on activation of one of the three master regulators ComA, DegU or Spo0A. Motile cells arise when these regulators are inactive at early time points in a growing culture and low cell densities (López and Kolter, 2010).

The development of motile cells is dependent on the fla/che operon. This operon consists of 31 genes encoding factors involved in chemotaxis, autolysis, flagellar and regulatory factors like $\sigma^{D}$, which is the master regulator for motility (Zuberi et al., 1990; Estacio et al., 1998). The sigma factor drives the transcription of genes for flagellum biosynthesis, motility development and autolysins that degrade the cell wall connection of dividing cells (Mirel and Chamberlin, 1989; Márquez et al., 1990; Margot et al., 1999). Four promotors are responsible for the regulation of $\sigma^{D}$. The $y \mid x F$ and $s i g D$ promoters are under the control of $\sigma^{\mathrm{D}}$ itself, leading to autoregulation, while further fla/che and $D-3$ promoters are located upstream of the fla/che operon and controlled by $\sigma^{A}$ (West et al., 2000; Cozy and Kearns, 2010). The antisigma factor FlgM regulates via direct interaction with $\sigma^{\mathrm{D}}$ by inhibiting the association of the sigma factor with the RNA polymerase (Bertero et al., 1999). The flgM gene is also regulated by $\sigma^{\mathrm{D}}$, which is also the target of FlgM inhibition. FlgM expression is forced by the DegU-P, that lowers the threshold of $\sigma^{D}$ at the flgM promoter and flgM expression is prioritized over further members of the $\sigma^{D}$ regulons such as the fla/che operon (Hsueh et al., 2011).

A reporter experiment underlines the bistable character of motile cells. GFP fusions to the promoter of $\sigma^{\mathrm{D}}$ revealed that it is expressed only in part of the population, while the cells that showed no GFP signal formed long chains of non-motile cells (Kearns and Losick, 2005; Dubnau and Losick, 2006). (Trautner and Darouiche, 2004)

\section{Biofilm formation and regulation of matrix production}

Biofilms are communities of microorganisms embedded in a self-produced matrix (Hall-Stoodley et al., 2004; Stewart and Franklin, 2008). The biofilm lifestyle of bacteria confronts humans not only in the laboratory. They can clog pipes and tubing, inhabit indwelling devices like catheters, and lead to an 
Introduction

increased resistance of bacteria against antibiotics (Trautner and Darouiche, 2004; Yu et al., 2010). Biofilms in nature consist often of multiple microbial species, while during infections or in the laboratory, the biofilm is formed by a single species (Watnick and Kolter, 2000; Stoodley et al., 2002). Among the model organisms, $B$. subtilis is as motile, non-pathogenic, Gram- positive, soil-borne bacterium intensively used in studies of biofilms.
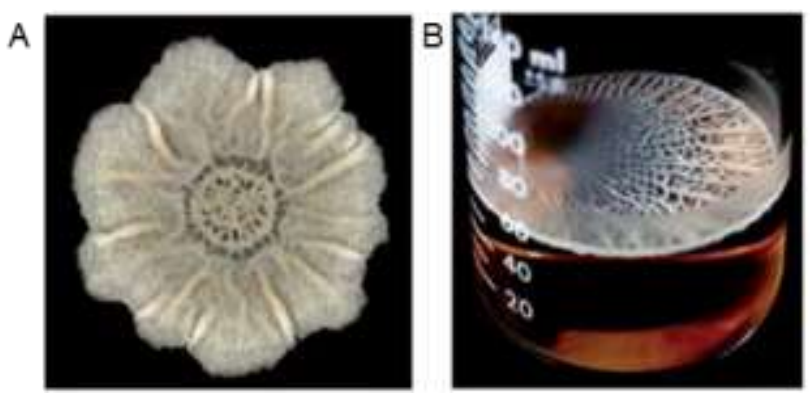

Figure 4 B. subtilis biofilm on agar and pellicle on liquid medium. A) Photograph of a B. subtilis colony grown at room temperature on biofilm-inducing agar (MSgg agar) for 1 week. B) Photograph of a pellicle grown at room temperature for 5 days (photographs from Branda et al., 2001).

The undomesticated B. subtilis strain NCIB3610 develops on special media highly structured floating pellicles that grow on the surface of liquid cultures or as macrocolonies on agar dishes (see Fig. 4A, B) (Branda et al., 2001; Vlamakis et al., 2013). The decreased production of the biofilm matrix in the domesticated 168 B. subtilis strain is dependent on five mutations, which lead to the defect in matrix secretion compared to the undomesticated NCIB3610 strain (Koetje et al., 2003; McLoon et al., 2011a).

Cells, which produce the matrix in which the community is embedded, are only a subpopulation of coexisting cell types in a biofilm (López and Kolter, 2010). The life cycle of a biofilm begins with the differentiation and adhesion of matrix producing cells that form long chains, stop separating and aggregate. The biofilm matures, and the cells still differentiate in their self-produced microenvironment. The development of different cell types is a dynamic process and seems to be an ordered differentiation: motile cells become matrix-producer, which can then develop endospores. Finally, if the nutrition is exhausted, the cells can form spores or differentiate to motile cells to find nutrient richer niches (Vlamakis et al., 2008; Vlamakis et al., 2013).

\section{Composition of the biofilm matrix from $B$. subtilis}

The matrix is essential to the integrity of the biofilm, as it holds the community together and protects the cells against harmful environmental influences (Branda et al., 2005; Flemming and Wingender, 2010; Marvasi et al., 2010). In the laboratory, the structured pellicles or macrocolonies are formed, when cells are grown in biofilm promoting medium and agar plates (MSgg medium and -agar) (Branda et al., 2001). This medium promotes the expression of genes required for extracellular matrix production by a combination of the components glycerol and manganese. These components promote the 
activity of the histidine kinase KinD and subsequently the phosphorylation of the master regulator, Spo0A (Shemesh and Chai, 2013). The secreted matrix of B. subtilis consists mainly of exopolysaccharides (EPS) and proteins. The EPS are mostly synthesized by the 15-gene eps(A-O) operon (Branda et al., 2001; Kearns et al., 2005; Terra et al., 2012). The EPS of B. subtilis consists majorly of poly- $N$-acetylglucosamine (Roux et al., 2015). The $b s / A$ gene and the tapA-sip $W$-tas $A$ operon encode the major proteins of the matrix. Tas $A$ assembles into long amyloid-like fibers (Branda et al., 2006). TapA is responsible for TasA assembly and anchoring to the cell wall (Romero et al., 2011). SipW is the type signal peptidase $\mathrm{W}$ that recognizes a signal sequence of TapA and TasA, cleaves this signal sequence off and secretes the proteins to the outer space of the cell (Tjalsma et al., 1998; Stöver and Driks, 1999a, 1999b). BsIA is the bacterial hydrophobin and responsible for the colony hydrophobicity and its morphology as well as for the floating of the pellicle (Kovács and Kuipers, 2011; Kobayashi and Iwano, 2012).

\section{Regulation of biofilm formation in B. subtilis}

The major regulatory pathway for biofilm formation in B. subtilis is controlled by the Spo0A phosphorelay and the epigenetic SIrR-SinR switch (Vlamakis et al., 2013). Since signal nucleotides play in bacteria an important role in the regulation of matrix gene expression, the specific action of two signal nucleotides and their role in biofilm formation shall be shortly described. Signal nucleotides such as cyclic di-GMP (c-di-GMP) or cyclic di-AMP (c-di-AMP) play a crucial role in adhesion and biofilm formation in various bacteria. In Gram-negative bacteria like E. coli or P. aeruginosa, accumulation of c-di-GMP leads to a block of motility, while the adhesion to surfaces and the matrix gene expression is forced (Kazmierczak et al., 2006; Hengge et al., 2015). C-di-GMP plays in B. subtilis only a minor role in biofilm formation. The intracellular concentration of c-di-GMP is relatively low under standard growth conditions in $B$. subtilis (Gao et al., 2013; Diethmaier et al., 2014). Moreover, it was shown that biofilm formation is not affected by the elevation or drop of the c-di-GMP levels (Chen et al., 2012; Blötz, 2013). However, c-di-GMP might play a role in biofilm formation under stress conditions in $B$. subtilis. The YdaK protein in B. subtilis harbors a PilZ and degenerated GGDEF domain, which is typical for c-di-GMP receptor proteins. It was shown that the putative c-di-GMP binding protein YdaK is involved in extracellular polysaccharide biosynthesis (Gao et al., 2013). The gene encoding for YdaK is located in the $y d a J K L M N$ operon, which also encodes the glycosyltransferase YdaJ and the potential glycosyltransferase YdaM. The expression of the operon leads to increased biofilm formation and altered biofilm structure. The c-di-GMP receptor YdaK proteins essential for the effect on biofilm formation of this complex. C-di-GMP binding to YdaK might stimulate YdaJKLMN activity during EPS synthesis, or processing under special environmental conditions, which could force the production of c-di-GMP (Bedrunka and Graumann, 2017; Kampf and Stülke, 2017). 
Introduction

Moreover, the overproduction of the essential second messenger cyclic di-AMP results in reduced expression of the genes required for matrix production and subsequently to a defect in biofilm formation (Gundlach et al., 2016). C-di-AMP is thought to be involved in cell wall homeostasis and known to limit potassium uptake, which could link c-di-AMP homeostasis and biofilm formation in B. subtilis (Vlamakis et al., 2013; Commichau et al., 2015; Gundlach et al., 2017). Interestingly, it was also shown for Streptococcus mutans, that increased c-di-AMP levels promote biofilm formation (Peng et al., 2016).

The major regulatory pathway for regulation of biofilm formation is the SpoOA phosphorelay. Regulation of matrix production in B. subtilis is achieved by low levels of phosphorylated Spo0A (Fujita et al., 2005; Chai et al., 2008). The phosphorelay starts with phosphorylation of SpoOF by the four kinases KinA-D. SpoOF passes the phosphoryl group to SpoOB. Finally, the phosphoryl group of SpoOB is passed to Spo0A (Perego and Hoch, 1996; Piggot and Hilbert, 2004; Vlamakis et al., 2013). No kinase is solely responsible for matrix production, but rather the contribution of the different kinases changes depending on signals from the environment (López et al., 2009; McLoon et al., 2011b). Low levels of Spo0A-P control indirectly the activity of the master regulator for biofilm formation SinR. SinR represses in a non-matrix producing cell the expression of the eps and tapA-sipW-tasA operons and the expression of its own antagonist SIrR (Kearns et al., 2005; Chu et al., 2006; Chu et al., 2008). Low levels of Spo0A-P lead to the expression of the SinR antirepressor Sinl. How can different levels of phosphorylated SpoOA control expression of different genetic programs? This is achieved by the sin/ promoter region. The promoter of sinl harbors a high-affinity operator and multiple low-affinity operators for Spo0A-P. Low Spo0A-P levels in the cell force the sinl expression by binding the high-affinity operator. When Spo0A-P accumulates, the low-affinity operators are occupied and expression of $\operatorname{sinl}$ is blocked (Chai et al., 2008). Sinl and SinR are very sensitive to expression dose: a doubling of the genes encoding $\sin /$ and $\sin R$ (e.g. during cell division) leads to a complete block the matrix production (Chai et al., 2011).Moreover, another mechanism turns matrix gene off, when sporulation commences. SpoOA-P inhibits the expression of the repressor of matrix genes AbrB (Strauch et al., 1990). AbrB does also repress the eps and tapA-sipW-tasA operons, bs/A and regulatory factors as SIrR and Abh (Hamon et al., 2004; Kearns et al., 2005; Chu et al., 2006; Strauch et al., 2007; Chu et al., 2008; Verhamme et al., 2009).

\subsection{The epigenetic SIrR-SinR switch}

A major stage of regulation of biofilm formation is the epigenetic SIrR-SinR switch, which has two states (see Fig. 5). A low SlrR state leads to motility gene expression, and a high SlrR state leads to matrix gene expression. Sinl achieves this switch between low and high SIrR. The antagonist Sinl is expressed 
under the control of SpoOA-P. Thus, the production of Sinl inhibits SinR activity, and allows SlrR levels to elevate (Vlamakis et al., 2013). When SIrR levels are low in the cell, SinR is free as tetramer (Scott et al., 1999), and $s / r R$ and the matrix genes are repressed. When SlrR levels increase, it binds to SinR. The SinRSIrR heterocomplex titrates SinR away from its DNA binding motifs. The consensus DNA binding motif ( $\sin$ box) of SinR contains a 7-bp sequence (5'-GTTCTYT-3', with Y representing an unspecified pyrimidine base), which can be found in various orientations and variations at SinR operator sites (Chu et al., 2006; Colledge et al., 2011).

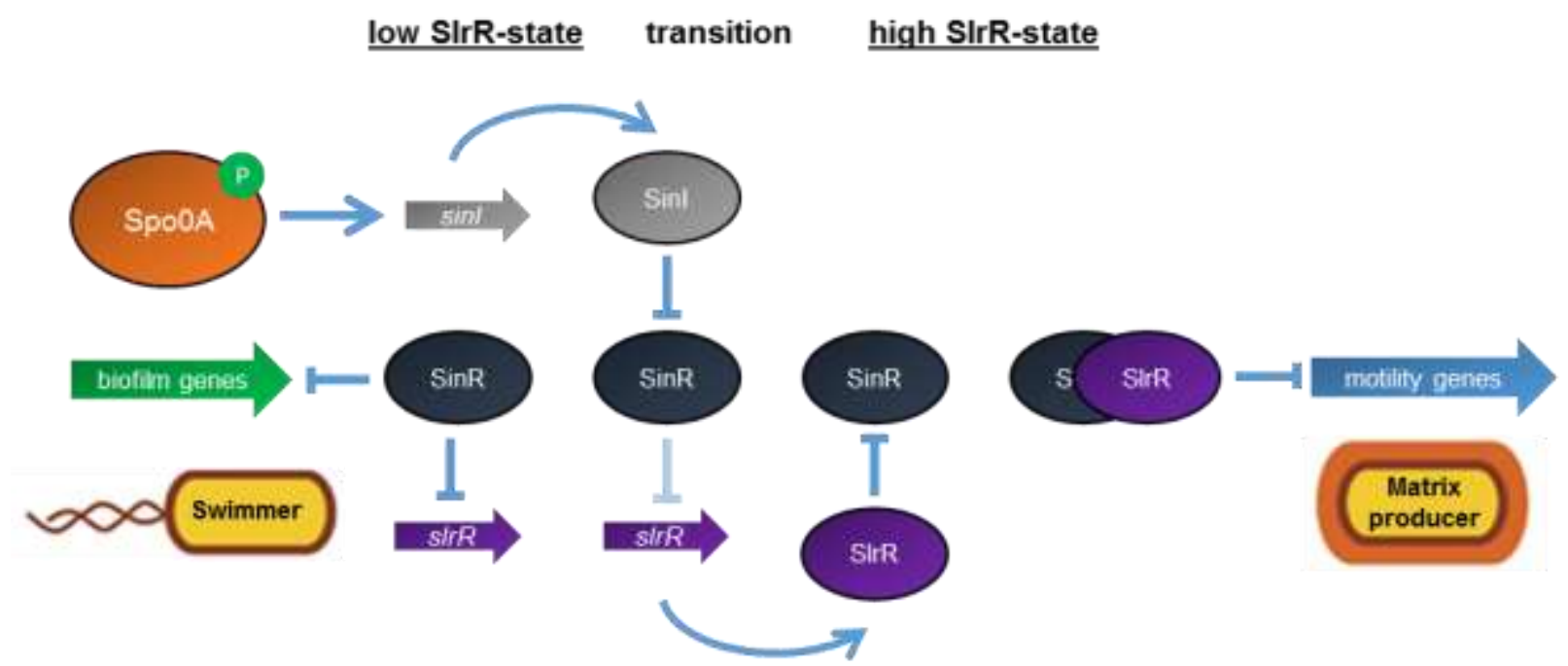

Figure 5 Simplified overview of the regulatory SIrR-SinR epigenetic switch, that controls the shift from motility to biofilm formation in B. subtilis. A double negative feedback loop (involving the s/rR gene, the SIrR protein and the SinR protein) exists in SIrR low (left side of the figure) and SIrR high (right side of the figure) states. Starting with low levels of SpoOA-P, that lead to expression of Sinl, which is a SinR antagonist. This inhibits the repression of $s / r R$ expression and allows the shift from a low SIrR-state to a high SIrR-state. The SinR-SIrR switch regulates biofilm genes (epsA-O and tapA-sipW-tasA operons), motility genes (hag) and autolysin for cell separation (lytABC and lytF). The $s / r R$ gene encodes another antagonist of the $\operatorname{SinR}$, SIrR. When expression of SIrR is low, SinR represses the $s / r R$ gene and the biofilm genes, keeping the levels of the SIrR protein low (left). When SIrR expression is high (right), SIrR binds to SinR, forming the heteromeric SIrR-SinR complex. SIrR repurposes SinR as SIrR-SinR complex to repress motility genes and autolysins (right). SIrR titrates $\operatorname{SinR}$, resulting in derepression of matrix genes and $s / r R$ itself, creating a selfreinforcing switch leading to high SIrR levels. Adapted and modified from López and Kolter, 2010; Vlamakis et al., 2013.

SinR favors binding to inverted repeats of this binding motif (Newman et al., 2013). SlrR has high affinity for SinR and binds to master regulator at equimolar stoichiometry (Chai et al., 2010b; Newman et al., 2013). The formation of the SIrR-SinR complex leads to derepression of the matrix genes and the s/rR gene. This regulatory mechanism results in a self-reinforcing double-negative feedback loop. SIrR expression 
Introduction

blocks also SinR activity, leading also to derepression of SinR target genes. When SlrR levels are high, the matrix genes are expressed, since free $\operatorname{SinR}$ levels are low. As the SIrR-SinR complex, SIrR re-purposes $\operatorname{SinR}$ to repress the promoters for hag (encoding flagellin) and lytA-C, $F$ (encoding autolysins, involved in cell separation) (Chai et al., 2010b; Chai et al., 2010a). The SIrR-SinR complex was shown to cover the promoter of IytABC. The genomic region harbors two putative SinR operator sites: one with a single-base-pair mismatch to the 7-bp sin box "GTTCTTT", and another one with a 2-bp mismatch. Additionally, there are two identical 7-bp repeat sequences present with the sequence "AATATAA". It is proposed that two protomers of SIrR probably bind to the repeated "AATATAA" sequences, and two protomers of SinR bind to the two SinR-like binding motifs (Chai et al., 2010b).

The switch back to derepression of the motility genes and repression of motility genes is probably achieved by self-cleavage of SIrR. SIrR is a member of the LexA family of autopeptidases. These proteins are proteolytically unstable by self-cleavage, and ClpCP protease also contributes to the degradation of SIrR (Chai et al., 2010a).

The deletion of different components of the SIrR-SinR switch shows different phenotypes in view of biofilm formation as well as expression pattern. The deletion of sinl leads to total lack of biofilm formation and suppressors, which restored biofilm formation with mutations in the $\sin R$ gene (Kearns et al., 2005). The deletion of $\sin R$ leads to the formation of a rough and compact macrocolony on biofilm promoting agar, and cell clumping in liquid medium (Kearns et al., 2005; see Results). A slrR mutant develops only smooth colonies on biofilm promoting agar (Pozsgai et al., 2012). Moreover, it was demonstrated, that $\operatorname{SinR}$ expression is bistable in $B$. subtilis. This bistable expression turns to a homogeneous expression in an rny (encoding RNase $\mathrm{Y}$ ) mutant, which also targets the mRNA transcripts of SinR (Lehnik-Habrink et al., 2011).

\subsection{The $y m d B$ mutant and the role of the phosphodiesterase $Y m d B$ in biofilm formation}

The $y m d B$ gene encodes for a phosphodiesterase (a calcineurin-like metallo phosphodiesterase), which is constitutively expressed and located in the same operon, downstream of the rny gene, which encodes for the major endoribonuclease RNase $Y$ in B. subtilis (Lehnik-Habrink et al., 2012; Diethmaier et al., 2014; Zhu and Stülke, 2018). RNase $Y$ and YmdB are not only located in the same operon, they also show physical interaction (Diethmaier, 2011). The deletion of the $y m d B$ gene leads to loss of matrix gene expression and a lack of biofilm formation (see Fig. 6A), and pellicle formation. Fluorescence microscopy with a $\mathrm{P}_{\text {tapA }}-\mathrm{yfp}$ (reporter for matrix genes) and a $\mathrm{P}_{\text {hag }}-c f p$ (reporter for motility genes) constructs showed that matrix genes are not expressed in the $y m d B$ mutant and more cells express the motility genes (see 
Fig. 6A, B). SDS-PAGE and mass spectrometric analysis revealed that the deletion of $y m d B$ leads to a strong overexpression of the Hag protein, which encodes flagellin. Further qRT-PCR showed on the transcriptional level an overexpression of the $\sigma^{\mathrm{D}}$ regulon (hag, $\operatorname{cheV}, \operatorname{mot} A, f l b B$ and $\operatorname{sig} D$ itself) and a down regulation of the SinR regulon (eps, slrR and tasA) (Diethmaier, 2011). A microarray analysis confirmed the results from the qRT-PCR and revealed that 800 mRNAs are affected by the deletion $y m d B$. The $\sigma^{\mathrm{D}}$-dependent motility regulon expression was increased more than 10 -fold as well as the SinR regulon equally repressed. Another group of operons involved in sugar utilization and sporulation showed also increased expression.

An orthologue of YmdB is found in Listeria monocytogenes seems to be involved in virulence, but the mechanism still needs to be elucidated (Zemansky et al., 2009). Furthermore, $44 \%$ sequence identity was determined to DR1281, a 2',3'-cyclic AMP phosphodiesterase from D. radiodurans (Shin et al., 2008). The crystal structure of $\mathrm{YmdB}$ was solved for a better understanding of the protein function. The obtained structure resembled the fold of a calcineurin-like metallo phosphodiesterase with a dimetal cluster in the active center. Size exclusion chromatography and the crystal structure reveals that YmdB naturally forms a tetramer by a dimer of dimers. The phosphodiesterase activity was determined using the artificial substrate bis-para-nitrophenylphosphate. The enzyme was positively tested for degradation of cyclic AMP (cAMP) and cyclic GMP (cGMP). The activity against cAMP and cGMP was relatively low but still in the range of known phosphodiesterases targeting these signal molecules. Strikingly, the enzymatic activity of YmdB is important for its role in the cell and the biofilm formation. The glutamate at position 39 in the catalytic center of YmdB was exchanged for a glutamine, leading to the loss of the enzymatic activity. This mutation was introduced in the genome of $B$. subtilis and showed a defect in biofilm formation and similar micro array changes as a ymdB deletion mutant (Diethmaier et al., 2014).

Interestingly, the determination of cAMP pools in $y m d B$ deletion mutants compared to wild type strains are contradictory. Mamou and colleagues showed that unspecified cAMP pools are increased in the $y m d B$ mutant using an ELISA assay (Mamou et al., 2016), while Kruse did not observe changes in the 2,3'-cAMP pools in the $y m d B$ mutant using a mass spectrometric approach (Kruse, 2013). Determination of c-di-AMP and c-di-GMP pools revealed no change of c-di-AMP concentration and, counterintuitively for a phosphodiesterase deletion mutant, the c-di-GMP concentration dropped to nearly zero in the $y m d B$ deletion strain. In addition, YmdB was tested for diguanylate cyclase activity, but no c-di-GMP formation could be detected. Furthermore, in vitro degradation assays with YmdB against c-di-GMP and c-di-AMP showed no traces of degradation products (Diethmaier et al., 2014).

Furthermore, YmdB was shown to be a potential RNA binding protein by EMSAs (electrophoretic mobility shift assay) with RNAs (Gerwig, 2014). Another approach showed, that YmdB is required for the formation of intercellular nanotubes (Dubey et al., 2016). In addition, it is hypothesized that the function 
Introduction

in nanotube formation, is needed in toxin (WapA) and nutrient extraction with other bacteria in a contactdependent manner. Both activities, toxin delivery and nutrient extraction, are abolished in a ymdB deletion mutant (Stempler et al., 2017). The $y m d B$ deletion strain is relatively unstable and forms quickly suppressor mutants that restored matrix gene expression. These suppressors harbored modifications by mutations in the $\sin R$ gene or deletions of the region between yqhH-yqzG (yghG, $\operatorname{sinl}, \sin R, \operatorname{tap} A$-sipW-tasA operon). The mutations in $\sin R$ were found in the HTH-DNA-binding domain and the helical hook, with a hotspot affecting Trp104 in the helical hook (see Fig. 6C) (Kruse, 2013; Gerwig, 2014). Interestingly, a silent mutation of proline at position 42 was also found, and restored biofilm formation (Kruse, 2013).

A

Wild type

$\Delta y m d B$
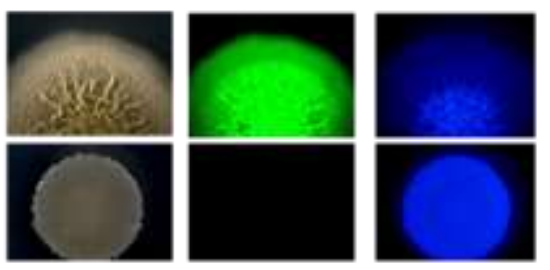

C

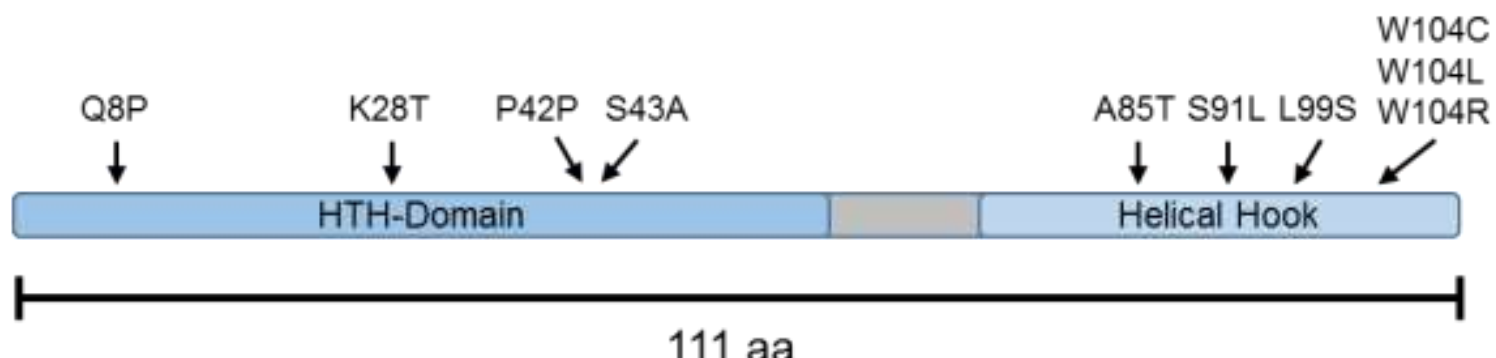

Figure 6 Phenotype of a $y m d B$ mutant and mutations found in SinR in $y m d B$ suppressor. Fluorescence microscopy of wild type and $y m d B$ deletion mutant $A$ ) macrocolonies and $B$ ) single cells. Expression of motility genes are detected by a $\mathrm{P}_{\operatorname{tap} A-} \mathrm{yfp}$ reporter fusion and expression of motility genes are detected by a $P_{\text {hag }}$-cfp fusion (adapted from Diethmaier, 2011 and Gerwig, 2014). C) Schematic overview of mutations in $\operatorname{SinR}$. Each mutation had the power to restore the matrix gene expression in the $y m d B$ deletion mutant. 


\subsection{The potential role of RNA-binding protein SpoVG in biofilm formation}

Another protein, which seems to be involved in biofilm formation, is SpoVG. A deletion of spoVG in $B$. subtilis affects spore formation, leads to altered asymmetric cell septation, and decreases hemolysin production (Segall and Losick, 1977; Rosenbluh et al., 1981; Matsuno and Sonenshein, 1999; Pan et al., 2014). Moreover, it was shown, that the master regulator of biofilm formation, SinR represses spoVG expression (Chu et al., 2006). Interestingly, spoVG is conserved in Gram-positive bacteria (Gupta et al., 2012), but also in nonsporulating bacteria, which led to the assumption, that SpoVG could fulfill more general regulatory functions in the cell (Bischoff et al., 2004). In Staphylococcus aureus, it was shown that SpoVG is involved in methicillin and glycopeptide resistance, and production of extracellular capsular polysaccharide (Schulthess et al., 2009). In Listeria monocytogenes, it was demonstrated that SpoVG is an RNA-binding protein and could have a role as global regulator. SpoVG binds the noncoding RNA Rli31. Furthermore, a spoVG deletion mutant rescued lysozyme sensitivity, pathogenesis and shows no motility (Burke and Portnoy, 2016).

\subsection{Objectives of this thesis}

Decision-making for different lifestyles and especially biofilm formation is essential for $B$. subtilis. It is still not known, how the phosphodiesterase YmdB leads to the lack in matrix gene expression. Already earlier works showed an increased amount of SinR protein in the $y m d B$ deletion mutant as reason for the lack of biofilm formation, but with strong variation and errors. We improved the determination of $\operatorname{Sin} R$ levels and showed in addition the effect of an exogenous overexpression of SinR. Moreover, we analyzed possible stages of post-transcriptional regulation for increased SinR amounts in the $y m d B$ mutant.

As YmdB was identified as phosphodiesterase and its target in the cell responsible for the loss of biofilm formation is not convincingly described yet, we decided to perform an DNase activity assay for YmdB to investigate if the enzyme could act via DNA processing or degradation.

Furthermore, new techniques using microfluidic chambers and fluorescence microscopy allowed us to study the expression of different genetic programs in real-time of single cells for wild type and the $y m d B$ deletion mutant. This allowed us to track cells and monitor proportions of cell types and development of the cells.

The quick introduction of suppressor mutations in $\sin R$, which restore biofilm formation in the non-biofilm forming ymdB mutant, indicates an advantage of the biofilm lifestyle in a bacterial culture. To understand the effect of these mutations found in $\sin R$, we analyzed biochemically five different $\operatorname{Sin} R$ 
Introduction

suppressor variants for the impact of the mutations on DNA binding, protein-protein binding and their oligomerization status.

Moreover, YmdB and SpoVG are potential RNA-binding or processing proteins and possibly involved via this function in biofilm regulation. We decided to perform RNA co-precipitation experiments and subsequent RNA sequencing for identification of possible interactions partners of the proteins. In addition, we tested possible interaction targets of $Y m d B$ by deletion or overexpression of the respective genes encoding enriched RNAs, to investigate the effect on biofilm formation.

Finally, the $y m d B$ mutant and the $\sin R$ mutant have strong phenotypes in biofilm formation in the respective other direction. In collaboration with the group of Prof. W. Eisenreich from the TU Munich, we developed proper labeling, cultivation and harvesting procedure for comparison of fluxes in the core metabolic networks of wild type, planktonic and sessile B. subtilis macrocolonies by gas chromatography/mass spectrometry (GC-MS). 


\section{Materials and methods}

\subsection{Materials}

Chemicals, utilities, equipment, antibodies, enzymes, software, and webpages, are listed in the appendix.

\subsection{Bacterial strains and plasmids}

Bacterial strains, oligonucleotides and plasmids are listed in the appendix.

\subsection{Media}

Buffers, solutions and media were prepared with deionized water and autoclaved $\left(20 \mathrm{~min}\right.$ at $121^{\circ} \mathrm{C}$, and 2 bar), if not other stated. Thermolabile substances were sterilized by filtration.

Bacterial growth media and optional additives

B. subtilis and E. coli was cultured in C-minimal, MSgg (see Biofilm methods) or LB medium, supplemented with additives as indicated. CSE-Glc minimal medium was supplemented with $0.5 \%$ (w/v) glucose (Glc), sodium succinate and potassium glutamate. Further variations of carbon sources are indicated. Basic media were supplemented with $1.7 \%$ (w/v) agar for solidification (Pietack, 2010).

Solutions and media

$\begin{array}{llrl}\text { 5x C-salts (1 I) } & \mathrm{KH}_{2} \mathrm{PO}_{4} & 20 & \mathrm{~g} \\ & \mathrm{~K}_{2} \mathrm{HPO}_{4} \times 3 \mathrm{H}_{2} \mathrm{O} & 80 & \mathrm{~g} \\ & \left(\mathrm{NH}_{4}\right)_{2} \mathrm{SO}_{4} & 16.5 & \mathrm{~g} \\ & & & \\ & & & \\ & & \\ & & \\ & \mathrm{MnSO}_{4} \times 3 \mathrm{H}_{2} \mathrm{O} & 0.232 & \mathrm{~g} \\ & \mathrm{MgSO}_{4} \times 7 \mathrm{H}_{2} \mathrm{O} & 12.3 \mathrm{~g}\end{array}$




\begin{tabular}{|c|c|c|c|}
\hline \multirow[t]{3}{*}{ 10x MN medium (1 I) } & $\mathrm{K}_{2} \mathrm{HPO}_{4} \times 3 \mathrm{H}_{2} \mathrm{O}$ & 136 & g \\
\hline & $\mathrm{KH}_{2} \mathrm{PO}_{4}$ & 60 & g \\
\hline & Sodium citrate $\times 2 \mathrm{H}_{2} \mathrm{O}$ & 10 & g \\
\hline \multirow[t]{6}{*}{ CSE medium (1 I) } & $5 \times C$ salts & 200 & $\mathrm{ml}$ \\
\hline & Tryptophan (5 $\mathrm{mg} \mathrm{m}^{-1}$ ) & 10 & $\mathrm{ml}$ \\
\hline & Ammonium iron citrate $\left(2.2 \mathrm{mg} \mathrm{ml}^{-1}\right)$ & 10 & $\mathrm{ml}$ \\
\hline & III' salts & 10 & $\mathrm{ml}$ \\
\hline & Potassium glutamate (40 \%) & 20 & $\mathrm{ml}$ \\
\hline & Sodium succinate (30 \%) & 20 & $\mathrm{ml}$ \\
\hline \multirow[t]{8}{*}{ MNGE medium (10 ml) } & 10x MN medium & 1 & $\mathrm{ml}$ \\
\hline & Glucose (50 \%) & 400 & $\mu l$ \\
\hline & Potassium glutamate (40 \%) & 50 & $\mu l$ \\
\hline & Ammonium iron citrate $\left(2.2 \mathrm{mg} \mathrm{ml}^{-1}\right)$ & 50 & $\mu l$ \\
\hline & Tryptophan (5 $\mathrm{mg} \mathrm{ml}^{-1}$ ) & 100 & $\mu l$ \\
\hline & $\mathrm{MgSO}_{4} \times 7 \mathrm{H}_{2} \mathrm{O}(1 \mathrm{M})$ & 30 & $\mu l$ \\
\hline & +/- CAA (10\%) & 100 & $\mu l$ \\
\hline & Add $\mathrm{H}_{2} \mathrm{O}_{\text {deion }}$ & 10 & $\mathrm{ml}$ \\
\hline \multirow[t]{3}{*}{ LB medium (1 I) } & Tryptone & 10 & g \\
\hline & Yeast extract & 5 & g \\
\hline & $\mathrm{NaCl}$ & 10 & $\mathrm{~g}$ \\
\hline \multirow[t]{7}{*}{ SP medium (1 I) } & Nutrient Broth & 0.8 & g \\
\hline & $\mathrm{MgSO}_{4} \times 7 \mathrm{H}_{2} \mathrm{O}$ & 0.25 & g \\
\hline & $\mathrm{KCl}$ & 1 & $\mathrm{~g}$ \\
\hline & autoclave, after cooling addition of: & & \\
\hline & $\mathrm{CaCl}_{2}(0.5 \mathrm{M})$ & 1 & $\mathrm{ml}$ \\
\hline & $\mathrm{MnCl}_{2}(10 \mathrm{mM})$ & 1 & $\mathrm{ml}$ \\
\hline & Ammonium iron citrate $\left(2.2 \mathrm{mg} \mathrm{ml}^{-1}\right)$ & 2 & $\mathrm{ml}$ \\
\hline
\end{tabular}




\section{Antibiotics}

Antibiotics were prepared as 500 - or 1000 -fold concentrated stock solutions. Ampicillin, spectinomycin, lincomycin and kanamycin were dissolved in deionized water, chloramphenicol, erythromycin and tetracycline in $70 \%$ ethanol and rifampicin in DMSO. All solutions were sterile filtrated and stored at $-20^{\circ} \mathrm{C}$. Autoclaved medium was cooled down to approximately $50^{\circ} \mathrm{C}$. Then the antibiotics were added to their final concentration.

\begin{tabular}{|c|c|c|c|}
\hline Selection concentration for $E$. coli & Ampicillin & 100 & $\mu g \mathrm{ml}^{-1}$ \\
\hline & Kanamycin & 50 & $\mu \mathrm{g} \mathrm{ml^{-1 }}$ \\
\hline & Streptomycin & 100 & $\mu \mathrm{g} \mathrm{ml}^{-1}$ \\
\hline Selection concentration for $B$. subtilis & Chloramphenicol & 5 & $\mu \mathrm{g} \mathrm{ml}^{-1}$ \\
\hline & Erythromycin ${ }^{1}$ & 2 & $\mu \mathrm{g} \mathrm{ml}^{-1}$ \\
\hline & Kanamycin & 10 & $\mu \mathrm{g} \mathrm{ml}^{-1}$ \\
\hline & Lincomycin $^{1}$ & 25 & $\mu \mathrm{g} \mathrm{ml}^{-1}$ \\
\hline & Rifampicin & 100 & $\mu \mathrm{g} \mathrm{ml}^{-1}$ \\
\hline & Spectinomycin & 150 & $\mu \mathrm{g} \mathrm{ml}^{-1}$ \\
\hline & Tetracycline & 12.5 & $\mu \mathrm{g} \mathrm{ml}^{-1}$ \\
\hline
\end{tabular}

${ }^{1}$ For selection on erythromycin, a mixture of erythromycin and lincomycin was used in their respective concentration. 


\subsection{Methods}

\section{Generals Methods}

An overview of general methods that are described in the literature and were used for this work, is given in the following Table 1.

Table 1 General methods

\begin{tabular}{l|l} 
Method & Reference \\
\hline Absorption measurement & Sambrook et al., 1989 \\
\hline Ethidium bromide staining of DNA & Sambrook et al., 1989 \\
\hline Precipitation of nucleic acids & Sambrook et al., 1989 \\
\hline Gel electrophoresis of DNA & Sambrook et al., 1989 \\
\hline Gel electrophoresis of proteins (denaturing) & Laemmli, 1970 \\
\hline Ligation of DNA fragments & Sambrook et al., 1989 \\
\hline Determination of protein amounts & Bradford, 1976 \\
\hline Plasmid preparation from E. coli & Sambrook et al., 1989 \\
\hline Sequencing according to the chain termination method & Sambrook et al., 1989 \\
\hline
\end{tabular}

\section{Cultivation and storage of bacteria}

\section{Cultivation}

Unless otherwise stated, E. coli was grown in LB medium at $37^{\circ} \mathrm{C}$ or $28^{\circ} \mathrm{C}$ and $200 \mathrm{rpm}$ in tubes and flasks. B. subtilis was grown in LB medium, CSE-Glc and MNGE medium at $37^{\circ} \mathrm{C}$ or $28^{\circ} \mathrm{C}$ in tubes and flasks. Fresh colonies from plates or DMSO cultures were used for inoculation. Furthermore, overnight liquid cultures were used for inoculation of main cultures. Growth was measured at a wavelength of $600 \mathrm{~nm}$ (Pietack, 2010).

\section{Storage}

E. coli was kept on LB medium agar plates up to 4 weeks at $4^{\circ} \mathrm{C}$. For long-term storage DMSO cultures were used. B. subtilis was cultured on SP medium agar plates. SP agar plates and tubes were used for the longterm storage of $B$. subtilis. For the storage of bacteria in DMSO, $900 \mu \mathrm{l}$ of a fresh overnight culture was gently mixed with $100 \mu \mathrm{l}$ of DMSO. Stocks were snap frozen and stored at $-80^{\circ} \mathrm{C}$ (Pietack, 2010). 


\section{Preparation of competent of E.coli and transformation}

Preparation of competent E. coli XL1 blue cells

At first, $250 \mathrm{ml} \mathrm{SOB}$ medium within a 1 I flask was inoculated with a colony of $E$. coli XL1 blue and incubated at $\mathrm{RT}$ and $200 \mathrm{rpm}$ for at least 36 hours until an $\mathrm{OD}_{600}$ of about $0.5-0.7$ was reached. Then, the cells were cooled down on ice for $10 \mathrm{~min}$ and centrifuged for $10 \mathrm{~min}$ at 2,500 g and $4^{\circ} \mathrm{C}$. The pellet was resuspended in $80 \mathrm{ml}$ transformation buffer (TB). The cell suspension was centrifuged as described before and resuspended in $20 \mathrm{ml}$ TB. The cell suspension was gentle agitated and DMSO was added to a final concentration of $7 \%$. The cell suspension was incubated on ice for 10 minutes and aliquots of $200 \mu l$ were snap frozen in liquid nitrogen. The long-term storage of the competent cells was performed at $-80^{\circ} \mathrm{C}$ (Inoue et al., 1990; Blötz et al., 2017).

$\begin{array}{llrl}\text { SOB medium (1 I) } & \text { Tryptone } & 20 & \mathrm{~g} \\ & \text { Yeast extract } & 5 & \mathrm{~g} \\ \mathrm{NaCl} & 0.584 & \mathrm{~g} \\ \mathrm{KCl} & 0.188 & \mathrm{~g} \\ \mathrm{MgCl}_{2} & 2.032 & \mathrm{~g} \\ \mathrm{MgSO}_{4} & 2.064 & \mathrm{~g} \\ & \mathrm{H}_{2} \mathrm{O}_{\text {deion }} & \text { add } 1000 & \mathrm{ml} \\ & & \\ & & 3.04 & \mathrm{~g} \\ \mathrm{PIPES} & 2.2 & \mathrm{~g} \\ & \mathrm{CaCl}_{2} \times \mathrm{H}_{2} \mathrm{O} & 18.64 & \mathrm{~g} \\ & \left.\mathrm{KCl}^{1}\right) & 10.84 & \mathrm{~g}\end{array}$

Preparation of competent E. coli BL21(DE3) cells

A single colony of $E$. coli BL21(DE3) was used to inoculate $4 \mathrm{ml} \mathrm{LB}$ medium at $37^{\circ} \mathrm{C}$, shaking. This culture was used to inoculate $100 \mathrm{ml}$ of LB medium and grown to an $\mathrm{OD}_{600}$ of $0.3 .10 \mathrm{ml}$ of cells were harvested for $6 \mathrm{~min}$ at $5000 \mathrm{rpm}$ and $4^{\circ} \mathrm{C}$. The pellet was resuspended in $5 \mathrm{ml} 50 \mathrm{mM} \mathrm{CaC}$ solution and $30 \mathrm{~min}$ incubated on ice. The cells were centrifuged again as described before and resuspended in $1 \mathrm{ml} 50 \mathrm{mM}$ $\mathrm{CaCl}_{2}$ solution. The cells are ready for standard transformation procedure (Blötz et al., 2017). 


\section{Transformation of E. coli}

Competent cells were thawed on ice or directly used after preparation for competent cells, and 10-100 ng DNA were added to $100-200 \mu$ l cells. The suspension was mixed and incubated on ice for $30 \mathrm{~min}$. The heat shock was performed at $42^{\circ} \mathrm{C}$ for $90 \mathrm{sec} .1 \mathrm{ml} \mathrm{LB}$ medium was added to the sample and incubated for $45 \mathrm{~min}$ at $37^{\circ} \mathrm{C}$ at $200 \mathrm{rpm} .100 \mu \mathrm{l}$ and the concentrated rest of the cells were plated on LB selection plates (Blötz et al., 2017).

Preparation of competent of $B$. subtilis and transformation Preparation of competent cells

$10 \mathrm{ml}$ MNGE medium containing 1 \% CAA were inoculated with an overnight culture of $B$. subtilis to an optical density of $\mathrm{OD}_{600}$ of 0.1 . This culture was grown at $37^{\circ} \mathrm{C}$ with until an $\mathrm{OD}_{600}$ of 1.3 . Then, the culture was diluted with $10 \mathrm{ml}$ MNGE medium without CAA and incubated again for $1 \mathrm{~h}$ as before. After the incubation step, the cells were directly used for transformation or harvested by centrifugation ( 5 min; $5,000 \mathrm{rpm}$ and RT). In case of centrifugation, the supernatant was retained in a sterile falcon tube. The pellet was resuspended in $1.8 \mathrm{ml}$ of the supernatant and supplemented with $1.2 \mathrm{ml} 50 \%$ glycerol to a final concentration of $10 \%$. Aliquots of $300 \mu \mathrm{l}$ were frozen in liquid nitrogen and stored at $-80^{\circ} \mathrm{C}$ (Kunst and Rapoport, 1995; Blötz et al., 2017).

\section{Transformation of the competent cells}

$400 \mu \mathrm{l}$ of competent cells or $300 \mu \mathrm{l}$ of cell aliquots were defrosted at $37^{\circ} \mathrm{C}$ and $1.7 \mathrm{ml} \mathrm{MN}$ medium, $17.5 \mu \mathrm{l}$ $50 \%$ glucose and $34 \mu \mathrm{l} 1 \mathrm{M} \mathrm{MgSO}_{4} .0 .1 \mu \mathrm{g}-1 \mu \mathrm{g}$ DNA was added to the cell suspension and incubated for 30 minutes at $37^{\circ} \mathrm{C}, 200 \mathrm{rpm}$. Then, $100 \mu$ l expression solution [500 $\mu$ l yeast extract (5\%), $250 \mu \mathrm{l} \mathrm{CAA}$ (10\%), $250 \mu \mathrm{l}$ deionized water and $50 \mu \mathrm{l}$ tryptophan $(5 \mathrm{mg} / \mathrm{ml})]$ was added and incubated for further 60 minutes at $37^{\circ} \mathrm{C}$. Afterwards the cells were plated on selective medium with the respective antibiotic(s) for selection (Blötz et al., 2017).

\section{Methods for working with DNA}

Isolation of genomic DNA of $B$. subtilis

B. subtilis was grown overnight in $4 \mathrm{ml} \mathrm{LB}$ medium and cells from $1.5 \mathrm{ml}$ culture volume were harvested. The pellet was resuspended in $200 \mu \mathrm{l}$ lysis buffer and incubated at $37^{\circ} \mathrm{C}$ for $30 \mathrm{~min}$, shaking. Further steps for the isolation of the genomic DNA were performed according to the manufacturer's instructions for the DNeasy Tissue Kit (Qiagen, Hilden, Germany) (Pietack, 2010). 
Preparation of plasmid DNA from E. coli

Plasmid DNA was prepared from E. coli carrying the desired plasmid. An overnight culture $(4 \mathrm{ml})$ with cells carrying the desired plasmid was harvested (2 min; 13,000 rpm; RT). The plasmid DNA was isolated using the Mini Prep Kit (Macherey-Nagel, Düren, Germany) according to the manufacturer's instructions. Plasmids were eluted with $50 \mu \mathrm{l} \mathrm{H}_{2} \mathrm{O}_{\text {deion. }}$. All steps were performed at room temperature (Pietack, 2010).

\section{Agarose gel electrophoresis}

For analytical separation of DNA fragments, agarose gels containing 1 to $2 \%(\mathrm{w} / \mathrm{v}$ ) agarose (according to the expected fragment size) were prepared in TAE buffer. The gel was supplemented with HDGreen ${ }^{\mathrm{TM}}$ DNADye Intas according to the manufactures instructions. The DNA samples were mixed with 5x DNA loading dye to facilitate loading and to indicate the migration of the samples in the gel. A voltage of about $100 \mathrm{~V}$ was applied until the color marker reached the last third of the gel. DNA fragments migrate towards the anode with a velocity that is proportional to the negative logarithm of their length. Fluorescence of HDGreen $^{\text {TM }}$ DNA-Dye bound to DNA was detected by excitation with UV light $(\lambda=254 \mathrm{~nm})$ using a GelDoc

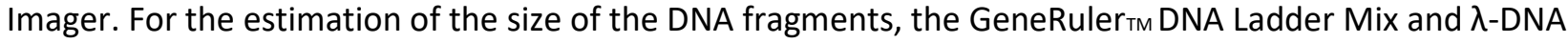
marker were used (Blötz et al., 2017).

Polymerase chain reaction (PCR)

The polymerase chain reaction was performed with chromosomal DNA or plasmid DNA as a template (Blötz et al., 2017).

Reaction mix for the Phusion polymerase reaction $(50 \mu l)$ :

\begin{tabular}{|c|c|}
\hline Template (1-100 ng) & 2 \\
\hline Oligonucleotide 1 (20 pmol) & 2.5 \\
\hline Oligonucleotide 2 (20 pmol) & 2.5 \\
\hline 5x Phusion HF buffer & 10 \\
\hline Phusion polymerase $\left(2 \cup \mu l^{-1}\right)$ & 0.2 \\
\hline dNTPs (each $12.5 \mu \mathrm{mol} \mathrm{ml}^{-1}$ ) & 2 \\
\hline $\mathrm{MgCl}_{2} 50 \mathrm{mM}$ & 2 \\
\hline $\mathrm{H}_{2} \mathrm{O}_{\text {deion }}$ & add 50 \\
\hline
\end{tabular}


Materials and methods

Reaction mix for the DreamTaq polymerase reaction $(50 \mu \mathrm{l})$ :

$\begin{array}{lrl}\text { Template }(1-100 \mathrm{ng}) & 2 & \mu \mathrm{l} \\ \text { Oligonucleotide } 1(20 \mathrm{pmol}) & 2.5 & \mu \mathrm{l} \\ \text { Oligonucleotide } 2(20 \mathrm{pmol}) & 2.5 & \mu \mathrm{l} \\ 10 x \text { DreamTaq buffer } & 10 & \mu \mathrm{l} \\ \text { DreamTaq polymerase }\left(5 \mathrm{U} \mathrm{\mu l}^{-1}\right) & 0.2 & \mu \mathrm{l} \\ \left.\text { dNTPs (each } 12.5 \mu \mathrm{mol} \mathrm{ml}^{-1}\right) & 2 & \mu \mathrm{l} \\ \mathrm{H}_{2} \mathrm{O}_{\text {deion }} & \text { add } 50 & \mu \mathrm{l}\end{array}$

The reaction mix was briefly vortexed and down centrifuged. The reaction was performed in a thermocycler with the following program:

Phusion polymerase

\begin{tabular}{l|cc|l}
\multicolumn{1}{c}{ Reaction } & Temperature $\left[{ }^{\circ} \mathrm{C}\right]$ & Duration per cycle & Repeats \\
\hline Initial denaturation & 98 & $3 \mathrm{~min}$ & \\
Denaturation & 98 & $15 \mathrm{sec}$ & $35 \mathrm{x}$ \\
Annealing & $50-65$ & $30 \mathrm{sec}$ & \\
Elongation & 72 & $30 \mathrm{sec} / 1 \mathrm{~kb}$ & \\
Final elongation & 72 & $3-10 \mathrm{~min}$ & \\
Cooling & 8 & $\infty$
\end{tabular}

DreamTaq polymerase

\begin{tabular}{l|cc|l}
\multicolumn{1}{c}{ Reaction } & Temperature $\left[{ }^{\circ} \mathrm{C}\right]$ & Duration per cycle & Repeats \\
\hline Initial denaturation & 98 & $3 \mathrm{~min}$ & \\
Denaturation & 98 & $15 \mathrm{sec}$ & \multirow{2}{*}{$35 \mathrm{x}$} \\
Annealing & $50-65$ & $30 \mathrm{sec}$ & \\
Elongation & 72 & $1 \mathrm{~min} / 1 \mathrm{~kb}$ & \\
Final elongation & 72 & $3-10 \mathrm{~min}$ & \\
Cooling & 8 & $\infty$
\end{tabular}


Long flanking homology PCR (LFH-PCR)

Deletion of a gene in $B$. subtilis was performed with the long flanking homology PCR (LFH-PCR) technique (Wach, 1996) that was adapted for application in B. subtilis. For this purpose, genes that mediate resistance against chloramphenicol, kanamycin, erythromycin, and spectinomycin were amplified from the plasmids pGEM-cat, pDG780, pDG1513 and pDG1726, respectively (Guérout-Fleury et al., 1995). DNA fragments of about $1 \mathrm{kbp}$ flanking the target gene at its 5' and 3' ends were amplified. The $3^{\prime}$ end of the upstream fragment as well as the $5^{\prime}$ end of the downstream fragment extended into the target gene in a way that all expression signals of genes up- and downstream of the gene remained intact (usually about $150 \mathrm{bp})$. The joining of the two fragments to the resistance cassette was performed in a second PCR. Joining was allowed by complementary sequences of $25 \mathrm{bp}$ that were attached to the single fragments by the respective primers. Thus, the $3^{\prime}$ end of the upstream fragment was linked with the $5^{\prime}$ end of the resistance cassette and the $3^{\prime}$ end of the resistance with the $5^{\prime}$ end of the downstream fragment. For the LFH joining reaction, about $150 \mathrm{ng}$ of the up- and downstream fragments and $150 \mathrm{ng}$ of the resistance cassette were used. The fused fragment was amplified by PCR using the forward primer of the upstream fragment and the reverse primer of the downstream fragment. B. subtilis was transformed with the PCR products and transformants were selected on plates. Clones were examined by check PCR for the integrity of the resistance cassette. The DNA sequence of the flanking regions was verified by sequencing (Blötz et al., 2017).

Reaction mix for the LFH-PCR with Phusion polymerase (100 $\mu$ l)

$\begin{array}{lrr}\text { Upstream flanking region (100 ng) } & x & \mu l \\ \text { Downstream flanking region (100 ng) } & x & \mu l \\ \text { Resistance cassette }(150 \mathrm{ng}) & x & \mu \mathrm{l} \\ \text { Oligonucleotide } 1(20 \mathrm{pmol})^{2} & 8 & \mu \mathrm{l} \\ \text { Oligonucleotide } 2\left(20 \mathrm{pmol}^{2}\right. & 8 & \mu \mathrm{l} \\ 5 \mathrm{x} \text { Phusion HF buffer } & 20 & \mu \mathrm{l} \\ \text { Phusion polymerase }\left(2 \mathrm{U} \mathrm{\mu l}^{-1}\right) & 2 & \mu \mathrm{l} \\ \left.\text { dNTPs (each } 12.5 \mu \mathrm{mol} \mathrm{ml}^{-1}\right) & 4 & \mu \mathrm{l} \\ \mathrm{MgCl}_{2} 50 \mathrm{mM} & 4 & \mu \mathrm{l} \\ \mathrm{H}_{2} \mathrm{O}_{\text {deion }} & \text { add } 100 & \mu \mathrm{l}\end{array}$

${ }^{2}$ Oligonucleotides were added after 10 cycles. 
The reaction mix was briefly vortexed and down centfuged. The reaction was performed in a thermocycler with the following program:

\begin{tabular}{l|cc|l}
\multicolumn{1}{c}{ Reaction } & Temperature $\left[{ }^{\circ} \mathrm{C}\right]$ & Duration per cycle & Number of repeats \\
\hline Initial denaturation & 98 & $3 \mathrm{~min}$ & \\
Denaturation & 98 & $15 \mathrm{sec}$ & $10 \mathrm{x}$ \\
Annealing & $50-60$ & $30 \mathrm{sec}$ & \\
Elongation & 72 & $2 \mathrm{~min}$ & \\
Pause & 16 & $\infty$ & \\
Denaturation & 98 & $15 \mathrm{sec}$ \\
Annealing & $50-60$ & $30 \mathrm{sec}$ & \\
Elongation & 72 & $4: 15 \mathrm{~min}$ & \\
Final elongation & 72 & $10 \mathrm{~min}$ & \\
Cooling & 8 & $\infty$
\end{tabular}

Combined-chain reaction (CCR)

The CCR allows fast and reliable site-specific mutagenesis. This method uses a mutagenic oligonucleotide that hybridize stronger to the template then the external nucleotides. The mutagenic oligonucleotides are phosphorylated at the $5^{\prime}$ end. These phosphorylated oligonucleotides allow the ligation to the $3^{\prime} \mathrm{OH}$ groups of the extended upstream oligonucleotides by a thermostable DNA ligase (ampligase). The DNA polymerase of the reaction must not exhibit 5' 3' exonuclease activity, to prevent degradation of the extended oligonucleotides (Blötz et al., 2017). 
Reaction mix for the CCR with Phusion polymerase:

\begin{tabular}{|c|c|}
\hline Template (1-100 ng) & 2 \\
\hline Oligonucleotide 1 (20 pmol) & 2 \\
\hline Oligonucleotide 2 (20 pmol) & 2 \\
\hline Mutagenesis oligonucleotide (20 pmol) & 4 \\
\hline 10x CCR buffer & 10 \\
\hline Phusion polymerase $\left(2 \cup \mu l^{-1}\right)$ & 1 \\
\hline Ampligase $\left(5 \cup \mu^{-1}\right)$ & 3 \\
\hline dNTPs (each $12.5 \mu \mathrm{mol} \mathrm{ml}^{-1}$ ) & 2 \\
\hline BSA $(20 \mathrm{mg} / \mathrm{ml})$ & 2 \\
\hline $\mathrm{H}_{2} \mathrm{O}_{\text {deion }}$ & add 50 \\
\hline
\end{tabular}

The reaction mix was briefly vortexed and down centrifuged. The reaction was performed in a thermocycler with the following program:

\begin{tabular}{lcc|l}
\multicolumn{1}{c}{ Reaction } & Temperature $\left[{ }^{\circ} \mathrm{C}\right]$ & Duration per cycle & Repeats \\
\hline Initial denaturation & 95 & $5 \mathrm{~min}$ & \\
Denaturation & 95 & $15 \mathrm{sec}$ & \\
Annealing & $52-55$ & $30 \mathrm{sec}$ & $35 \mathrm{x}$ \\
Elongation & 68 & $30 \mathrm{sec} / 1 \mathrm{~kb}$ & \\
Final elongation & 68 & $10 \mathrm{~min}$ & \\
Cooling & 8 & $\infty$
\end{tabular}

Buffer for CCR

10x CCR buffer

$\begin{array}{lrl}\text { Tris- } \mathrm{HCl} \mathrm{pH} 8.5 & 200 & \mathrm{mM} \\ \mathrm{MgCl}_{2} & 30 & \mathrm{mM} \\ \mathrm{KCl} & 500 & \mathrm{mM} \\ \mathrm{NAD}^{+} & 5 & \mathrm{mM} \\ \mathrm{BSA} & 4 & \mathrm{mg} / \mathrm{ml}\end{array}$

Digestion of DNA

The digestion of DNA with endonucleases was performed with buffers recommended by the manufacturer. Reaction buffers, concentration of enzymes and DNA as well as incubation temperatures 
were chosen according to the manufacturer's instructions. The digestion was allowed to proceed for 30 $\min -2 \mathrm{~h}$ and was, if possible, followed by heat inactivation of the restriction endonucleases. The DNA was purified using the PCR Purification Kit (Qiagen, Hilden, Germany) following the manufacturer's instructions (Pietack, 2010).

\section{Dephosphorylation of DNA}

To avoid re-circularization of a previously digested plasmid, the $5^{\prime}$ phosphate groups of the linearized vectors were removed prior to the ligation reaction. The dephosphorylation of the $5^{\prime}$ prime end of DNA fragments was performed with the FastAP (alkaline phosphatase) (Thermo Fisher, Germany) with buffers supplied by the manufacturer. Approximately $10-20 \mathrm{ng} / \mu \mathrm{l}$ DNA were mixed with $1 \mu$ FastAP $(1 \mathrm{U} / \mu \mathrm{l})$ and incubated at $37^{\circ} \mathrm{C}$ for $10 \mathrm{~min}$. The FastAP was separated from the DNA via PCR purification (Pietack, 2010).

\section{Ligation of DNA}

DNA fragments were ligated using T4-DNA ligase (Thermo Fisher, Lithuania) with buffers supplied by the manufacturer. The ligation reaction contained 20-200 ng of vector DNA and an excess of the DNA fragment (insert to vector molar ratio of 3:1 to 10:1). The reaction was started by adding 5 U T4-DNA ligase to a final volume of $20 \mu \mathrm{l}$. The ligation occurred for $30 \mathrm{~min}$ at RT or overnight (or even more days) at $16^{\circ} \mathrm{C}$ (Pietack, 2010).

\section{Purification of PCR and DNA digestion products}

Purification of PCR and DNA digestion products were purified with the PCR-Purification Kit (Qiagen, Germany) according to the manufacturer's instructions. The DNA was diluted using $30-50 \mu \mathrm{l} \mathrm{H}_{2} \mathrm{O}_{\text {deion. }}$.

\section{Sequencing of DNA}

Sequencing was performed based on the chain termination method (Sanger) with fluorescence labelled dideoxynucleotides. The sequencing reactions were conducted by Microsynth AG (Göttingen). 
Solutions for working with DNA

Agarose gel 1-2 \%

DNA color marker $(5 x)$

TAE buffer (50x)

TE buffer $\mathrm{pH} 8.0$

RNase A

Lysis buffer

for chromDNA isolation
$1-2 \%(w / v)$ agarose in TAE

$\begin{array}{lrl}\text { Glycerol } & 5 & \mathrm{ml} \\ \text { TAE (50x) } & 200 & \mu \mathrm{l} \\ \text { Bromophenol blue } & 10 & \mathrm{mg} \\ \text { Xylene cyanol } & 10 & \mathrm{mg} \\ \mathrm{H}_{2} \mathrm{O}_{\text {deion }} & 4.5 \mathrm{ml}\end{array}$

Tris free base

$242 \mathrm{~g}$

Acetic acid (100\%)

$57.1 \mathrm{ml}$

EDTA

$18.61 \mathrm{~g}$

$\mathrm{H}_{2} \mathrm{O}_{\text {deion }}$

add $1000 \mathrm{ml}$

Tris- $\mathrm{HCl} \mathrm{pH} 8.0$

$10 \mathrm{mM}$

EDTA pH 8.0

$1 \mathrm{mM}$

$20 \mathrm{mg} / \mathrm{ml}$ in $\mathrm{H}_{2} \mathrm{O}_{\text {deion }}$

Inactivation of DNAses by heating for 20 minutes at $85^{\circ} \mathrm{C}$

Lysozyme

Tris-HCl pH 8.0 (1 M)

EDTA pH $8.0(0.5 \mathrm{M})$

$\mathrm{H}_{2} \mathrm{O}_{\text {deion }}$
$50 \mathrm{mg}$

$50 \mu \mathrm{l}$

$10 \mu \mathrm{l}$

$2.5 \mathrm{ml}$

\section{Methods for biofilm analysis}

Complex colony formation on agar plates

To monitor complex colony formation a fresh single colony of $B$. subtilis was used to inoculate $4 \mathrm{ml}$ of LB medium supplemented with the appropriate antibiotics and the cells were cultivated at $37^{\circ} \mathrm{C}$ and $200 \mathrm{rpm}$ until they reached an $\mathrm{OD}_{600}$ between 0.5 and 1.0 (mid-exponential growth phase). Then $5 \mu$ l of the cells were dropped carefully on top of an MSgg medium agar plate. To ensure that the agar plates has been dried appropriately, the plates were placed under the laminar flow cabinet for 30 min (while cells were 
growing). Next, the plates were incubated at $30^{\circ} \mathrm{C}$ for three days. Complex colony structure documented with a digital reflex camera (Olympus) and a stereo microscope (Carl Zeiss Microscopy) equipped with digital camera AxioCam MRc. All microscopy pictures were taken at 9.6 fold magnification and processed with ZEN 2012 (blue edition) software (Carl Zeiss Microscopy) Kruse, 2013; Gerwig, 2014).

\section{Preparation of MSgg medium}

Since it is not possible to autoclave all components of MSgg medium, single components were sterilized first and mixed afterwards. For the preparation of plates $1.5 \%(\mathrm{w} / \mathrm{v})$ Bacto agar for minimal medium (BD, Heidelberg) was added to the medium. For the preparation of $500 \mathrm{ml}$ medium, deionized water was added to $7.5 \mathrm{~g}$ agar to a total volume of $300 \mathrm{ml}$ and the mixture was autoclaved. Next, the salts and the other components (preheated) were added to the warm agar to obtain a final volume of $500 \mathrm{ml}$. The single components are listed in the following Table 2. To avoid precipitation of the salts, the agar was mixed continuously prior to pouring the plates. To ensure reproducible colony phenotypes, exactly $25 \mathrm{ml}$ medium were used for every plate. The plates were stored in the refrigerator at $4^{\circ} \mathrm{C}$ (Branda et al., 2001).

Table 2 Scheme for addition of MSgg components to Bacto agar at $55^{\circ} \mathrm{C}$.

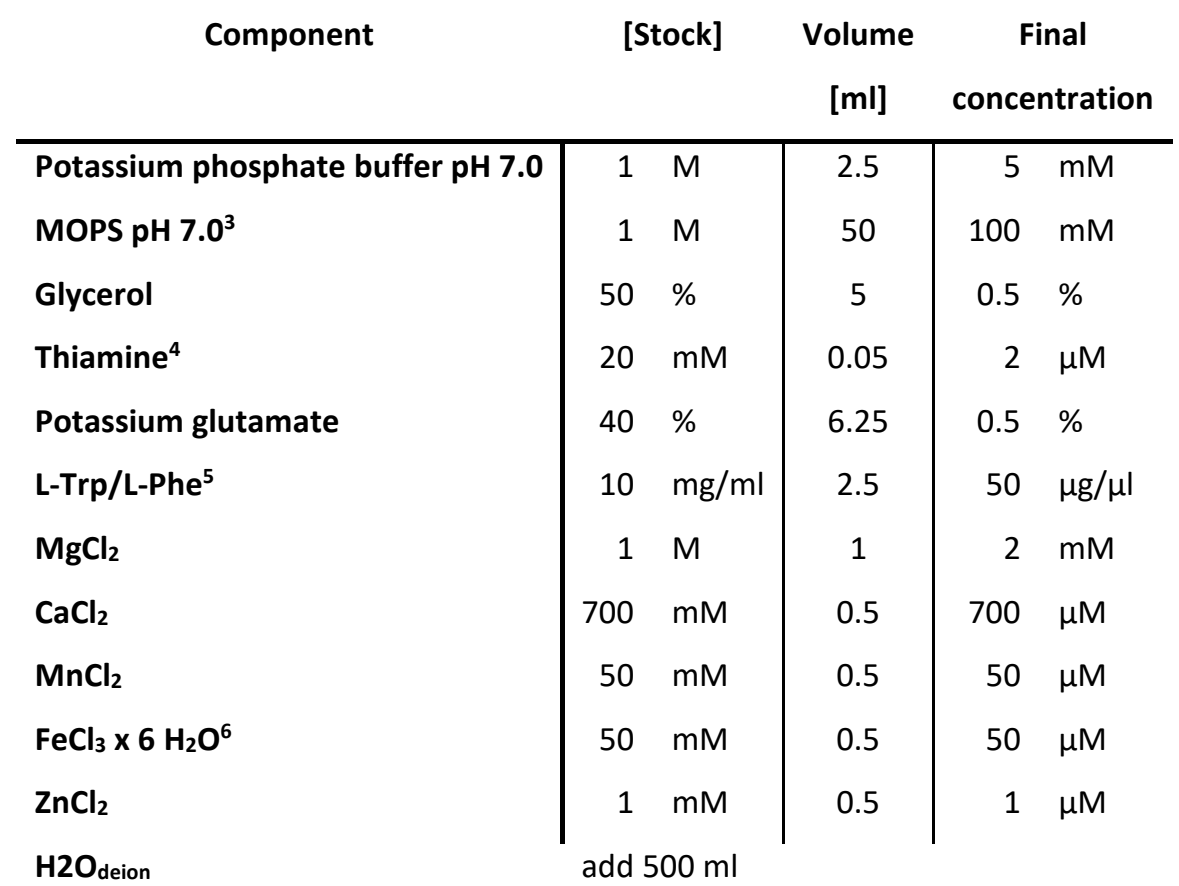

\footnotetext{
${ }^{3}$ autoclaved, store in the dark at $4^{\circ} \mathrm{C} ;{ }^{4}$ autoclaved, store in the dark at $-20^{\circ} \mathrm{C} ;{ }^{5}$ sterile filtrated, store at $4^{\circ} \mathrm{C}$;

${ }^{6}$ prepare freshly; not sterilized.
} 


\section{Cell disruption methods}

French Press

The precooled bomb was filled with the cell suspension and the remaining air was squeezed out before the bomb was locked. After closing the release valve, the bomb was placed in the French press and set under pressure. The disruption took place with a pressure of $18,000 \mathrm{psi}$ and was performed three times (Blötz et al., 2017).

\section{One Shot Cell Disruptor}

The device was used according to manufacturer's instructions (Constant Systems Limited, UK. The system was precooled to $4^{\circ} \mathrm{C}$. The cell was equilibrated with the according buffer and filled with $20 \mathrm{ml}$ cell suspension. Two cycles of cell disruption were applied per sample at 23,000 psi (Blötz et al., 2017).

\section{Sonification}

The $40 \mathrm{ml}$ cell suspension was kept on ice during the disruption process to avoid degradation of proteins. The cells suspension was applied to sonification for five cycles for $30 \mathrm{sec}$ with $30 \mathrm{sec}$ rest between each cycle to mix and cool down the cell suspension (Blötz et al., 2017).

\section{Methods for working with proteins}

Overexpression of recombinant proteins in E. coli

An overnight culture of E. coli BL21(DE3), carrying the relevant plasmid, was used to inoculate 1 I of LB medium to an $\mathrm{OD}_{600}$ of 0.1 . Cultures were grown at $37^{\circ} \mathrm{C}$ and $200 \mathrm{rpm}$ until they had reached an optical density of 0.6 to 0.8 . Expression of recombinant proteins was induced by the addition of isopropyl- $\beta-D-$ thio-galactopyranoside (IPTG, final concentration: $1 \mathrm{mM}$ ). The cultures were cultivated for additional three hours. To test the expression, small aliquots (sample $\left.[\mu l]=100 / \mathrm{OD}_{600}\right)$ were taken before induction $\left(\mathrm{t}_{0}\right)$, and every hour after induction ( $t_{1}$ to $\left.t_{3}\right)$. The samples were boiled in SDS loading dye for 15 min and analyzed by SDS-PAGE. The main culture was harvested by centrifugation (10 min; 5,000 rpm; $4^{\circ} \mathrm{C}$ ). After removing the supernatant, the cells were washed in cold buffer $W$, transferred to a falcon tube and centrifuged again $\left(5 \mathrm{~min}\right.$ at $8,500 \mathrm{rpm}$ and $4^{\circ} \mathrm{C}$ ). The pellets were stored at $-20^{\circ} \mathrm{C}$ (Blötz et al., 2017).

\section{Purification of YmdB (E39Q)-Strep via a StrepTrap HP column}

For the purification on proteins with a Strep-tagll sequence a StrepTrap HP (GE Healthcare, Europe) with a matrix volume $5 \mathrm{ml}$ was used for 2 I culture. This matrix binds a sequence of eight amino acids (WSHPQFEK). Furthermore, this binding can be reversed by applying D-desthiobiotin, which displaces the 
Strep peptide. The specific binding of the peptide to the matrix allows the purification of tagged proteins out of a protein mixture. E. coli BL21 (DE3) carrying expression plasmids were used for the overexpression of $\mathrm{YmdB}$ variants for affinity purification. The cultures were grown in $1 \mathrm{I} \mathrm{LB}$ medium at $37^{\circ} \mathrm{C}$. Expression was induced by the addition of 1 mM IPTG to logarithmically growing cultures $\left(\mathrm{OD}_{600}\right.$ of 0.5$)$, and cultivation was continued for three hours. Cells were harvested and the pellets from 2 I of culture medium were resuspended in $20 \mathrm{ml}$ buffer W. The cells were lysed by French Press before insoluble cellular debris was pelleted by centrifugation. The supernatant was filtered through a $0.45 \mu \mathrm{m}$ syringe filter before loading onto a StrepTrap HP column (GE, UK), pre-equilibrated in buffer W. The bound proteins were eluted using buffer E, 5 - 10 column volumes. Those fractions that were determined by SDS-PAGE to contain the tagged protein, fractions were pooled, concentrated, and further purified by size exclusion using a HiLoad ${ }^{\mathrm{TM}}$ 16/600 Superdex 200 pg (GE Healthcare, Europe) gel filtration column, pore-equilibrated in 50 mM Tris$\mathrm{HCl}, \mathrm{pH}$ 8.0, $150 \mathrm{mM} \mathrm{NaCl} 2 \mathrm{mM}$ DTT. The protein-containing fractions were pooled, concentrated and directly used or snap-frozen in small aliquots in liquid nitrogen for storage at $-80^{\circ} \mathrm{C}$ (Blötz et al., 2017).

Buffers for Strep-tag purification

$\begin{array}{llrl} & \text { Tris- } \mathrm{HCl} \mathrm{pH} 8.0 & 100 & \mathrm{mM} \\ & \mathrm{NaCl} & 150 & \mathrm{mM} \\ & & & \\ & \text { Tris-HCl pH } 8.0 & 100 & \mathrm{mM} \\ \text { Buffer E } & \text { NaCl } & 150 & \mathrm{mM} \\ & \text { D-Desthiobiotin } & 2.5 & \mathrm{mM}\end{array}$


Purification of SinR via Heparin Sepharose

E. coli BL21 (DE3) carrying expression plasmids was used for the overexpression of SinR variants for affinity purification. The cultures were grown in 1 I LB medium at $37^{\circ} \mathrm{C}$. Expression was induced by the addition of IPTG (final concentration $1 \mathrm{mM}$ ) to logarithmically growing cultures $\left(\mathrm{OD}_{600}\right.$ of 0.5$)$, and cultivation was continued for one hour. Cells were harvested and the pellets from $2 \mathrm{I}$ of culture medium were resuspended in $20 \mathrm{ml}$ disruption buffer $(50 \mathrm{mM}$ Tris/ $\mathrm{HCl}, \mathrm{pH}$ 8.0). The cells were lysed by sonication or OneShot before insoluble cellular debris was pelleted by centrifugation. The supernatant was filtered through a $0.45 \mathrm{mM}$ syringe filter before loading onto a Heparin Sepharose (GE Healthcare) pseudo-affinity column, preequilibrated in $50 \mathrm{mM}$ Tris $/ \mathrm{HCl}, \mathrm{pH}$ 8.0. The bound proteins were eluted using a linear $\mathrm{NaCl}$ gradient, from 0 to $1 \mathrm{M} \mathrm{NaCl}$, over 20 column volumes. Those fractions that were determined by SDS-PAGE to contain SinR protein were pooled, concentrated, and further purified by size exclusion using a Superdex 75 HR 16/60 (GE Healthcare) gel filtration column, pore-equilibrated in $50 \mathrm{mM}$ Tris- $\mathrm{HCl}, \mathrm{pH} 8.0,250 \mathrm{mM} \mathrm{NaCl}$. The SinR-containing fractions were pooled, concentrated and snap-frozen in small aliquots in liquid nitrogen for storage at $-80^{\circ} \mathrm{C}$.

\section{Purification of Sinl via ANX ion exchange column}

Sinl was expressed, resuspended, lysed and clarified as described above for SinR. The clarified cell lysate was loaded onto an ANX (GE Healthcare) ion exchange column, and purified by the application of a linear, 0 to $1 \mathrm{M} \mathrm{NaCl}$ gradient. Those fractions that were determined by SDS-PAGE to contain Sinl proteins were pooled, concentrated, and further purified by size exclusion as described above. The Sinl-containing fractions were pooled, concentrated and snap-frozen in small aliquots in liquid nitrogen for storage at $80^{\circ} \mathrm{C}$.

\section{Denaturing gel electrophoresis of proteins (SDS-PAGE)}

Denaturing protein gels were prepared as described by Laemmli et al. (1970). The gels consist of a stacking and a separating gel, which were poured to a thickness of $1 \mathrm{~mm}$. Before applying the samples on the gel, they were mixed with SDS sample buffer $(5 x)$ and heated for $5 \mathrm{~min}$ at $95^{\circ} \mathrm{C}$. The separation of the proteins was performed at 120 to $150 \mathrm{~V}$. 
Materials and methods

Solution for SDS-PAGE

\begin{tabular}{|c|c|c|c|}
\hline \multirow[t]{6}{*}{$5 x$ SDS sample buffer } & Tris-HCl pH 7.0 (1 M) & 1.4 & $\mathrm{Ml}$ \\
\hline & Glycerol & 3 & $\mathrm{Ml}$ \\
\hline & SDS (20 \%) & 2 & $\mathrm{Ml}$ \\
\hline & $\beta$-mercaptoethanol & 1.6 & $\mathrm{Ml}$ \\
\hline & Bromphenol blue & 10 & $\mathrm{mg}$ \\
\hline & $\mathrm{H}_{2} \mathrm{O}_{\text {deion }}$ & 2 & $\mathrm{Ml}$ \\
\hline \multirow[t]{6}{*}{ Stacking gel } & Rotiphorese Gel 30 & 1.3 & $\mathrm{Ml}$ \\
\hline & Tris-HCl pH 6.8 & 1 & $\mathrm{Ml}$ \\
\hline & SDS (10 \%) & 80 & $\mu l$ \\
\hline & APS (10\%) & 80 & $\mu l$ \\
\hline & TEMED & 8 & $\mu l$ \\
\hline & $\mathrm{H}_{2} \mathrm{O}_{\text {deion }}$ & 5.5 & $\mathrm{Ml}$ \\
\hline \multirow[t]{6}{*}{ Separating gel (12/15 \%) } & Rotiphorese Gel 30 & $4 / 5$ & $\mathrm{Ml}$ \\
\hline & Tris- $\mathrm{HCl}$ pH 8.8 & 2.5 & $\mathrm{Ml}$ \\
\hline & SDS (10 \%) & 100 & $\mu l$ \\
\hline & APS (10\%) & 100 & $\mu l$ \\
\hline & TEMED & 4 & $\mu l$ \\
\hline & $\mathrm{H}_{2} \mathrm{O}_{\text {deion }}$ & $3.3 / 2.3$ & $\mathrm{Ml}$ \\
\hline \multirow[t]{3}{*}{ 10x PAGE buffer } & L-Glycine & 1.92 & M \\
\hline & Tris- $\mathrm{HCl}$ pH 8.3 & 250 & $\mathrm{mM}$ \\
\hline & SDS & 1 & $\%(w / v)$ \\
\hline
\end{tabular}

Coomassie staining of polyacrylamide gels

Protein gels were stained with Coomassie Brilliant Blue. For this purpose, the gels were fixated for 30 at $\mathrm{RT}$, incubated in Coomassie staining solution for $30 \mathrm{~min}$ (fixation of proteins in parallel) for about 10-15 minutes and the gels were destained until an optimal contrast between protein bands and background was reached. This step was usually performed over night at room temperature (Blötz et al., 2017). 
Solutions for Coomassie staining of proteins

$\begin{array}{llll}\text { Fixation solution } & \text { Acetic Acid } & 10 & \%(\mathrm{v} / \mathrm{v}) \\ & \text { Methanol } & 50 & \%(\mathrm{v} / \mathrm{v}) \\ & & & \\ \text { Staining solution } & \text { Coomassie brilliant blue } & 0.5 & \%(\mathrm{w} / \mathrm{v}) \\ & \text { Acetic acid } & 10 & \%(\mathrm{v} / \mathrm{v}) \\ & \text { Methanol } & 45 & \%(\mathrm{v} / \mathrm{v}) \\ & & & \\ \text { Destaining solution } & \text { Acetic Acid } & 5 & \%(\mathrm{v} / \mathrm{v}) \\ & \text { Ethanol } & 20 & \%(\mathrm{v} / \mathrm{v})\end{array}$

Silver staining of polyacrylamide gels

Silver stainings are widely used to check the purity of protein extracts and to identify protein purification and protein-protein interactions. One advantage is the high sensitivity with a detection limit of about $5 \mathrm{ng}$ protein per band. This is linked to the physics of the accumulation of silver particles. During the staining, silver ions build up complexes with the glutamate, aspartate and cysteine amino acid residues of the proteins and thereby get reduced to metallic silver. Therefore, the intensity of the silver staining depends on the amino acid sequence of the respective proteins and can vary considerably. The gels were incubated on a shaker with the following reagents and in the stated order (see Tab. 3) (Blötz et al., 2017).

Table 3 Scheme for workflow of silver staining

\begin{tabular}{lccc} 
Step & Reagent & Duration & Repeats \\
\hline Fixing & Fixer & $1-24 \mathrm{~h}$ & \\
Washing & Ethanol $50 \%$ & $20 \mathrm{~min}$ & $3 \mathrm{x}$ \\
Reducing & Thiosulfate solution & $1: 30 \mathrm{~min}$ & \\
Washing & $\mathrm{H}_{2} \mathrm{O}_{\text {deion }}$ & $1 \mathrm{~min}$ & \\
Staining & Impregnator & $25 \mathrm{~min}$ & \\
Washing & $\mathrm{H}_{2} \mathrm{O}_{\text {deion }}$ & $20 \mathrm{sec}$ & $2 \mathrm{x}$ \\
Development & Developer & Until stained & \\
Washing & $\mathrm{H}_{2} \mathrm{O}_{\text {deion }}$ & $20 \mathrm{sec}$ & \\
Stop development & Stop solution & $5 \mathrm{~min}$ &
\end{tabular}




\section{Solutions for silver staining}

All solutions are prepared with $\mathrm{H}_{2} \mathrm{O}_{\text {deion. }}$.

\begin{tabular}{|c|c|c|c|}
\hline \multirow[t]{3}{*}{ Fixer } & Methanol & 50 & $\%(v / v)$ \\
\hline & Acetic acid & 12 & $\%(v / v)$ \\
\hline & Formaldehyde & 0.037 & $\%(v / v)$ \\
\hline Thiosulfate solution & $\mathrm{Na}_{2} \mathrm{~S}_{2} \mathrm{O}_{3} \times 5 \mathrm{H}_{2} \mathrm{O}$ & 0.02 & $\%(w / v)$ \\
\hline \multirow[t]{2}{*}{ Impregnation solution } & $\mathrm{AgNO}_{3}$ & 0.2 & $\%(w / v)$ \\
\hline & Formaldehyde & 0.037 & $\%(v / v)$ \\
\hline \multirow[t]{3}{*}{ Developer } & $\mathrm{Na}_{2} \mathrm{CO}_{3}$ & 6 & $\%(w / v)$ \\
\hline & Thiosulfate solution & 2 & $\%(v / v)$ \\
\hline & Formaldehyde & 0.05 & $\%(v / v)$ \\
\hline Stop solution & EDTA & 1.86 & $\%(w / v)$ \\
\hline
\end{tabular}

\section{Western blotting}

The Western blotting of proteins on PVDF membranes (Bio-Rad, USA) was carried out with semi dry blotting equipment. After the electrophoresis, the gels were equilibrated in transfer buffer for $30 \mathrm{sec}$. The PVDF membrane was activated in methanol (100 \%) for a short time and subsequently incubated in transfer buffer for 5 minutes. Then the transfer of the protein was performed for one hour at $0.8 \mathrm{~mA} / \mathrm{cm}_{2}$. In order to block unspecific binding sites, the membrane was incubated in skim milk blocking solution (Blotto) for 1-3 hours. In a next step, polyclonal antibodies against the protein of interest were applied onto the membrane. The antibodies against, the SinR (gift by Daniel B. Kearns), the Sinl (gift by Daniel B. Kearns) and the GapA (laboratory collection) proteins were used as dilutions of 1:10,000 in Blotto (overnight). After three washing steps of 30 minutes each, the membrane was incubated with the second antibody (anti-rabbit IgG, coupled to an alkaline phosphatase), which was diluted 1:100,000 in Blotto. Then the membrane was washed twice for $20 \mathrm{~min}$ in Blotto and rinsed with deionized water. Before applying the substrate CDP* (Roche Diagnostics, Mannheim, Germany) on the membrane, the membrane was incubated in buffer III for 5 minutes to increase the $\mathrm{pH}$ value. The signal of the chemiluminescent substrate $C D P *$ was detected with a ChemoCam imager (Intas, Göttingen) (Blötz et al., 2017). 
Solutions for Western blotting

All solutions are prepared with $\mathrm{H}_{2} \mathrm{O}_{\text {deion, }}$, if not other stated.

\begin{tabular}{|c|c|c|c|}
\hline \multirow[t]{2}{*}{ Blotto (in TBS) } & Skim milk powder & 2.5 & $\%(w / v)$ \\
\hline & Tween 20 & 0.1 & $\%(v / v)$ \\
\hline \multirow[t]{2}{*}{ Buffer III } & Tris-HCl pH 9.5 & 100 & $\mathrm{mM}$ \\
\hline & $\mathrm{NaCl}$ & 100 & $\mathrm{mM}$ \\
\hline \multirow[t]{4}{*}{ Transfer buffer } & Tris free base & 0.125 & $M$ \\
\hline & Glycine & 0.192 & $M$ \\
\hline & Methanol & 200 & $\mathrm{ml}$ \\
\hline & add $\mathrm{H}_{2} \mathrm{O}_{\text {deion }}$ & 1000 & $\mathrm{ml}$ \\
\hline \multirow[t]{4}{*}{$10 x$ TBS } & Tris free base & 0.5 & M \\
\hline & $\mathrm{NaCl}$ & 1.5 & M \\
\hline & \multicolumn{3}{|c|}{ adjust $\mathrm{pH}$ with $37 \% \mathrm{HCl}$} \\
\hline & add $\mathrm{H}_{2} \mathrm{O}_{\text {deion }}$ & 1000 & $\mathrm{ml}$ \\
\hline
\end{tabular}

\section{Quantitative Western blots for the determination of SinR and Sinl amounts}

To determine SinR protein amounts quantitative Western blotting was applied. For this purpose, $4 \mathrm{mI} \mathrm{LB}$ medium was inoculated with a fresh colony and grown over day at $37^{\circ} \mathrm{C}$ and $200 \mathrm{rpm}$. This culture was used to inoculate another $4 \mathrm{ml} \mathrm{LB}$ medium culture for overnight growth at $28^{\circ} \mathrm{C}$ and $200 \mathrm{rpm}$ so that the cells had reached the late exponential (early stationary) growth phase in the morning. With this culture 50 ml LB medium supplemented with the appropriate antibiotics was inoculated to an OD 600 of 0.1 . The cells were cultivated at $37^{\circ} \mathrm{C}$ and $200 \mathrm{rpm}$ until they reached an $\mathrm{OD}_{600}$ of about $2.0-2.5$. Then, $25 \mathrm{ml}$ aliquots of this culture were harvested by centrifugation at 8,500 rpm for $25 \mathrm{~min}$ and washed with buffer W. Cell pellets were stored at $-20^{\circ} \mathrm{C}$ or directly disrupted with the French press. For this purpose, cell pellets were resuspended in $2 \mathrm{ml}$ buffer $\mathrm{W}$ and cells disrupted. Subsequently, samples were centrifuged for $10 \mathrm{~min}$ at $13,000 \mathrm{rpm}$ and $4^{\circ} \mathrm{C}$ to separate cell debris from the soluble cell contents. Supernatants were transferred to new reaction tubes and the protein content was determined as described by Bradford et al. (1976). Protein extracts ( 15 or $20 \mu \mathrm{g}$ ) were mixed with $5 \times$ PAP, heated for $15 \mathrm{~min}$ at $95^{\circ} \mathrm{C}$ and applied to $15 \%$ SDS-PAGE. Detection of the SinR or Sinl proteins was performed with a specific antibody (gift of D. Kearns and Y. Chai). As a control the GapA protein was detected in aliquots from the same extraction that were 
applied to a separate gel for subsequent blotting with an GapA-specific antibody modified from Blötz et al., 2017.

Determination of relative SinR protein amounts by ImageJ

Quantification of the density (intensity) of Western blot signals was performed with the image processing software ImageJ and as described at http://www.lukemiller.org/ImageJ_gel_analysis.pdf (Miller, 2010; Schneider et al., 2012). In brief, a Western blot image derived from detection with a SinR-specific antibody was imported into ImageJ and the rectangular selection tool was used to measure signal intensity of each Western blot lane. For this purpose, the number " 1 " on the keyboard was pressed to mark the first selection, by pressing " 2 " the rectangular selection field for every further lane was duplicated and by pressing " 3 " the profile plots for each lane were shown. Then, the straight line selection tool was used to separate the highest peak (main signal) from the background noise by creating a closed area. Next, the socalled wand tool was used to select the area of interest of every single signal by clicking into the closed area. Finally, the intensity values for every area appeared in a new window and were used for further calculations. The same procedure was performed for the Western blot signals with the GapA-specific antibodies. To normalize the resulting intensity values for SinR protein of a certain cultivation, they were divided by the respective values for GapA protein. Then, the mean of the normalized values of three biological replicates was calculated and the value for the reference strain was set to 1 by dividing all values by the value for the reference. Now changes in SinR intensity (protein amounts) of the strains of interest could be visualized in a bar chart (Gerwig, 2014).

\section{Determination of $\beta$-galactosidase activity}

For the determination of translational activity, the $\beta$-galactosidase activity of the $\sin R$ region was measured. For this purpose, the genomic region of interest was cloned into the pAC7 vector for fusion to lacZ gene. This vector allows the integration of the construct in the amyE region via homologous recombination. The integration into the correct region can be detected via an $\alpha$-amylase activity test on starch plates. Transformed strains were grown overnight at $37^{\circ} \mathrm{C}$. On the next day, Luol's solution was dropped on the plate. If the amyE gene was still functional, a halo appeared around the colony. When a halo around the colony was absent, the lacZ construct did correctly integrate (Hübner, 2008; Blötz et al., 2017). The respective strain was grown in $4 \mathrm{ml} \mathrm{LB}$ medium overnight at $37^{\circ} \mathrm{C}$ and $200 \mathrm{rpm} .10 \mathrm{ml} \mathrm{LB}$ medium were inoculated to an $\mathrm{OD}_{600}$ of 0.1 and grown at $37^{\circ} \mathrm{C}$ and $200 \mathrm{rpm}$ until an $\mathrm{OD}_{600}$ of $2.0 .2 \mathrm{ml}$ aliquots were harvested via centrifugation for $1 \mathrm{~min}$ at 13,000 rpm and $4^{\circ} \mathrm{C}$. Cells were washed with $2 \mathrm{ml}$ ice-cold ZAP buffer, snap frozen and stored at $-20^{\circ} \mathrm{C}$. For the actual $\beta$-galactosidase activity assay, cell 
pellets were disrupted by resuspension in $400 \mu$ l buffer Z / LD-mix and incubated for $10 \mathrm{~min}$ at $37^{\circ} \mathrm{C}$. The cells suspension was cleared by centrifugation for $2 \mathrm{~min}$ at $13,000 \mathrm{rpm}$ and $4^{\circ} \mathrm{C}$. The supernatant was transferred to a fresh reaction tube. $100 \mu \mathrm{l}$ of the supernatant was mixed with $700 \mu \mathrm{l}$ buffer $\mathrm{Z}$ and preincubated for $5 \mathrm{~min}$ at $28^{\circ} \mathrm{C}$. The assay was started by addition of $200 \mu \mathrm{l}$ ONPG-solution and the time determined until a yellow color shift was detected. The reaction was stopped by adding $500 \mu \mathrm{l}$ of $1 \mathrm{M}$ $\mathrm{Na}_{2} \mathrm{CO}_{3}$ as soon as the reaction showed a clear yellow color shift and the time noted. The absorption of the reaction suspension was then measured at $\Lambda$ of $420 \mathrm{~nm}$. An identical sample without cell extract was used as a blank. The protein amount of the cell extracts was determined via Bradford assay (Bradford, 1976). The specific $\beta$-galactosidase activity was determined using following equation (Blötz et al., 2017).

$$
\text { Units } \mathrm{mg}^{-1} \text { Protein }=\frac{1500 \times \mathrm{A}_{420}}{\Delta \mathrm{t} \times \mathrm{V} \times \mathrm{A}_{595} \times 1.7 \times 4.4}
$$

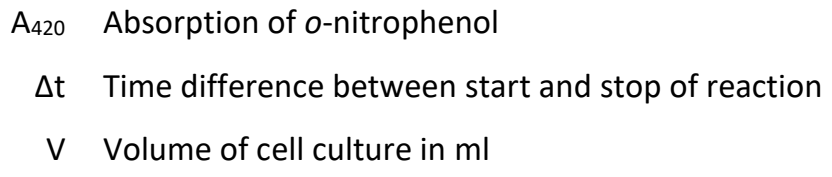

Solutions and material for $\beta$-galactosidase assay

$\begin{array}{llrl}\text { Starch plates (1 l) } & \text { Agar } & 1.5 & \%(w / v) \\ & \text { Nutrient broth } & 7.5 & \mathrm{~g} \\ & \text { Starch } & 5 & \mathrm{~g} \\ & & & \\ & \text { Tris-HCl pH 7.5 } & 50 & \mathrm{mM} \\ \text { ZAP buffer } & \mathrm{NaCl} & 200 \mathrm{mM} \\ & & \\ & \text { Lysozyme } & 100 \mathrm{mg} \\ \text { LD-mix } & 10 \mathrm{mg} \\ & \text { DNase I } & 10 \mathrm{ml}\end{array}$




\begin{tabular}{|c|c|c|c|}
\hline \multirow[t]{6}{*}{ Z buffer } & $\mathrm{Na}_{2} \mathrm{HPO}_{4} \times 2 \mathrm{H}_{2} \mathrm{O}$ & 60 & $\mathrm{mM}$ \\
\hline & $\mathrm{NaH}_{2} \mathrm{PO}_{4}$ & 40 & $\mathrm{mM}$ \\
\hline & $\mathrm{KCl}$ & 10 & $\mathrm{mM}$ \\
\hline & $\mathrm{MgSO}_{4}$ & 1 & $\mathrm{mM}$ \\
\hline & $\beta$-mercaptoethanol & 50 & $\mathrm{mM}$ \\
\hline & (add just before use) & & \\
\hline \multirow[t]{2}{*}{ ONPG } & ONPG & 0.4 & $\%(w / v)$ \\
\hline & in Z buffer & & \\
\hline Stop solution & $\mathrm{Na}_{2} \mathrm{CO}_{3}$ & 1 & $M$ \\
\hline
\end{tabular}

\section{Determination of SinR protein stability in vivo}

For this purpose, $4 \mathrm{ml} \mathrm{LB}$ medium was inoculated with a fresh colony and grown over day at $37^{\circ} \mathrm{C}$ and 200 rpm. On the next day $50 \mathrm{ml} L B$ medium were inoculated to an $\mathrm{OD}_{600} 0.1$ and grown $37^{\circ} \mathrm{C}$ and $200 \mathrm{rpm}$ to an $\mathrm{OD}_{600}$ of 1.0. A Sample of $2 \mathrm{ml}$ were taken and cleared via centrifugation for $2 \mathrm{~min}$ at 13,000 rpm and $4^{\circ} \mathrm{C}$, washed with ZAP buffer, snap frozen and stored at $-20^{\circ} \mathrm{C}$ (also for further samples). Then, rifampicin and chloramphenicol to a concentration of $100 \mu \mathrm{g} / \mathrm{ml}$ were added to inhibit transcription and translation (Blötz et al., 2017). Further samples were taken after 5, 15, 30 and 60 minutes. Cells pellets were resuspended in $250 \mu \mathrm{l} \mathrm{Z}$ buffer with $1.25 \mu \mathrm{LD}$-mix and incubated for $10 \mathrm{~min}$ at $37^{\circ} \mathrm{C}$ for cell lysis (compare Determination of $\beta$-galactosidase activity). To get rid of the cell debris, the disrupted samples were centrifuged for $10 \mathrm{~min}$ at $13,000 \mathrm{rpm}$ and $4^{\circ} \mathrm{C}$. The supernatant was transferred to a fresh reaction tube and the protein concentration determined via Bradford assay. $15 \mu \mathrm{g}$ of protein were mixed with 5x PAP and loaded on a $15 \%$ SDS-PAGE gel and separated at 150 V. A Western blot with antibodies against SinR performed to determine the protein level in each sample. An antibody against GapA was used as loading control (Buchanan et al., 2016; Blötz et al., 2017).

\section{Characterization of $\operatorname{SinR}$ :DNA and $\operatorname{SinR}: \operatorname{Sin}$ interactions via Fluorescence polarization}

$50 \mu \mathrm{M}$ oligodeoxynucleotides (FAM1721 and C-1723), labelled at the $5^{\prime}$-terminus with fluorescein, were annealed with an equimolar equivalent of their unlabeled complements in a buffer of $20 \mathrm{mM} \mathrm{Tris-HCl,} \mathrm{pH}$ $8.0,100 \mathrm{mM} \mathrm{NaCl}, 1 \mathrm{mM}$ EDTA by heating the mixture to $95^{\circ} \mathrm{C}$ for $10 \mathrm{~min}$, followed by a slow cool to room 
temperature for at least 30 minutes. For fluorescence polarization, $10 \mathrm{nM}$ DNA was mixed in a serial dilution of SinR proteins, from a starting concentration of $20 \mu \mathrm{M}$, in $10 \mathrm{mM} \mathrm{Tris-HCl,} \mathrm{pH} \mathrm{8.0,} 100 \mathrm{mM} \mathrm{NaCl}$, 1 mM EDTA. Fluorescence polarization was measured in a PHERAstar FS plate reader using Corning 384 well low volume black round bottom polystyrene NB microplates. For the titration of Sinl to SinR bound to DNA, a mixture of $50 \mu \mathrm{M} \operatorname{Sinl}, 5 \mu \mathrm{M} \operatorname{SinR}$ and $10 \mathrm{nM}$ DNA was serially diluted with a mixture containing 10 nM DNA and $5 \mu \mathrm{M} \operatorname{SinR}$ (Lea and Simeonov, 2011). The binding data were fitted to calculate an equilibrium dissociation constant using SigmaPlot.

\section{Determination of protein molecular mass via SEC-MALS}

The purified proteins were concentrated to $5 \mathrm{mg} / \mathrm{ml}$ for SEC-MALS analysis of their absolute molecular masses. $150 \mu \mathrm{l}$ samples of each SinR protein were loaded onto a Superdex 200 Increase 10/300 GL size exclusion chromatography column (GE Healthcare) pre-equilibrated in $50 \mathrm{mM}$ Tris- $\mathrm{HCl}, \mathrm{pH} 8.0,250 \mathrm{mM}$ $\mathrm{NaCl}$ buffer, attached to an ÄKTA ${ }^{\mathrm{TM}}$ Pure chromatography workstation (GE Healthcare). The chromatogram was developed at a flowrate of $0.5 \mathrm{ml} / \mathrm{min}$ using an ÄKTA ${ }^{\text {TM }}$ Pure (GE Healthcare), and the eluent was fed directly into a DAWN HELEOS II MALS detector (Wyatt Technology), operating with a laser source of $664 \mathrm{~nm}$ and 8 fixed angle detectors. Absolute and differential refractive indices (dRI) were also measured at $664 \mathrm{~nm}$ and $25^{\circ} \mathrm{C}$ using an Optilab T-rEX differential refractometer (Wyatt Technology). Data were collected and analyzed using ASTRA 6 software (Wyatt Technology) (Folta-Stogniew, 2006).

\section{RNA-protein co-purification with B. subtilis (RNA co-precipitation)}

B. subtilis cells harboring a plasmid for constitutive expression of C- or N-terminal Strep tagged proteins were cultured in $4 \mathrm{ml} \mathrm{LB}$ medium overnight at $37^{\circ} \mathrm{C}$ and $200 \mathrm{rpm}$. On the next day, $500 \mathrm{ml} \mathrm{CSE} \mathrm{Glucose} \mathrm{or}$ LB medium were inoculated to an $\mathrm{OD}_{600}$ of 0.1 and grown until an $\mathrm{OD}_{600}$ of 2.0. The cultures were harvested, resuspended and washed with buffer W. Pellets were snap frozen and stored at $-80^{\circ} \mathrm{C}$. The cells were resuspended in buffer W (see Purification of Strep-YmdB (E39Q) via a StrepTrap HP column) and disrupted using the French Press. The lysates were cleared by centrifugation for $30 \mathrm{~min}, 8,500 \mathrm{rpm}$ and $4^{\circ} \mathrm{C}$. The cleared crude extract was applied to a Streptactin matrix ( $500 \mu \mathrm{l}$ of matrix per $500 \mathrm{ml}$ of culture), then washed four times with $5 \mathrm{ml}$ buffer W. $2 \mu$ of Protector RNase inhibitor (Roche Diagnostics, Mannheim, Germany) were added to the empty reaction tubes for collecting elution fractions. The Streptactin bound proteins were eluted three times with $500 \mu \mathrm{l}$ buffer E (compare Purification of StrepYmdB (E39Q) via a StrepTrap HP column). For RNA extraction, $350 \mu \mathrm{l}$ of each elution fraction was mixed with one volume of Phenol:Chloroform:Isoamylalcohol (25:24:1) (PCI). The mixture was shaken for $30 \mathrm{sec}$ and then applied to a $2 \mathrm{ml}$ Phase Lock gel heavy tube (PLG; 5 PRIME, Hamburg), incubated for 2 min and 
then centrifuged for $30 \mathrm{~min}, 14,800 \mathrm{rpm}, 15^{\circ} \mathrm{C}$. The supernatant (usually $350 \mu \mathrm{l}$ ) was transferred into a fresh reaction tube, three volumes of ice-cold $96 \% \mathrm{EtOH}: 4 \mathrm{M} \mathrm{LiCl} \mathrm{(30:1)} \mathrm{and} 1 \mu$ l Glycoblue were added and mixed. Then, the RNA was precipitated overnight at $-20^{\circ} \mathrm{C}$. The protein purification was tested via SDSPAGE and silver staining and the protein amounts in the elution fractions were determined via Bradford assay. The RNA was centrifuged for $30 \mathrm{~min}, 14,800 \mathrm{rpm}, 4^{\circ} \mathrm{C}$ and the supernatant discarded. The RNA pellet was washed two times with $70 \% \mathrm{EtOH}$ and air-dried. The RNA was dissolved in $33 \mu \mathrm{l}$ RNase-free water for $60 \mathrm{~min}, 37^{\circ} \mathrm{C}$, shaking. The RNA of the different elution fractions per sample was pooled. $2.5 \mu$ l DNase I (20 $\mathrm{mg} / \mathrm{ml}$ ) and $12 \mu \mathrm{l}$ DNase I buffer was added to each sample and incubate $1 \mathrm{~h}$ at $37^{\circ} \mathrm{C}$. The sample was tested for digestion of DNA via PCR. When no DNA was left, the $\mathrm{PCl}$ extraction, precipitation and washing of RNA was applied as before to get rid of DNase I. The dried RNA was dissolved in $50 \mu$ l RNase-free water (Göpel et al., 2013). The final RNA concentration was determined via Qubit, quality checked, and Illumina sequencing applied at the G2L, Göttingen. Sequencing data were mapped against B. subtilis 168 from the G2L and accessible via TraV software (Dietrich et al., 2014). TraV is a browser-based tool that allows the visualization and download of the normalized reads of the samples as an Excel file. These normalized reads for nucleotide activities per kilobase of exon model per million mapped reads (NPKM) values. These NPKM values represent the transcriptional activity or covering of all identified regions.

\section{Microfluidic chamber video analysis}

B. subtilis cells were recorded by M. Dormeyer at the Forschungszentrum Jülich in the group of Prof. D. Kohlheyer. The processing and analyzes of the video material was performed using ImageJ. The mean fluorescence values of each cell were analyzed using the ImageJ plug-in MicrobeJ (Ducret et al., 2016).

\section{Preparation of samples for metabolome analysis of biofilms}

Preparation of samples with labeled glucose

B. subtilis cells were cultured in $4 \mathrm{ml} \mathrm{LB}$ medium overnight at $37^{\circ} \mathrm{C}$ and $200 \mathrm{rpm}$. On the next day, $4 \mathrm{mI} \mathrm{LB}$ medium were inoculated to an $\mathrm{OD}_{600}$ of 0.1 and grown until they reached an $\mathrm{OD}_{600}$ of $0.5-0.9 .2 \mathrm{ml}$ of the cells were harvested for $5 \mathrm{~min}$ at $6000 \mathrm{rpm}$, washed twice in MSgg medium with $0.5 \%$ glucose and resuspended in $2 \mathrm{ml} \mathrm{MSgg}$ medium with $0.5 \%$ glucose. $3 \times 5 \mu \mathrm{l}$ of the cell suspension per biological replicate were dropped on MSgg agar plates with $0.5 \%$ glucose. $1 / 3$ of the glucose was $D$-glucose- ${ }^{13} \mathrm{C}_{6}$ for labeling samples for the metabolomic analysis. Colonies were grown for three days at $30^{\circ} \mathrm{C}$. The colonies were scratched off the surface and twice washed with ice-cold PBS pH 7.4. The pellets were harvested for $10 \mathrm{~min}$ at $8,500 \mathrm{rpm}$ and $4^{\circ} \mathrm{C}$. Samples were then snap frozen and stored at $-80^{\circ} \mathrm{C}$ until they were shipped on dry ice for metabolomic analysis to the group of Prof. Eisenreich at the TU Munich, Garching. 
Preparation of samples with labeled glutamate

B. subtilis was cultured as before for labeling with glucose but the cells were washed and resuspended in standard MSgg medium. The cell suspension was dropped on MSgg agar plates, which had $20 \%$ of the potassium glutamate exchanged for $\mathrm{U}^{-{ }^{13} \mathrm{C}_{5}}$ glutamate. The further processing of the cultures was performed as for the glucose labeled samples (see above).

Solutions for preparation of samples for metabolome analysis

$\begin{array}{lrl}\text { PBS (10x) } & \mathrm{NaCl} & 1.37 \mathrm{M} \\ \mathrm{KCl} & 2 \mathrm{mM} \\ & \mathrm{Na}_{2} \mathrm{HPO}_{4} & 100 \mathrm{mM} \\ & \mathrm{KH}_{2} \mathrm{PO}_{4} & 18 \mathrm{mM} \\ & \text { add } \mathrm{H}_{2} \mathrm{O}_{\text {deion }} & 1000 \mathrm{ml} \\ & \text { Adjust pH to 7.4 with } \mathrm{HCl} & \end{array}$




\section{Determination of DNase activity of $Y m d B$}

To test DNase activity, Strep-tagged active and inactive variants of YmdB were purified and incubated at $37^{\circ} \mathrm{C}$ with DNA, which were obtained by PCR with the oligonucleotides ML251 and ML252. As positive control, DNase I was used. As a negative control, the DNA was incubated without protein. $10 \mu \mathrm{l}$ samples were taken after various time intervals after addition of the protein $(1[\mathrm{~min}], 5,15,30,60,120)$, mixed with the respective loading dye and snap frozen. The degradation was analyzed on $1 \% \mathrm{TAE}$-agarose gels.

DNase activity assay reaction

$\begin{array}{lrl}\text { Tris-HCl pH 8.5 } & 50 & \mathrm{mM} \\ \text { Protein of interest } & 1 & \mu \mathrm{M} \\ \text { DNA target } & 1.75 & \mu \mathrm{g} \\ \mathrm{NaCl} & 150 & \mathrm{mM} \\ \mathrm{MnCl}_{2} & 1 & \mathrm{mM} \\ \text { DTT } & 1 & \mathrm{mM} \\ \text { add } 70 \mu \text { l nuclease-free } \mathrm{H}_{2} \mathrm{O} & & \end{array}$




\section{Results}

\subsection{Elevated SinR levels are responsible for the biofilm defect in the $y m d B$ mutant}

Biofilm formation is probably an energetical expensive lifestyle of $B$. subtilis cells, since moieties such as poly- $N$-acetylglucosamine (PNAG), and their precursors for the matrix need to be produced and secreted (Bertram et al., 2011; Roux et al., 2015). Thus, the switch between motile and sessile behavior must be tightly regulated. SinR is the master regulator in this dynamic process of biofilm formation (Chu et al., 2006) and it controls with its antagonists Sinl, SIrR, and SIrA the expression of genes responsible for motility and biofilm formation. The goal of the regulatory action of $\operatorname{SinR}$ is to guarantee exclusive states in each cell, that only one genetic program is expressed at a time. Several studies investigated the SIrR-SinR switch of $B$. subtilis, and, amongst others, they analyzed, if a lack of SIrR is responsible for the $y m d B$ phenotype. The $y m d B$ deletion mutant is not able to express matrix genes and form a biofilm anymore. It was demonstrated, that an overexpression of SIrR restores biofilm formation in the $y$ mdB mutant (Diethmaier et al., 2011). Moreover, the expression of SIrR is under the control of the master regulator SinR. Here, an overexpression of SinR would lead to a permanent low SIrR (or no SIrR) expression state, thus, force motility gene expression. High SinR levels cannot be titrated from the antagonist SIrR and free SinR permanently inhibits the expression of $s / r R$ and matrix genes. The amounts of $\operatorname{Sin} R$ in a bacterial population were already determined by quantitative Western blotting for the $y m d B$ mutant. SinR amounts were increased up to 10-fold above wild type level, with a high error (Diethmaier, 2011; Gerwig, 2014). This high error in the determination of SinR amounts, led to the decision to determine the SinR amounts in the $B$. subtilis wild type 168 and $y m d B$ mutant GP583, once more.

For this purpose, the SinR amounts were determined for three biological replicates of the B. subtilis wild type 168 and the $y m d B$ mutant via quantitative Western blotting. GapA was used as loading control at approximately $35 \mathrm{kDa}$. SinR as protein of interest has a molecular weight of approximately 13 kDa. GapA signal was detected for $2 \mathrm{~min}$ and the SinR signal for was detected for $10 \mathrm{~min}$ (see Fig. 7A). SinR amounts were then determined via the signal strength with ImageJ (see Fig. 7B). In contrast to the previous works, we detected a rather minor increase of $\operatorname{SinR}$ in the $y m d B$ mutant, of up to 2.4-fold above the wild type level. Furthermore, we analyzed the Sinl protein amounts as another protein of the SIrR-SinR switch. Sinl connects the SIrR-SinR switch with the Spo0A phosphorelay. Medium amounts of SpoOA-P lead to expression of Sinl, which inhibits SinR activity (Vlamakis et al., 2013). This process is the initiator of the switch from low SIrR to high SIrR. Quantitative Western blotting was performed for the determination of Sinl protein amounts in wild type and ymdB deletion strain (GP2560 and GP2552). The determination of 
Results

Sinl levels revealed no change in Sinl amounts (see Fig. 7C). Thus, the lack of biofilm formation is most probably only dependent on the elevated SinR levels.

To investigate, if SinR overexpression is responsible for the defect in biofilm formation in the $y m d B$ deletion mutant, we introduced an overexpression plasmid for $\operatorname{SinR}$ (pGP2330) into the transformable wild type strain DK1042. In addition, the overexpression of YmdB (pGP1039) was tested in the wild type and the $y m d B$ mutant to investigate the effects on biofilm formation. For this purpose, genes of interest were cloned into the vector pBQ200, which allows a constitutive expression of proteins. It was already shown, that SinR acts epistatically over YmdB in the B. subtilis 168 background (Diethmaier et al., 2014). We repeated the experiment in the DK1042 background. In addition, we also analyzed the effect of a $\sin R$ deletion on biofilm formation in the DK1042 background. The phenotypes were analyzed via a biofilm drop assay on biofilm-inducing agar (see Fig. 7D). The introduction of the empty vector pBQ200 into DK1042 resulted in stronger wrinkles all over the biofilm, while the transformation with the empty vector had no effect on the phenotype of the $y m d B$ mutant. The overexpression of SinR led to total loss of biofilm formation in the wild type background, while the $y m d B$ mutant did not change its phenotype. The overexpression of YmdB in the wild type led to fewer but stronger developed wrinkles. The overexpression in the $y m d B$ mutant resulted in the restoring of biofilm formation. The deletion of $\sin R$ in the wild type and $y m d B$ mutant led compact macrocolonies with rough surfaces in both genetic backgrounds.

This experiment underlined that elevated SinR amounts in the $y m d B$ mutant are responsible for the defect in biofilm formation. The overexpression of YmdB could only slightly affects the biofilm formation in the wild type but compensates the lack of biofilm formation of the $y m d B$ mutant. The deletion of $\sin R$ (GP2570) leads to strong biofilm formation and a compact macrocolony and the double deletion mutant $\sin R$ ymdB (GP2554) shows that SinR acts also in the DK1042 background epistatically over YmdB. 
A

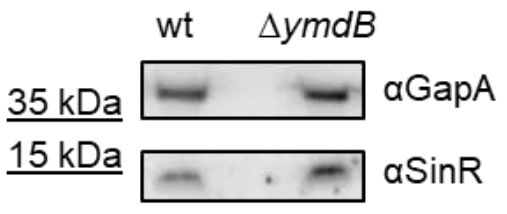

C

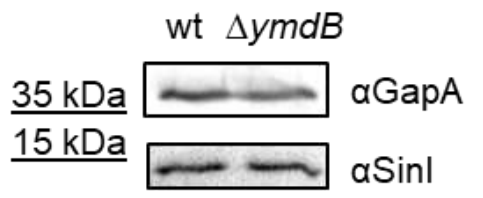

D

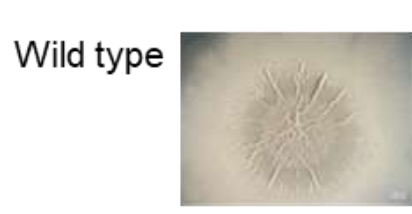

$\Delta y m d B$

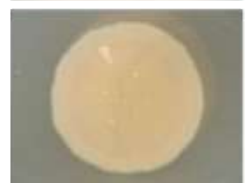

B

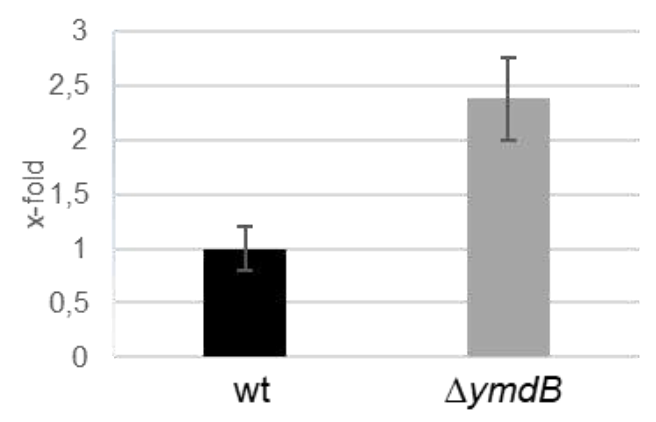

SinR

YmdB

$\Delta \sin R$ overexp. overexp.
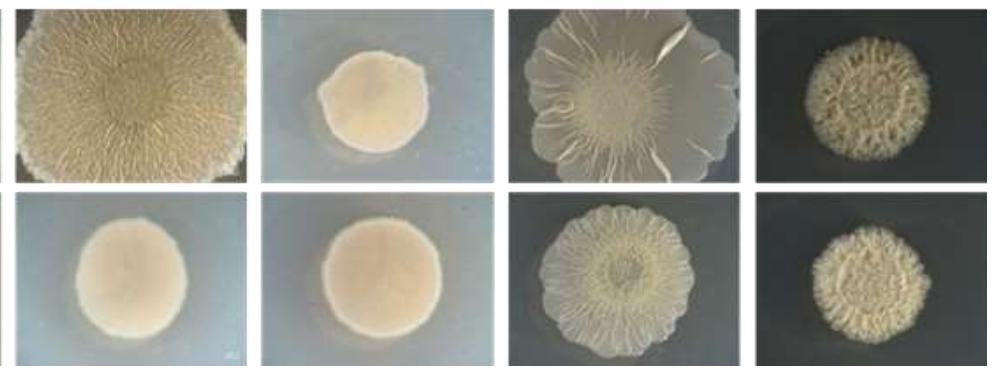

Figure 7 SinR and Sinl protein amounts for wild type and ymdB mutant and effects of SinR and YmdB overexpression on biofilm formation. A) shows a quantitative Western blot for SinR. $15 \mu \mathrm{g}$ of the cytosolic protein fraction was separated by a $15 \%$ SDS-PAGE and transferred to a PVDF membrane. The membrane was separated and probed for GapA as loading control with anti-GapA antibody and for SinR with anti-SinR antibody, respectively. B) shows the relative and normalized SinR amounts of digitalized Western blot images. The relative protein amounts were determined via ImageJ. C) Sinl protein amounts determination for wild type (GP2560) and $y m d B$ mutant (GP2552). Quantitative Western blot of with $10 \mu \mathrm{g}$ of the cytosolic protein fraction was separated by a $12 \%$ SDS-PAGE and transferred to a PVDF membrane. The membrane was separated and probed for GapA as loading control with anti-GapA antibody and for Sinl with anti-Sinl antibody, respectively. D) Biofilm assay for influence of $y m d B$ and $\sin R$ overexpression (overexp.) and deletions $(\Delta)$. Genes were deleted via LFH or overexpressed via the vector pBQ200. The cells were grown until $\mathrm{OD}_{600}$ of 0.9 and $5 \mu$ pipetted on MSgg agar plates. Biofilms were grown for 3 days at $30^{\circ} \mathrm{C}$. All images were taken at the same magnification.

\subsection{Analysis of translational activity and protein stability of SinR in the $y m d B$ mutant}

The overexpression of $\operatorname{Sin} R$ in the $y m d B$ mutant and a subsequent loss of SinR homeostasis seems to be the reason for the loss of biofilm formation. A stronger promoter activity in the $y m d B$ mutant as reason for the increased SinR protein levels can be excluded. RNAseq and microarray data did not reveal 
Results

elevated levels of the mRNA of $\sin R$ (Diethmaier et al., 2014; Gerwig, 2014). It was decided to determine the translational activity for $\sin R$ via a $\beta$-galactosidase assay with translational lacz fusions for the wild type and $y m d B$ mutant. About $960 \mathrm{bp}$ of the upstream region of $\sin R$ and the first four-amino acids (reporter fusion A, pGP2325) and the full-length SinR protein without stop codon (fusion B, pGP2306) were fused to the lacZ gene, respectively. The relatively long upstream region of about $960 \mathrm{bp}$ was chosen, since three promoters are responsible for the synthesis of the transcripts harboring the $\sin R$ mRNA. The plasmids were transformed into the $B$. subtilis 168 wild type and the ymdB mutant GP922.

The expression of reporter fusion A was very low, while the reporter fusion B showed proper expression (see Fig. 8A). Both constructs showed a slightly higher expression in the wild type as in the $y m d B$ mutant. This experiment did not show the repressing effect on SinR levels by YmdB in the wild type.

A

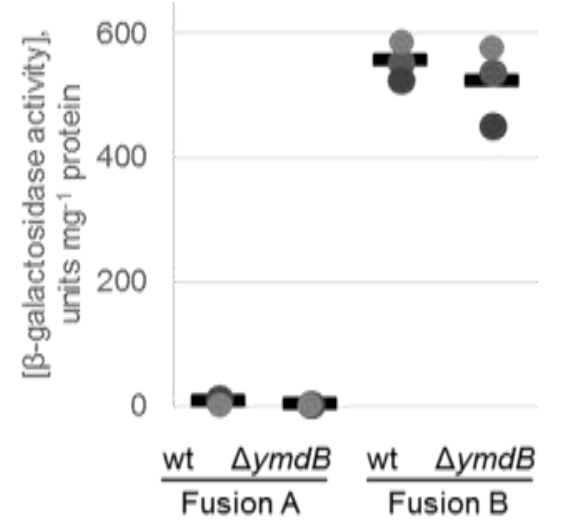

B [Time],
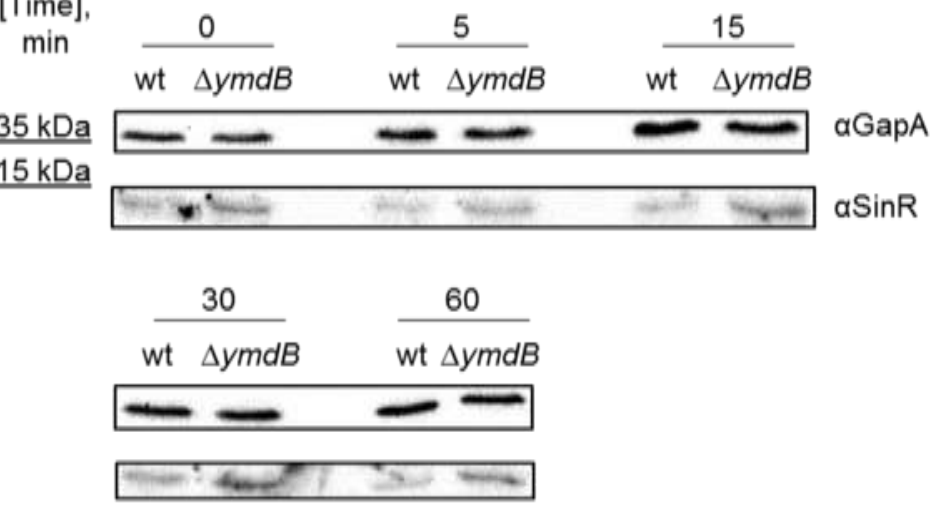

Figure 8 Determination of $\sin R$ translational activity and SinR protein stability in the wild type and $y m d B$ mutant. A) $\beta$-galactosidase assay of reporter fusion A (4-amino acids of SinR) and reporter fusion B (fulllength $\operatorname{SinR}$ without stop codon). Each dot represents one measurement, while the line represents the mean. B) Western blot stability assay for the stability of SinR after inhibition of transcription and translation for analysis of the influence of YmdB on SinR.

Another reason for the decreased levels of $\operatorname{SinR}$ in the wild type could be an influence of YmdB on the stability of $\operatorname{SinR}$. The presence of $Y m d B$ could lead to a faster degradation of SinR, leading to lower SinR protein amounts. We performed an experiment by which we analyzed the SinR amounts in the wild type 168 and the $y m d B$ mutant GP583 over time after the inhibition of transcription and translation via rifampicin and chloramphenicol, respectively (Blötz et al., 2017). When no SinR is synthesized in the cell, a quicker degradation of the protein would be revealed by fading of the Western blot signal over the sampling time. SinR amounts were detected via Western blotting (see Fig. 8B). As loading control, an antibody against GapA was used. We could not detect a destabilizing effect of YmdB in the wild type. The 
SinR protein was over the sampling time range always lower abundant in the wild type cells, compared to the $y m d B$ mutant. A process of a fading signal was not detectable in the wild type. Thus, YmdB does not lead to a faster degradation of SinR. Neither the $\beta$-galactosidase assay, nor the analysis of SinR indicated the mechanism by which the $\operatorname{SinR}$ amounts are increased $y m d B$ mutant. The $\beta$-galactosidase assay data would suggest that the protein amount is equal in wild type and $y m d B$ deletion mutant. Apparently, another regulatory mechanism is for the elevated $\operatorname{Sin} R$ amounts in the $y m d B$ mutant responsible.

\subsection{Influence of the $5^{\prime}$ UTR of $\sin R$ on biofilm formation in the wild type and the $y m d B$ mutant}

A deletion of $y m d B$ leads to an increased amount of $\operatorname{Sin} R$ in $B$. subtilis cultures resulting in a permanent repression of the genes involved in biofilm formation and an increased expression of motility genes. The mRNA amounts of $\sin R$ in the wild type do not differ from the $\sin R$ mRNA amounts in the $y m d B$ mutant and do not explain an overproduction of $\operatorname{Sin} R$ protein in the $y m d B$ mutant. Moreover, a translational lacZ fusion did not show any difference in translational activity for $\sin R$. Finally, it was shown, that the SinR protein amount does not depend on destabilization by e.g. faster degradation in the wild type than in the $y m d B$ mutant. It was tempting to speculate that secondary structures of the $\sin R$ mRNA at the 5' UTR such as a riboswitch might influence the translational activity in the cell, and YmdB directly or indirectly affects this translational activity (Breaker, 2012). Such RNA structures could be influenced by the fusion to large genes such as the lacZ gene $(3 \mathrm{~kb})$. This large $\sin R$-lacZ construct could be one reason for the lack of differences in $\beta$-galactosidase activity of the wild type and the $y m d B$ mutant. In addition, Kruse found also a silent mutation in $\sin R$ (GP1669 $\operatorname{Sin} R^{\text {P42P }}$ harboring a C $\rightarrow$ T transition at bp 126 of $\sin R$ ), when she isolated $y m d B$ suppressor mutants, which restored the ability to form a biofilm (Kruse, 2013). Such a silent mutation, which changes the DNA and subsequently the RNA sequence, but not the primary structure of the protein, could lead to a change of the secondary structure of the $\sin R$ transcripts. A change in mRNA structure could decrease translation rate and subsequently the SinR protein amounts in the $y m d B$ suppressor mutant with the silent mutation and allow the switch from motility to a sessile lifestyle again.

The "RNAstructure" software (Mathews et al., 2016) was used to analyze the sequence of $\sin R$ beginning at the $5^{\prime}$ UTR of $\sin R$ at position -33 bp until its stop codon for RNA structure prediction (see Fig. 9 and 10C). This in silico structure showed a stem loop directly at the beginning of the transcript, which includes the RBS, the spacer between the RBS and the start codon, and ends at the +10 position of $\sin R$. Interestingly, this structure was predicted to be altered by introduction of the mutation, which was found by Kruse (2013) (see Fig. 9A, B II). Furthermore, the spacer between RBS and the start codon was mutated in silico leading to a strongly altered RNA structure (see Fig. 9A, B III). The DK1042 and the isogenic ymdB 
Results

mutant GP2559 were transformed with $\sin R$ with the native and mutated 5' UTR via CCR. The different $\sin R$ upstream variants were then introduced via LFH. For this purpose, the $\sin R$ gene with and without mutated 5' UTR was fused to a tetracycline resistance cassette and introduced into wild type and ymdB mutant. The following strains were constructed harboring either the native 5' UTR of $\sin R$ (see Fig. 9A, I) or the mutated 5' UTR of $\sin R$ (see Fig. 9A, III) in the wild type or the ymdB mutant background: GP2560

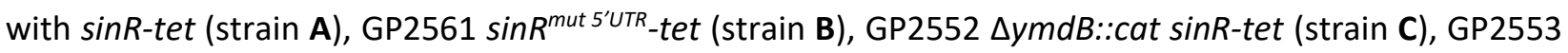
$\triangle y m d B:: c a t \sin R^{m u t 5^{\prime} U T R}$-tet (strain D). These strains were analyzed for their biofilm phenotype on MSgg agar (see Fig. 10A).

The strain A showed proper biofilm formation as a wild type strain. This excludes an effect of the 3' UTR from $\sin R$ on biofilm formation. The fusion of the tet-cassette did not change the biofilm phenotype. The strain B showed the phenotype as a $\sin R$ mutant by forming a compact and strongly structured macrocolony. Strain $C$ showed a smooth colony as documented for a $y m d B$ mutant. The strain $D$ resulted in another phenotype by forming a macrocolony with a structured center and a surrounding halo with an unwrinkled structure. The structured center of the macrocolony of strain $D$ was not as strongly wrinkled as strain B or a $\sin R$ deletion mutant. The mutation of the $5^{\prime}$ UTR of $\sin R$ has the effect of a $\sin R$ mutant in the wild type, while in the $y m d B$ mutant, this effect is not observed.

Furthermore, we investigated the SinR amounts in these strains by Western blotting (see Fig. 10B). We could detect a higher molecular weight for $\operatorname{Sin} \mathrm{R}$ of approximately $1.3 \mathrm{kDa}$ in strain $\mathrm{B}$, compared to the Western blot signal of strain A. The SinR amounts of strain A and B were similar. We found another start codon upstream of $\sin R$, which is positioned directly after the $\operatorname{sinl}$ stop codon. This start codon is in frame and would increase the SinR molecular weight from $12.98 \mathrm{kDa}$ to $14.31 \mathrm{kDa}$ (see Fig. 9A, I; see Fig. 10C). This increase in molecular weight would perfectly fit to our observations for the increased molecular weight detected in the Western blot for strain B. The strain D revealed no increase in molecular weight of SinR from 12.98 to $14.31 \mathrm{kDa}$ and showed lower amounts of SinR compared to strain C, which revealed the typical overexpression of $\operatorname{Sin} R$ in the $y m d B$ mutant background (see Fig. 10C). This would explain the phenotype of the biofilm from strain $D$, since the strong SinR overexpression got lost, while enough intact protein in the cell was produced. This experiment showed that the upstream region of $\sin R$ could be the major target for regulation of biofilm formation in a YmdB dependent manner. The ribosome seems to have no access to the native RBS in strain B, leading to a translation start at the start codon upstream. Using the second start codon upstream would explain the elongated but probably inactive protein, according to the phenotype of the macrocolony. The strain $D$ shows a decrease in $\operatorname{Sin} R$ expression compared to a $y m d B$ mutant, and no elongated $\operatorname{Sin} R$ protein as in strain $B$, indicating that the second start codon upstream is not used, and a functional protein of original length is produced in strain D. It seems 
like the access of the ribosome to the RBS in front of $\sin R$ start codon is impeded in the presence of YmdB, while the absence of YmdB allows the ribosome an easier access and synthesis of the active protein.

A

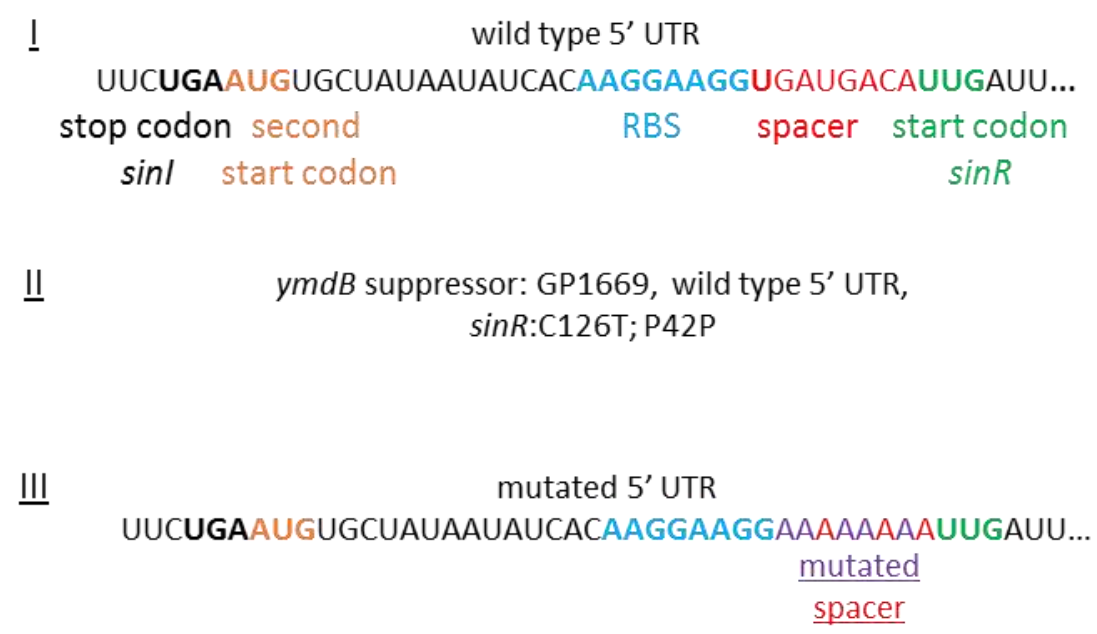

B

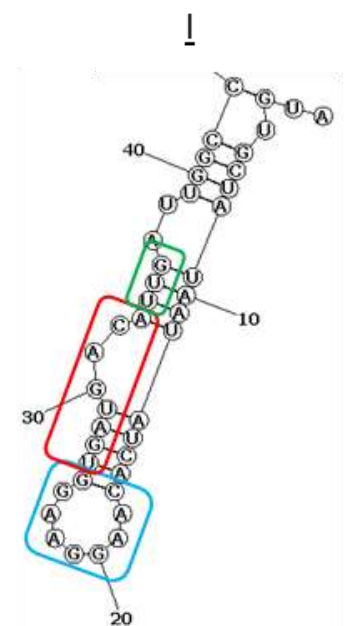

II
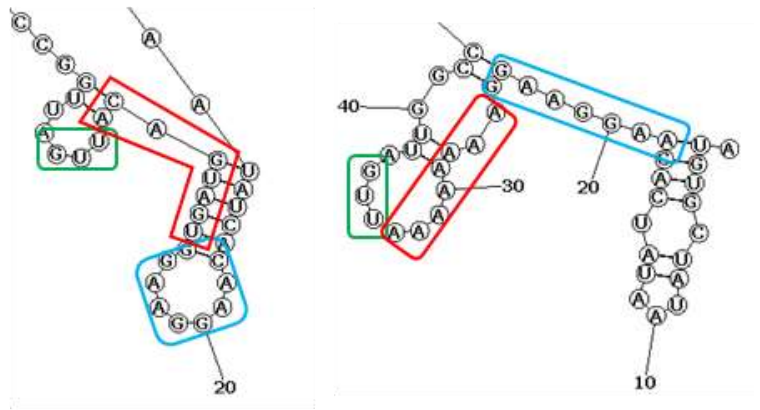

Figure 9 Analysis of the effect of the $\sin R 5^{\prime}$ UTR on biofilm formation in wild type and ymdB mutant.

A) The region from $\sin /$ stop codon (bold) to the native $\sin R$ start codon (green) is shown with highlighted RBS (blue), and spacer (red/purple), which was mutated by CCR. The second start codon, upstream of the original $\sin R$ start codon is highlighted in orange. $\ln \mathrm{A})$, the different RNA sequences are listed, which were used to predict the secondary mRNA structures (only the secondary structure with highest likelihood is presented, the whole region for the RNA structure prediction is indicated in Fig. 10C) in B), using the "RNAstructure" software. The RBS, spacer and the start codon in the predicted secondary structures are shown in blue, red, and green, respectively. 
A

$\sin R^{\text {mut }} 5$ UTR

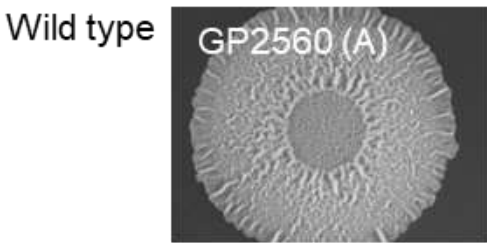

$\Delta y m d B$
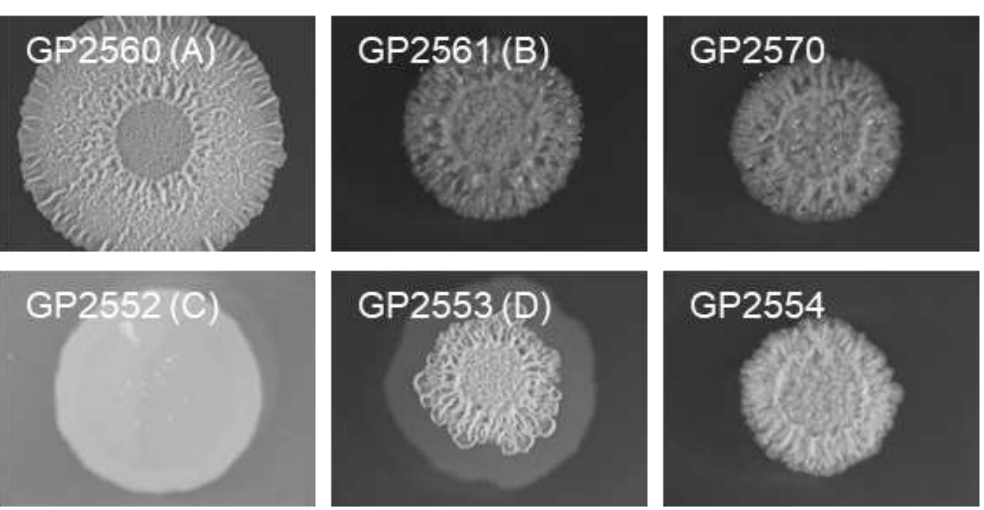

B

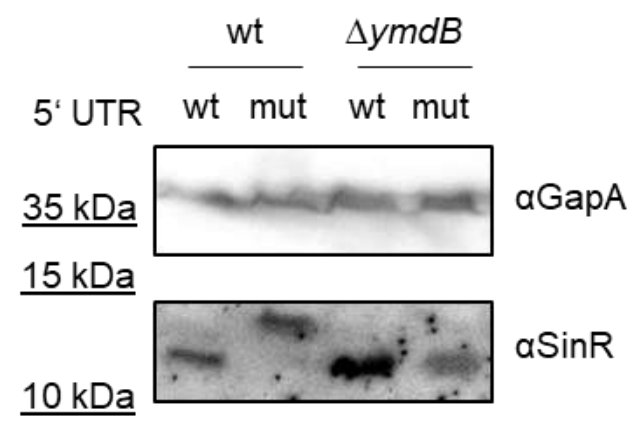

C

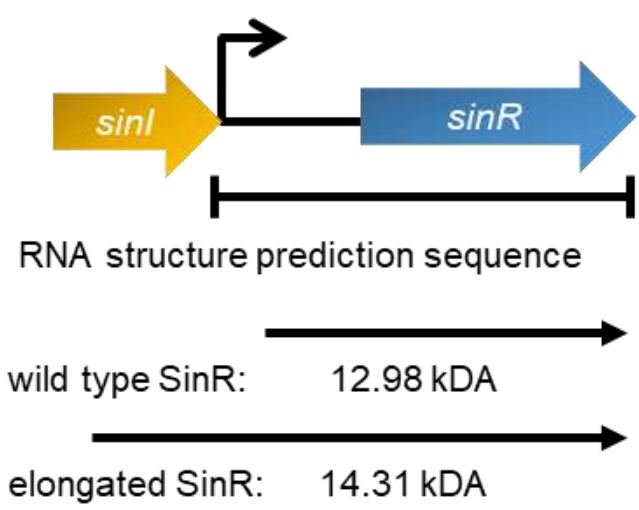

Figure 10 Influence of the 5' UTR of $\operatorname{sinR}$ mRNA. A) Biofilm assay on MSgg agar grown for 3 days of B. subtilis wild type and $y m d B$ deletion strains harboring original and mutated $5^{\prime}$ UTR in the DK1042 background. Additionally, $\sin R$ and $\sin R y m d B$ deletion strains are shown for comparison of the phenotypes. All images were taken at the same magnification. B) Western blot for wild type harboring original and mutated 5' UTR, respectively, (GP2560 and GP2561), and ymdB deletion mutant harboring original (wt) and mutated 5' UTR (mut), respectively (GP2552 and GP2553). The membrane was probed with GapA antibody as loading control and SinR antibody as protein of interest. C) Genomic context of $\sin R$, with indications for the used sequence for in silico RNA structure prediction, and possible protein variants of SinR by using the original and upstream start codon.

\subsection{YmdB does not act as DNase}

Since $Y m d B$ is known to be a phosphodiesterase, it was promising to analyze the activity of YmdB for degradation of different molecules in the cell, which could act as target of the protein. It was already shown, that YmdB hydrolyses the artificial phosphodiesterase substrate bis-pNPP. Only weak activity was shown against signal nucleotides. However, the actual target of $\mathrm{YmdB}$ regulatory function is not described yet. Since phosphodiester bonds are not only present in signal nucleotides, there are further targets for 
phosphodiesterases in a cell. The DNA or the RNA backbone, and phospholipids at their head group harbor phosphodiester bonds (Berg et al., 2018). We decided to test YmdB for degradation of DNA. We amplified DNA targets via PCR by amplification of the $\sin R$ gene. We purified YmdB-Strep (pGP1917) and the inactive YmdB ${ }^{\mathrm{E} 39}$-Strep (pGP1916) via a StrepTrap and gel filtration. YmdB proteins were verified to be active after purification and in the reaction buffer by using the bis-pNPP-assay for determination of the phosphodiesterase activity of YmdB (Diethmaier et al., 2014). The proteins were incubated with DNA at $37^{\circ} \mathrm{C}$ under conditions used for the phosphodiesterase activity assay. Samples were taken from 1 min to 2 $\mathrm{h}$ after addition of the protein. The samples were snap frozen, and DNA targets tested for degradation via TAE-agarose electrophoresis (see Fig. 11). DNase I was used as positive control, DNA target without additive protein was used as negative control as well as the DNA incubated with inactive YmdB ${ }^{\mathrm{E} 39 \mathrm{Q}}$. The test for DNase activity showed no degradation of DNA for the negative control as well as for the active or inactive $\mathrm{YmdB}$ variants. The positive control showed after $5 \mathrm{~min}$ incubation time degradation of the DNA target and nearly no DNA was present after $2 \mathrm{~h}$ incubation with DNase I. YmdB seems to have no activity against DNA and it can be excluded, that the enzyme influences the behavior of the cell via DNA degrading activity.

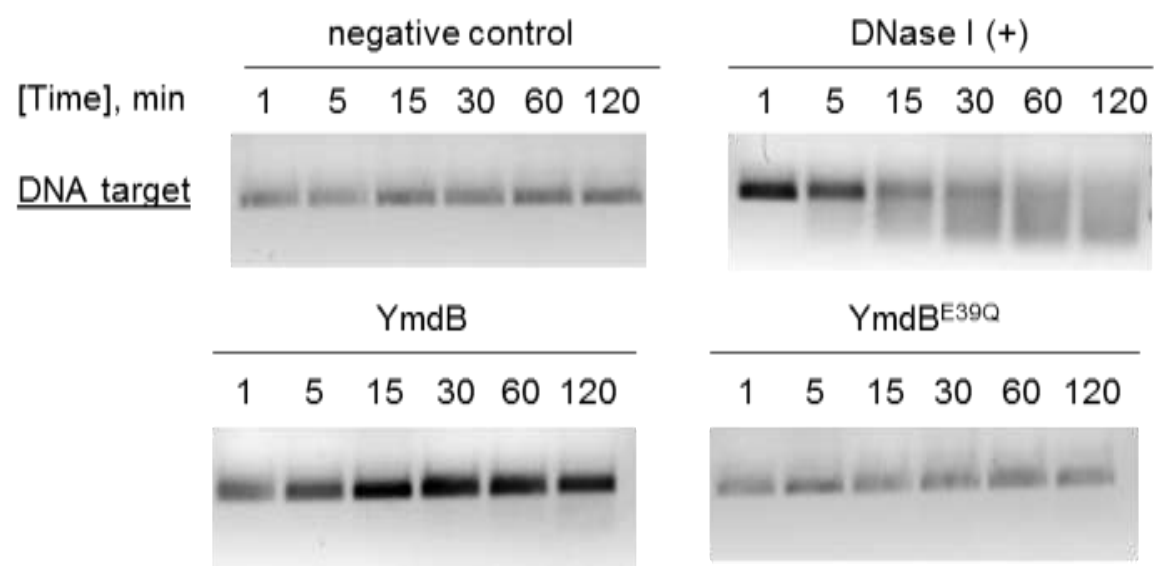

Figure 11 DNase assay for YmdB. A) DNase degradation assay over time on $1 \%$ TAE-agarose gel separated for $45 \mathrm{~min}$ at $60 \mathrm{~V}$. Gels are stained with HDGreen. 
Results

\subsection{Identification of potential RNA interaction partners of $\mathrm{YmdB}$ and its influence on biofilm formation}

The $y m d B$ gene is clustered with rny and spovs in one operon. The rny gene codes for the important RNase $\mathrm{Y}$ in $B$. subtilis. RNase $\mathrm{Y}$ also influences biofilm formation and targets $\sin R$ transcripts (Lehnik-Habrink et al., 2011). It was shown by pull down experiments and bacterial-two hybrid screens that YmdB interacts with RNase $Y$ (Diethmaier, 2011). Furthermore, Gerwig found that YmdB binds nonspecifically to RNA (Gerwig, 2014). Moreover, YmdB shows phosphodiesterase activity, which is also typical for an RNase (Diethmaier et al., 2014). Taken together, YmdB could act as RNA adaptor protein or processing protein leading indirectly to the elevated SinR amounts in the $y m d B$ mutant. Therefore, we wanted to study, if another RNA or transcript is influenced by YmdB acting on biofilm formation or influencing SinR expression. We performed an RNA co-precipitation experiment with active and inactive YmdB proteins to answer this question. The inactive YmdB variant (Diethmaier et al., 2014) was used to find also targets, which could be directly processed or degraded by the active YmdB enzyme. We used Strep-tagged proteins for purifying the proteins of interest and their bound RNAs. For the RNA coprecipitation experiment, we used B. subtilis 168 strains, which harbored deletions of the encoding genes for the proteins of interest and reintroduced constitutively expressed Strep-tagged protein variants. As a negative control, we used the $y m d B$ deletion strain GP583 with the empty vector pGP382. The strain GP469 harboring a csrA deletion transformed with the pGP380 for constitutive expression of Strep-CsrA was used as positive control. CsrA is known to bind to hag mRNA to inhibit its expression (Yakhnin et al., 2007). As a protein control, we used the MZ303 strain harboring a deletion of $p t s H$ transformed with pGP961 for a constitutive expression of Strep-PtsH. The protein control was first introduced into the co-precipitation experiments, when samples in LB medium were prepared. This control is used to detect RNAs, which are purified by a Strep-tag purification with a protein, which is not known for interaction with RNAs. The co-precipitated RNAs from the negative and protein controls can be excluded after sequencing of the RNA samples. Cells were cultivated in minimal medium and complex medium, the proteins purified, the RNAs precipitated from the proteins and samples finally sequenced in the G2L, Göttingen. SDS-PAGE and silver staining verified the purification of the proteins (see Fig. 12). We performed two experiments in minimal medium (CSE glucose) and one experiment in complex medium (LB medium). For the minimal medium experiments, the mean NPKM was used for further analyzes. A threshold of at least a NPKM value of 500 and a 2-fold enrichment compared to the empty vector was determined for RNAs of interest.

The RNA co-precipitation for the positive and protein control are shown in Table 4. The CsrA coprecipitation as positive control in minimal medium showed enrichment of hag and csrA mRNAs, while the 
determined threshold excluded further RNAs. Co-precipitation with CsrA in rich medium showed a proper enrichment of hag as well and csrA RNAs, but also of RNAs involved in translation such as rp/N were strongly enriched compared to the empty vector control (Zhu and Stülke, 2018). However, the highest NPKM values were identified hag mRNA in minimal and rich medium. The positive control with CsrA showed clearly a strong enrichment of hag mRNA indicating that a proper method was applied for identifying interacting RNAs of RNA-binding proteins. The co-precipitation with $\mathrm{PtsH}$ as protein control in rich medium showed enrichment of $r p / V$ mRNA, which is also involved in translation (Zhu and Stülke, 2018). Moreover, an enrichment for $\mathrm{pts} H$ itself was also detected. The enrichment of the active and inactive $\mathrm{YmdB}$ NPKM values were compared with the controls for the respective experiments. In addition, the selected RNAs were compared to RNAseq data from strains harboring active and inactive $y m d B$ variants for the possible RNA targets for RNA processing hints and expression strength. The potential RNA targets of YmdB variants are summed up in Table 5 with the according RNAseq data (ratio: $y m d B^{E 39 Q} /$ wt are given (Gerwig, 2014)). Compared to the control experiments, we found several RNAs highly enriched, which are shortly summed in the following part. Strikingly, active and inactive YmdB showed a strongest enrichment of its own mRNA in each experiment. The strongest enriched mRNA, next to $y m d B$ itself, was $y p p F$ in minimal medium with inactive $\mathrm{YmdB}$. $y p p F \mathrm{mRNA}$ was also strongly enriched by co-precipitation with the inactive YmdB in rich medium. The essential trxA was the strongest enriched mRNA for the co-precipitation by the active $Y m d B$ in rich medium and also enriched in minimal and rich medium by the inactive YmdB. $y h d X$ $m$ RNA was strong enriched by fishing in minimal medium with the active and inactive YmdB. Furthermore, the $h p f$ and yuzK mRNAs were enriched by active and inactive $Y m d B$ in minimal medium. speD, dctP, ysbB, and lutP mRNAs were enriched by inactive YmdB in rich medium. ytzE, spoVG, Idh, and IctP mRNAs were enriched by active $\mathrm{YmdB}$ in minimal medium. qoxC mRNA was enriched by active $\mathrm{YmdB}$ in rich medium and $g c v H$ mRNA was enriched by inactive YmdB in minimal medium. Furthermore, an enrichment for the S6 RNA was found by YmdB fishing in rich medium.

Finally, the genes, which encoded for identified RNAs were deleted, or overexpressed in case of essentiality, using the DK1042 and the isogenic ymdB deletion mutant GP2559. When YmdB would act as protector of a respective RNA, the RNA levels would decrease in the absence of $y m d B$. A deletion of the respective gene in the wild type would lead to a similar biofilm phenotype as in the $y m d B$ mutant. A deletion in $y m d B$ mutant of the encoding gene would not affect the lack of biofilm formation. An overexpression of the respective feature in the $y m d B$ mutant would restore biofilm formation or result in an overproduction of the matrix in the wild type. When YmdB would degrade or process the potential RNA interaction partner, an accumulation of the respective RNA or part of the RNA should be present in the $y m d B$ mutant. The deletion of the gene encoding the RNA would lead the restoring of biofilm formation in 
Results

the $y m d B$ mutant or an overproduction of the biofilm matrix in the wild type background. An overexpression of the respective feature should lead in the wild type background to a lack of biofilm formation and should not affect the lack of biofilm formation in the $y m d B$ mutant.

The strains were tested on biofilm-inducing agar for effects on biofilm formation (see Fig. 13). The introduction of the deletions into the $y m d B$ strain did not lead to a restoring of biofilm formation with any additional gene deletion. Interestingly, the introduction of the deletions into the wild type showed different effects on biofilm formation. The $g c v H$ mutant showed the most remarkable macrocolony with a ring like structure. Further investigations of the $\mathrm{gcvH}$ mutant showed, that the defect in biofilm formation is probably caused by an auxotrophy for lipoic acid, and more a growth defect on MSgg minimal agar instead of a lack of biofilm formation (Christensen et al., 2011). The speD mutant also showed a lack of biofilm formation by a less structured macrocolony but no total loss of biofilm formation. This was not surprising, since the speD mutant showed also a defect in biofilm formation in the NCBI3610 background (Hobley et al., 2017). Furthermore, the deletion mutants of $q 0 x C, \operatorname{dct} P$, hpf and $y h d X$ showed an even stronger wrinkled and compact macrocolony morphology than the wild type. The deletion mutants of $y s b B, y u z K$ and lutP developed a macrocolony with less wrinkles but the wrinkles seem to be stronger developed than the ones of the wild type. Since we were not able to delete trxA and the S6 RNA, we overexpressed them via $\mathrm{pBQ} 200$. These overexpressions of trxA and S6 RNA showed no or only a weak effect on biofilm formation of the wild type and no restoring of biofilm formation in the $y m d B$ mutant.

The experiments showed for the RNA co-precipitation with the YmdB variants an increased variety compared to the CsrA control. I might be possible that YmdB acts on a global level as RNA-binding protein influencing biofilm formation, or the responsible RNA target for the lack of biofilm formation in the $y m d B$ mutant was not involved in the selection. Finally, it could be possible that YmdB acts not as RNA-binding protein and another feature of the enzyme is responsible for the regulatory mechanism for the switch from motility and biofilm formation in the cell.

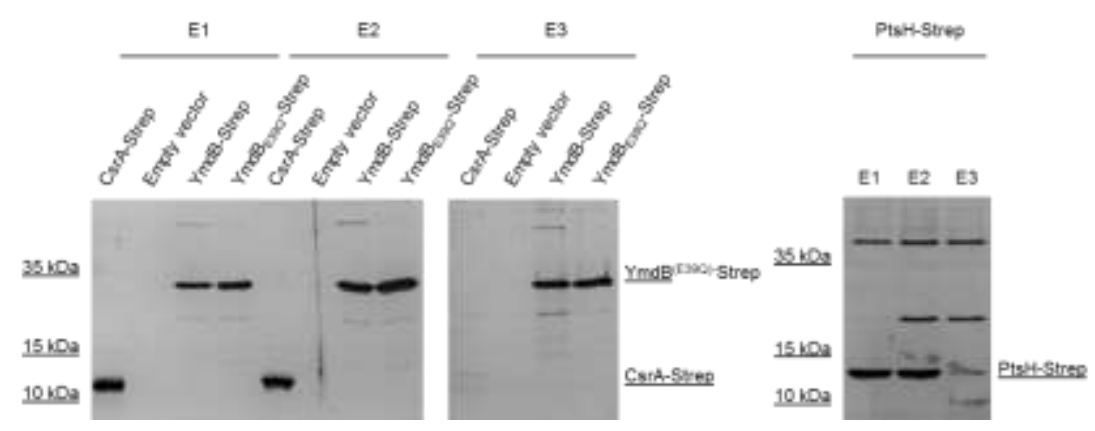

Figure 12 Validation of Streptactin purification of protein of interest. Exemplary protein purification via Streptactin packed gravity flow columns. $500 \mathrm{ml}$ cultures were grown in LB or CSE glucose medium, cells disrupted via the French Press and proteins purified as in the method section described. The purification of the proteins for RNA precipitation was verified via $15 \%$ SDS-PAGE and silver staining. 
Table 4 Overview of enriched RNA with CsrA (positive control, hag mRNA interaction) and PtsH (protein control). Data sorted by enrichment to the empty vector control. mRNAs of the proteins used for co-precipitation, and the positive control hag mRNA are shown in bold.

\begin{tabular}{|c|c|c|c|c|c|c|}
\hline \multirow[b]{2}{*}{ Gene } & \multicolumn{3}{|c|}{ NPKM values ${ }^{1}$} & \multicolumn{3}{|c|}{$\begin{array}{l}\text { x-fold enrichment } \\
\text { compared to }\end{array}$} \\
\hline & $\begin{array}{r}\text { Empty } \\
\text { vector (-) }\end{array}$ & $\begin{array}{r}\text { PtsH } \\
(-)\end{array}$ & $\begin{array}{r}\text { CsrA } \\
(+)\end{array}$ & $\begin{array}{r}\text { Empty } \\
\text { vector (-) }\end{array}$ & $\begin{array}{r}\text { PtsH } \\
(-)\end{array}$ & $\begin{array}{r}\text { CsrA } \\
(+)\end{array}$ \\
\hline \multicolumn{7}{|c|}{ Top enriched RNAs by fishing with CsrA in minimal medium (CSE glucose) } \\
\hline csrA & 58 & & 695 & 12.0 & & \\
\hline hag & 11533 & & 46826 & 4.1 & & \\
\hline \multicolumn{7}{|c|}{ Top enriched RNAs by fishing with CsrA in complex medium (LB) } \\
\hline$r p / N$ & 44 & 5336 & 3028 & 68.8 & 0.6 & \\
\hline$r p / V$ & 22 & 4856 & 1371 & 62.3 & 0.3 & \\
\hline$r p s Q$ & 44 & 4646 & 2714 & 61.7 & 0.6 & \\
\hline$r p m D$ & 45 & 5670 & 2691 & 59.8 & 0.5 & \\
\hline$r p / L$ & 38 & 2254 & 2138 & 56.3 & 0.9 & \\
\hline hag & 8516 & 21185 & 288713 & 33.9 & 13.6 & \\
\hline csrA & 200 & 60 & 966 & 4.8 & 16.1 & \\
\hline \multicolumn{7}{|c|}{ Top enriched RNAs by fishing with PtsH in complex medium (LB) } \\
\hline$r p / V$ & 22 & 4856 & 1371 & 220.7 & & 3.5 \\
\hline$r p m D$ & 45 & 5670 & 2691 & 126.0 & & 2.1 \\
\hline$r p / N$ & 44 & 5336 & 3028 & 121.3 & & 1.8 \\
\hline$r p s Q$ & 44 & 4646 & 2714 & 105.6 & & 1.7 \\
\hline$r p s H$ & 49 & 5029 & 1536 & 102.6 & & 3.3 \\
\hline$p t s H$ & 158 & 3798 & 1435 & 24.0 & & 2.7 \\
\hline
\end{tabular}

\footnotetext{
${ }^{1}$ These are normalized reads for nucleotide activities per kilobase of exon model per million mapped reads (NPKM) values. NPKM values represent the transcriptional activity or covering of all identified regions.
} 
Results

Table 5 Overview of enriched RNA with YmdB and $\mathrm{YmdB}^{\mathrm{E39Q}}$. Data sorted by enrichment to empty vector control. Multiple identified mRNAs by different experiments are clustered and shaded in the same grey.

\begin{tabular}{|c|c|c|c|c|c|c|c|c|c|c|}
\hline \multirow[b]{2}{*}{ Gene } & \multirow[b]{2}{*}{$\begin{array}{l}\text { YmdB } \\
\text { variant }\end{array}$} & \multirow[b]{2}{*}{ Medium } & \multicolumn{4}{|c|}{ NPKM values } & \multicolumn{3}{|c|}{\begin{tabular}{|c|} 
x-fold enrichment \\
by fishing with YmdB compared to
\end{tabular}} & \multirow[b]{2}{*}{$\begin{array}{r}\text { RNAseq } \\
\text { ia/a } 2\end{array}$} \\
\hline & & & $\begin{array}{r}\text { Empty } \\
\text { vector (-) }\end{array}$ & $\begin{array}{r}\text { PtsH } \\
(-)\end{array}$ & $\begin{array}{r}\text { CsrA } \\
(+)\end{array}$ & YmdB & $\begin{array}{r}\text { Empty } \\
\text { vector (-) }\end{array}$ & $\begin{array}{r}\text { PtsH } \\
(-)\end{array}$ & $\begin{array}{r}\text { CsrA } \\
(+)\end{array}$ & \\
\hline$\overline{y m d B}$ & inactive & $\overline{C S E G}$ & 12 & & 5 & 17632 & 1469.3 & & 3526.4 & 0.7 \\
\hline$y m d B$ & active & CSEG & 12 & & 5 & 17000.5 & 1416.7 & & 3400.1 & 0.7 \\
\hline$y m d B$ & inactive & LB & 47 & 80 & 61 & 3912 & 83.2 & 48.9 & 64.1 & 0.7 \\
\hline$y m d B$ & active & LB & 47 & 80 & 61 & 1105 & 23.5 & 13.8 & 18.1 & 0.7 \\
\hline$y p p F$ & inactive & CSEG & 20.5 & & 5.5 & 718.5 & 35.0 & & 130.6 & 0.9 \\
\hline yppF & inactive & LB & 63 & 226 & 52 & 636 & 10.1 & 2.8 & 12.2 & 0.9 \\
\hline $\operatorname{tr} x A$ & inactive & CSEG & 86 & & 23 & 2168 & 25.2 & & 94.3 & 1.4 \\
\hline $\operatorname{trxA}$ & inactive & LB & 233 & 435 & 241 & 1154 & 5.0 & 2.7 & 4.8 & 1.4 \\
\hline $\operatorname{tr} x A$ & active & LB & 233 & 435 & 241 & 875 & 3.8 & 2.0 & 3.6 & 1.4 \\
\hline$y h d X$ & active & CSEG & 204 & & 20 & 2626 & 12.9 & & 131.3 & 1.7 \\
\hline$y h d x$ & inactive & CSEG & 204 & & 20 & 1716 & 8.4 & & 85.8 & 1.7 \\
\hline speD & inactive & LB & 971 & 3537 & 148 & 8449 & 8.7 & 2.4 & 57.1 & 0.6 \\
\hline$d c t P$ & inactive & LB & 1036 & 684 & 158 & 5901 & 5.7 & 8.6 & 37.4 & 2 \\
\hline$y s b B$ & inactive & LB & 679 & 14 & 165 & 2938 & 4.3 & 209.9 & 17.8 & 1.1 \\
\hline$h p f$ & active & CSEG & 3530.5 & & 1213 & 14329.5 & 4.1 & & 11.8 & 2.7 \\
\hline$h p f$ & inactive & CSEG & 3530.5 & & 1213 & 7476 & 2.1 & & 6.2 & 2.7 \\
\hline yuzK & active & CSEG & 454 & & 119 & 1481 & 3.3 & & 12.4 & 0.3 \\
\hline yuzK & inactive & CSEG & 454 & & 119 & 1017 & 2.2 & & 8.5 & 0.3 \\
\hline$y t z E$ & active & CSEG & 249.5 & & 36.5 & 784 & 3.1 & & 21.5 & 2.3 \\
\hline$g c v H$ & inactive & CSEG & 802.5 & & 142.5 & 2455 & 3.1 & & 17.2 & 0.7 \\
\hline qoxC & active & LB & 1314 & 1736 & 1151 & 4010 & 3.1 & 2.3 & 3.5 & 0.6 \\
\hline lutP & Inactive & LB & 959 & 149 & 1126 & 2515 & 2.6 & 16.9 & 2.2 & 6.45 \\
\hline spoVG & active & CSEG & 1204 & & 343 & 2991 & 2.5 & & 8.7 & 1.5 \\
\hline Idh & active & CSEG & 10577.5 & & 2516 & 22734 & 2.1 & & 9.0 & 0.5 \\
\hline IctP & active & CSEG & 2304.5 & & 817.5 & 4915 & 2.1 & & 6.0 & 0.5 \\
\hline \multicolumn{11}{|c|}{ Enriched RNA features } \\
\hline S6 RNA & active & LB & 1649 & 362 & 308 & 4861 & 3.0 & 13.4 & 15.8 & 0.5 \\
\hline
\end{tabular}

${ }^{2}$ RNAseq ia/a: RNA sequencing NPKM values from a strain harboring the inactive YmdB ${ }^{\text {E39Q }}$ variant divided by NPKM values from the wild type strain. 


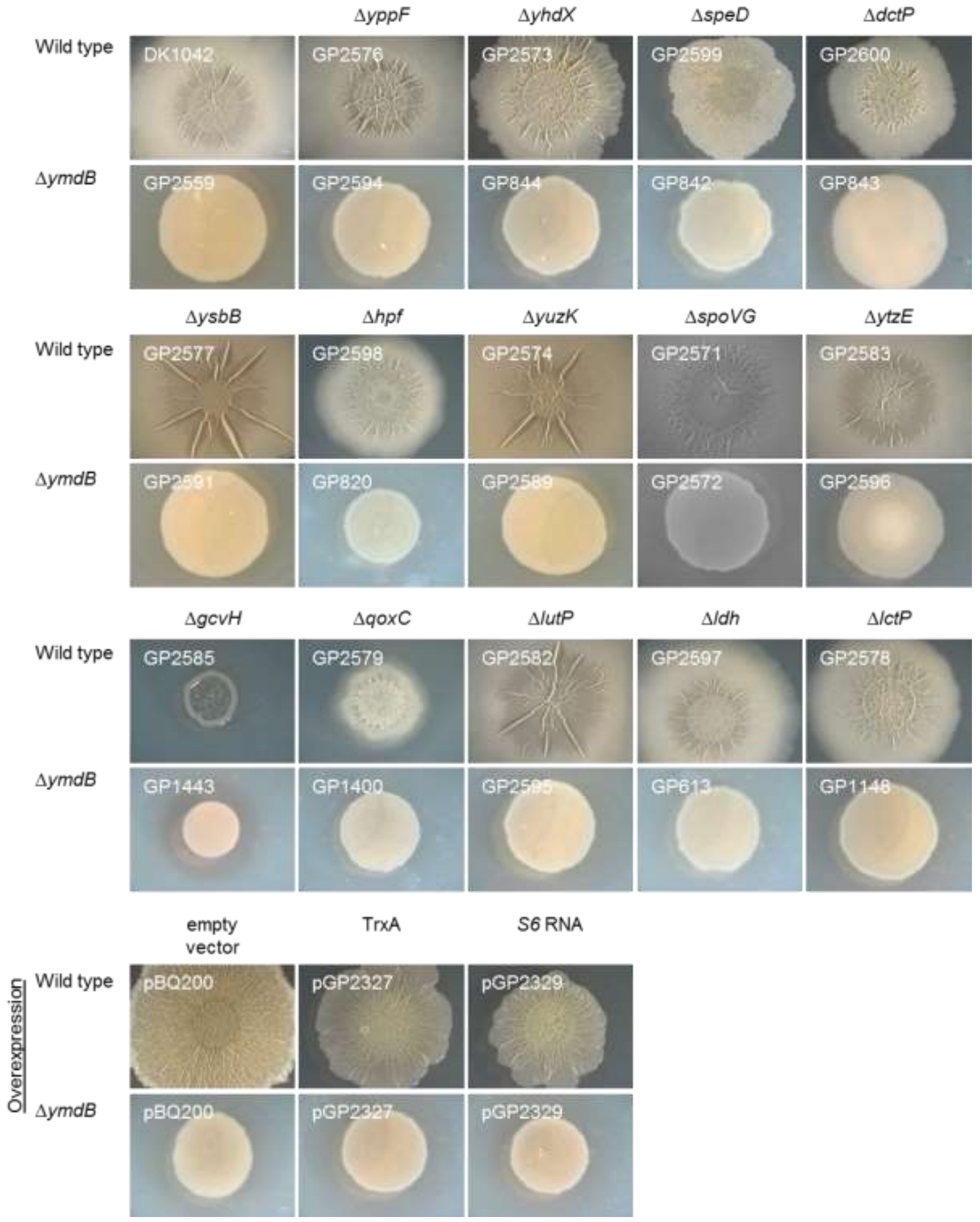

Figure 13 Influence of deletion or overexpression of possible RNA interaction partners of YmdB. The biofilm assay shows deletions and overexpression of genes of selected RNAs (see Tab. 5) in the DK1042 wild type and the $y m d B$ mutant (GP2559). The overexpression was performed using the pBQ200 vector. The biofilm assay was performed on MSgg agar plates. The plates were incubated for 3 days at $30^{\circ} \mathrm{C}$. All images were taken at the same magnification. 
Results

\subsection{Influence of SpoVG on biofilm formation and fishing for potential RNA binding partners of the} protein

It was shown for L. monocytogenes that the conserved RNA-binding protein SpoVG has an effect on resistance, virulence, and swarming motility (Burke and Portnoy, 2016). The SpoVG protein is also present in B. subtilis. Interestingly, spoVG RNA was also detected in RNA co-precipitation experiments with active YmdB in minimal medium (see Results 4.5.). Since SpoVG is involved in behavior like swarming motility, we checked the influence of the spoVG gene deletion in combination with $\sin R$ and $y m d B$ mutants, as well as in the $\sin R y m d B$ double mutant for changes in biofilm formation. Furthermore, we tested the effect of overexpression in the wild type and spoVG mutant itself. The different genetic modifications were screened by a biofilm assay (see Fig. 14A). Moreover, we performed RNA co-precipitation experiment with the protein.

A deletion of spoVG (GP2571) led to an extended macrocolony and wrinkle formation all over the colony. A single deletion of $\sin R$ (GP2570) led to a very compact and rough structured macrocolony phenotype. The introduction of the spoVG mutation into a $\sin R$ mutant (GP2587) resulted in a wide extended macrocolony with less but very well-developed wrinkles. In addition, the wrinkled surface of the sinR spoVG double mutant (GP2587) showed liquid droplets (properly condensed water) on the unwrinkled party of the surface, indicating a strong hydrophobicity of the surface. This could be reached by an overexpression of BsIA, the bacterial hydrophobin (Vlamakis et al., 2013). The ymdB spoVG double mutant (GP2572) showed a smooth and shiny macrocolony without wrinkles, which seems to be more extended over the surface of the agar than the $y m d B$ mutant. The $\sin R y m d B$ double mutant (GP2554) appeared as a compact and rough structured macrocolony as for the sinR mutant (GP2570). The introduction of the spoVG deletion in addition to the $\sin R y m d B$ deletions (GP2588) showed a wide extended macrocolony with liquid droplets on the surface. This is a surface structure comparable to the $\sin R$ spoVG double mutant (GP2587). The colony of the triple $\sin R$ spoVG ymdB mutant (GP2588) was less extended over the surface of the agar than the sinR spoVG mutant (GP2587). The deletion of spoVG has a minor effect in the wild type but shows a very strong effect on biofilm formation in combination with a $\sin R$ deletion. As seen before, the deletion of spoVG has not the power to overcome the $y m d B$ mutant phenotype in biofilm formation. The overexpression of SpoVG led to a compact structured macrocolony. The overexpression in the SpoVG deletion mutant resulted in a weakly structured macrocolony. Moreover, it is striking that the empty vector changed the structure of the macrocolony from the spovG mutant remarkable. 
The SpoVG RNA co-precipitation experiment was performed as for the YmdB protein. We used the spoVG deletion strain GP2109 in the B. subtilis 168 background and introduced the constitutively expressed fusion protein SpoVG-Strep (pGP2310) and cultivated the strain in rich medium. Interestingly, the plasmid needed to be cloned and transformed directly into B. subtilis since E. coli XL1 blue cells introduced mutations into the plasmid at conserved amino acids (see Appendix 7.1.). This indicates that SpoVG reveals to be a conserved RNA-binding protein, which possibly interferes in E. coli with the original RNA regulatory mechanisms. The used controls, the empty vector (negative), and Strep-tagged PtsH (protein control), and CsrA (positive control) were used as for the YmdB co-precipitation experiment. The protein purification of the fishing experiment was tested via SDS-PAGE and silver staining (see Fig. 14B). The sequencing and processing of the data was performed as before for the YmdB RNA co-precipitation.

Several RNAs were highly enriched by co-precipitation with SpoVG. A threshold of at least a NPKM value of 600 and a 3-fold enrichment compared to the empty vector was determined for RNAs of interest. A selection of fished RNAs with SpoVG is shown in Table 6. The strongest enrichment compared to the empty vector control was found for $y k r k$ mRNA. Furthermore, we found enrichments for genomically clustered genes such as $\operatorname{mcs} A B, \operatorname{roc} D-F, \operatorname{spoll} A A / A B, y s b A B$, and $y x c D E$ indicating a pull down of whole transcripts. Interestingly, we also found an enrichment of the $\sin R$ RNA. The strong enrichment of $\sin R$ mRNA and the effect of spoVG deletion on biofilm formation, suggests SpoVG as an important factor in the decision-making and/or development of the sessile lifestyle in B. subtilis. Further highly enriched mRNAs were secY, yjzD, yhfH, yoxD, ald, ykuQ, buk, yheG, sufA, yukE, pdhC, yjbO, papA, abbA, nadF, and yqhS. Interestingly, we found no enrichment of sRNAs or further free transcript RNA elements, which indicates, that SpoVG could majorly function via mRNA interactions.
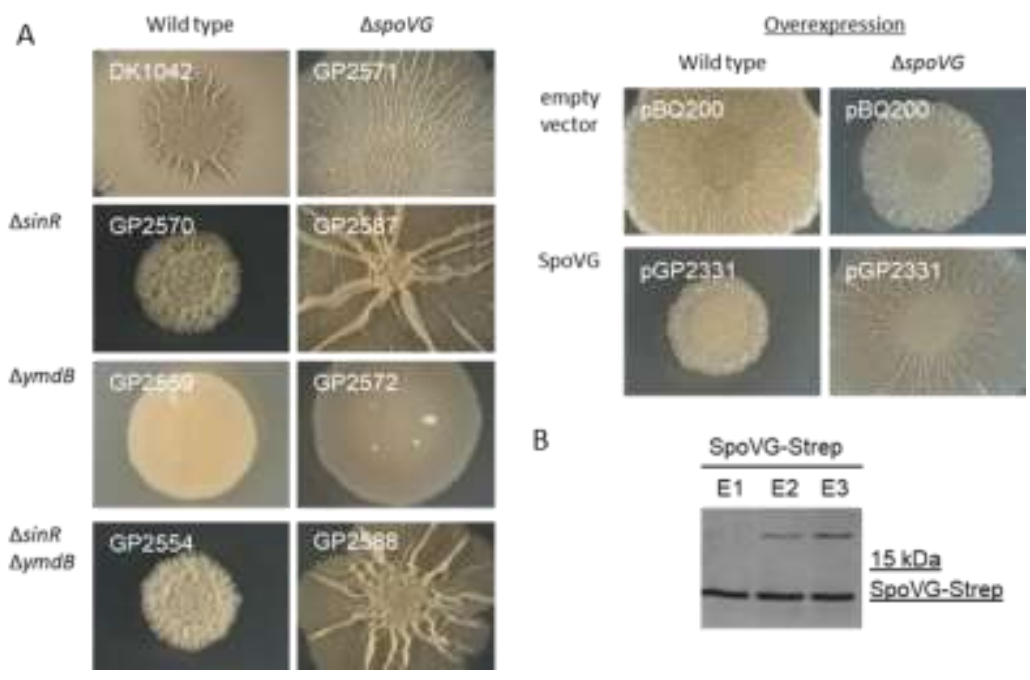

Figure 14 Analysis of influence of SpoVG on biofilm formation and purification of SpoVG-Strep. A) Biofilm assay of DK1042 derivates of spoVG, $\sin R$ and $y m d B$ solely and in combination on MSgg agar grown for 3 days at $30^{\circ} \mathrm{C}$. All images were taken at the same magnification. SpoVG was constitutively expressed using the $\mathrm{pBQ} 200$ vector. B) Verification of protein purification via silver stained $15 \%$ SDS-PAGE of elution fractions of Strep-tagged SpoVG. 
Results

Table 6 Overview of enriched RNAs (selection) by RNA co-precipitation with SpoVG. Data sorted by enrichment to empty vector. Operons are clustered and shaded in the same color.

\begin{tabular}{|c|c|c|c|c|c|c|c|}
\hline \multirow[b]{2}{*}{ Gene } & \multicolumn{4}{|c|}{ NPKM values } & \multicolumn{3}{|c|}{$x$-fold enrichment by fishing with SpoVG } \\
\hline & $\begin{array}{r}\text { Empty } \\
\text { vector (-) }\end{array}$ & $\begin{array}{r}\text { PtsH } \\
(-)\end{array}$ & $\begin{array}{r}\text { CsrA } \\
(+)\end{array}$ & SpoVG & $\begin{array}{r}\text { Empty } \\
\text { vector (-) }\end{array}$ & $\begin{array}{r}\text { PtsH } \\
(-)\end{array}$ & $\begin{array}{r}\text { CsrA } \\
(+)\end{array}$ \\
\hline$y k r k$ & 10 & 43 & 38 & 1109 & 110.90 & 25.79 & 29.18 \\
\hline $\sec Y$ & 408 & 5677 & 7112 & 28814 & 70.62 & 5.08 & 4.05 \\
\hline$y j z D$ & 102 & 98 & 59 & 6800 & 66.67 & 69.39 & 115.25 \\
\hline$y h f H$ & 24 & 22 & 68 & 1509 & 62.88 & 68.59 & 22.19 \\
\hline yoxD & 68 & 156 & 89 & 3832 & 56.35 & 24.56 & 43.06 \\
\hline$m c s A$ & 51 & 149 & 66 & 2631 & 51.59 & 17.66 & 39.86 \\
\hline$m c s B$ & 220 & 246 & 122 & 1015 & 4.61 & 4.13 & 8.32 \\
\hline ald & 844 & 1709 & 391 & 43430 & 51.46 & 25.41 & 111.07 \\
\hline ykuQ & 153 & 502 & 408 & 7708 & 50.38 & 15.35 & 18.89 \\
\hline buk & 92 & 659 & 80 & 4180 & 45.43 & 6.34 & 52.25 \\
\hline yheG & 21 & 32 & 66 & 934 & 44.48 & 29.19 & 14.15 \\
\hline $\sin R$ & 53 & 55 & 61 & 2348 & 44.30 & 42.69 & 38.49 \\
\hline sufA & 57 & 130 & 86 & 2496 & 43.79 & 19.20 & 29.02 \\
\hline yukE & 443 & 3135 & 406 & 18826 & 42.50 & 6.01 & 46.37 \\
\hline$p d h C$ & 133 & 1414 & 1653 & 4914 & 36.95 & 3.48 & 2.97 \\
\hline rocF & 991 & 4610 & 685 & 35024 & 35.34 & 7.60 & 51.13 \\
\hline rocE & 1567 & 4930 & 752 & 53035 & 33.84 & 10.76 & 70.53 \\
\hline $\operatorname{roc} D$ & 1730 & 5378 & 666 & 12019 & 6.95 & 2.23 & 18.05 \\
\hline spollAA & 49 & 13 & 13 & 1177 & 24.02 & 90.54 & 90.54 \\
\hline spollaB & 57 & 33 & 7 & 1003 & 17.60 & 30.39 & 143.29 \\
\hline yjbO & 73 & 222 & 140 & 999 & 13.68 & 4.50 & 7.14 \\
\hline papA & 213 & 489 & 276 & 2799 & 13.14 & 5.72 & 10.14 \\
\hline$a b b A$ & 70 & 92 & 75 & 846 & 12.09 & 9.20 & 11.28 \\
\hline$y x c D$ & 70 & 74 & 84 & 838 & 11.97 & 11.32 & 9.98 \\
\hline$y x c E$ & 149 & 44 & 91 & 1211 & 8.13 & 27.52 & 13.31 \\
\hline$n a d F$ & 55 & 213 & 150 & 617 & 11.22 & 2.90 & 4.11 \\
\hline yqhs & 178 & 292 & 116 & 1185 & 6.66 & 4.06 & 10.22 \\
\hline$y s b B$ & 679 & 14 & 165 & 3481 & 5.13 & 248.64 & 21.10 \\
\hline$y s b A$ & 1269 & 9 & 144 & 3892 & 3.07 & 432.44 & 27.03 \\
\hline
\end{tabular}




\subsection{Analysis of lifestyle decisions from $B$. subtilis on single cell level in real-time ${ }^{3}$}

It was already shown that the deletion of $y m d B$ leads no expression of matrix genes. $A y m d B$ deletion strain does not express genes, which are involved in biofilm formation. The development of microfluidic cultivation chambers allows the study of heterogeneous gene expression of these two states in real-time and on single cell level. By deletion of the hag gene encoding flagellin, we immobilized $B$. subtilis strains causing the inhibition of the movement of the cells in the microfluidic chambers. The strain harbored in addition two promotor fusions. A translational hag promotor fusion with cyan fluorescent protein ( $\mathrm{P}_{h a g}-c f p$, blue) in the bg/S locus, which allows the detection of cells, which drive the genetic program for motility, since the hag promotor is activated during motile lifestyle and is the major protein of the flagellum. Additionally, we introduced a translational tapA promotor fusion with yellow fluorescent protein ( $\mathrm{P}_{\text {tapA- }} \mathrm{y} f \mathrm{f}$, yellow) in the lacA locus, which allows the detection of cells, which express genes for biofilm formation since TapA is the major protein of the biofilm matrix of $B$. subtilis. Immobilized wild type cells (GP2130) and cells harboring an additional ymdB deletion (GP2551) were then analyzed via fluorescence, time-lapse microscopy of growing cells in LB medium in microfluidic cultivation chambers over $10 \mathrm{~h}$ at $37^{\circ} \mathrm{C}$.

We compared the ratio of cells after 360 min growth (see Fig. 15). For the wild type, about $60 \%$ of cells expressed the $\mathrm{P}_{\text {hag }}-c f p$ fusion while $9 \%$ of the cells expressed the $\mathrm{P}_{\text {tapA }}-y f p$ fusion. The rest of the population neither showed an expression of the $c f p$ nor the $y f p$ fusion, indicating the expression of another genetic program. Furthermore, we detected very few cells, which expressed both $\mathrm{P}_{\text {hag }}-c f p$ and $\mathrm{P}_{\text {tapA }}-\mathrm{yfp}$ at the same time. For the $y m d B$ mutant, most of the cells with about $70 \%$ expressed $\mathrm{P}_{\text {hag }}$-cfp fusion, cells with an activated $\mathrm{P}_{\text {tapa- }} \mathrm{yfp}$ fusion appeared only transiently. The third subpopulation, which did not show any activation of fluorescence was present as the for the wild type cells with about $30 \%$ indicating a genetic program, which is very independent from YmdB. We tracked single cells and documented the shifts from one status to another one for the wild type GP2130. The cells switched actively from one state into another. Cells, which showed no fluorescence activated either the expression of motility or biofilm genes, cell stayed relatively small in length (see Fig. 16A, B). Furthermore, cells, which initial started with expression of biofilm genes inactivated the expression again and were relatively long when neither matrix or motility genes were expressed (see Fig. 16C). Cells, which initially activated the hag promoter cfp fusion, three shifts in genetic programs were documented: the cells could turn off the hag promoter expression, with or without following induction of the tapA promoter.

${ }^{3}$ The data were kindly recorded by Miriam Dormeyer at the group of Prof. D. Kohlheyer at the Forschungszentrum Jülich. 
Results

Cells were longest in these tracking of cells when neither matrix genes and motility genes were expressed (see Fig. 16D, E). Interestingly, a relatively small fourth subpopulation showed an activation of the tapA promoter followed by the activation hag

promotor, expressing both programs at the same time. The tracked cell stayed short when they expressed both, matrix and motility genes (see Fig. 16F). For the YmdB mutant, a switch from black to motility gene expression and vice versa has been observed (data not shown). The results of the microfluidic cultivation chamber show clearly the strong dynamics in this multistable culture for different genetic programs. An interconversion from one into another state was trackable for the observed different genetic programs of the cells (see Fig. 16G).

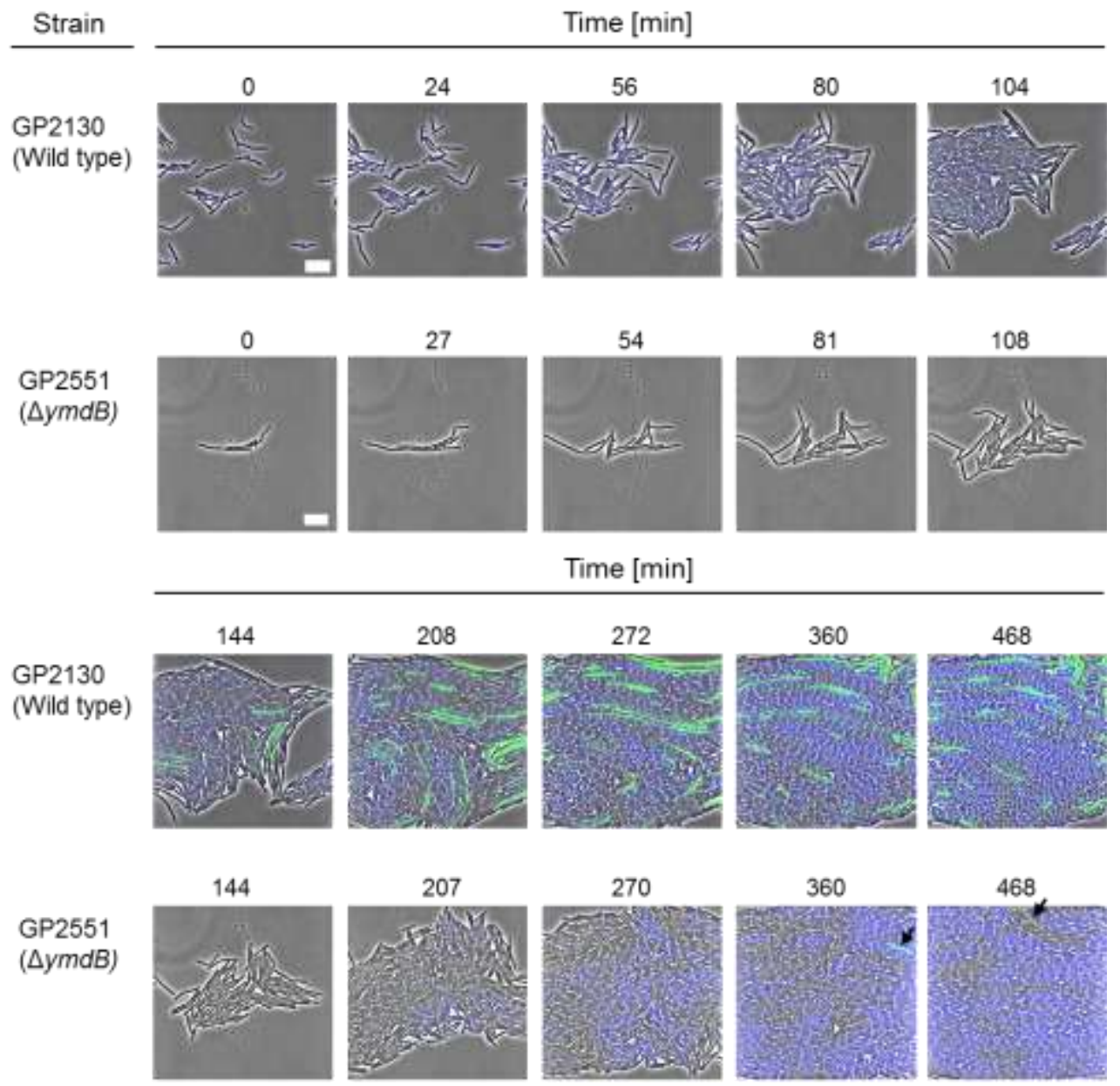

Figure 15 Microfluidic single-cell cultivation and analysis of $\boldsymbol{B}$. subtilis. Detailed time-lapse image series of wild type cells (GP2130) harboring $\mathrm{P}_{\text {hag }}-c f p$ (motility genes), $\mathrm{P}_{\text {tapA- }} \mathrm{yfp}$ (biofilm genes) fusions, $\Delta$ hag (for immobilization of the cells), and the isogenic $\triangle y m d B$ mutant (GP2551) grown in LB-media at $37^{\circ} \mathrm{C}$ in microfluidic chambers. Black arrows indicate the event of the formation of suppressor mutants that restored the ability to express biofilm genes (documented by $\mathrm{P}_{\text {tapA }}-\mathrm{yfp}$ ). Scale bar: $10 \mu \mathrm{M}$. Videos were kindly recorded by Miriam Dormeyer. 
A
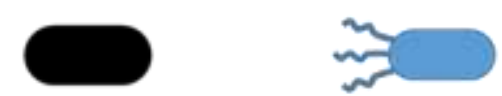

- CFP-intensity

a YFP-intensity

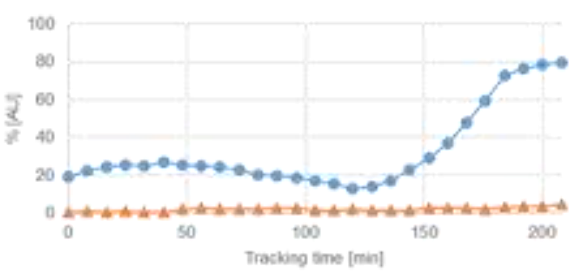

Phase-contrast

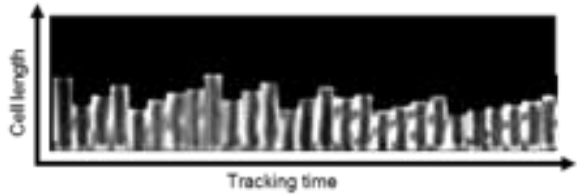

GFP
Motibly genes

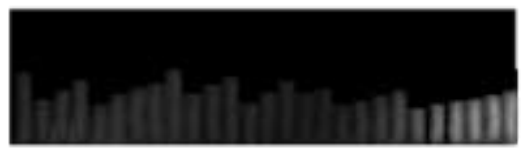

YFF

Biotim genes

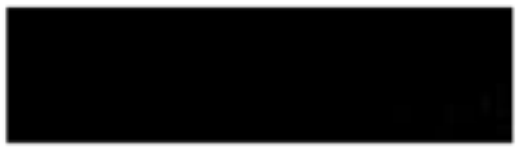

C
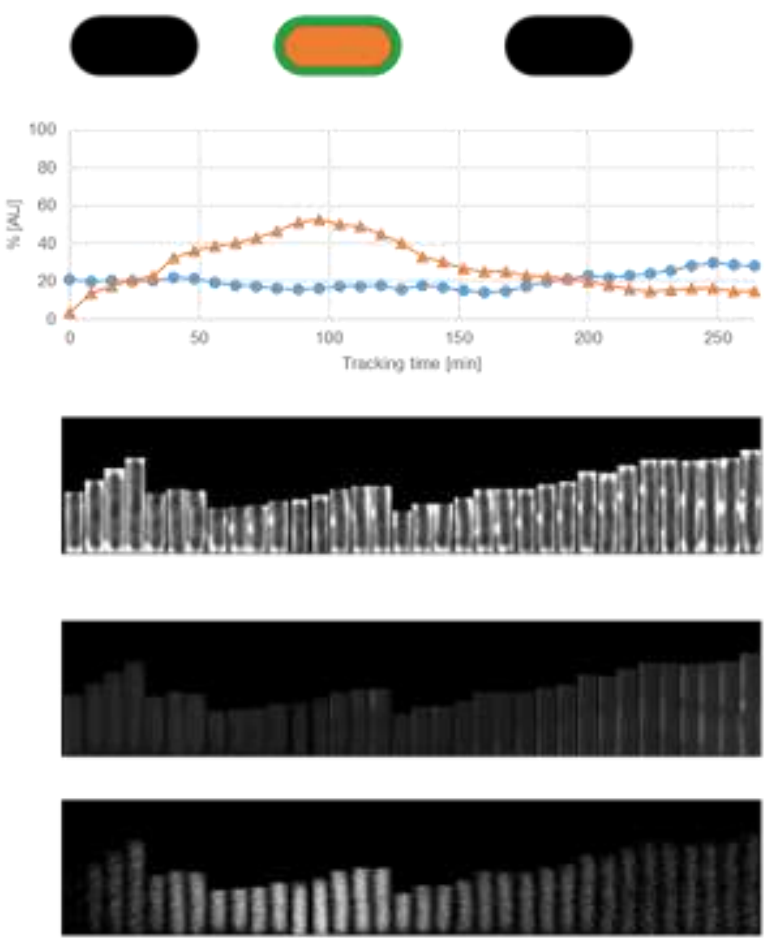

B
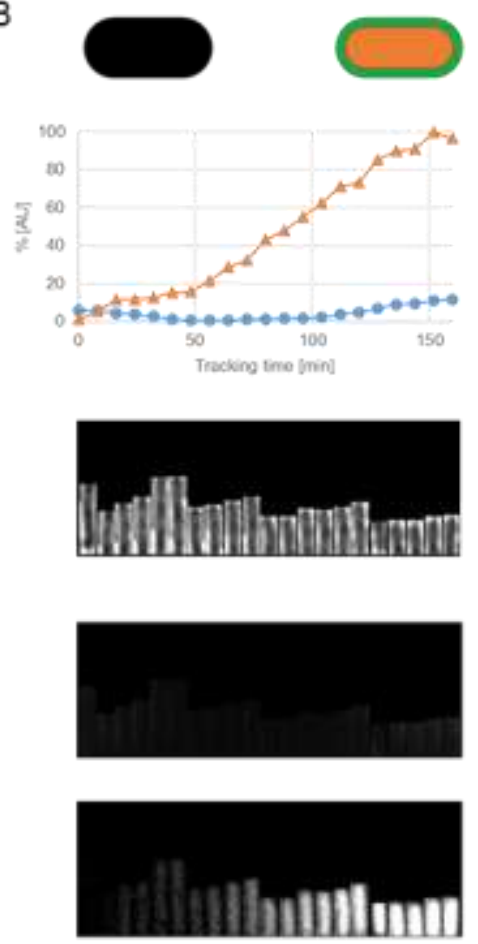

D
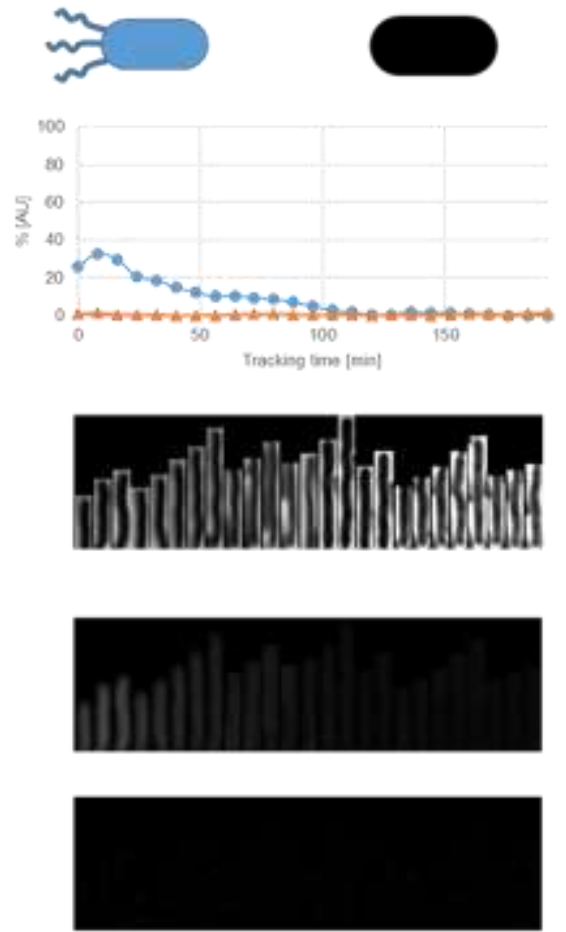
$\mathrm{E}$
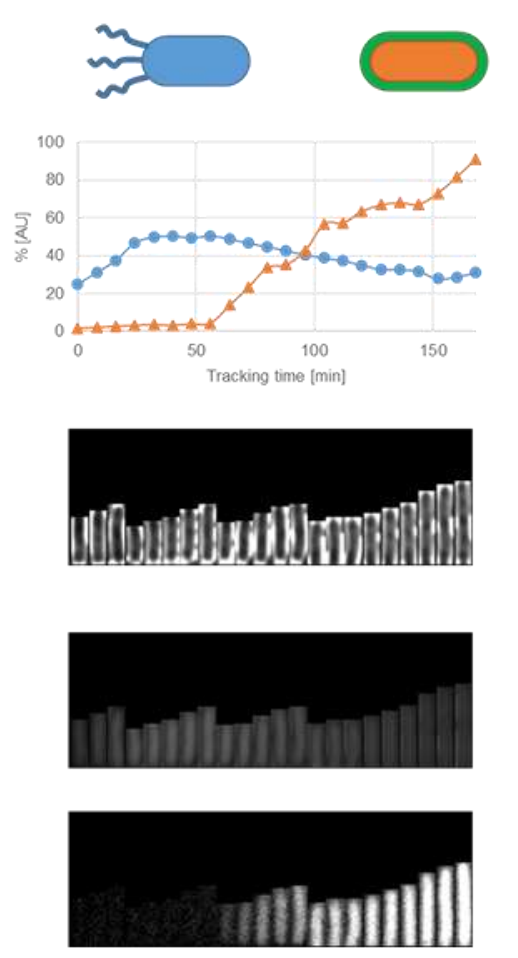

$\mathrm{F}$
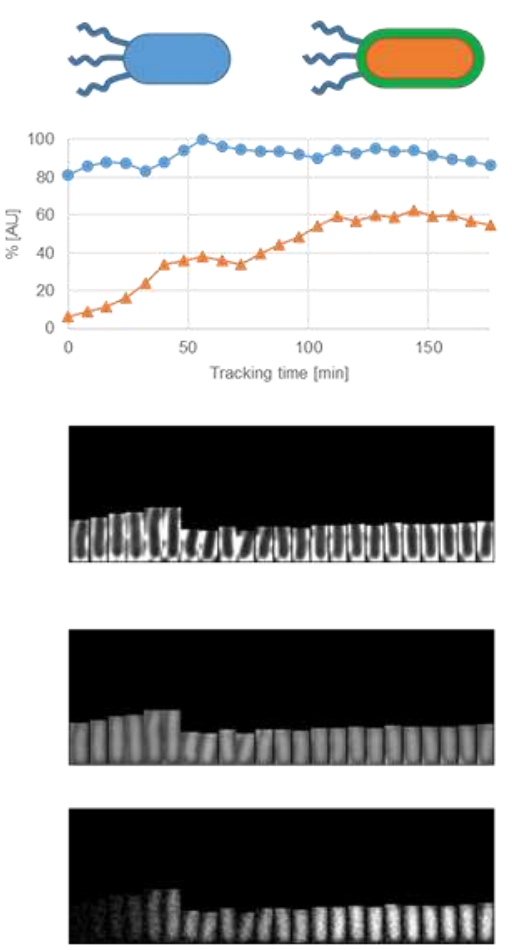

G

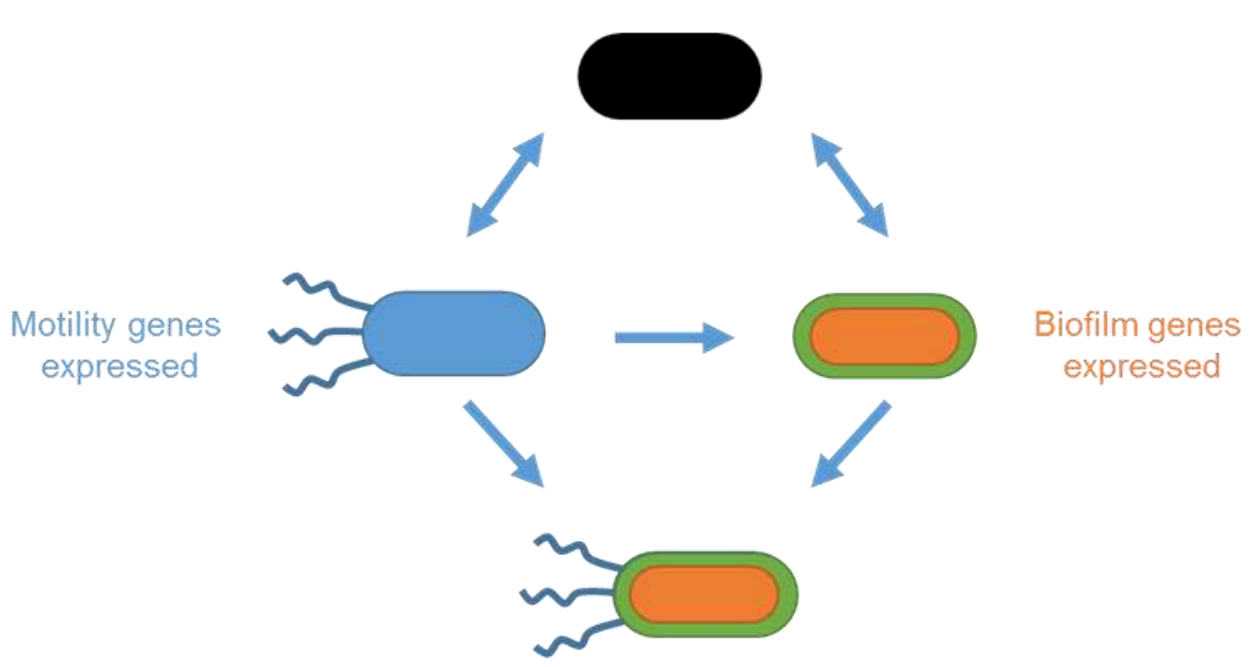

Figure 16 Tracking of single cells during microfluidic single cell cultivation of $\boldsymbol{B}$. subtilis. Single cell tracking of B. subtilis wild type cells (GP2130) carrying $\mathrm{P}_{\text {hag }}$-cfp (motility genes) and $\mathrm{P}_{\text {tapA-yfp (biofilm genes) }}$ transcriptional fusions grown in microfluidic chambers. Phase contrast, CFP, and YFP signals were separately recorded for analyses of motility and biofilm gene expression of each individual cell during the cultivation. All cells were tracked at the same magnification. Single cells were cropped and tracked every eight minutes using the ImageJ plug-in MicrobeJ. Different cells were tracked for different periods of time and during different growth phases in the same microfluidic chamber to demonstrate the dynamic changes in expression pattern (e.g. in C) a cell was tracked for 264 min to show the development from a black cell to a matrix producer, and back to a black cell). (A) A black cell (no expression, neither CFP nor YFP) becomes a motile cell. (B) A black cell that becomes a biofilm former. (C) A black cell that converts to a biofilm 
former and then to a black cell again. (D) A motile cell, which becomes a black cell. (E) A motile cell becoming a biofilm former. (F) A motile cell in which the expression of biofilm genes increases while the expression of motility genes remains constant. Both genetic programs are expressed simultaneously. $\mathrm{G}$ ) We created a schematic overview of possible lifestyle decisions of $B$. subtilis on the background of single cell tracking of $B$. subtilis wild type cells (GP2130) harboring $\mathrm{P}_{\text {hag }}-c f p$ (motility genes), $\mathrm{P}_{\text {tapA- }}-\mathrm{yfp}$ (biofilm genes) fusions. A black (no expression of motility or biofilm genes) cell can become a motile or a biofilm former as well as the other way around (compare Fig. 16A-D). A motile cell can become a biofilm former (compare Fig. 16E), but a biofilm former cannot become directly a motile cell. We also observed the expression of motility and biofilm genes at the same time (compare Fig. 16F).

\subsection{Characterization of the influence of $\operatorname{Sin} R$ mutations found in $y m d B$ suppressors on DNA binding, oligomerization and binding to its antagonist Sinl}

The analysis of $y m d B$ suppressor mutants, which had restored the ability to form a biofilm, revealed that several mutations in SinR did not lead to a total loss of SinR activity in each suppressor strain. The suppressor mutants were analyzed for biofilm formation and protein stability in an earlier work (Kruse, 2013; Gerwig, 2014). ymdB suppressor mutants, which showed a stable SinR protein, were chosen for biochemical characterization. The different SinR versions and the antagonist Sinl were purified ( $p C 2$ (native

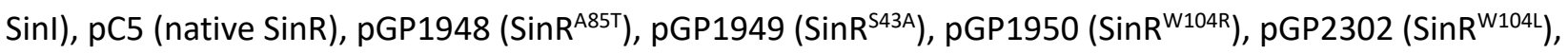
pGP2304 (SinR $\left.{ }^{\mathrm{K} 28 \mathrm{~T}}\right)$ ) and analyzed for DNA binding, oligomerization status and interaction with Sinl.

The DNA binding of SinR variants, (see Fig. 17A), were tested via fluorescence polarization. A fluorescein-labeled 21 bp DNA duplex harboring two inverted repeats of the SinR DNA binding motif was used as binding target. The polarization data were fitted with a 1:1 binding model determining the dissociation constant of approx. $180 \mathrm{nM}$ for interaction of the native SinR protein. This is in reasonable agreement with an earlier work by Newman and Lewis, who measured a value of $360 \mathrm{nM}$ as dissociation constant for SinR using isothermal titration calorimetry (Newman et al., 2013). The dissociation constant was characterized for each $\operatorname{SinR}$ variant (see Fig. 17B). The $K_{D}$ values and oligomerization states are summarized in Table 7. The DNA binding capability of the $\operatorname{SinR}^{\mathrm{W} 104 \mathrm{~L}}$ and $\operatorname{SinR}^{\mathrm{W} 104 \mathrm{R}}$ mutants was reduced 10-fold, the DNA binding capability of the $\operatorname{Sin} R^{A 85 T}$ mutant was reduced about 5 -fold, and the $\operatorname{Sin} R^{S 43 A}$ variant reduced the DNA binding affinity only 2 -fold. No significant change for fluorescence polarization was detectable for the $\operatorname{Sin} \mathrm{R}^{\mathrm{K} 28 \mathrm{~T}}$ mutant at up to $20 \mu \mathrm{M}$ protein concentration in the assay, indicating a total loss of DNA-binding for this SinR mutant.

Size exclusion chromatography with multi-angle static light scattering (SEC-MALS) was used to measure masses of the SinR variants. The proteins were concentrated up to $5 \mathrm{mg} / \mathrm{ml}$ and applied to 
Results

SEC-MALS analysis for the determination of the oligomeric status of the protein and influence of the mutations on their status (see Fig. 18).

A

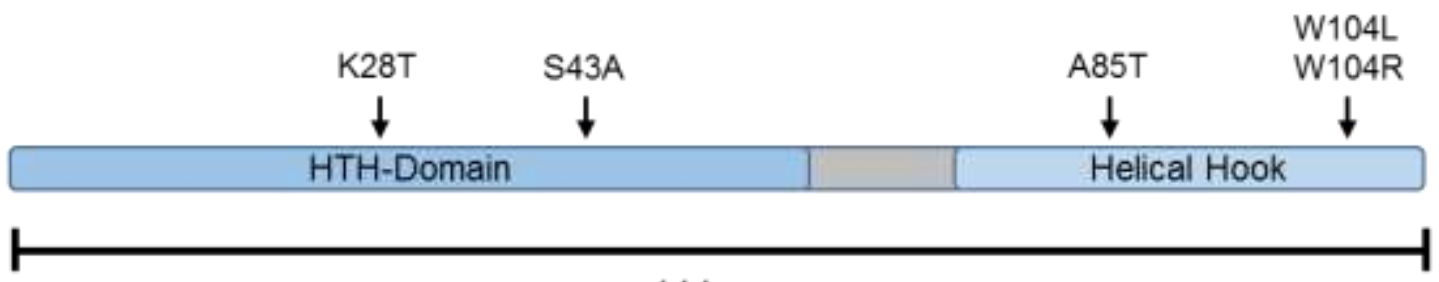

111 aa

B

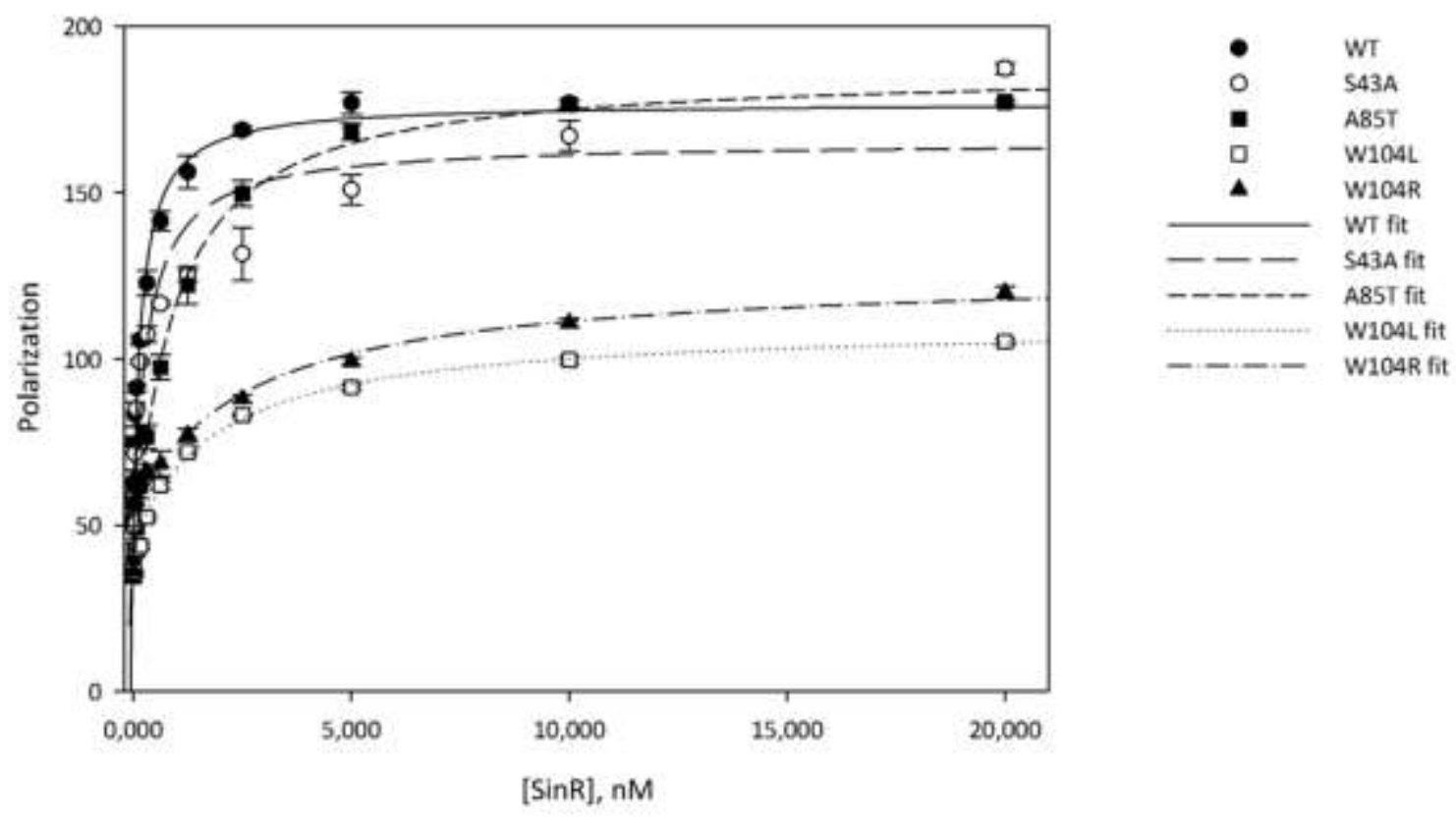

Figure 17 Schematic overview of mutations and fluorescence polarization of wild type and suppressor SinR variants at different SinR concentrations. A) Schematic overview of SinR domains and mutations found in $y m d B$ suppressor mutants. B) A fluorescence polarization assay was performed to determine the dissociation constants $\left(K_{D}\right)$ for binding of SinR variants to its DNA operator motif. A mixture of $10 \mathrm{nM}$ of fluorescently labeled DNA and $20 \mu \mathrm{M} \operatorname{SinR}$ was serially diluted with $10 \mathrm{nM}$ fluorescently labeled DNA. Fluorescence polarization was measured as triplicates. The collected data were analyzed and plotted via SigmaPlot software.

The SEC-MALS chromatograms of the native, $\operatorname{Sin}^{\mathrm{K} 28 \mathrm{~T}}$ and $\operatorname{Sin} \mathrm{R}^{\mathrm{S43A}}$ variants showed a single symmetric peak corresponding to a tetramer, indicated by the uniform deconvoluted molecular weight of about $50 \mathrm{kDa}$. For the $\operatorname{Sin} \mathrm{R}^{\mathrm{A} 85 \mathrm{~T}}$ mutant, the SEC-MALS chromatogram revealed a less symmetric peak, indicating a $\operatorname{SinR}$ species with molecular weights ranging between $20-40 \mathrm{kDa}$. The tetramer formed by the $\operatorname{Sin} \mathrm{R}^{\mathrm{A} 85 \mathrm{~T}}$ mutant 
is less stable compared to the native $\operatorname{SinR}$ tetramer. The $\operatorname{Sin} \mathrm{R}^{\mathrm{A85T}}$ mutant seems to dissociate during gel filtration chromatography. The SEC-MALS chromatograms of the $\operatorname{Sin} \mathrm{R}^{\mathrm{W} 104 \mathrm{~L}}$ and $\operatorname{Sin} \mathrm{R}^{\mathrm{W} 104 \mathrm{R}}$ versions had a single symmetrical peak, which showed a deconvoluted molecular weight of $25 \mathrm{kDa}$. The $\mathrm{SinR}^{\mathrm{W} 104 \mathrm{~L}}$ and $\operatorname{SinR}{ }^{\mathrm{W} 104 \mathrm{R}} \operatorname{SinR}$ versions are dimers. The protein-protein interactions of the SinR mutants with their antagonist Sinl was assessed qualitatively by determination of the displacement of SinR-bound DNA by Sinl using fluorescence polarization (see Fig. 19). More than half of the bound DNA was released upon the addition of $\operatorname{Sin}$ l to a SinR:DNA mixture up to a $1: 1$ stoichiometric ratio of $\operatorname{Sinl}: \operatorname{SinR}$. Therefore, in a qualitative sense none of the mutations fully abrogates interaction with Sinl. Since no DNA-binding of the $\operatorname{SinR}^{\mathrm{K} 28 \mathrm{~T}}$ mutant was measured, we were not able to show the effect of addition of Sinl to the mutant variant.
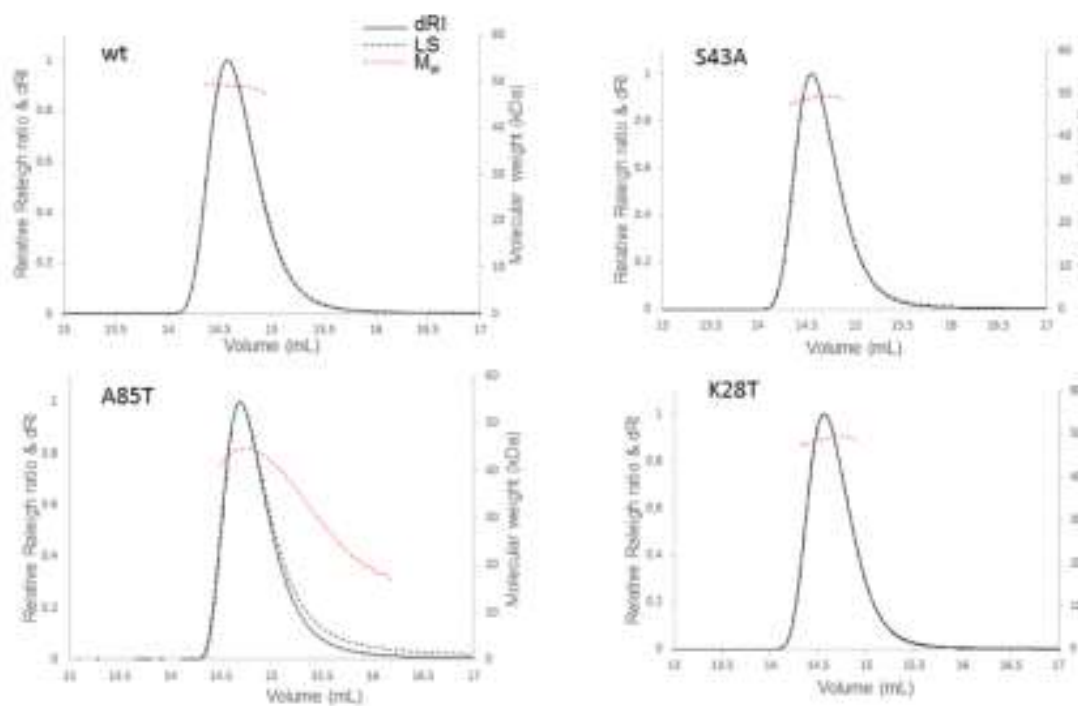

WIO4R

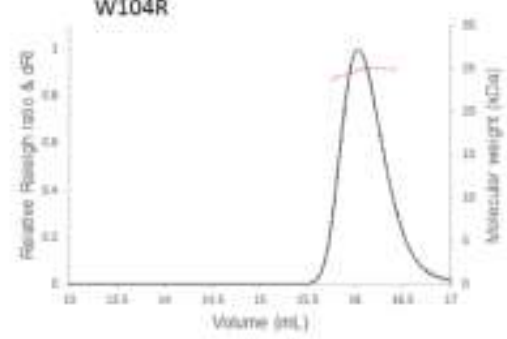

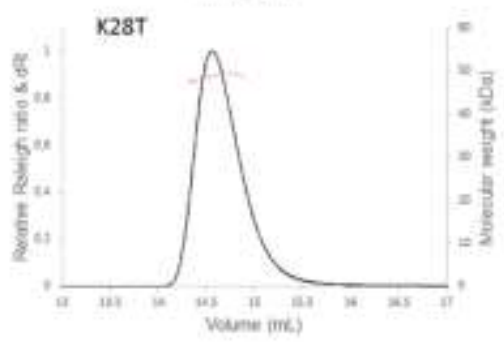

W104L.

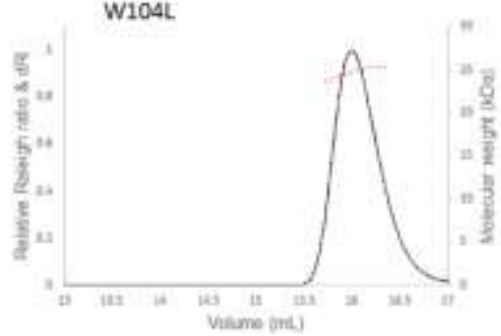

Figure 18 Oligomerization analyzes of SinR wild type and suppressor mutants via SEC-MALS. Absolute molar masses of SinR variants were determined through sizeexclusion chromatography multi-angle light scattering (SEC-MALS). The purified SinR proteins were concentrated up to $5 \mathrm{mg} / \mathrm{ml}$. The SEC-MALS were performed and processed by Owen Davies. $150 \mu$ l protein samples were loaded onto size exclusion chromatography column for SEC-MALS analyzes. Data were collected and analyzed by the ASTRA $^{\circledast} 6$ software. Molecular masses were calculated across the eluted protein peaks through extrapolation from Zimm plots using a $\mathrm{dn} / \mathrm{dc}$ value of $0.1850 \mathrm{ml} / \mathrm{g}$; quoted molecular weights and estimated errors relate to the overall mass calculation across a single peak. 


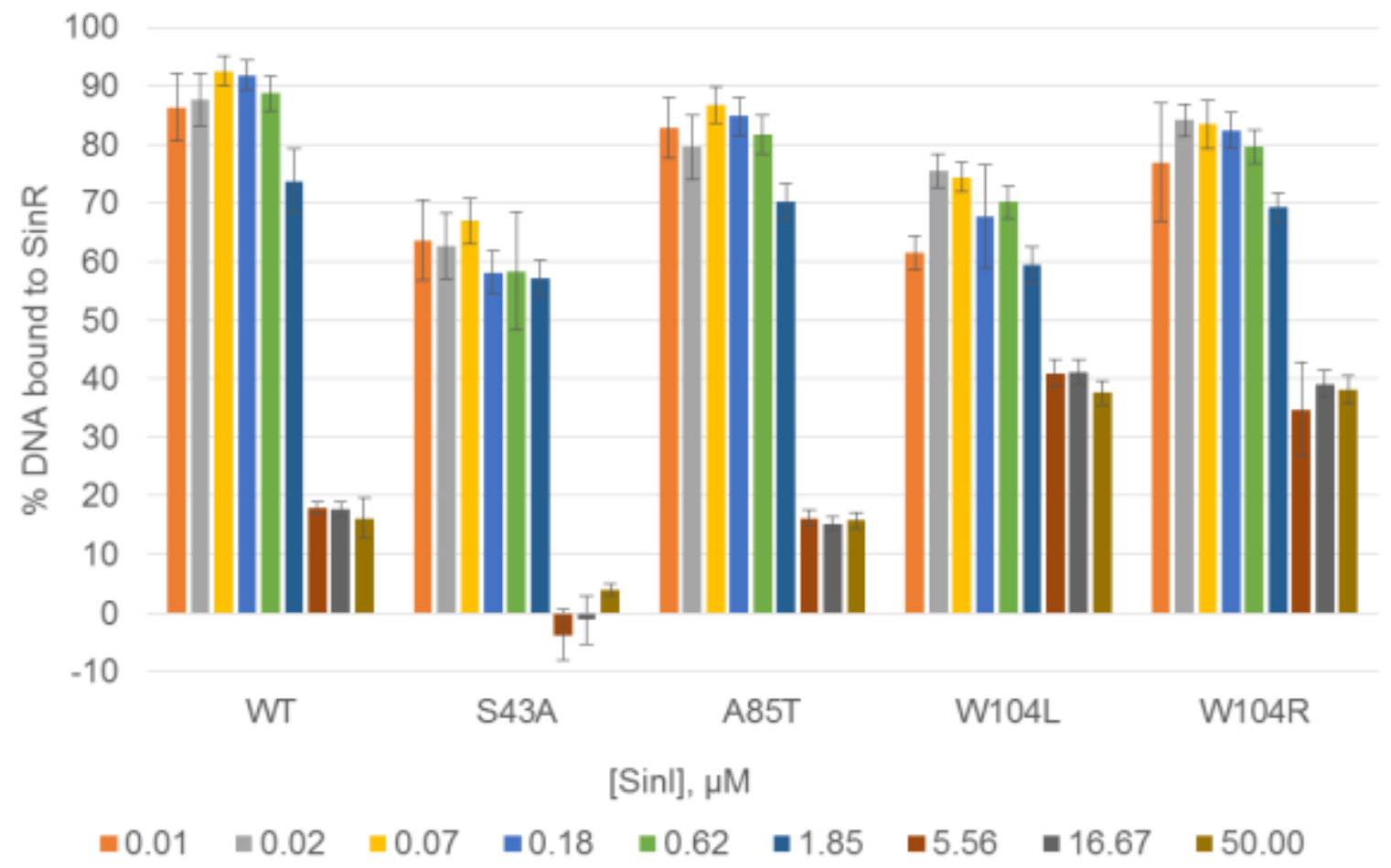

Figure 19 Percentage of SinR variants bound to DNA at different Sinl concentrations. We titrated Sinl to SinR bound to its native operator site to analyze the ability of SinR mutants to bind to its antagonist Sinl. $10 \mathrm{nM}$ fluorescently labeled DNA, $5 \mu \mathrm{M}$ of SinR and 3-fold serial dilution of Sinl were used to analyze the binding of the antagonist to SinR versions. The buffer and setup of the fluorescence polarization were the same as for the SinR binding to fluorescently labeled DNA.

Table 7 Overview of dissociation constants for DNA binding and oligomerization of different SinR variants

\begin{tabular}{ccc}
\hline $\begin{array}{c}\text { SinR } \\
\text { variant }\end{array}$ & $\begin{array}{c}\text { Binding DNA motif [nM] by } \\
\text { Fluorescence polarization }\end{array}$ & Oligomerization status by SEC-MALS \\
\hline Wild type & $179 \pm 24$ & Tetramer \\
K28T & No binding & Tetramer \\
S43A & $350 \pm 81$ & Tetramer \\
A85T & $852 \pm 39$ & Dissociating/Unstable Tetramer \\
W104L & $1896 \pm 298$ & Dimer \\
W104R & $2580 \pm 545$ & Dimer \\
\hline
\end{tabular}




\subsection{Sample preparation for metabolome flux analysis of wild type, biofilm producers and non-biofilm producers}

A metabolome analysis identifies the metabolic state of a cell or culture under given conditions. Comparison of different metabolomes allows to understand the status of the organisms and the dynamics of metabolites in the cell under different influences. In this approach, we used three different strains B. subtilis to analyze the carbon metabolism, using labeled glucose and the amino acid metabolism using labeled glutamate. We compared wild type cells represented by the wild type NCIB3610 and derivates, which either are sessile cells, represented by the GP1562 $\sin R$ mutant, or planktonic, represented by the GP921 ymdB deletion mutant. The reason for using the NCIB3610 and its derivates is the absence of strong biofilm formation in the domesticated B. subtilis strain 168. The domesticated B. subtilis strain 168 shows decreased biofilm expression caused by the presence of five mutations (Zeigler et al., 2008; McLoon et al., 2011a). The metabolome analysis was performed in collaboration with the group of Prof. Dr. W. Eisenreich of TU Munich. The analysis and optimization of the cultivation process and the actual cultivation and harvest of the samples was performed in the group of Prof. Dr. Jörg Stülke at the University of Göttingen.

First, we tested different combinations of glycerol and glucose in MSgg agar. The addition of glucose is necessary, since the labeled glucose is needed for the analysis of the carbon metabolism. Normally, MSgg agar contains only glycerol as carbon source. It was tested, if glycerol could be replaced by glucose or be combined with glucose and analyzed for the effect on biofilm formation of the strains. Glycerol enforces biofilm formation (see Fig. 20A). The comparison of MSgg agar with and without glycerol replaced or combined with glucose showed strong influence on the biofilm phenotype of $B$. subtilis (see Fig. 20A). The combination $0.5 \%$ glycerol, $0.5 \%$ glucose and the combination of $0.25 \%$ glycerol, $0.25 \%$ glucose showed proper biofilm formation. To ensure a proper labeling of the carbon metabolism, we decided to use the $0.5 \%$ glycerol, $0.5 \%$ glucose combination for the cultivation of the metabolome samples. The cultivation and sample preparation are described in the Material and methods part of this work. Shorty, the macrocolonies were grown for 3 days at $30^{\circ} \mathrm{C}$ (see Fig. 20B) and harvested by scratching off the agar surface with a spatula. The samples were sent for the metabolome analysis to the TU Munich. First measurements showed already proper labeling with glucose and glutamate. 
Results

A

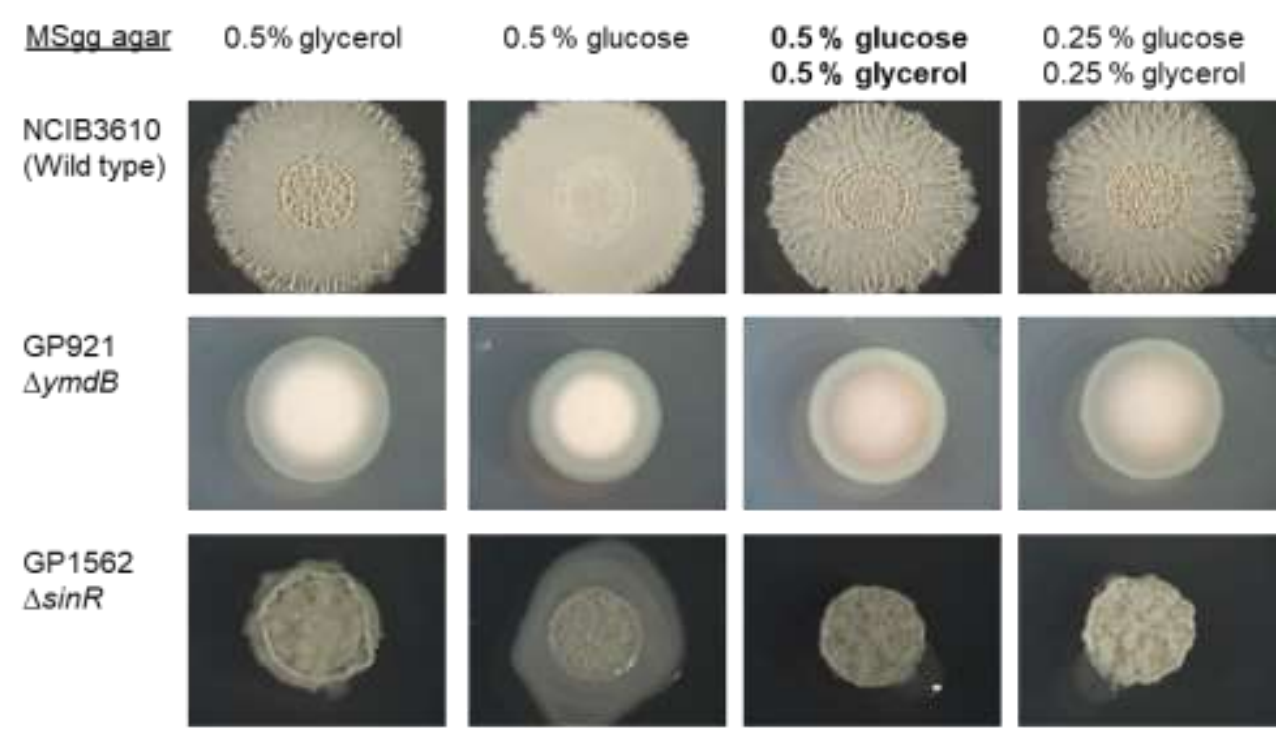

B

Labeling

Wild type

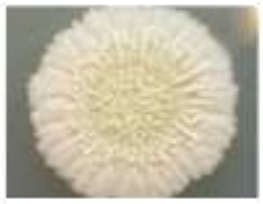

\begin{abstract}
$40 \%$ K-Glutamate (20\% U-13 C-Glutamate)

$0.5 \%$ Glucose

(33\% U-13 C-Glucose) / $0.5 \%$ Glycerol solution
\end{abstract}

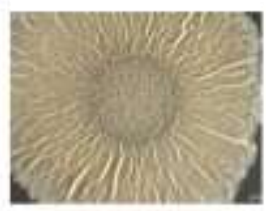

$\Delta y m d B$ planktonic cells
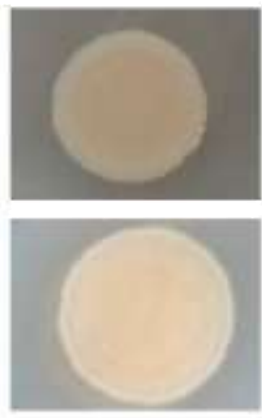

$\Delta \sin R$ sessile cells
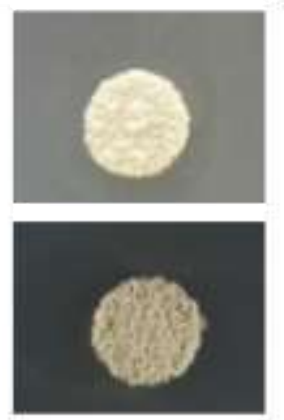

Figure 20 Analyzes of the influence on biofilm formation for different carbon source combinations and samples for metabolome analysis. A) Cells were grown in LB medium until an $\mathrm{OD}_{600}$ of $0.4-0.9$, and $5 \mu \mathrm{l}$ dropped on an MSgg agar plate. The plates were incubated for 3 days at $30^{\circ} \mathrm{C}$. The fat labeled combination was then used for cultivation of the glucose labeled samples for the metabolome analysis. B) Wild type

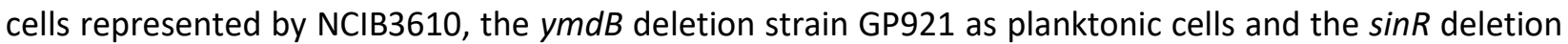
strain GP1562 as sessile cells. Cells are grown on respective labeled MSgg agar plates for 3 days at $30^{\circ} \mathrm{C}$. All images were taken at the same magnification. 


\section{Discussion}

This thesis elucidated the effect of the phosphodiesterase YmdB on biofilm formation and its regulation as well as decision-making for different lifestyles in $B$. subtilis. The deletion of the ymdB gene results in the loss of biofilm formation and an increased expression of the $\sigma^{D}$ regulon, which is responsible for motility of B. subtilis. Earlier works by Diethmaier and Gerwig considered an effect of YmdB on the epigenetic SIrR-SinR switch (Diethmaier et al., 2014; Gerwig, 2014). We could verify that the deletion of $y m d B$ leads to increased $\operatorname{SinR}$ amounts, which permanently represses matrix gene expression and the expression of the SinR antagonist SIrR (see Fig. 7). Moreover, the $y m d B$ mutant quickly evolves suppressors with mutations in $\sin R$, leading to restoring of biofilm formation. These mutations point once more in direction of the tight relationship of $\mathrm{YmdB}$ and $\mathrm{SinR}$ as regulators in biofilm formation. We investigated different SinR mutants found in the $y m d B$ suppressor strains and could shed new light on the interactions of the master regulator SinR with DNA, its antagonist Sinl and itself as a tetramer.

\subsection{The role of $Y m d B$ in the cell}

How does YmdB influence SinR levels in the cell?

The deletion of $y m d B$ leads to an overexpression of SinR (see Fig. 7). The elevated SinR levels result in a permanent repression of s/rR and matrix genes (see Fig. 21), while the motility genes and autolysins are upregulated (Diethmaier et al., 2011). Western blots for determination of amount of SinR and Sinl revealed that the imbalance of the epigenetic switch is caused by an increase in SinR levels, since Sinl levels are not affected in the $y m d B$ mutant (see Fig. 7). Earlier studies suggested lowered amounts of the antagonist SIrR in the $y m d B$ mutant to be responsible for the lack of biofilm formation (Diethmaier, 2011), but the decreased levels of SIrR might be the consequence of the elevated SinR amounts in the cell. It is plausible that 2.4-fold increase of SinR amounts in the $y m d B$ mutant blocks biofilm formation, since the SlrR-SinR epigenetic switch is very sensitive to expression dose of its components. A duplication of the genes encoding e.g. $\sin l$ and $\sin R$ results in total inhibition of the matrix production (Chai et al., 2011). However, a low SIrR state in B. subtilis favors the repression of matrix genes and of the s/rR gene (Vlamakis et al., 2013).

Several studies indicated that an increased transcriptional activity, or an increased mRNA stability is not responsible for the elevated $\operatorname{SinR}$ amounts in the $y m d B$ mutant (Diethmaier et al., 2014; Gerwig, 
2014).We investigated possible causes for the overexpression of $\operatorname{SinR}$ on the post-transcriptional level. The regulatory stage, by which the deletion of $y m d B$ increases $\operatorname{SinR}$ amounts, still needs to be revealed (see Fig. 8). Earlier studies already investigated the SinR expression pattern in B. subtilis (Ogura, 2016).

low SIrR-state

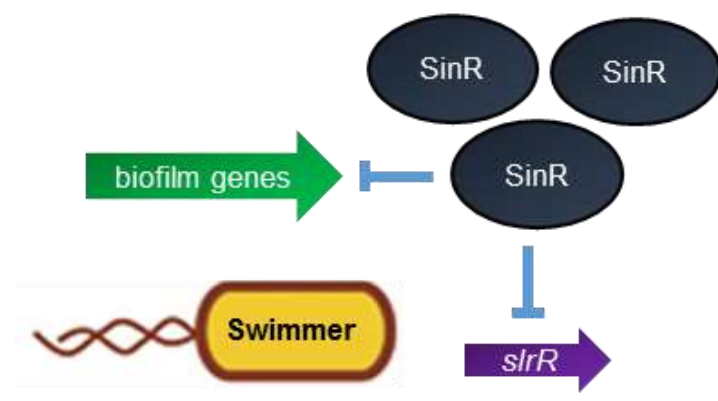

Figure 21 Effect of SinR overexpression on the epigenetic SlrR-SinR switch. An overexpression of $\operatorname{Sin} R$ (as documented for the $y m d B$ mutant) leads to a permanent repression of the matrix genes and the $s / r R$ gene, encoding the SinR antagonist SlrR. The system stays in the low SIrR-state that forces motility gene expression and represses biofilm formation (compare Fig. 5 for wild type situation). Adapted and modified from López and Kolter, 2010; Vlamakis et al., 2013.

Interestingly, it was shown, that $\operatorname{SinR}$ expression is heterogeneous, only a subpopulation of the cells expresses $\operatorname{SinR}$ (Ogura, 2016). Moreover, in the absence of RNase $Y$, the major RNase of B. subtilis, which targets also $\sin R$ mRNA, the expression SinR turned to a homogeneous pattern (Lehnik-Habrink et al., 2011; Ogura, 2016). It is important to note that an rny deletion mutant shows a strong defect in biofilm formation (DeLoughery et al., 2016), and it is documented a genomic clustering, expression and physical interaction with YmdB (Diethmaier, 2011). Does the $y m d B$ deletion result in the elevation of SinR levels by turning the heterogeneous SinR expression in the population to a homogeneous expression pattern? Another opportunity would be an increased SinR expression in the cells already expressing $\operatorname{Sin} R$, or the elevation of $\operatorname{Sin} R$ expression in all cells by an addition to the already present $\operatorname{SinR}$ expression in the individual cells (see Fig. 22). Such a reporter system of $P_{\text {sinR }}$-mCherry as used by Ogura (2016) might help to understand the effect of $Y m d B$ on SinR expression.

Moreover, the use of a third fluorescence reporter system such as $\mathrm{P}_{\operatorname{sinR}}-m$ Cherry (Ogura, 2016), in addition to the reporter fusions for motility genes and biofilm genes (see Fig. 15) could lead to new insights into the expression pattern in SinR dependent manner. An additional third reporter fusion for sinR would allow studying the expression of the three genetic programs depending on SinR expression on single cell level using the microfluidic chambers. The following questions could be addressed by the combination of all three reporter systems: which developmental state have cells without $\operatorname{Sin} R$ ? Is the expression of $\operatorname{SinR}$ always necessary in a cell for the repression of motility genes or matrix genes? The $\sin R$ mutant shows strong overproduction of the biofilm matrix (see Fig. 10). It might be possible that not every cell needs to 
express SinR for regulating the switch from biofilm formation and motility. The subpopulation of cells that expresses $\operatorname{Sin} R$, might stimulate the decision-making of other cells in the community by a quorum sensing like mechanism, as documented for other lifestyles of $B$. subtilis such as competence development (López and Kolter, 2010).

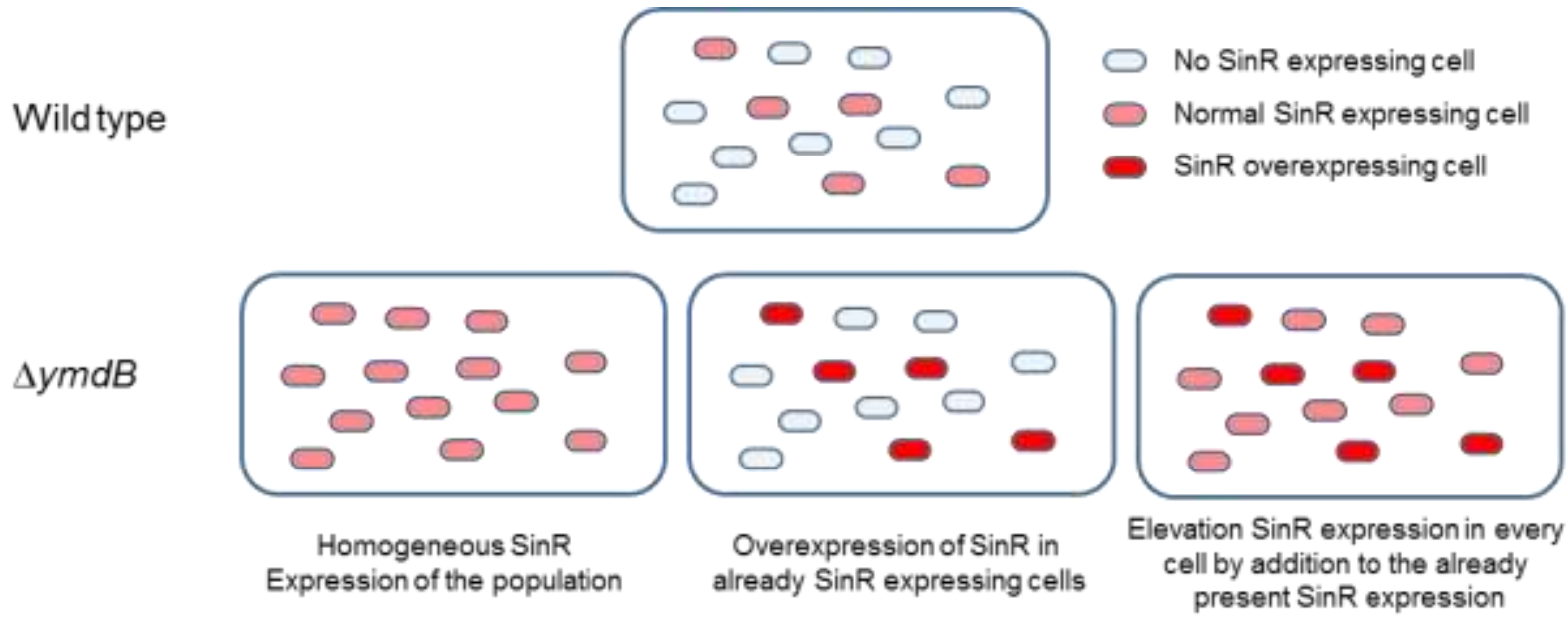

Figure 22 Schematic overview of the hypothetically SinR expression pattern in the wild type and in the $y m d B$ mutant. SinR levels are increased in the $y m d B$ deletion mutant. The increased expression can be obtained by a collective homogeneous expression of $\operatorname{SinR}$, by single cells that already express $\operatorname{Sin} R$ by increasing the expression of SinR, or the elevated SinR expression in every cell by an addition to the already existing SinR expression in the individual cells.

mRNA levels of $\sin R$ are not elevated in the $y m d B$ mutant, which could lead to increased $\operatorname{Sin} R$ levels, but we described the impact of a mutation of the $5^{\prime}$ UTR from $\sin R$ on protein size and amounts (see Fig. 10). The wild type harboring this mutation formed biofilms similar to a sinR deletion mutant and synthesis of a SinR protein, which showed increased molecular weight and was probably non-functional. Using different start codons of a transcript, which leads to proteins of different size is a known phenomenon in bacteria, even for leaderless mRNA sequences (Moll et al., 2002; Di Martino et al., 2016). Strikingly, the $y m d B$ deletion mutant harboring the mutated 5' UTR showed proper biofilm formation, and no extended $\operatorname{Sin} R$, as well as no $\operatorname{Sin} R$ overexpression anymore. YmdB prevents the initiation of the translation at the original start codon of $\sin R$ in the wild type strain harboring the mutated 5' UTR and uses instead the upstream positioned start codon. YmdB impedes the initiation of translation in the wild type. The $y m d B$ mutant is no longer able to repress the initiation of $\operatorname{SinR}$ translation, resulting in overexpression of $\operatorname{SinR}$. It would be interesting to determine the ribosomal density of $\sin R$ mRNA to analyze the impact of a $y m d B$ deletion on this value to determine how effective the ribosomes bind to $\sin R$ mRNA in these two genetic backgrounds (Subramaniam et al., 2013). Especially, the restoring of biofilm formation in 
suppressor mutants harboring silent mutations point in the direction of codon usage or secondary RNA structures, influencing the SinR expression in concert with YmdB. It was documented for mutants with lack of biofilm formation that a single mutation in the $5^{\prime}$ UTR of $\sin R$ or a silent mutation at position the amino acid 42 of SinR resulted in a restoring of biofilm formation, indicating the sensitivity of $\sin R$ mRNA structures (Kearns et al., 2005; Kruse, 2013).

In addition, another study dealt with the codon usage of serine codons in the $\sin R$ mRNA (Subramaniam et al., 2013). Different synonymous serine codons were introduced, which affected the SinR amounts and subsequently biofilm formation in some cases. A substitution of the three TCA codons to AGT codons led to a total lack of biofilm formation and increased SinR levels, while a change of TCA codons to TCG codons led to a total overproduction of the matrix as for a $\sin R$ null mutant. This study gives evidence that increased SinR levels lead to lack of biofilm formation and in addition the impact of codon usage on translational efficiency. Synonymous codon variations affect the synthesis of the according protein through alterations in the translation initiation rate, mRNA levels or the ribosome elongation rate (Plotkin and Kudla, 2011). It is worth to note that the fusion of lacZ could disturb the effect of YmdB on the $5^{\prime}$ UTR and explain the equal expression documented by $\sin R$-lacZ fusions for the wild type and $y m d B$ deletion mutant (see Fig. 8A).

\section{Further potential targets of $\mathrm{YmdB}$ and approaches to identify these targets}

In this study, different potential targets or interaction partners of $Y \mathrm{mdB}$ were investigated, but the actual molecular target for regulation of the switch between planktonic and sessile lifestyle by YmdB was not identified. As phosphodiesterase, YmdB could hydrolyze the head group of phospholipids, cyclic signal nucleotides, or the backbone of DNA and RNA molecules. The potential targets, and processes which might be affected by $Y m d B$, as well as strategies to identify the actual target of $Y m d B$, shall be elucidated in this part of the discussion (see Fig. 23).

\section{YmdB and its relation to nanotube structures}

One opportunity is that the biofilm formation is inhibited in the $y m d B$ mutant by a lack of signal exchange through a loss of cell connections by a decreased number of nanotubes in the $y m d B$ mutant (Dubey et al., 2016). Nanotubes are molecular structures that facilitate cell-to-cell communication of neighboring bacteria. YmdB is thought to be involved in nanotube formation and nutrient extraction (Dubey et al., 2016; Stempler et al., 2017). Furthermore, the interaction of YmdB with RNase Y locates YmdB at the membrane of the cell (Diethmaier, 2011). One question that arises quickly: is the 
overexpression of $\operatorname{Sin} \mathrm{R}$ in the $y m d B$ deletion mutant responsible for the decrease of nanotubes or is it vice versa? Either SinR overexpression is dependent directly on YmdB or indirectly by an effect caused by the lack of nanotube connections.

One experiment to test the relation of these ideas would be the overexpression of $\operatorname{SinR}$, and to investigate the number of nanotubes compared to the wild type. If increased amounts of SinR lead to a decrease in the number of nanotubes, then $\mathrm{YmdB}$ would act probably primarily in the cell on the regulation of $\operatorname{SinR}$ expression. The effect on nanotube number would be a downstream effect of SinR overexpression. When SinR overexpression has no effect on the number of nanotubes, YmdB would act primarily on these structures, and the maintenance of nanotube number would be the major function of YmdB.

It might be possible that the role of nanotubes in biofilm formation in a YmdB dependent manner is another emerging process in the regulation of switch between motile and sessile lifestyle. The nanotubes and the physical contact between cells may be necessary for the initiation of the lifestyle as matrix producers. Here, YmdB may act as phospholipase, targeting the phosphodiester bond of phospholipids. The degradation of the phosphodiester bond could be needed for penetration of the membrane and to "cut" holes for the connections of the nanotubes. Variants of phospholipases C and D are also present in bacteria and an example for phosphodiesterases, which target the phosphodiester bonds in phospholipids (Titball, 1993; Selvy et al., 2011; Gresset et al., 2012). However, no significant identity is documented for YmdB and phospholipases.

Finally, it might be possible that the action of $\mathrm{YmdB}$ on $\operatorname{SinR}$ expression, and on nanotube formation are unrelated, and YmdB acts as a moonlighting enzyme with different, unconnected functions in the cell (Huberts and van der Klei, 2010).

Signal nucleotides as potential targets of YmdB

YmdB could act by influencing the signal nucleotide concentrations in the cell. The deletion of $y m d B$ results in a drop of c-di-GMP (Diethmaier et al., 2014), and, contrary observed, to no change of $2^{\prime} 3^{\prime}$-cAMP levels (Kruse, 2013), or to an increase of an undefined cAMP species in B. subtilis (Mamou et al., 2016). Interestingly, in the Gram-negative bacteria like Pseudomonas aeruginosa, high levels of 3'5'cAMP positively regulate motility and repress biofilm formation, especially the transition from reversible to irreversible attachment, and the cell hydrophobicity (Ono et al., 2014). The opposite is shown for c-di-GMP in P. aeruginosa by forcing biofilm formation (Starkey et al., 2009). In B. subtilis, there is no evidence for the present of $3^{\prime} 5^{\prime}$-cAMP as signal molecule. Furthermore, the c-di-GMP levels have only minor impact on biofilm formation (Chen et al., 2012; Blötz, 2013). Further signal nucleotides such as cyclic 
Discussion

hybrid molecules of AMP and GMP, or cyclic oligoadenylates harbor also phosphodiesters bonds, which could be hydrolyzed by a phosphodiesterase like YmdB (Davies et al., 2012; Zhang et al., 2013; Kazlauskiene et al., 2017). There is no evidence for the presence of such hybrid molecules, or cyclic oligoadenylates in B. subtilis that could act also as a signal molecule in the Gram-positive model organism. These molecules can be excluded as potential targets of YmdB. Another signal nucleotide, which was not tested yet to be degraded by $Y m d B$, is (p)ppGpp. The molecule is involved in the stringent response as an so-called alarmone provoked by amino acid starvation (Potrykus and Cashel, 2008). Interestingly, these signal molecules are produced and hydrolyzed by bifunctional enzymes, which can harbor domains with remarkable similarities to phosphodiesterases of $3^{\prime} 5^{\prime}$-cyclic-nucleotides (Hogg et al., 2004). Today, there is no evidence for the alarmone to be involved in biofilm formation of B. subtilis or to be a target of YmdB.

YmdB could act as RNase in the cell

We showed that YmdB does not degrade DNA (see Fig. 11), which means DNA is no target for regulatory function of $\mathrm{YmdB}$ in the cell. Aside from that, $\mathrm{YmdB}$ is known to interact with RNase $\mathrm{Y}$ (Diethmaier, 2011), but the deletion of $y m d B$ does not alter the RNase activity of RNase $Y$ against SinR mRNA or affect the SinR transcripts, since the mRNA levels are not affected in a ymdB mutant (Diethmaier et al., 2014). Further studies revealed, that RNase $Y$ is part of the degradosome which involves enzymes like the RNase J1, the PNPase, or the helicase CshA (Lehnik-Habrink et al., 2012). Furthermore, RNase $\mathrm{Y}$ is considered to interact with the multisubunit complex YlbF, YmcA and YaaT, which controls its activity for $\sin R$ mRNA degradation. This endoribonuclease-containing complex is also involved in proper regulation of biofilm formation of B. subtilis (DeLoughery et al., 2016). Contradictory, YmdB does not interact with one of the listed proteins that interact with RNase Y. Having this in mind, the following question is triggered immediately: what is the purpose of the interaction of YmdB and RNase Y? Since YmdB might act via binding or processing the 5' UTR of $\sin R$ or other RNA species (see Fig. 13; Tab. 5), and RNase Y targets $\sin R$ transcripts and RNA molecules, it is worth to consider that the interaction of $\mathrm{YmdB}$ and RNase $\mathrm{Y}$ is detected via the natural location of the proteins in the cell by binding similar molecule species.

Furthermore, it is still not clear, if YmdB degrades or processes RNA molecules in the cell. It might be the case that the interaction of $Y m d B$ and RNase $Y$ does not stimulate the activity of RNase $Y$, but vice versa, RNase $\mathrm{Y}$ stimulates the activity of $\mathrm{YmdB}$ as RNase. It was already shown, that RNases are essential for the activity of another RNA degrading protein (Naka et al., 2014). It might be worth to examine, if YmdB acts solely or in combination with RNase $\mathrm{Y}$ as RNase for specific RNA species. YmdB might not hydrolyze 
RNA molecules without activation by another protein such as RNase $Y$, leading to the absence of RNA degradation in EMSAs in the work of Gerwig (2014).

Degradation of phospholipids

at the cell membrane

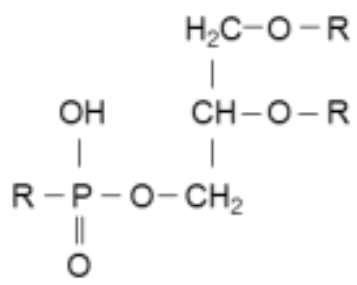

Degradation, processing, or protection of other RNA species, or molecules

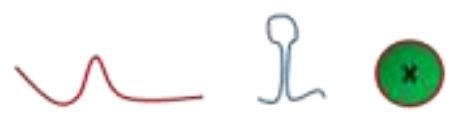

Function as RNA chaperone

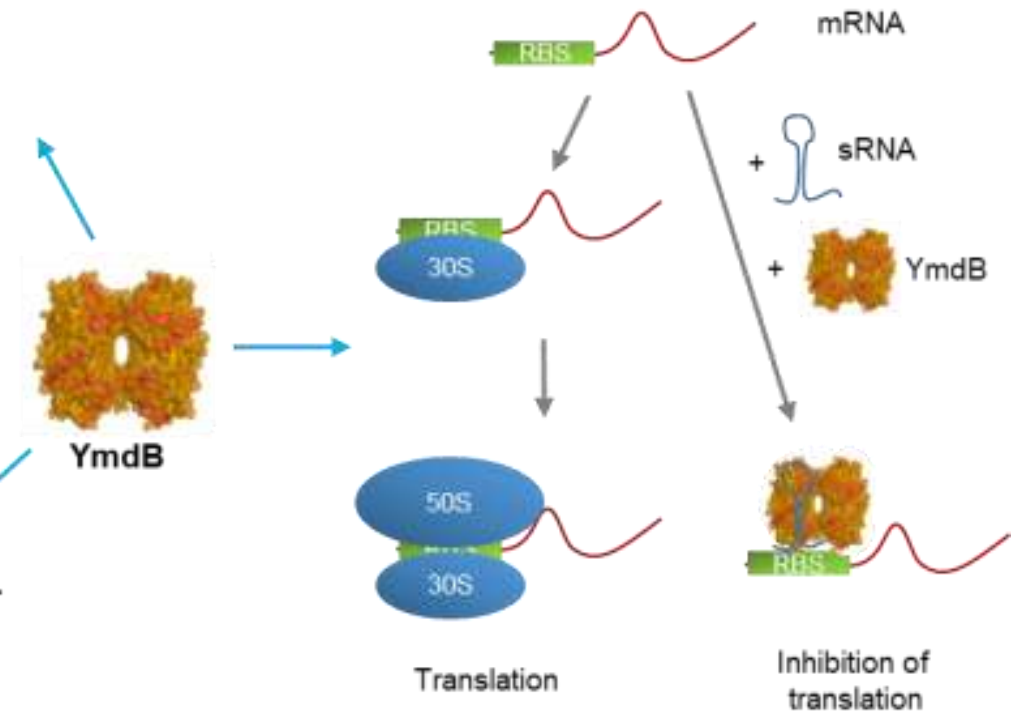

Figure 23 Schematic overview of possible targets of YmdB, or regulatory mechanisms, the enzyme might be involved in the cell. The RNA chaperon mechanism is adapted from Vogel and Luisi (2011). An unrevealed molecule is represented by the " $x$ " and an additional protein needed for YmdB activity by "?". The structure of YmdB is adapted from Diethmaier et al., 2014.

Searching for targets using -omicsanalysis

Another approach for identifying the role of $\mathrm{YmdB}$ would be the analysis of different -omics data of subpopulations, such as the matrix gene expressing cells, motility gene expressing cells and nonexpressing cells described in this thesis (see Fig. 15). Cells expressing a specific program, indicated by reporter genes, may be identified via fluorescence-activated cell sorting (FACS) and further processed for analyzes of different -omics datasets (Harst et al., 2017). In "unsorted" -omics experiments without FACS, the whole population is analyzed for changes. Only mixed cell populations are compared, which may not reveal the specific imbalance of a specific molecule of the cell in a defined state. The state of the subpopulation of cells expressing matrix genes in the wild type can be exclusively analyzed and compared to cells with the same expression pattern of the $y m d B$ mutant. This could allow to understand the molecular mechanism regulated by YmdB. 
Discussion

Furthermore, the development and improvement of high-throughput untargeted metabolomics, allows the simultaneous investigation of a large number of metabolites. Such experiments function via a top-down strategy and avoid the need for a specific hypothesis and labeling for a specific set of metabolites such as sugars or amino acids. In the untargeted analyzes, the global metabolome profile is identified (Alonso et al., 2015). The comparison of the wild type and $y m d B$ mutant could reveal the presence or the absence of specific metabolites such as signal molecules, and finally, help to reveal the secret of the degrading or protecting function of YmdB.

\subsection{Insights by RNA co-precipitations of YmdB and SpoVG}

The RNA co-precipitation experiments for YmdB and SpoVG revealed enrichments of various RNAs. SpoVG clearly affects biofilm formation in B. subtilis. The deletion of the spoVG gene results in an extended spreading and less wrinkled structure of the macrocolony (see Fig. 14). Furthermore, the spoVG $\sin R$ double mutant changed the biofilm phenotype of a $\sin R$ mutant by extended spreading of the macrocolony, while a $\sin R$ mutant grows as a very compact and rough macrocolony (see Fig. 14). Interestingly, the $\sin R$ deletion acts epistatically over genes that influence the biofilm phenotypes such as the biofilm lacking $y m d B$ mutant by restoring biofilm formation (Diethmaier et al., 2011). Aside from that, SpoVG revealed to interact with several RNAs (see Tab. 6). Especially the interaction of SpoVG with $\sin R$ and $a b b A$ mRNAs allows speculating about a regulatory role in biofilm formation. The enrichment of $a b b A$ mRNA by SpoVG points even more into the direction of a regulatory role in biofilm formation. The expression of AbbA is positively controlled by Spo0A-P (Banse et al., 2008). AbbA binds N-terminally to the DNA binding domain of AbrB and inhibits the DNA-binding of AbrB (Tucker et al., 2014). AbrB is a global regulator and operates as repressor of genes involved in stress response (Sullivan et al., 2008). AbrB represses, like the master regulator $\operatorname{SinR}$, the $\operatorname{tap} A$-sip $W$-tas $A$ and eps operons, as well as the $b$ sIA gene (Hamon et al., 2004; Kearns et al., 2005; Chu et al., 2006; Strauch et al., 2007; Chu et al., 2008; Verhamme et al., 2009). Aside from that, the regulator proteins Abh and SIrR are repressed by AbrB. However, the SinR and AbrB targets are highly overlapping (Strauch et al., 2007; Chu et al., 2008)AbrB expression is repressed by Spo0A-P. Taken together, Spo0A-P leads by repression of AbrB expression, and forcing the expression of AbbA, to an inhibition on expression- and protein level of AbrB.. Due to the mRNA involved in regulation of biofilm formation, and the influence of spovG deletion on biofilm formation, it is reasonable to assume that SpoVG has an important role in regulation of biofilm formation. Further interactions of SpoVG with mRNAs encoding of activator proteins such as $m c s A / B$, enzymes involved in 
amino acid metabolism such as $\operatorname{roc} D-F$ and $a l d$, as well as transcriptional regulators such as $y k r K$ or $s p o l l A / B$ (see Tab. 6) indicates that SpoVG has a role as global RNA-binding protein in B. subtilis.

YmdB bound also several RNAs in co-precipitation experiments (see Tab. 5). No deletion or overexpression of the genes for the respective RNAs, led to a lack of biofilm formation in the wild type, nor resulted in the restoring of biofilm formation in the $y m d B$ mutant. Several deletion mutants showed changes in their phenotype of biofilm formation (see Fig. 13). The effect of the respective deletion might lead in concert to a lack of biofilm formation in the wild type or to restoring of biofilm formation in the $y m d B$ mutant. $y m d B$ mutants quickly acquire mutations in $\operatorname{SinR}$, which restore biofilm formation (Kruse, 2013; Gerwig, 2014). The introduction of mutations in SinR might be the easiest way for the cell to restore biofilm formation by a single mutation, while the $y m d B$ deletion may influence various targets in the cell, leading to the lack of biofilm formation.

SpoVG or YmdB might work on a global level as RNA chaperone such as $\mathrm{Hfq}$ in E. coli (Vogel and Luisi, 2011). It is reasonable that another protein in B. subtilis could act as a global RNA chaperone. The Hfq protein of B. subtilis does not act in such a global way as the orthologue in E. coli (Mars et al., 2016). In addition, $\mathrm{Hfq}$ is involved in the formation of persister cells in E. coli populations and is necessary for the decision-making of the Gram-negative bacterium. Overexpression of the RNA-binding protein leads to a decrease in number of persister cells, while a deletion increases the number of persister cells (Kim and Wood, 2010). This observation indicates the power of RNA-binding proteins in the decision-making of bacteria.

The Hfq protein in E. coli is supposed to be the major component of a global post-transcriptional network, in which the protein facilitates interactions of regulatory small RNAs (sRNAs) with trans-encoded target mRNAs by binding to the ring-like RNA-binding protein (Link et al., 2009; Vogel and Luisi, 2011). Hfq can delay protein synthesis by assisting a cognate sRNA to bind the $5^{\prime}$ region of its target mRNA, thus rendering this 5' UTR inaccessible for translation initiation by the ribosome (Aiba, 2007). Interestingly, this mechanism of inhibition of protein synthesis, involves RNase E from E. coli. A similar mechanism as described for $\mathrm{Hfq}$ might be responsible for the regulatory effect of $\mathrm{YmdB}$, which might impede the ribosomal access for $\sin R$ translation (see Fig. 10 and 23). YmdB could associate with a sRNA and may sequester the ribosome-binding site (RBS) of the target mRNA, thus hindering the binding of the ribosomal subunits and repressing translation. In addition, the interaction of $Y m d B$ with RNase $Y$ is in perfect agreement with the scenario described for Hfq (Diethmaier, 2011).

It is possible that in the RNA co-precipitation experiments with the tagged YmdB and SpoVG proteins, the tag-fusion masked specific RNA interactions sites of the respective proteins. Important interaction partners such as sRNAs or further mRNAs could have been unrecognized. Additionally, it is 
Discussion

worth to analyze the sequence of enriched mRNAs and their 5' UTR for the presence of recurring patterns in their sequences.

\subsection{Selective pressure in the $y m d B$ mutant and the dynamic decision-making in real-time}

We documented the active switching of different genetic programs in B. subtilis in real-time and revealed the quick emergence of suppressor mutants in the $y m d B$ mutant (see Fig. 15). The phosphodiesterase $\mathrm{YmdB}$ is required for the expression of matrix genes in B. subtilis. The $y m d B$ mutant, the population majorly expresses the genetic program for motility and chemotaxis, but not those for matrix production (Diethmaier et al., 2011; Diethmaier et al., 2014) (see Fig. 15). EPS and matrix protein secretion seem to be disadvantageous under laboratory conditions. The ability to form a highly structured biofilm was lost during domestication of $B$. subtilis, probably also by the preferred selection of single, unstructured colonies by the researchers (Zeigler et al., 2008; McLoon et al., 2011a). Since B. subtilis evolved such a reduction in biofilm formation, $y m d B$ mutants may have a selective advantage in the artificial environment of the laboratory. The contrary is the case. ymdB mutant cells of $B$. subtilis quickly introduce suppressor mutations that restore biofilm formation. B. subtilis seems to undergo selective pressure to restore matrix gene expression and biofilm formation. It is remarkable that both, domesticated and the non-domesticated strains quickly formed suppressor mutants and restored biofilm formation (Kruse, 2013; Gerwig, 2014).

On the one hand, it has already been proposed that the introduction of mutations that support biofilm formation may cause a fitness benefit for B. subtilis (Leiman et al., 2014). On the other hand, the lack of SinR-repressed genes might cause the selective pressure, and biofilm formation may be a byproduct from the mutations in SinR, which led to the restoring of matrix production. The latter hypothesis might be rather unlikely, since suppressor screens with regulatory events already showed that mutations affect the transcription and/or its target site (Zaprasis et al., 2014; Rosenberg et al., 2016; Dormeyer et al., 2017). However, SinR represses two respective and unconnected operons, which are responsible for proper matrix secretion, the eps operon for the EPS moiety and the tasA operon for protein moiety of the biofilm; thus, introduction of mutations affecting the $\sin$ box of only one operon would be insufficient to restore biofilm formation. The presence of mutations affecting SinR in all analyzed suppressor mutants leads to the assumption that the selective pressure is directed towards expression of various and independent SinR repression targets, and that biofilm formation is indeed the relevant function. 
The impact of various parameters like the addition of stressors, presence of different carbon- or nitrogen sources or the deletion of genes on the response of individual cells in real-time is a clear advantage of microfluidic platforms. The microfluidic chamber, used in our approach, allows monitoring the effect of higher cell densities, but only for a shorter period of time, since the cells grow in the chambers until it is packed with bacteria, which then just die. It would be interesting, if a longer period of time for the experiment, and a permanent low cell density like in a "mother machine" (Wang et al., 2010) would lead to different result of the dynamic changes in the expression pattern that we observed in our experiments (see Fig. 16).

\subsection{The impact on protein functions of mutations in SinR mutants found in $y m d B$ suppressors}

The goal of studying suppressor mutations in the $y m d B$ mutant, which restored biofilm formation, was to identify the molecular target of $\mathrm{YmdB}$, as a mutation might change the target in such a way that protects the molecule and restores biofilm formation (Kruse, 2013; Gerwig, 2014). For example, if the function of YmdB as a phosphodiesterase was the degradation of a signal nucleotide, suppressor mutants that stopped the synthesis of the corresponding molecule could accumulate. However, all the suppressor mutants discovered and described in the chapter 2.4. affected the expression or activity of the master regulator of biofilm formation, SinR.

An explanation on the molecular level of the effects of the mutations in SinR, which led to the restoration of biofilm formation in the $y m d B$ mutants, can be provided by reference to the biochemical characterization and crystal structures of the $\operatorname{SinR}$ :Sinl complex, the isolated $\mathrm{N}$ - and C-terminal domains of SinR, as well as the SinR:DNA complex (Lewis et al., 1998; Colledge et al., 2011; Newman et al., 2013). There are two contrasting proposals for SinR tetramer formation - by works of Colledge et al. (2011) and Newman et al. (2013) (see Fig. 24) and the impact of mutations in SinR found in this study might answer whether either proposal has physiological relevance.

The $\operatorname{Sin} \mathrm{R}^{\mathrm{K} 2 \mathrm{~T}}$ mutation does not change the oligomeric state (see Fig. 18); moreover, Lys 28 is not needed for interactions with antagonist proteins (Lewis et al., 1998; Colledge et al., 2011). Lys28 is positioned at the proximal end of the DNA recognition helix of $\operatorname{Sin} \mathrm{R}$ in the HTH domain (Lewis et al., 1998), and the Lys 28 side chain provides base-specific contacts to the guanine at position 1 of the SinR binding motif (Newman et al., 2013). The exchange of Lys28 for the shorter amino acid threonine will lead to the loss of important interactions between protein and DNA. Thus, the inability of $\operatorname{SinR}^{\mathrm{k} 28 \mathrm{~T}}$ to bind to $\sin$ box DNA can be explained by the structural requirements for SinR:DNA interactions. 
Discussion

The Ser43Ala substitution in SinR does not alter the tetramer formation of SinR (see Fig. 18), which is also not surprising since this amino acid is not responsible for the oligomerization of the protein. The serine at position 43 interacts with the DNA backbone at the base at position 6 of the sin box (Newman et al., 2013). The loss of this side chain will lead to the loss of one hydrogen bond interaction to the DNA per $\operatorname{SinR}$ protomer. This variant of $\operatorname{SinR}$ is two-fold reduced in DNA affinity (see Tab. 7), which indicates that probably other features of $\operatorname{Sin} R$ are more important than the serine at position 43 for high affinity DNA binding. When the $\operatorname{Sin}^{S 43 T}$ variant is titrated with increasing amounts of the antagonist Sinl, the kinetics of dissociation from DNA and/or the assembly of the SinR:Sinl heterocomplex are affected by this mutation in $\operatorname{SinR}$ (see Fig. 19). In the SinR structure bound to a pair of inverted $\sin$ box-containing DNA motif, Ser43 is positioned at the protein dimer interface, and in addition, a hydrogen bond contact is formed between Ser43 and Asn41 across the dimer interface. It is thus possible that the association between the subunits of the $\operatorname{Sin} R$ homotetramer in the $\operatorname{Sin} \mathrm{R}^{\mathrm{S} 43 \mathrm{~A}}$ :DNA interaction is weakened by this mutation. This characteristic may favor the formation of the Sinl:SinR heterocomplex, as this is a process necessitating dissociation of the $\operatorname{Sin} R$ homotetramer. It is possible that the interaction of $\operatorname{Sin} R^{S 43 A}$ with $\operatorname{SIrR}$ is affected to a greater degree, which could explain the biofilm restoration phenotype of $B$. subtilis strains harboring the mutation $\operatorname{Sin} \mathrm{R}^{\mathrm{S} 43 \mathrm{~A}}$ in addition to a deletion of $y m d B$.

Furthermore, the exchange of alanine at position 85 for threonine leads to a protein that still forms a tetramer in solution, but the SEC-MALS analysis revealed that the $\operatorname{Sin}^{\mathrm{A} 85 T}$ variant dissociates readily from a tetramer to dimers and even monomers. The dissociation of $\operatorname{Sin} \mathrm{R}^{\mathrm{A} 85 \mathrm{~T}}$ can be explained by the structure of the isolated C-terminal domain of $\operatorname{SinR}$ (Colledge et al., 2011); here Ala85 from one protomer in a SinR dimer is in a hydrophobic environment that also includes the side chains of Trp78, Phe95 and Leu99 from the other SinR protomer (Lewis et al., 1998). The semi-orthogonal association of the C-terminal helices of SinR (amino acids GIn94-Ser107) lead to the formation of the SinR tetramer (Colledge et al., 2011). The introduction of a larger amino acid, such as a threonine, will result in a re-organization of the hydrophobic core in the immediate environment of Thr85 to accommodate the additional volume of this larger residue. Moreover, phenylalanines at position 95 and 98 pack against each other at the dimer interface and minor adjustments in the local arrangement of Phe95, Phe98 and Leu99, as a consequence of the introduction of threonine at position 85 , will probably destabilize the dimer:dimer and monomer:monomer interfaces in the SinR tetramer. This could result in the dissociation of the $\operatorname{SinR}^{\mathrm{A} 85 T}$ variant, consistent with the oligomerization status of this protein variant (see Fig. 18). The dissociation of the $\operatorname{Sin} \mathrm{R}^{\mathrm{A} 85 \mathrm{~T}}$ tetramer may also explain the 4-fold lowered affinity of this variant for an inverted pair of $\sin$ boxes, assumed that wild type $\operatorname{SinR}$ binds the same DNA motif as the SinR tetramer (Colledge et al., 2011). Interestingly, the strain 
harboring the $\operatorname{Sin} R^{A 85 T}$ variant still shows bistable expression of motility and biofilm genes (Gerwig, 2014) and the bistability may result from the reduced, but not lost, SinR activity as repressor.

Finally, the tryptophan at position 104 in $\operatorname{SinR}$ is a hot spot for mutations in $y m d B$ suppressor mutants. Mutations at this residue restored the biofilm formation to the $y m d B$ deletion mutants of parental domesticated and non-domesticated strains, including substitutions by arginine and leucine that are described by Gerwig, 2014. Both SinR variants do not form tetramers, only dimers were detected in SEC-MALS (see Fig. 18). There are two different suggestions regarding the tetramerization of SinR: Colledge and colleagues unraveled the structure of the isolated C-terminal domain of SinR (Colledge et al., 2011). This domain arranges as a tetramer by crystallographic symmetry. In this model the four C-terminal helices of $\operatorname{Sin} R$ are associated loosely as two semi-orthogonal pairs of anti-parallel helices. For this association the tryptophan at position 104 plays an important role as two pairs of these residues stack against each other (see Fig. 24) stabilized by pairs of Tyr101 to form a tetramer. An alternative SinR tetramerization model was proposed by Newman et al. (Newman et al., 2013)., based upon residual electron density that was insufficient in quality to permit the building of the C-terminal helices of $\operatorname{Sin} R$ in the $\operatorname{SinR}$ :DNA complex.

A

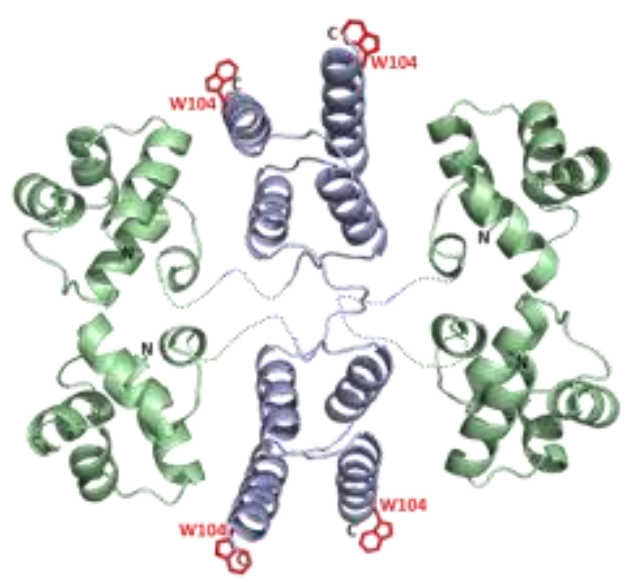

B

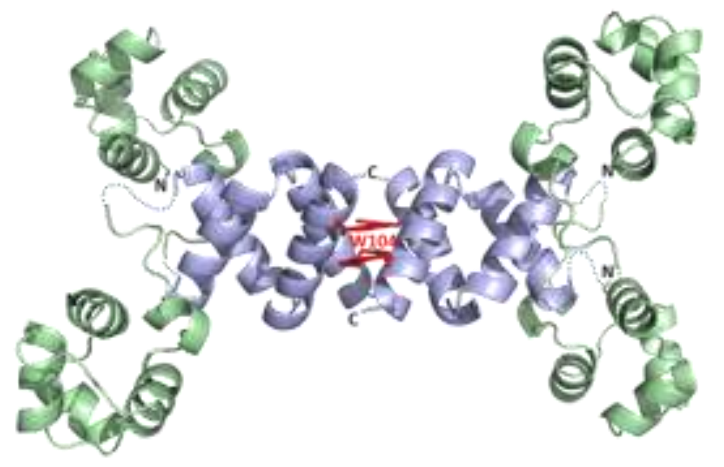

Figure 24 W104 mutants discriminate between different SinR tetramer models. Ribbon representation of the proposed models of SinR tetramers. The DNA binding domains are colored in pale green and the tetramerization domains are colored in pale blue. The linkers are represented as dashed lines between the domains that cannot be modelled in any SinR-containing structure because of flexibility. The $\mathrm{N}$ - and C-termini are labeled, if they are visible. The residue for W104 is drawn in 'stick' format and colored and red labeled. A) represents the model from Newman et al. (2013), in which the structure of SinR bound to DNA was described; the DNA is not included in this model for clarity. In this model W104 is not responsible for self-assembly of SinR. B) represents the model from Colledge et al. (2011), in which the structure of the C-terminal domain of SinR was solved in isolation, and possible positions for the DNA-binding domains of $\operatorname{SinR}$ were identified by superimposition of $\operatorname{SinR}$ atoms from the Sinl:SinR complex (Lewis et al., 1998). The DNA-binding domains of SinR in the model B) are too far apart to be consistent with binding to pairs 
Discussion

of $\sin$ boxes as found in promoters of genes repressed by $\operatorname{SinR}$. The position of W104 in this model, critical to tetramerization, is consistent with the biochemistry and genetics described in this work. The models were kindly designed by Prof. R. Lewis from the Newcastle University.

The tryptophan at position 104 was not involved in any protomer:protomer interface in this alternative model. The SEC-MALS analysis revealed that the mutation of the tryptophan at position 104 prevented the tetramerization of SinR. This observation confirms that the original proposal of the SinR tetramer by Colledge et al. has greater probability as the proposal of Newman et al. (2013). Trp104 is essential for SinR tetramerization and for its function as a repressor (see Fig. 18). The substitutions of this tryptophan for smaller amino acids like leucine and arginine results in a form of the SinR protein that does not form tetramers anymore. The buried hydrophobic surface area in this region of the structure will be decreased by these mutations, consistent with the decreased stability of the tetrameric assembly. The near 10-fold reduction in the affinity for DNA binding of the $\operatorname{Sin} R^{W 104 L / R}$ variants in comparison to native SinR (see Fig. 16; Tab. 7) is also reasonable, since these SinR variants interact with the DNA as dimers instead of tetramers as is the case for the wild type. Furthermore, Sinl was less effective at titrating off DNA SinR proteins containing mutations at Trp104 than wild type SinR (see Fig. 19). These observations indicate that Trp104 may have some involvement in the formation of a stable Sinl-SinR heterocomplex and/or in the dissociation of SinR multimers that is a requisite for the formation of its complex with the antagonist Sinl.

\subsection{Outlook}

The YmdB phosphodiesterase has a huge impact on the decision-making of B. subtilis. We could show that the loss of biofilm formation in a $y m d B$ mutant is probably dependent on an overexpression of the master regulator of biofilm formation, SinR, leading to permanent repression of matrix genes and keeping the SIrR-SinR epigenetic switch in a permanent low SIrR state. We found hints that YmdB could function by impeding the access of ribosomes to the 5' UTR of $\sin R$, but we could not reveal, if YmdB functions directly or indirectly post-transcriptionally on the expression of SinR. It might be possible that YmdB targets or protects another molecule that subsequently affects the expression of SinR. Revealing the actual mechanisms, how YmdB suppresses the expression of SinR will be part of investigations in the future.

Moreover, the $y m d B$ mutant shows not only a defect in biofilm formation by an overexpression of SinR, but also a drop of c-di-GMP levels, a decreased number of nanotubes, and lacks in nutrient extraction (Diethmaier et al., 2014; Dubey et al., 2016; Stempler et al., 2017). It would be interesting to investigate, 
which is the primary effect of the $y m d B$ deletion, and which effects are just downstream consequences. It might be possible, that the actual target of $\mathrm{YmdB}$ in the cell is not noticed and an unbiased approach such an untargeted metabolome analysis might help to identify the actual molecule of interest for YmdB. Further potential targets or mechanism by which YmdB might act, are shown in Figure 23. YmdB could function as an RNA chaperone, as a phospholipase, by degradation, processing or protecting of unexamined signal molecules, and RNA species, alone or in combination with another protein .

The RNA co-precipitation with SpoVG showed clear enrichment of different mRNAs. These enrichments need to be experimentally verified by methods like an EMSA. Furthermore, it is reasonable to perform further RNA co-precipitation experiments with differently tagged SpoVG variants to find out, if the protein binds further RNA species like sRNAs that has been unrecognized due to masking important interactions sides, due to the tag.

Furthermore, the presence of such microfluidic platforms used in this study allowed us to study switching of different genetic programs of individual cells in a population at the presence of different parameters and genetic backgrounds on single cell level and visualize such events in real-time. Today, data collection is a minor issue, compared to the analyzes of the collected data. Development of software for automated cell counting and tracking will allow to ask and to answer far more questions regarding the decision-making and activation of genetic programs in individual cells.

Finally, the metabolome analysis of the carbon and nitrogen fluxes will shed light on the core metabolism during biofilm formation and can give a detailed overview of planktonic and sessile metabolism of $B$. subtilis as well as their special needs during the different developmental states. 
References

\section{References}

Acar, M., Mettetal, J.T., and van Oudenaarden, A. (2008) Stochastic switching as a survival strategy in fluctuating environments. Nat Genet 40: 471-475.

Ackermann, M. (2015) A functional perspective on phenotypic heterogeneity in microorganisms. Nat Rev Microbiol 13: 497-508.

Aiba, H. (2007) Mechanism of RNA silencing by Hfq-binding small RNAs. Curr Opin Microbiol 10: 134139.

Alonso, A., Marsal, S., and Julià, A. (2015) Analytical methods in untargeted metabolomics: state of the art in 2015. Front Bioeng Biotechnol 3: 23.

Amati, G., Bisicchia, P., and Galizzi, A. (2004) DegU-P represses expression of the motility fla-che operon in Bacillus subtilis. J Bacteriol 186: 6003-6014.

Amellal, N., Burtin, G., Bartoli, F., and Heulin, T. (1998) Colonization of wheat roots by an exopolysaccharide-producing pantoea agglomerans strain and its effect on rhizosphere soil aggregation. Applied and Environmental Microbiology 64: 3740-3747.

Arnaud, M., Vary, P., Zagorec, M., Klier, A., Debarbouille, M., Postma, P., and Rapoport, G. (1992) Regulation of the SacPA operon of Bacillus subtilis: identification of phosphotransferase system components involved in SacT activity: : identification of phosphotransferase system components involved in SacT activity. J Bacteriol 174: 3161-3170.

Auchtung, J.M., Lee, C.A., and Grossman, A.D. (2006) Modulation of the ComA-dependent quorum response in Bacillus subtilis by multiple Rap proteins and Phr peptides. J Bacteriol 188: 52735285.

Avery, S.V. (2005) Cell individuality: the bistability of competence development. Trends Microbiol 13: 459-462.

Avery, S.V. (2006) Microbial cell individuality and the underlying sources of heterogeneity. Nat Rev Microbiol 4: 577-587.

Bais, H.P., Fall, R., and Vivanco, J.M. (2004) Biocontrol of Bacillus subtilis against infection of Arabidopsis roots by Pseudomonas syringae is facilitated by biofilm formation and surfactin production. Plant Physiol 134: 307-319.

Banse, A.V., Chastanet, A., Rahn-Lee, L., Hobbs, E.C., and Losick, R. (2008) Parallel pathways of repression and antirepression governing the transition to stationary phase in Bacillus subtilis. Proc Natl Acad Sci U S A 105: 15547-15552.

Barbosa, T.M., Serra, C.R., La Ragione, R.M., Woodward, M.J., and Henriques, A.O. (2005) Screening for Bacillus isolates in the broiler gastrointestinal tract. Applied and Environmental Microbiology 71: 968-978.

Bedrunka, P. and Graumann, P.L. (2017) Subcellular clustering of a putative c-di-GMP-dependent exopolysaccharide machinery affecting macro colony architecture in Bacillus subtilis. Environ Microbiol Rep 9: 211-222.

Beer, D. de, Stoodley, P., Roe, F., and Lewandowski, Z. (1994) Effects of biofilm structures on oxygen distribution and mass transport. Biotechnol Bioeng 43: 1131-1138.

Berg, J.M., Tymoczko, J.L., Gatto jr., G.J., and Stryer, L. (2018) Stryer Biochemie. Berlin, Heidelberg, Berlin: Springer Berlin Heidelberg; Springer Spektrum.

Bergmiller, T. and Ackermann, M. (2011) Pole age affects cell size and the timing of cell division in Methylobacterium extorquens AM1. J Bacteriol 193: 5216-5221. 
Berman-Frank, I., Lundgren, P., and Falkowski, P. (2003) Nitrogen fixation and photosynthetic oxygen evolution in cyanobacteria. Res Microbiol 154: 157-164.

Bertero, M.G., Gonzales, B., Tarricone, C., Ceciliani, F., and Galizzi, A. (1999) Overproduction and characterization of the Bacillus subtilis anti-sigma factor FlgM. J Biol Chem 274: 12103-12107.

Bertram, R., Rigali, S., Wood, N., Lulko, A.T., Kuipers, O.P., and Titgemeyer, F. (2011) Regulon of the Nacetylglucosamine utilization regulator NagR in Bacillus subtilis. J Bacteriol 193: 3525-3536.

Bischoff, M., Dunman, P., Kormanec, J., Macapagal, D., Murphy, E., Mounts, W., et al. (2004) Microarray-based analysis of the Staphylococcus aureus sigmaB regulon. J Bacteriol 186: 40854099.

Blake, W.J., Balázsi, G., Kohanski, M.A., Isaacs, F.J., Murphy, K.F., Kuang, Y., et al. (2006) Phenotypic consequences of promoter-mediated transcriptional noise. Mol Cell 24: 853-865.

Blötz, C. (2013) Der Einfluss von zyklischem di-Guanosinmonophosphat auf die Biofilmbildung von Bacillus subtilis. Bachelor thesis.

Blötz, C., Commichau, F.M., and Stülke, J. (2017) Method collection General Microbiology, Göttingen.

Bradford, M.M. (1976) A rapid and sensitive method for the quantitation of microgram quantities of protein utilizing the principle of protein-dye binding. Analytical Biochemistry 72: 248-254.

Branda, S.S., Chu, F., Kearns, D.B., Losick, R., and Kolter, R. (2006) A major protein component of the Bacillus subtilis biofilm matrix. Mol Microbiol 59: 1229-1238.

Branda, S.S., González-Pastor, J.E., Ben-Yehuda, S., Losick, R., and Kolter, R. (2001) Fruiting body formation by Bacillus subtilis. Proc Natl Acad Sci U S A 98: 11621-11626.

Branda, S.S., Vik, S., Friedman, L., and Kolter, R. (2005) Biofilms: the matrix revisited. Trends Microbiol 13: $20-26$.

Breaker, R.R. (2012) Riboswitches and the RNA world. Cold Spring Harb Perspect Biol 4.

Buchanan, B.W., Lloyd, M.E., Engle, S.M., and Rubenstein, E.M. (2016) Cycloheximide chase analysis of protein degradation in Saccharomyces cerevisiae. J Vis Exp.

Burke, T.P. and Portnoy, D.A. (2016) SpoVG Is a conserved RNA-binding protein that regulates Listeria monocytogenes lysozyme resistance, virulence, and swarming motility. MBio 7: e00240.

Cascante Estepa, N. (2016) Localization and function of RNases in Bacillus subtilis. PhD thesis.

Chai, Y., Chu, F., Kolter, R., and Losick, R. (2008) Bistability and biofilm formation in Bacillus subtilis. Mol Microbiol 67: 254-263.

Chai, Y., Kolter, R., and Losick, R. (2010a) Reversal of an epigenetic switch governing cell chaining in Bacillus subtilis by protein instability. Mol Microbiol 78: 218-229.

Chai, Y., Norman, T., Kolter, R., and Losick, R. (2010b) An epigenetic switch governing daughter cell separation in Bacillus subtilis. Genes Dev 24: 754-765.

Chai, Y., Norman, T., Kolter, R., and Losick, R. (2011) Evidence that metabolism and chromosome copy number control mutually exclusive cell fates in Bacillus subtilis. EMBO J 30: 1402-1413.

Chen, Y., Chai, Y., Guo, J.-H., and Losick, R. (2012) Evidence for cyclic di-GMP-mediated signaling in Bacillus subtilis. J Bacteriol 194: 5080-5090.

Christensen, Q.H., Martin, N., Mansilla, M.C., Mendoza, D., and Cronan, J.E. (2011) A novel amidotransferase required for lipoic acid cofactor assembly in Bacillus subtilis. Mol Microbiol 80: 350-363.

Chu, F., Kearns, D.B., Branda, S.S., Kolter, R., and Losick, R. (2006) Targets of the master regulator of biofilm formation in Bacillus subtilis. Mol Microbiol 59: 1216-1228.

Chu, F., Kearns, D.B., McLoon, A., Chai, Y., Kolter, R., and Losick, R. (2008) A novel regulatory protein governing biofilm formation in Bacillus subtilis. Mol Microbiol 68: 1117-1127. 
References

Chung, J.D., Stephanopoulos, G., Ireton, K., and Grossman, A.D. (1994) Gene expression in single cells of Bacillus subtilis: evidence that a threshold mechanism controls the initiation of sporulation. $J$ Bacteriol 176: 1977-1984.

Claverys, J.-P. and Håvarstein, L.S. (2007) Cannibalism and fratricide: mechanisms and raisons d'être. Nat Rev Microbiol 5: 219-229.

Colledge, V.L., Fogg, M.J., Levdikov, V.M., Leech, A., Dodson, E.J., and Wilkinson, A.J. (2011) Structure and organisation of SinR, the master regulator of biofilm formation in Bacillus subtilis. $J \mathrm{Mol}$ Biol 411: 597-613.

Commichau, F.M., Dickmanns, A., Gundlach, J., Ficner, R., and Stülke, J. (2015) A jack of all trades: the multiple roles of the unique essential second messenger cyclic di-AMP. Mol Microbiol 97: 189204.

Cozy, L.M. and Kearns, D.B. (2010) Gene position in a long operon governs motility development in Bacillus subtilis. Mol Microbiol 76: 273-285.

Dahl, M.K., Msadek, T., Kunst, F., and Rapoport, G. (1991) Mutational analysis of the Bacillus subtilis DegU regulator and its phosphorylation by the DegS protein kinase. J Bacteriol 173: 2539-2547.

Darmon, E. and Leach, D.R.F. (2014) Bacterial genome instability. Microbiology and Molecular Biology Reviews 78: 1-39.

Davey, M.E. and O'toole, G.A. (2000) Microbial biofilms: from ecology to molecular genetics. Microbiology and Molecular Biology Reviews 64: 847-867.

Davies, B.W., Bogard, R.W., Young, T.S., and Mekalanos, J.J. (2012) Coordinated regulation of accessory genetic elements produces cyclic di-nucleotides for V. cholerae virulence. Cell 149: 358-370.

DeLoughery, A., Dengler, V., Chai, Y., and Losick, R. (2016) Biofilm formation by Bacillus subtilis requires an endoribonuclease-containing multisubunit complex that controls mRNA levels for the matrix gene repressor SinR. Mol Microbiol 99: 425-437.

Di Martino, M.L., Romilly, C., Wagner, E.G.H., Colonna, B., and Prosseda, G. (2016) One gene and two proteins: a leaderless mRNA supports the translation of a shorter form of the Shigella VirF regulator. MBio 7.

Diethmaier, C. (2008) CsrA-abhängige Regulation in Bacillus subtilis. Diploma thesis.

Diethmaier, C. (2011) YmdB als Regulator der Zelldifferenzierung in Bacillus subtilis. PhD thesis.

Diethmaier, C., Newman, J.A., Kovács, A.T., Kaever, V., Herzberg, C., Rodrigues, C., et al. (2014) The YmdB phosphodiesterase is a global regulator of late adaptive responses in Bacillus subtilis. $J$ Bacteriol 196: 265-275.

Diethmaier, C., Pietack, N., Gunka, K., Wrede, C., Lehnik-Habrink, M., Herzberg, C., et al. (2011) A novel factor controlling bistability in Bacillus subtilis: the $\mathrm{YmdB}$ protein affects flagellin expression and biofilm formation. J Bacteriol 193: 5997-6007.

Dietrich, S., Wiegand, S., and Liesegang, H. (2014) TraV: a genome context sensitive transcriptome browser. PLoS ONE 9: e93677.

Dormeyer, M., Lübke, A.L., Müller, P., Lentes, S., Reuß, D.R., Thürmer, A., et al. (2017) Hierarchical mutational events compensate for glutamate auxotrophy of a Bacillus subtilis gltC mutant. Environ Microbiol Rep 9: 279-289.

D'Souza, C., Nakano, M.M., and Zuber, P. (1994) Identification of comS, a gene of the srfA operon that regulates the establishment of genetic competence in Bacillus subtilis. Proc Natl Acad Sci U S A 91: 9397-9401.

Dubey, G.P., Malli Mohan, G.B., Dubrovsky, A., Amen, T., Tsipshtein, S., Rouvinski, A., et al. (2016) Architecture and characteristics of bacterial nanotubes. Dev Cell 36: 453-461. 
Dubnau, D. (1991) The regulation of genetic competence in Bacillus subtilis. Mol Microbiol 5: 11-18.

Dubnau, D. (1999) DNA uptake in bacteria. Annu Rev Microbiol 53: 217-244.

Dubnau, D. and Losick, R. (2006) Bistability in bacteria. Mol Microbiol 61: 564-572.

Ducret, A., Quardokus, E.M., and Brun, Y.V. (2016) MicrobeJ, a tool for high throughput bacterial cell detection and quantitative analysis. Nat Microbiol 1: 16077.

Ellermeier, C.D., Hobbs, E.C., Gonzalez-Pastor, J.E., and Losick, R. (2006) A three-protein signaling pathway governing immunity to a bacterial cannibalism toxin. Cell 124: 549-559.

Elowitz, M.B., Levine, A.J., Siggia, E.D., and Swain, P.S. (2002) Stochastic gene expression in a single cell. Science 297: 1183-1186.

Estacio, W., Anna-Arriola, S.S., Adedipe, M., and Márquez-Magaña, L.M. (1998) Dual promoters are responsible for transcription initiation of the fla/che operon in Bacillus subtilis. J Bacteriol 180: 3548-3555.

Flemming, H.-C. and Wingender, J. (2010) The biofilm matrix. Nat Rev Microbiol 8: 623-633.

Folta-Stogniew, E. (2006) Oligomeric states of proteins determined by size-exclusion chromatography coupled with light scattering, absorbance, and refractive index detectors. Methods Mol Biol 328 : 97-112.

Freese, E. (1972) Sporulation of bacilli, a model of cellular differentiation. Curr Top Dev Biol 7: 85-124.

Fujita, M., González-Pastor, J.E., and Losick, R. (2005) High- and low-threshold genes in the Spo0A regulon of Bacillus subtilis. J Bacteriol 187: 1357-1368.

Gao, X., Mukherjee, S., Matthews, P.M., Hammad, L.A., Kearns, D.B., and Dann, C.E. (2013) Functional characterization of core components of the Bacillus subtilis cyclic-di-GMP signaling pathway. $J$ Bacteriol 195: 4782-4792.

Gerwig, J. (2014) Control of biofilm formation in Bacillus subtilis. PhD thesis.

González-Pastor, J.E., Hobbs, E.C., and Losick, R. (2003) Cannibalism by sporulating bacteria. Science 301: 510-513.

Göpel, Y., Papenfort, K., Reichenbach, B., Vogel, J., and Görke, B. (2013) Targeted decay of a regulatory small RNA by an adaptor protein for RNase $E$ and counteraction by an anti-adaptor RNA. Genes Dev 27: 552-564.

Gresset, A., Sondek, J., and Harden, T.K. (2012) The phospholipase C isozymes and their regulation. Subcell Biochem 58: 61-94.

Grote, J., Krysciak, D., Streit, W.R., and Lovell, C.R. (2015) Phenotypic heterogeneity, a phenomenon that may explain why quorum sensing does not always result in truly homogenous cell behavior. Appl. Environ. Microbiol. 81: 5280-5289.

Guérout-Fleury, A.M., Shazand, K., Frandsen, N., and Stragier, P. (1995) Antibiotic-resistance cassettes for Bacillus subtilis. Gene 167: 335-336.

Gundlach, J., Herzberg, C., Kaever, V., Gunka, K., Hoffmann, T., Weiß, M., et al. (2017) Control of potassium homeostasis is an essential function of the second messenger cyclic di-AMP in Bacillus subtilis. Sci Signal 10.

Gupta, R.S., Bhandari, V., and Naushad, H.S. (2012) Molecular signatures for the PVC clade (Planctomycetes, Verrucomicrobia, Chlamydiae, and Lentisphaerae) of bacteria provide insights into their evolutionary relationships. Front Microbiol 3: 327.

Hallet, B. (2001) Playing Dr Jekyll and Mr Hyde: Combined mechanisms of phase variation in bacteria. Curr Opin Microbiol 4: 570-581.

Hall-Stoodley, L., Costerton, J.W., and Stoodley, P. (2004) Bacterial biofilms: from the natural environment to infectious diseases. Nat Rev Microbiol 2: 95-108. 
References

Hamon, M.A., Stanley, N.R., Britton, R.A., Grossman, A.D., and Lazazzera, B.A. (2004) Identification of AbrB-regulated genes involved in biofilm formation by Bacillus subtilis. Mol Microbiol 52: 847860.

Harst, A., Albaum, S.P., Bojarzyn, T., Trötschel, C., and Poetsch, A. (2017) Proteomics of FACS-sorted heterogeneous Corynebacterium glutamicum populations. J Proteomics 160: 1-7.

Hengge, R., Galperin, M.Y., Ghigo, J.-M., Gomelsky, M., Green, J., Hughes, K.T., et al. (2015) Systematic nomenclature for GGDEF and EAL domain-containing cyclic di-GMP turnover proteins of Escherichia coli. J Bacteriol 198: 7-11.

Herzberg, C., Weidinger, L.A.F., Dörrbecker, B., Hübner, S., Stülke, J., and Commichau, F.M. (2007) SPINE: a method for the rapid detection and analysis of protein-protein interactions in vivo. Proteomics 7: 4032-4035.

Hobley, L., Li, B., Wood, J.L., Kim, S.H., Naidoo, J., Ferreira, A.S., et al. (2017) Spermidine promotes Bacillus subtilis biofilm formation by activating expression of the matrix regulator slrR. J Biol Chem 292: 12041-12053.

Hogg, T., Mechold, U., Malke, H., Cashel, M., and Hilgenfeld, R. (2004) Conformational antagonism between opposing active sites in a bifunctional RelA/SpoT homolog modulates (p)ppGpp metabolism during the stringent response corrected. Cell 117: 57-68.

Hsueh, Y.-H., Cozy, L.M., Sham, L.-T., Calvo, R.A., Gutu, A.D., Winkler, M.E., and Kearns, D.B. (2011) DegU-phosphate activates expression of the anti-sigma factor FlgM in Bacillus subtilis. Mol Microbiol 81: 1092-1108.

Huberts, D.H.E.W. and van der Klei, I.J. (2010) Moonlighting proteins: an intriguing mode of multitasking. Biochim Biophys Acta 1803: 520-525.

Hübner, S. (2008) Untersuchung der Spezifität von Antiterminationsproteinen in Bacillus subtilis. PhD thesis.

Inoue, H., Nojima, H., and Okayama, H. (1990) High efficiency transformation of Escherichia coli with plasmids. Gene 96: 23-28.

Jiang, M., Grau, R., and Perego, M. (2000a) Differential processing of propeptide inhibitors of Rap phosphatases in Bacillus subtilis. J Bacteriol 182: 303-310.

Jiang, M., Shao, W., Perego, M., and Hoch, J.A. (2000b) Multiple histidine kinases regulate entry into stationary phase and sporulation in Bacillus subtilis. Mol Microbiol 38: 535-542.

Johnson, D.R., Goldschmidt, F., Lilja, E.E., and Ackermann, M. (2012) Metabolic specialization and the assembly of microbial communities. ISME J 6: 1985-1991.

Jordan, S., Rietkötter, E., Strauch, M.A., Kalamorz, F., Butcher, B.G., Helmann, J.D., and Mascher, T. (2007) LiaRS-dependent gene expression is embedded in transition state regulation in Bacillus subtilis. Microbiology (Reading, Engl) 153: 2530-2540.

Kampf, J. and Stülke, J. (2017) Cyclic-di-GMP signalling meets extracellular polysaccharide synthesis in Bacillus subtilis. Environ Microbiol Rep 9: 182-185.

Kazlauskiene, M., Kostiuk, G., Venclovas, Č., Tamulaitis, G., and Siksnys, V. (2017) A cyclic oligonucleotide signaling pathway in type III CRISPR-Cas systems. Science 357: 605-609.

Kazmierczak, B.I., Lebron, M.B., and Murray, T.S. (2006) Analysis of FimX, a phosphodiesterase that governs twitching motility in Pseudomonas aeruginosa. Mol Microbiol 60: 1026-1043.

Kearns, D.B., Chu, F., Branda, S.S., Kolter, R., and Losick, R. (2005) A master regulator for biofilm formation by Bacillus subtilis. Mol Microbiol 55: 739-749.

Kearns, D.B. and Losick, R. (2005) Cell population heterogeneity during growth of Bacillus subtilis. Genes Dev 19: 3083-3094. 
Kim, Y. and Wood, T.K. (2010) Toxins Hha and CspD and small RNA regulator Hfq are involved in persister cell formation through MqsR in Escherichia coli. Biochem Biophys Res Commun 391: 209-213.

Kobayashi, K. (2007) Gradual activation of the response regulator DegU controls serial expression of genes for flagellum formation and biofilm formation in Bacillus subtilis. Mol Microbiol 66: 395409.

Kobayashi, K. and Iwano, M. (2012) BsIA (YuaB) forms a hydrophobic layer on the surface of Bacillus subtilis biofilms. Mol Microbiol 85: 51-66.

Koetje, E.J., Hajdo-Milasinovic, A., Kiewiet, R., Bron, S., and Tjalsma, H. (2003) A plasmid-borne Rap-Phr system of Bacillus subtilis can mediate cell-density controlled production of extracellular proteases. Microbiology (Reading, Engl) 149: 19-28.

Kolenbrander, P.E. and London, J. (1993) Adhere today, here tomorrow: oral bacterial adherence. J Bacteriol 175: 3247-3252.

Konkol, M.A., Blair, K.M., and Kearns, D.B. (2013) Plasmid-encoded Coml inhibits competence in the ancestral 3610 strain of Bacillus subtilis. J Bacteriol 195: 4085-4093.

Kovács, A.T. and Kuipers, O.P. (2011) Rok regulates yuaB expression during architecturally complex colony development of Bacillus subtilis 168. J Bacteriol 193: 998-1002.

Kruse, K. (2013) The link between the enzymatic activity of YmdB and its role in biofilm formation in Bacillus subtilis. Master thesis.

Kudoh, J., Ikeuchi, T., and Kurahashi, K. (1984) Identification of the sporulation gene spoOA product of Bacillus subtilis. Biochem Biophys Res Commun 122: 1104-1109.

Kunst, F., Msadek, T., Bignon, J., and Rapoport, G. (1994) The DegS/DegU and ComP/ComA twocomponent systems are part of a network controlling degradative enzyme synthesis and competence in Bacillus subtilis. Res Microbiol 145: 393-402.

Kunst, F. and Rapoport, G. (1995) Salt stress is an environmental signal affecting degradative enzyme synthesis in Bacillus subtilis. J Bacteriol 177: 2403-2407.

Kussell, E. and Leibler, S. (2005) Phenotypic diversity, population growth, and information in fluctuating environments. Science 309: 2075-2078.

Laemmli, U.K. (1970) Cleavage of structural proteins during the assembly of the head of bacteriophage T4. Nature 227: 680-685.

Larkin, M.A., Blackshields, G., Brown, N.P., Chenna, R., McGettigan, P.A., McWilliam, H., et al. (2007) Clustal W and Clustal X version 2.0. Bioinformatics 23: 2947-2948.

Lazazzera, B.A. (2001) The intracellular function of extracellular signaling peptides. Peptides 22: 15191527.

Lazazzera, B.A., Kurtser, I.G., McQuade, R.S., and Grossman, A.D. (1999) An autoregulatory circuit affecting peptide signaling in Bacillus subtilis. J Bacteriol 181: 5193-5200.

Lazazzera, B.A., Solomon, J.M., and Grossman, A.D. (1997) An exported peptide functions intracellularly to contribute to cell density signaling in B. subtilis. Cell 89: 917-925.

Lea, W.A. and Simeonov, A. (2011) Fluorescence polarization assays in small molecule screening. Expert Opin Drug Discov 6: 17-32.

LeDeaux, J.R., Yu, N., and Grossman, A.D. (1995) Different roles for KinA, KinB, and KinC in the initiation of sporulation in Bacillus subtilis. J Bacteriol 177: 861-863.

Lehnik-Habrink, M. (2011) An mRNA degradation complex in Bacillus subtilis. PhD thesis.

Lehnik-Habrink, M., Lewis, R.J., Mäder, U., and Stülke, J. (2012) RNA degradation in Bacillus subtilis: An interplay of essential endo- and exoribonucleases. Mol Microbiol 84: 1005-1017. 
References

Lehnik-Habrink, M., Schaffer, M., Mäder, U., Diethmaier, C., Herzberg, C., and Stülke, J. (2011) RNA processing in Bacillus subtilis: identification of targets of the essential RNase Y. Mol Microbiol 81: 1459-1473.

Leiman, S.A., Arboleda, L.C., Spina, J.S., and McLoon, A.L. (2014) SinR is a mutational target for finetuning biofilm formation in laboratory-evolved strains of Bacillus subtilis. BMC Microbiol 14: 301.

Levine, J.H., Lin, Y., and Elowitz, M.B. (2013) Functional roles of pulsing in genetic circuits. Science 342: 1193-1200.

Lewis, R.J., Brannigan, J.A., Offen, W.A., Smith, I., and Wilkinson, A.J. (1998) An evolutionary link between sporulation and prophage induction in the structure of a repressor: anti-repressor complex. J Mol Biol 283: 907-912.

Link, T.M., Valentin-Hansen, P., and Brennan, R.G. (2009) Structure of Escherichia coli Hfq bound to polyriboadenylate RNA. Proc Natl Acad Sci U S A 106: 19292-19297.

López, D., Fischbach, M.A., Chu, F., Losick, R., and Kolter, R. (2009) Structurally diverse natural products that cause potassium leakage trigger multicellularity in Bacillus subtilis. Proc Natl Acad Sci U S A 106: 280-285.

López, D. and Kolter, R. (2010) Extracellular signals that define distinct and coexisting cell fates in Bacillus subtilis. FEMS Microbiol Rev 34: 134-149.

Lorenzo, V. de, Sekowska, A., and Danchin, A. (2015) Chemical reactivity drives spatiotemporal organisation of bacterial metabolism. FEMS Microbiol Rev 39: 96-119.

Lünsdorf, H., Wenderoth, D.F., and Abraham, W.-R. (2002) Composite biofilms grown in acidic mining lakes and assessed by electron microscopy and molecular techniques. Water, Air and Soil Pollution: Focus 2: 69-79.

Magnuson, R., Solomon, J., and Grossman, A.D. (1994) Biochemical and genetic characterization of a competence pheromone from B. subtilis. Cell 77: 207-216.

Mamou, G., Malli Mohan, G.B., Rouvinski, A., Rosenberg, A., and Ben-Yehuda, S. (2016) Early developmental program shapes colony morphology in bacteria. Cell Rep 14: 1850-1857.

Margot, P., Pagni, M., and Karamata, D. (1999) Bacillus subtilis 168 gene lytF encodes a gamma-Dglutamate-meso-diaminopimelate muropeptidase expressed by the alternative vegetative sigma factor, sigmaD. Microbiology (Reading, Engl) 145 (Pt 1): 57-65.

Márquez, L.M., Helmann, J.D., Ferrari, E., Parker, H.M., Ordal, G.W., and Chamberlin, M.J. (1990) Studies of sigma D-dependent functions in Bacillus subtilis. J Bacteriol 172: 3435-3443.

Mars, R.A.T., Nicolas, P., Denham, E.L., and van Dijl, J.M. (2016) Regulatory RNAs in Bacillus subtilis: a Gram-positive perspective on bacterial RNA-mediated regulation of gene expression. Microbiol Mol Biol Rev 80: 1029-1057.

Martin-Verstraete, I., Débarbouillé, M., Klier, A., and Rapoport, G. (1994) Interactions of wild-type and truncated LevR of Bacillus subtilis with the upstream activating sequence of the levanase operon. J Mol Biol 241: 178-192.

Marvasi, M., Visscher, P.T., and Casillas Martinez, L. (2010) Exopolymeric substances (EPS) from Bacillus subtilis: polymers and genes encoding their synthesis. FEMS Microbiol Lett 313: 1-9.

Mathews, D.H., Turner, D.H., and Watson, R.M. (2016) RNA secondary structure prediction. Curr Protoc Nucleic Acid Chem 67: 11.2.1-11.2.19.

Matsuno, K. and Sonenshein, A.L. (1999) Role of SpoVG in asymmetric septation in Bacillus subtilis. J Bacteriol 181: 3392-3401.

McLoon, A.L., Guttenplan, S.B., Kearns, D.B., Kolter, R., and Losick, R. (2011a) Tracing the domestication of a biofilm-forming bacterium. J Bacteriol 193: 2027-2034. 
McLoon, A.L., Kolodkin-Gal, I., Rubinstein, S.M., Kolter, R., and Losick, R. (2011b) Spatial regulation of histidine kinases governing biofilm formation in Bacillus subtilis. J Bacteriol 193: 679-685.

McQuade, R.S., Comella, N., and Grossman, A.D. (2001) Control of a family of phosphatase regulatory genes (phr) by the alternate sigma factor sigma-H of Bacillus subtilis. J Bacteriol 183: 4905-4909.

Mielich-Süss, B. and Lopez, D. (2014) Molecular mechanisms involved in Bacillus subtilis biofilm formation. Environ Microbiol 17: 555-565.

Miller, L. (2010) ImageJ gel analysis. [WWW document]. URL http://www.lukemiller.org/ImageJ_gel_analysis.pdf.

Mirel, D.B. and Chamberlin, M.J. (1989) The Bacillus subtilis flagellin gene (hag) is transcribed by the sigma 28 form of RNA polymerase. J Bacteriol 171: 3095-3101.

Misra, H.S. and Tuli, R. (2000) Differential expression of photosynthesis and nitrogen fixation genes in the cyanobacterium Plectonema boryanum. Plant Physiol 122: 731-736.

Moll, I., Grill, S., Gualerzi, C.O., and Bläsi, U. (2002) Leaderless mRNAs in bacteria: surprises in ribosomal recruitment and translational control. Mol Microbiol 43: 239-246.

Msadek, T. (1999) When the going gets tough: survival strategies and environmental signaling networks in Bacillus subtilis. Trends Microbiol 7: 201-207.

Msadek, T., Kunst, F., Henner, D., Klier, A., Rapoport, G., and Dedonder, R. (1990) Signal transduction pathway controlling synthesis of a class of degradative enzymes in Bacillus subtilis: expression of the regulatory genes and analysis of mutations in degS and degU. J Bacteriol 172: 824-834.

Naka, K., Koga, M., Yonesaki, T., and Otsuka, Y. (2014) RNase HI stimulates the activity of RnIA toxin in Escherichia coli. Mol Microbiol 91: 596-605.

Nakano, M.M., Magnuson, R., Myers, A., Curry, J., Grossman, A.D., and Zuber, P. (1991a) srfA is an operon required for surfactin production, competence development, and efficient sporulation in Bacillus subtilis. J Bacteriol 173: 1770-1778.

Nakano, M.M., Xia, L.A., and Zuber, P. (1991b) Transcription initiation region of the srfA operon, which is controlled by the comP-comA signal transduction system in Bacillus subtilis. J Bacteriol 173: 5487-5493.

Newman, J.A., Rodrigues, C., and Lewis, R.J. (2013) Molecular basis of the activity of SinR protein, the master regulator of biofilm formation in Bacillus subtilis. J Biol Chem 288: 10766-10778.

Nowak, M.A. and May, R.M. (1992) Evolutionary games and spatial chaos. Nature 359: 826-829.

Ogura, M. (2016) Post-transcriptionally generated cell heterogeneity regulates biofilm formation in Bacillus subtilis. Genes Cells 21: 335-349.

Ogura, M., Shimane, K., Asai, K., Ogasawara, N., and Tanaka, T. (2003) Binding of response regulator DegU to the aprE promoter is inhibited by RapG, which is counteracted by extracellular PhrG in Bacillus subtilis. Mol Microbiol 49: 1685-1697.

Ono, K., Oka, R., Toyofuku, M., Sakaguchi, A., Hamada, M., Yoshida, S., and Nomura, N. (2014) cAMP signaling affects irreversible attachment during biofilm formation by Pseudomonas aeruginosa PAO1. Microb. Environ. 29: 104-106.

Ozbudak, E.M., Thattai, M., Kurtser, I., Grossman, A.D., and van Oudenaarden, A. (2002) Regulation of noise in the expression of a single gene. Nat Genet 31: 69-73.

Pan, X., Chen, X., Su, X., Feng, Y., Tao, Y., and Dong, Z. (2014) Involvement of SpoVG in hemolysis caused by Bacillus subtilis. Biochem Biophys Res Commun 443: 899-904.

Peng, X., Zhang, Y., Bai, G., Zhou, X., and Wu, H. (2016) Cyclic di-AMP mediates biofilm formation. Mol Microbiol 99: 945-959. 
References

Perego, M. and Hoch, J.A. (1996) Cell-cell communication regulates the effects of protein aspartate phosphatases on the phosphorelay controlling development in Bacillus subtilis. Proc Natl Acad Sci U S A 93: 1549-1553.

Pietack, N. (2010) Investigation of Glycolysis in Bacillus subtilis. PhD thesis.

Piggot, P.J. and Hilbert, D.W. (2004) Sporulation of Bacillus subtilis. Curr Opin Microbiol 7: 579-586.

Plotkin, J.B. and Kudla, G. (2011) Synonymous but not the same: the causes and consequences of codon bias. Nat Rev Genet 12: 32-42.

Potrykus, K. and Cashel, M. (2008) (p)ppGpp: Still magical? Annu Rev Microbiol 62: 35-51.

Pozsgai, E.R., Blair, K.M., and Kearns, D.B. (2012) Modified mariner transposons for random inducibleexpression insertions and transcriptional reporter fusion insertions in Bacillus subtilis. Applied and Environmental Microbiology 78: 778-785.

Rempeters, L. (2011) Functional analysis of the glycolytic enzyme enolase and the DEAD-box RNA helicase CshA in the RNA metabolism of Bacillus subtilis. Master thesis.

Reuven, P. and Eldar, A. (2011) Macromotives and microbehaviors: The social dimension of bacterial phenotypic variability. Curr Opin Genet Dev 21: 759-767.

Romero, D., Vlamakis, H., Losick, R., and Kolter, R. (2011) An accessory protein required for anchoring and assembly of amyloid fibres in B. subtilis biofilms. Mol Microbiol 80: 1155-1168.

Rosenberg, J., Müller, P., Lentes, S., Thiele, M.J., Zeigler, D.R., Tödter, D., et al. (2016) ThrR, a DNAbinding transcription factor involved in controlling threonine biosynthesis in Bacillus subtilis. $\mathrm{Mol}$ Microbiol 101: 879-893.

Rosenbluh, A., Banner, C.D., Losick, R., and Fitz-James, P.C. (1981) Identification of a new developmental locus in Bacillus subtilis by construction of a deletion mutation in a cloned gene under sporulation control. J Bacteriol 148: 341-351.

Roux, D., Cywes-Bentley, C., Zhang, Y.-F., Pons, S., Konkol, M., Kearns, D.B., et al. (2015) Identification of poly-N-acetylglucosamine as a major polysaccharide component of the Bacillus subtilis biofilm matrix. J Biol Chem 290: 19261-19272.

Sambrook, J., Fritsch, E., and Maniatis, T. (1989) Molecular cloning: a laboratory manual : Vol. 2. S.I.: Cold Spring Harbor.

Schindelin, J., Rueden, C.T., Hiner, M.C., and Eliceiri, K.W. (2015) The ImageJ ecosystem: an open platform for biomedical image analysis. Mol Reprod Dev 82: 518-529.

Schneider, C.A., Rasband, W.S., and Eliceiri, K.W. (2012) NIH Image to ImageJ: 25 years of image analysis. Nat Methods 9: 671-675.

Schulthess, B., Meier, S., Homerova, D., Goerke, C., Wolz, C., Kormanec, J., et al. (2009) Functional characterization of the sigmaB-dependent yabJ-spoVG operon in Staphylococcus aureus: role in methicillin and glycopeptide resistance. Antimicrob Agents Chemother 53: 1832-1839.

Schwabe, A. and Bruggeman, F.J. (2014) Contributions of cell growth and biochemical reactions to nongenetic variability of cells. Biophys J 107: 301-313.

Scott, D.J., Leejeerajumnean, S., Brannigan, J.A., Lewis, R.J., Wilkinson, A.J., and Hoggett, J.G. (1999) Quaternary re-arrangement analysed by spectral enhancement: the interaction of a sporulation repressor with its antagonist. J Mol Biol 293: 997-1004.

Segall, J. and Losick, R. (1977) Cloned Bacillus subtilis DNA containing a gene that is activated early during sporulation. Cell 11: 751-761.

Selvy, P.E., Lavieri, R.R., Lindsley, C.W., and Brown, H.A. (2011) Phospholipase D: enzymology, functionality, and chemical modulation. Chem Rev 111: 6064-6119. 
Shapiro, J.A. (1998) Thinking about bacterial populations as multicellular organisms. Annu Rev Microbiol 52: 81-104.

Shemesh, M. and Chai, Y. (2013) A combination of glycerol and manganese promotes biofilm formation in Bacillus subtilis via histidine kinase KinD signaling. J Bacteriol 195: 2747-2754.

Shin, D.H., Proudfoot, M., Lim, H.J., Choi, I.-K., Yokota, H., Yakunin, A.F., et al. (2008) Structural and enzymatic characterization of DR1281: a calcineurin-like phosphoesterase from Deinococcus radiodurans. Proteins 70: 1000-1009.

Smits, W.K., Eschevins, C.C., Susanna, K.A., Bron, S., Kuipers, O.P., and Hamoen, L.W. (2005) Stripping Bacillus: ComK auto-stimulation is responsible for the bistable response in competence development. Mol Microbiol 56: 604-614.

Smits, W.K., Kuipers, O.P., and Veening, J.-W. (2006) Phenotypic variation in bacteria: The role of feedback regulation. Nat Rev Microbiol 4: 259-271.

Snijder, B., Sacher, R., Rämö, P., Damm, E.-M., Liberali, P., and Pelkmans, L. (2009) Population context determines cell-to-cell variability in endocytosis and virus infection. Nature 461: 520-523.

Solomon, J.M., Magnuson, R., Srivastava, A., and Grossman, A.D. (1995) Convergent sensing pathways mediate response to two extracellular competence factors in Bacillus subtilis. Genes Dev 9: 547558.

Starkey, M., Hickman, J.H., Ma, L., Zhang, N., Long, S. de, Hinz, A., et al. (2009) Pseudomonas aeruginosa rugose small-colony variants have adaptations that likely promote persistence in the cystic fibrosis lung. J Bacteriol 191: 3492-3503.

Stempler, O., Baidya, A.K., Bhattacharya, S., Malli Mohan, G.B., Tzipilevich, E., Sinai, L., et al. (2017) Interspecies nutrient extraction and toxin delivery between bacteria. Nat Commun 8: 315.

Stewart, P.S. and Franklin, M.J. (2008) Physiological heterogeneity in biofilms. Nat Rev Microbiol 6: 199210.

Stoodley, P., Sauer, K., Davies, D.G., and Costerton, J.W. (2002) Biofilms as complex differentiated communities. Annu Rev Microbiol 56: 187-209.

Stöver, A.G. and Driks, A. (1999a) Control of synthesis and secretion of the Bacillus subtilis protein YqxM. J Bacteriol 181: 7065-7069.

Stöver, A.G. and Driks, A. (1999b) Regulation of synthesis of the Bacillus subtilis transition-phase, sporeassociated antibacterial protein TasA. J Bacteriol 181: 5476-5481.

Strauch, M., Webb, V., Spiegelman, G., and Hoch, J.A. (1990) The SpoOA protein of Bacillus subtilis is a repressor of the abrB gene. Proc Natl Acad Sci U S A 87: 1801-1805.

Strauch, M.A., Bobay, B.G., Cavanagh, J., Yao, F., Wilson, A., and Le Breton, Y. (2007) Abh and AbrB control of Bacillus subtilis antimicrobial gene expression. J Bacteriol 189: 7720-7732.

Studier, F.W. and Moffatt, B.A. (1986) Use of bacteriophage T7 RNA polymerase to direct selective highlevel expression of cloned genes. J Mol Biol 189: 113-130.

Subramaniam, A.R., DeLoughery, A., Bradshaw, N., Chen, Y., O'Shea, E., Losick, R., and Chai, Y. (2013) A serine sensor for multicellularity in a bacterium. Elife 2: e01501.

Süel, G.M., Kulkarni, R.P., Dworkin, J., Garcia-Ojalvo, J., and Elowitz, M.B. (2007) Tunability and noise dependence in differentiation dynamics. Science 315: 1716-1719.

Sullivan, D.M., Bobay, B.G., Kojetin, D.J., Thompson, R.J., Rance, M., Strauch, M.A., and Cavanagh, J. (2008) Insights into the nature of DNA binding of AbrB-like transcription factors. Structure 16: 1702-1713.

Taylor, B.L. and Zhulin, I.B. (1999) PAS domains internal sensors of oxygen, redox potential, and light. Microbiol Mol Biol Rev 63: 479-506. 
References

Terra, R., Stanley-Wall, N.R., Cao, G., and Lazazzera, B.A. (2012) Identification of Bacillus subtilis SipW as a bifunctional signal peptidase that controls surface-adhered biofilm formation. J Bacteriol 194: 2781-2790.

Thattai, M. and van Oudenaarden, A. (2004) Stochastic gene expression in fluctuating environments. Genetics 167: 523-530.

Titball, R.W. (1993) Bacterial phospholipases C. Microbiological Reviews 57: 347-366.

Tjalsma, H., Bolhuis, A., van Roosmalen, M.L., Wiegert, T., Schumann, W., Broekhuizen, C.P., et al. (1998) Functional analysis of the secretory precursor processing machinery of Bacillus subtilis: identification of a eubacterial homolog of archaeal and eukaryotic signal peptidases. Genes Dev 12: 2318-2331.

Trautner, B.W. and Darouiche, R.O. (2004) Role of biofilm in catheter-associated urinary tract infection. American journal of infection control 32: 177-183.

Tucker, A.T., Bobay, B.G., Banse, A.V., Olson, A.L., Soderblom, E.J., Moseley, M.A., et al. (2014) A DNA mimic: the structure and mechanism of action for the anti-repressor protein AbbA. J Mol Biol 426: 1911-1924.

van Sinderen, D., Luttinger, A., Kong, L., Dubnau, D., Venema, G., and Hamoen, L. (1995) comK encodes the competence transcription factor, the key regulatory protein for competence development in Bacillus subtilis. Mol Microbiol 15: 455-462.

Veening, J.-W., Igoshin, O.A., Eijlander, R.T., Nijland, R., Hamoen, L.W., and Kuipers, O.P. (2008a) Transient heterogeneity in extracellular protease production by Bacillus subtilis. Mol Syst Biol 4: 184.

Veening, J.-W., Smits, W.K., and Kuipers, O.P. (2008b) Bistability, epigenetics, and bet-hedging in bacteria. Annu Rev Microbiol 62: 193-210.

Velicer, G.J. (2003) Social strife in the microbial world. Trends Microbiol 11: 330-337.

Verhamme, D.T., Kiley, T.B., and Stanley-Wall, N.R. (2007) DegU co-ordinates multicellular behaviour exhibited by Bacillus subtilis. Mol Microbiol 65: 554-568.

Verhamme, D.T., Murray, E.J., and Stanley-Wall, N.R. (2009) DegU and Spo0A jointly control transcription of two loci required for complex colony development by Bacillus subtilis. J Bacteriol 191: 100-108.

Vlamakis, H., Aguilar, C., Losick, R., and Kolter, R. (2008) Control of cell fate by the formation of an architecturally complex bacterial community. Genes Dev 22: 945-953.

Vlamakis, H., Chai, Y., Beauregard, P., Losick, R., and Kolter, R. (2013) Sticking together: building a biofilm the Bacillus subtilis way. Nat Rev Microbiol 11: 157-168.

Vogel, J. and Luisi, B.F. (2011) Hfq and its constellation of RNA. Nat Rev Microbiol 9: 578-589.

Wach, A. (1996) PCR-synthesis of marker cassettes with long flanking homology regions for gene disruptions in S. cerevisiae. Yeast 12: 259-265.

Wang, P., Robert, L., Pelletier, J., Dang, W.L., Taddei, F., Wright, A., and Jun, S. (2010) Robust growth of Escherichia coli. Curr Biol 20: 1099-1103.

Waters, C.M. and Bassler, B.L. (2005) Quorum sensing: Cell-to-cell communication in bacteria. Annu Rev Cell Dev Biol 21: 319-346.

Watnick, P. and Kolter, R. (2000) Biofilm, city of microbes. J Bacteriol 182: 2675-2679.

Weinrauch, Y., Msadek, T., Kunst, F., and Dubnau, D. (1991) Sequence and properties of comQ, a new competence regulatory gene of Bacillus subtilis. J Bacteriol 173: 5685-5693. 
Weinrauch, Y., Penchev, R., Dubnau, E., Smith, I., and Dubnau, D. (1990) A Bacillus subtilis regulatory gene product for genetic competence and sporulation resembles sensor protein members of the bacterial two-component signal-transduction systems. Genes Dev 4: 860-872.

West, J.T., Estacio, W., and Márquez-Magaña, L. (2000) Relative roles of the fla/che $\mathrm{P}_{\mathrm{A}}, \mathrm{P}_{\mathrm{D}-3}$, and $\mathrm{P}_{\text {sigD }}$ promoters in regulating motility and sigD expression in Bacillus subtilis. J Bacteriol 182: 48414848.

Wolf, D.M., Vazirani, V.V., and Arkin, A.P. (2005) Diversity in times of adversity: probabilistic strategies in microbial survival games. Journal of Theoretical Biology 234: 227-253.

Yakhnin, H., Pandit, P., Petty, T.J., Baker, C.S., Romeo, T., and Babitzke, P. (2007) CsrA of Bacillus subtilis regulates translation initiation of the gene encoding the flagellin protein (hag) by blocking ribosome binding. Mol Microbiol 64: 1605-1620.

Youngman, P. (1990) Use of transposons and integrational vectors for mutagenesis and construction of gene fusions in Bacillus subtilis. In Molecular biological methods for Bacillus. Harwood, C.R. (ed.). Chichester: Wiley, pp. 221-266.

Yu, J., Kim, D., and Lee, T. (2010) Microbial diversity in biofilms on water distribution pipes of different materials. Water Sci Technol 61: 163-171.

Zaprasis, A., Hoffmann, T., Wünsche, G., Flórez, L.A., Stülke, J., and Bremer, E. (2014) Mutational activation of the RocR activator and of a cryptic rocDEF promoter bypass loss of the initial steps of proline biosynthesis in Bacillus subtilis. Environ Microbiol 16: 701-717.

Zeigler, D.R., Prágai, Z., Rodriguez, S., Chevreux, B., Muffler, A., Albert, T., et al. (2008) The origins of 168, W23, and other Bacillus subtilis legacy strains. J Bacteriol 190: 6983-6995.

Zemansky, J., Kline, B.C., Woodward, J.J., Leber, J.H., Marquis, H., and Portnoy, D.A. (2009) Development of a mariner-based transposon and identification of Listeria monocytogenes determinants, including the peptidyl-prolyl isomerase PrsA2, that contribute to its hemolytic phenotype. J Bacteriol 191: 3950-3964.

Zhang, X., Shi, H., Wu, J., Zhang, X., Sun, L., Chen, C., and Chen, Z.J. (2013) Cyclic GMP-AMP containing mixed phosphodiester linkages is an endogenous high-affinity ligand for STING. Mol Cell 51: 226235.

Zhu, B. and Stülke, J. (2018) SubtiWiki in 2018: from genes and proteins to functional network annotation of the model organism Bacillus subtilis. Nucleic Acids Res 46: D743-D748.

Zuberi, A.R., Ying, C.W., Parker, H.M., and Ordal, G.W. (1990) Transposon Tn917lacZ mutagenesis of Bacillus subtilis: Identification of two new loci required for motility and chemotaxis. $J$ Bacteriol 172: 6841-6848. 


\section{Appendix}

\subsection{Conservations of SpoVG and location of mutations during cloning}

spoVG was cloned into the pGP382 for constitutive expression with a C-terminal Strep-tag. Sequencing of the plasmids reveal a high rate of mutations in about $90 \%$ of the plasmids. Mutations were documented and compared to SpoVG variants of different organisms.

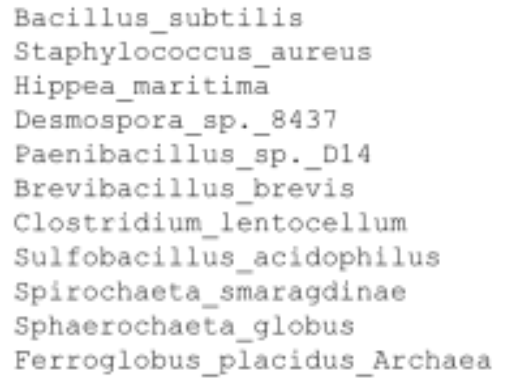

Mutated aa by cloning with $E \cdot \operatorname{col} i$

\begin{abstract}
MEVT DVRLRRVNT DRMRAIASI TLDHEFVVHDIRVIDGNNGLFVAMPSKRTPDGEFRDITHPINSSTRGKIQDAVLNEYHRLGDTEALEFEEAGAS MKVTDVRLRKIOTDGRMKALVSITLDEAFVIHDLRVIEGNSGLFVAMPSKRTPDGEFRDIAHPINSDMROEIODAVMKVY--1.--1.--MEVT DVRLRRVNT DGRMRAIASI TLDHEFVVHDIRVI DGNNGLFVAMP SRKMKDGSFKDVAHPLNNEMRQKLEKAVLGEYEKAKAEKQEEAQE----

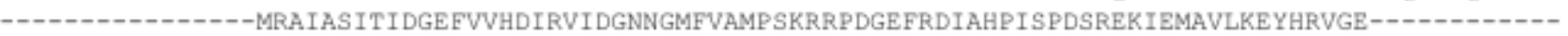
MQI TDVRLRRVSSEGRMKAIASITIDNEFVVHDIRVIDGNNGMFVAMPSKRTPDGEFRDIAHPISSGTREKIQA.AVLAEYERAAEQEEAIEEGA--MEVTDVRLRRVNTDGRMKAIASITIDHEFVVHDIRVIDGNNGMFVAMPSKRTPDGEFRDIAHPISSTTREKIQA.AVLTEYDRVGQEEEST IEAGA-ME I TDIRVRKINKDGKMKAVVSVTFDNEFVVHDIKVIEGDKGRFIAMPSRKTLDGEFRDIAHPINSETRDRIQNQVLEKYEMVLLSDEVAI------

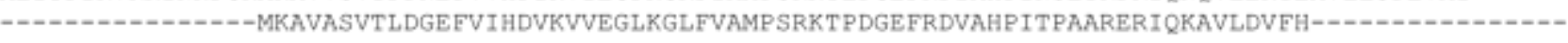
MEI TDIRIRKLGSDSKLKAYVT I TFDDCFVVHNVKI I DGKNGAFIAMPSRKTRSGEYKDVAHPINSDFRGRLQQQILDEYERV------------MDI SEVRVRKVNQTGKLKAYVTVTFDSQFVVHNI KVIEGRDGDFIAMPSRQLANGEFKDVAHPISSDFRDHLQKVIMEAYASDTGETALEEE------EITEVRIYKAKGNGVVKAYASVSLDNE FVVKGIKIVEGESGLWVSMPSRKAKDGSYQDIFHPT SREAREKIVSAVLEAY---------------

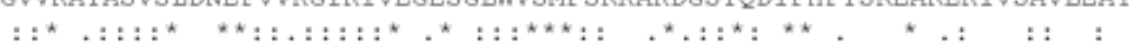

MEVT DVRLRRVNT DGRIRAIAFITLDHEFVVHDICVIDGNNGLFAAMPSKCTTDGEFRNITHSINSSTRGKIRDAVLNGCHRLGDTEALEFEEAGAS
\end{abstract}

Figure 25 Conservation of SpoVG protein sequence in different species, and mutations found introduced by cloning SpoVG in E. coli. Mutations are highlighted in red. The sequences were aligned using ClustalW with additional manual processing. 


\subsection{Bacterial strains}

B. subtilis strains used in this study:

\begin{tabular}{|c|c|c|c|}
\hline Strain & Genotype & Reference/Construction & Remarks \\
\hline GP309 & $\operatorname{trpC2}$ amyE::(sinl-sinR-lacZ aphA3) & pGP2306 $\rightarrow 168$ & 1 \\
\hline GP310 & $\operatorname{trpC2}$ ymdB::cat amyE::(sinl-sinR-lacZ aphA3) & GP922 $\rightarrow$ GP309 & 1 \\
\hline GP613 & comIQ12L $\Delta y m d B::$ cat $\Delta / d h:: t e t$ & GP2597 $\rightarrow$ GP2559 & \\
\hline GP820 & comIQ12L $\Delta y m d B:: c a t \Delta h p f:: t e t$ & GP2598 $\rightarrow$ GP2559 & \\
\hline GP842 & comIQ12L $\triangle y m d B::$ cat $\Delta s p e D:: t e t$ & LFH $\rightarrow$ GP2559 & \\
\hline GP1148 & comIQ12L $\Delta y m d B:: c a t \Delta l c t P:: t e t$ & GP2578 $\rightarrow$ GP2559 & \\
\hline GP1400 & comIQ12L $\triangle y m d B::$ cat $\triangle$ qoxC::tet & GP2579 $\rightarrow$ GP2559 & \\
\hline GP1443 & comIQ12L $\triangle y m d B:: c a t \Delta g c v H:: t e t$ & $\mathrm{LFH} \rightarrow \mathrm{GP} 2559$ & \\
\hline GP2109 & $\operatorname{trpC2} \triangle$ spoVG::tet & $\mathrm{LFH} \rightarrow 168$ & \\
\hline GP2130 & $\begin{array}{l}\operatorname{trpC2} \text { bgIS::(hag-cfp aphA3) lacA:: p(tapA-yfp ermC) } \\
\text { Shag::tet }\end{array}$ & GP902 $\rightarrow$ GP845 & \\
\hline GP2551 & $\begin{array}{l}\operatorname{trpC2} \text { bg/S::(hag-cfp aphA3) lacA:: p(tapA-yfp ermC) } \\
\Delta \text { hag::tet } \triangle y m d B:: s p c\end{array}$ & GP583 $\rightarrow$ GP2130 & \\
\hline GP2552 & comIQ12L $\triangle y m d B:: c a t$ sinR-tet & $\begin{array}{l}\text { PCR Pro. CD145/146 GP2124 } \rightarrow \\
\text { GP2559 }\end{array}$ & 2 \\
\hline GP2553 & comIQ12L $\triangle y m d B:: c a t$ sinR_mutated-tet & $\begin{array}{l}\text { PCR Pro. CD145/146 GP2125 } \rightarrow \\
\text { GP2559 }\end{array}$ & 3 \\
\hline GP2554 & comIQ12L $\triangle y m d B::$ cat $\triangle \sin R:: s p c$ & $\begin{array}{l}\text { PCR Pro. CD145/146 TMB079 } \\
\rightarrow \text { GP2559 }\end{array}$ & \\
\hline GP2559 & comIQ12L $\triangle y m d B:: c a t$ & $\begin{array}{l}\text { PCR Pro. SHU63/NP61 GP922 } \rightarrow \\
\text { DK1042 }\end{array}$ & \\
\hline GP2560 & comIQ12L sinR-tet & $\begin{array}{l}\text { PCR Pro. CD145/146 GP2124 } \rightarrow \\
\text { DK1042 }\end{array}$ & \\
\hline GP2561 & comIQ12L sinR_mutated-tet & $\begin{array}{l}\text { PCR Pro. CD145/146 GP2125 } \rightarrow \\
\text { DK1042 }\end{array}$ & \\
\hline GP2566 & $\operatorname{trpC2}$ amyE::(sinR-lacZ aphA3) & pGP2125 $\rightarrow 168$ & 4 \\
\hline GP2568 & $\operatorname{trpC2} \triangle y m d B::$ cat amyE::(sinR-lacZ aphA3) & pGP2125 $\rightarrow$ GP922 & 4 \\
\hline
\end{tabular}




\begin{tabular}{|c|c|c|}
\hline GP2570 & comIQ12L $\triangle \sin R:: s p c$ & $\begin{array}{l}\text { PCR Pro. CD145/CD146 TMB079 } \\
\rightarrow \text { DK1042 }\end{array}$ \\
\hline GP2571 & comIQ12L $\Delta$ spoVG::tet & $\begin{array}{l}\text { PCR Pro. JK143/146 GP2109 } \rightarrow \\
\text { DK1042 }\end{array}$ \\
\hline GP2572 & comIQ12L $\Delta y m d B:: c a t \Delta s p o V G:: t e t$ & $\begin{array}{l}\text { PCR Pro. JK143/146 GP2109 } \rightarrow \\
\text { GP2559 }\end{array}$ \\
\hline GP2573 & comIQ12L $\Delta y h d X::$ tet & LFH $\rightarrow$ DK1042 \\
\hline GP2574 & comIQ12L $\Delta y u z K:: t e t$ & $\mathrm{LFH} \rightarrow \mathrm{DK} 1042$ \\
\hline GP2576 & comIQ12L $\Delta y p p F:: t e t$ & $\mathrm{LFH} \rightarrow \mathrm{DK} 1042$ \\
\hline GP2577 & comIQ12L $\triangle y s b B:: t e t$ & LFH $\rightarrow$ DK1042 \\
\hline GP2578 & comIQ12L $\Delta / c t P:: t e t$ & $\mathrm{LFH} \rightarrow \mathrm{DK} 1042$ \\
\hline GP2579 & comIQ12L $\Delta$ qoxC::tet & LFH $\rightarrow$ DK1042 \\
\hline GP2582 & comIQ12L $\Delta$ lutP::tet & LFH $\rightarrow$ DK1042 \\
\hline GP2583 & comIQ12L $\Delta y t z E:: t e t$ & LFH $\rightarrow$ DK1042 \\
\hline GP2585 & comIQ12L $\Delta g c v H:: t e t$ & LFH $\rightarrow$ DK1042 \\
\hline GP2587 & comIQ12L $\Delta$ spoVG::tet $\Delta \sin R:: s p c$ & $\begin{array}{l}\text { PCR Pro. sinR_up_fwd/CD146 } \\
\text { TMB079 } \rightarrow \text { GP2571 }\end{array}$ \\
\hline GP2588 & comIQ12L $\triangle y m d B::$ cat $\Delta$ spoVG::tet $\Delta \sin R:: s p c$ & $\begin{array}{l}\text { PCR Pro. sinR_up_fwd/CD146 } \\
\text { TMB079 } \rightarrow \text { GP2572 }\end{array}$ \\
\hline GP2589 & comIQ12L $\triangle y m d B:: c a t \Delta y u z K: t e t$ & GP2574 $\rightarrow$ GP2559 \\
\hline GP2591 & comIQ12L $\Delta y m d B:: c a t \Delta y s b B::$ tet & GP2577 $\rightarrow$ GP2559 \\
\hline GP2594 & comIQ12L $\Delta y m d B::$ cat $\Delta y p p F:: t e t$ & $\mathrm{LFH} \rightarrow \mathrm{GP} 2559$ \\
\hline GP2595 & comIQ12L $\Delta y m d B::$ cat $\Delta l u t P::$ tet & $\mathrm{LFH} \rightarrow \mathrm{GP} 2559$ \\
\hline GP2596 & comIQ12L $\triangle y m d B:: c a t \Delta y t z E:: t e t$ & $\mathrm{LFH} \rightarrow \mathrm{GP} 2559$ \\
\hline GP2597 & comIQ12L $\Delta / d h:: t e t$ & LFH $\rightarrow$ DK1042 \\
\hline GP2598 & comIQ12L $\Delta h p f::$ tet & LFH $\rightarrow$ DK1042 \\
\hline GP2599 & comIQ12L $\Delta$ speD::tet & LFH $\rightarrow$ DK1042 \\
\hline GP2600 & comIQ12L $\triangle$ dctP::tet & $\mathrm{LFH} \rightarrow \mathrm{DK} 1042$ \\
\hline
\end{tabular}

${ }^{1} 976 \mathrm{bp}$ of upstream region of $\sin R$, and full-length $\sin R$ without stop codon fused to lac $Z$ and integrated into the amyE locus 
${ }^{2}$ Integration of tet-cassette after $\sin R$

${ }^{3}$ Integration of tet-cassette after $\sin R$; CCR $\sin R$ upstream spacer between RBS and start codon to AAAAAAAA

${ }^{4} 976 \mathrm{bp}$ of upstream region of $\sin R$, start codon and additional $14 \mathrm{bp}$ fused to lac $Z$ and integrated into the amyE locus

Foreign bacterial strains used in this study

\begin{tabular}{|c|c|c|c|}
\hline Strain & Genotype & Reference/ Construction & Remarks \\
\hline \multicolumn{4}{|c|}{ Escherichia coli } \\
\hline \multirow{3}{*}{ BL21(DE3) } & fhuA2 [lon] ompT gal ( $\lambda$ DE3) [dcm] $\Delta h s d S \lambda$ & Studier and Moffatt, & \\
\hline & $D E 3=\lambda$ sBamHlo $\triangle E c o R I-B$ int::(lacl::PlacUV5::T7 gene1) & 1986 & \\
\hline & $i 21 \Delta \operatorname{nin} 5$ & & \\
\hline XL1-Blue & recA1 endA1 gyrA96 thi-1 hsdR17 supE44 relA1 lac & Stratagene & \\
\hline \multicolumn{4}{|c|}{ Bacillus subtilis } \\
\hline 168 & $\operatorname{trpC2}$ & Laboratory collection & \\
\hline DK1042 & comIQ12L & Konkol et al., 2013 & \\
\hline NCIB3610 & Nondomesticated wild type & Laboratory collection & \\
\hline MZ303 & $\Delta p t s H:: c a t$ & Arnaud et al., 1992 & \\
\hline TMB079 & $\Delta \sin R:: s p c$ & Jordan et al., 2007 & \\
\hline GP469 & $\operatorname{trpC2} \Delta$ csrA::spec & Hübner, 2008 & \\
\hline GP583 & $\operatorname{trpC2} y m d B:: s p c$ & Diethmaier et al., 2011 & \\
\hline GP845 & $\operatorname{trpC2}$ bg/S::(hag-cfp aphA3) lacA:: p(tapA-yfp ermC) & Diethmaier et al., 2011 & \\
\hline GP902 & $\operatorname{trpC2} \Delta$ hag::tet & Diethmaier, 2008 & \\
\hline GP921 & $\Delta y m d B:: s p c$ & Diethmaier et al., 2011 & \\
\hline GP922 & $\operatorname{trpC2} \triangle y m d B:: c a t$ & Diethmaier et al., 2011 & \\
\hline GP1561 & amyE::p(tapA-yfp spc) bg/S::(hag-cfp aphA3) & Gerwig, 2014 & \\
\hline GP1574 & amyE::p(tapA-yfp spc) bgls::(hag-cfp aphA3) $\Delta y m d B:: s p c$ & Gerwig, 2014 & \\
\hline GP1562 & $\Delta \sin R:: s p c$ & Gerwig, 2014 & \\
\hline GP1650 & $\begin{array}{l}\triangle y m d B:: c a t \text { amyE::p(tapA-yfp spc) bglS::(hag-cfp aphA3) } \\
\sin R \text { G253A }\end{array}$ & Gerwig, 2014 & SinR: A85T \\
\hline
\end{tabular}


Appendix

\begin{tabular}{|c|c|c|c|}
\hline GP1657 & $\Delta y m d B:: s p c \sin R$ T127G & Kruse, 2013 & SinR: S43A \\
\hline GP1658 & $\Delta y m d B:: s p c \sin R$ G310C & Kruse, 2013 & SinR: W104R \\
\hline \multirow[t]{2}{*}{ GP1665 } & $\operatorname{trpC2}$ bg/S::(hag-cfp aphA3) lacA:: p(tapA-yfp ermC) & Kruse, 2013 & SinR: W104L \\
\hline & $\Delta y m d B:: s p c \sin R$ G311T & & \\
\hline
\end{tabular}

Arrows indicate construction by transformation. *, Construction by phage transduction. LFH, long flanking homology PCR.

\subsection{Oligonucleotides}

Oligonucleotides used in this study $\left(5^{\prime} \rightarrow 3^{\prime}\right)$

Oligonucleotides were ordered at Sigma-Aldrich, Germany.

\begin{tabular}{|c|c|c|}
\hline Oligo & Sequence & Purpose \\
\hline C-1723 & AAGTTCTCTTTAGAGAACAAT & oligonucleotide for FP \\
\hline FAM1721 & 5'FAM-ATTGTTCTCTAAAGAGAACTT & fluorescein oligonucleotide for FP \\
\hline JK110 & 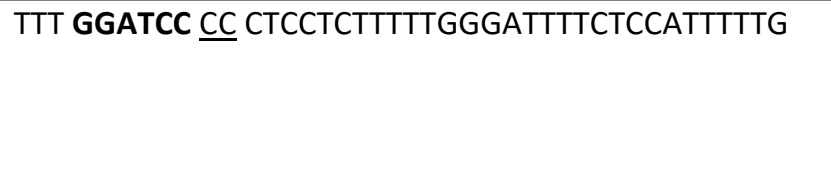 & $\begin{array}{l}\text { rev; translational lacZ fusion of full- } \\
\text { length sinR into pAC7; no stop codon; } \\
\text { BamHI }\end{array}$ \\
\hline JK125 & AAA CAATTG CGCCAAAAGACCTAGATGGTG & $\begin{array}{l}\text { fwd; C-terminal lacZ fusion of } \sin R \text { (1 kb } \\
\text { upstream) into pAC7; Mfel }\end{array}$ \\
\hline JK142 & CTGTACTCTCCAAGGTAGGGAAG & $\begin{array}{l}\text { fwd; sequencing LFH-PCR spoVG } B \text {. } \\
\text { subtilis }\end{array}$ \\
\hline JK143 & GAAAGGCATCCCTCTTGCG & fwd; upstream LFH-PCR spoVG B. subtilis \\
\hline JK144 & $\begin{array}{l}\text { CCTATCACCTCAAATGGTTCGCTGGCGTAATCTTACGTCAGT } \\
\text { AACTTCC }\end{array}$ & rev; upstream LFH-PCR spoVG B. subtilis \\
\hline JK145 & $\begin{array}{l}\text { CGAGCGCCTACGAGGAATTTGTATCGACTGAAGCATTAGAA } \\
\text { TTCGAAGAAGC }\end{array}$ & $\begin{array}{l}\text { fwd; downstream LFH-PCR spoVG } B . \\
\text { subtilis }\end{array}$ \\
\hline JK146 & CGATAACAGCGTCAGGAGAAATATAC & $\begin{array}{l}\text { rev; downstream LFH-PCR spoVG } B \text {. } \\
\text { subtilis }\end{array}$ \\
\hline JK147 & CCGTATGAGGGCCAATAATCG & $\begin{array}{l}\text { rev; sequencing LFH-PCR spoVG } B \text {. } \\
\text { subtilis }\end{array}$ \\
\hline
\end{tabular}




\begin{tabular}{|c|c|c|}
\hline JK157 & CGCTGGCCAATCAATIIITTITCCTTCCTTGTGATATTATAGC & $\begin{array}{l}\text { CCR } \sin R \text { upstream spacer between RBS } \\
\text { and start codon to AAAAAAAA; } 5 \text { '- } \\
\text { phosphorylated } B \text {. subtilis }\end{array}$ \\
\hline JK179 & AAAGGATCCCGCTGGCCAATCAATGTCATC & $\begin{array}{l}\text { rev; translational lacZ fusion of 4-amino } \\
\text { acids of } \sin R \text { into } \mathrm{pAC7} \text {; BamHI }\end{array}$ \\
\hline JK187 & AATGCTTGAAAACGCTGGATTAATC & fwd; sequencing LFH-PCR yuzK B. subtilis \\
\hline JK188 & AAAAGTAGCGCCTGAATTAACGG & fwd; upstream LFH-PCR yuzK B. subtilis \\
\hline JK189 & $\begin{array}{l}\text { CCTATCACCTCAAATGGTTCGCTGCAATTCCGTGTGACAGCT } \\
\text { GC }\end{array}$ & rev; upstream LFH-PCR yuzK B. subtilis \\
\hline JK190 & $\begin{array}{l}\text { CGAGCGCCTACGAGGAATTTGTATCGGCGGATTTCTGCGG } \\
\text { GAG }\end{array}$ & $\begin{array}{l}\text { fwd; downstream LFH-PCR yuzK } B . \\
\text { subtilis }\end{array}$ \\
\hline JK191 & TAATCCCCCTAACGCTTACGC & $\begin{array}{l}\text { rev; downstream LFH-PCR yuzK } B . \\
\text { subtilis }\end{array}$ \\
\hline JK192 & GCGCAGGTTCTTCAGCC & rev; sequencing LFH-PCR yuzK B. subtilis \\
\hline JK193 & CTATTTAACCACACTTTCAATTTTGCTTC & fwd; sequencing LFH-PCR yppF B. subtilis \\
\hline JK194 & CGGTGGCGATATTGGAATTCC & fwd; upstream LFH-PCR yppF B. subtilis \\
\hline JK197 & AATTAACGCGAGCTGAGCAAA & $\begin{array}{l}\text { rev; downstream LFH-PCR yppF } B . \\
\text { subtilis }\end{array}$ \\
\hline JK198 & GGGAGGTACACGAATGTCCG & rev; sequencing LFH-PCR yppF B. subtilis \\
\hline JK221 & AAGTGCACAAAGCCCTCTG & fwd; sequencing LFH-PCR lutP B. subtilis \\
\hline JK222 & GTATCATTCGGAACCGGCG & fwd; upstream LFH-PCR lutP B. subtilis \\
\hline JK223 & $\begin{array}{l}\text { CCTATCACCTCAAATGGTTCGCTGCTGTGTCCATTGCATCCC } \\
\text { AAA }\end{array}$ & rev; upstream LFH-PCR lutP B. subtilis \\
\hline JK224 & $\begin{array}{l}\text { CGAGCGCCTACGAGGAATTTGTATCGCAGCATCACGTATTC } \\
\text { AGCTGG }\end{array}$ & $\begin{array}{l}\text { fwd; downstream LFH-PCR lutP B. } \\
\text { subtilis }\end{array}$ \\
\hline JK225 & AGGAGGCAGCACGGC & rev; downstream LFH-PCR lutP B. subtilis \\
\hline JK226 & GCAGTCACTCGATATGAATCTGAC & rev; sequencing LFH-PCR lutP B. subtilis \\
\hline JK227 & ATGACCGCATGCAACACTTTAAA & fwd; sequencing LFH-PCR ytzE B. subtilis \\
\hline JK228 & TCATAGCCGATCACCTTGAACT & fwd; upstream LFH-PCR ytzE B. subtilis \\
\hline JK229 & $\begin{array}{l}\text { CCTATCACCTCAAATGGTTCGCTGAAAAAACCACTCCCTATC } \\
\text { ATAAGATCG }\end{array}$ & rev; upstream LFH-PCR ytzE B. subtilis \\
\hline
\end{tabular}




\begin{tabular}{|c|c|c|}
\hline JK230 & $\begin{array}{l}\text { CGAGCGCCTACGAGGAATTTGTATCGGAGAAAGAAAGTAA } \\
\text { AGATTACCTCATAAATTG }\end{array}$ & $\begin{array}{l}\text { fwd; downstream LFH-PCR ytzE } B \text {. } \\
\text { subtilis }\end{array}$ \\
\hline JK231 & GCGGCTACCGATTAGGATTTT & rev; downstream LFH-PCR ytzE B. subtilis \\
\hline JK232 & GGATGGCCAGATGCAAGCT & rev; sequencing LFH-PCR ytzE B. subtilis \\
\hline JK233 & $\begin{array}{l}\text { CCTATCACCTCAAATGGTTCGCTGAACGTTTGCTTAAGTATG } \\
\text { ATACGTTC }\end{array}$ & rev; upstream LFH-PCR yppF B. subtilis \\
\hline JK234 & $\begin{array}{l}\text { CGAGCGCCTACGAGGAATTTGTATCGAGCCCGGCATATGA } \\
\text { GATGAATTA }\end{array}$ & $\begin{array}{l}\text { fwd; downstream LFH-PCR yppF B. } \\
\text { subtilis }\end{array}$ \\
\hline JK239 & GTCAATAGATTTCACAATGTGATGGCT & fwd; sequencing LFH-PCR Idh B. subtilis \\
\hline JK240 & TCAGCGCGGCTCACATG & fwd; upstream LFH-PCR Idh B. subtilis \\
\hline JK241 & $\begin{array}{l}\text { CCTATCACCTCAAATGGTTCGCTGCTCCGATTAAAGCTACTT } \\
\text { TATTTACATGTTTG }\end{array}$ & rev; upstream LFH-PCR Idh B. subtilis \\
\hline JK242 & $\begin{array}{l}\text { CGAGCGCCTACGAGGAATTTGTATCGAAACATTTTAAAACC } \\
\text { TCATTTTGCAGAAC }\end{array}$ & fwd; downstream LFH-PCR Idh B. subtilis \\
\hline JK243 & GAAGGCAGGAAGGCTCCAG & rev; downstream LFH-PCR Idh B. subtilis \\
\hline JK244 & GGCATTTTCATAATTTGCTGATGCAG & rev; sequencing LFH-PCR Idh B. subtilis \\
\hline JK245 & CGCAGATTGGTACAGGCAAATATC & fwd; sequencing LFH-PCR hpf B. subtilis \\
\hline JK246 & TCGCGATGCTTGGAAACAAG & fwd; upstream LFH-PCR hpf B. subtilis \\
\hline JK247 & $\begin{array}{l}\text { CCTATCACCTCAAATGGTTCGCTGCTTCAATATTTTCTCCTCT } \\
\text { GATGTTATAGTTC }\end{array}$ & rev; upstream LFH-PCR $h p f B$. subtilis \\
\hline JK248 & $\begin{array}{l}\text { CGAGCGCCTACGAGGAATTTGTATCGGAAATGACGGGAAA } \\
\text { TATGGCTTAATTG }\end{array}$ & fwd; downstream LFH-PCR hpf B. subtilis \\
\hline JK249 & GCTTCACATCAAAGAGGTTATCGAT & rev; downstream LFH-PCR hpf B. subtilis \\
\hline JK250 & TGTCCGTCTTCCACTACATAGTC & rev; sequencing LFH-PCR hpf B. subtilis \\
\hline JK251 & GCAGATACGACAAAGAGGTTGTG & fwd; sequencing LFH-PCR speD B. subtilis \\
\hline JK252 & CAGCCGTGATCCAAAACAGC & fwd; upstream LFH-PCR speD B. subtilis \\
\hline JK253 & $\begin{array}{l}\text { CCTATCACCTCAAATGGTTCGCTGCGGAGATAACGTGACGC } \\
\text { C }\end{array}$ & rev; upstream LFH-PCR speD B. subtilis \\
\hline JK254 & $\begin{array}{l}\text { CGAGCGCCTACGAGGAATTTGTATCGGTGCAAATTAAACAG } \\
\text { GCGCAAG }\end{array}$ & $\begin{array}{l}\text { fwd; downstream LFH-PCR speD } B . \\
\text { subtilis }\end{array}$ \\
\hline
\end{tabular}




\begin{tabular}{|c|c|c|}
\hline JK255 & GTTTTGTTCAAGCTCTCCCCAC & $\begin{array}{l}\text { rev; downstream LFH-PCR speD } B . \\
\text { subtilis }\end{array}$ \\
\hline JK256 & TTCCCCTGTTCCTGATGGATC & rev; sequencing LFH-PCR speD B. subtilis \\
\hline JK257 & TCGGCTCATTTGAAACCGTTC & fwd; sequencing LFH-PCR dctP B. subtilis \\
\hline JK258 & TCCTTGCTATTTTAATAGAAGATAACGGC & fwd; upstream LFH-PCR dctP B. subtilis \\
\hline JK259 & $\begin{array}{l}\text { CCTATCACCTCAAATGGTTCGCTGAATGACCCCGATGATGA } \\
\text { CCG }\end{array}$ & rev; upstream LFH-PCR dctP B. subtilis \\
\hline JK260 & $\begin{array}{l}\text { CGAGCGCCTACGAGGAATTTGTATCGCGCCACGATCATTGT } \\
\text { TGCC }\end{array}$ & $\begin{array}{l}\text { fwd; downstream LFH-PCR dctP B. } \\
\text { subtilis }\end{array}$ \\
\hline JK261 & AAATAGGTTTCGATCGCATGAATGG & rev; downstream LFH-PCR dctP B. subtilis \\
\hline JK262 & CCGAAGAAGTGTTCAGAGAAAATGAG & rev; sequencing LFH-PCR dctP B. subtilis \\
\hline JK263 & AAGGCTGCCTGCCGC & fwd; sequencing LFH-PCR $y h d X B$. subtilis \\
\hline JK264 & CCGATAAAAACCGCGCTATATATTTTC & fwd; upstream LFH-PCR yhdX B. subtilis \\
\hline JK265 & $\begin{array}{l}\text { CCTATCACCTCAAATGGTTCGCTGCTTTCCTCCACTCTGATTC } \\
\text { TCCC }\end{array}$ & rev; upstream LFH-PCR yhdX B. subtilis \\
\hline JK266 & $\begin{array}{l}\text { CGAGCGCCTACGAGGAATTTGTATCGCTTGATCAGACACAA } \\
\text { ACGAAAAAAGG }\end{array}$ & $\begin{array}{l}\text { fwd; downstream LFH-PCR yhdX B. } \\
\text { subtilis }\end{array}$ \\
\hline JK267 & TCATTATCAACGCCCTCATGC & $\begin{array}{l}\text { rev; downstream LFH-PCR yhdX B. } \\
\text { subtilis }\end{array}$ \\
\hline JK268 & GTTTTCAGCCCAAACCGTCG & rev; sequencing LFH-PCR $y h d X$ B. subtilis \\
\hline JK269 & CGGTGATAGCTTCTCGTTCAGG & fwd; sequencing LFH-PCR IctP B. subtilis \\
\hline JK270 & TGTGAGGTTCCCGGGGA & fwd; upstream LFH-PCR IctP B. subtilis \\
\hline JK271 & $\begin{array}{l}\text { CCTATCACCTCAAATGGTTCGCTGCATAACTGCTTCCAACAA } \\
\text { AACCC }\end{array}$ & rev; upstream LFH-PCR IctP B. subtilis \\
\hline JK272 & $\begin{array}{l}\text { CGAGCGCCTACGAGGAATTTGTATCGGCGTCCTTAAAAACA } \\
\text { TTTTAAAACCTC }\end{array}$ & fwd; downstream LFH-PCR IctP B. subtilis \\
\hline JK273 & GCGCTTTGAAGGCAGGAAG & rev; downstream LFH-PCR IctP B. subtilis \\
\hline JK274 & GCGGCATTTTCATAATTTGCTGATG & rev; sequencing LFH-PCR IctP B. subtilis \\
\hline JK275 & ATGGTTGGTTCTATTATCGCCATCTC & fwd; sequencing LFH-PCR qoxC B. subtilis \\
\hline JK276 & CGTTAACTCATTCTTCTCAATTACGAC & fwd; upstream LFH-PCR qoxC B. subtilis \\
\hline
\end{tabular}




\begin{tabular}{|c|c|c|}
\hline JK277 & $\begin{array}{l}\text { CCTATCACCTCAAATGGTTCGCTGCCATAACTCACGCCTCCT } \\
\text { TATTC }\end{array}$ & rev; upstream LFH-PCR qoxC B. subtilis \\
\hline JK278 & $\begin{array}{l}\text { CGAGCGCCTACGAGGAATTTGTATCGCATGGGATTGGGGG } \\
\text { GTCTG }\end{array}$ & $\begin{array}{l}\text { fwd; downstream LFH-PCR qoxC } B \text {. } \\
\text { subtilis }\end{array}$ \\
\hline JK279 & TTCAAATGAAAAAAACGCCATACCAATAG & $\begin{array}{l}\text { rev; downstream LFH-PCR qoxC } B \text {. } \\
\text { subtilis }\end{array}$ \\
\hline JK280 & GCATTTGCGGCGCTTTTTC & rev; sequencing LFH-PCR qoxC B. subtilis \\
\hline JK281 & CCTGAAGAGCCTGGAAGCG & fwd; sequencing LFH-PCR gcvH B. subtilis \\
\hline JK282 & GCGTTGTTTGCTGCCGG & fwd; upstream LFH-PCR gcvH B. subtilis \\
\hline JK283 & $\begin{array}{l}\text { CCTATCACCTCAAATGGTTCGCTGCGCAAATCTTTTGGTATG } \\
\text { CTCAA }\end{array}$ & rev; upstream LFH-PCR gcvH B. subtilis \\
\hline JK284 & $\begin{array}{l}\text { CGAGCGCCTACGAGGAATTTGTATCGGCAATACGAAGAGA } \\
\text { TGACACAAGAA }\end{array}$ & $\begin{array}{l}\text { fwd; downstream LFH-PCR gcvH B. } \\
\text { subtilis }\end{array}$ \\
\hline JK285 & TGAAATGCATATCCTCTTTCGACC & $\begin{array}{l}\text { rev; downstream LFH-PCR gcvH B. } \\
\text { subtilis }\end{array}$ \\
\hline JK286 & GATATGCTGAGAAATATGTCATAAATGGG & rev; sequencing LFH-PCR gcvH B. subtilis \\
\hline
\end{tabular}

Foreign oligonucleotides used in this study $\left(5^{\prime} \rightarrow 3^{\prime}\right)$

\begin{tabular}{llll} 
Oligo & Sequence & Purpose & Reference \\
\hline cat-fwd & CAGCGAACCATTTGAGGTGATAGGCGGCAATAGTTAC & fwd; amplification of cat- & Laboratory \\
(kan) & CCTTATTATCAAG & resistance cassette & collection \\
\hline cat-rev & CGATACAAATTCCTCGTAGGCGCTCGGCCAGCGTGGA & rev; amplification of cat- & Laboratory \\
(kan) & CCGGCGAGGCTAGTTACCC & resistance cassette & collection \\
\hline CD145 & GCTGCCAAATCGTCGATCAAGGC & fwd; amplification of & Diethmaier, \\
& & $\Delta s i n R:: s p c$ fromTMB079 & 2011 \\
\hline CD146 & GACGATCAGCAGCGCCATTAGAG & rev; amplification of & Diethmaier, \\
& & $\Delta s i n R:: s p c$ from TMB079 & 2011 \\
\hline G10 & CGTATAGAATTCTCACTCCTCTTTTTGGGATTTC & rev; amplification of & Newman et al., \\
& & native sinR; EcoRI & 2013
\end{tabular}




\begin{tabular}{|c|c|c|c|}
\hline LR27 & $\begin{array}{l}\text { CCTATCACCTCAAATGGTTCGCTGGATGCCGAATGCA } \\
\text { GCAAGTGATACG }\end{array}$ & $\begin{array}{l}\text { rev; LFH-PCR ysbB } \\
\text { up-fragment }\end{array}$ & Rempeters, 2011 \\
\hline LR28 & GCTATCTGTGGGGGAATCGATTGTG & $\begin{array}{l}\text { fwd; LFH-PCR ysbB } \\
\text { up-fragment }\end{array}$ & Rempeters, 2011 \\
\hline LR29 & $\begin{array}{l}\text { CGAGCGCCTACGAGGAATTTGTATCGCTGTCATCGTA } \\
\text { TATGCGCTCGGAG }\end{array}$ & $\begin{array}{l}\text { fwd; LFH-PCR ysbB } \\
\text { down-fragment }\end{array}$ & Rempeters, 2011 \\
\hline LR30 & CTGACACATGAACAAACTGATACAGCTTG & $\begin{array}{l}\text { LFH-PCR ysbB rev } \\
\text { down-fragment }\end{array}$ & Rempeters, 2011 \\
\hline LR31 & GTCAATCGGGATATTGTAGAAACAGAGC & $\begin{array}{l}\text { LFH-PCR ysbB fwd } \\
\text { up-fragment, } \\
\text { Sequenzierprimer }\end{array}$ & Rempeters, 2011 \\
\hline LR32 & CCACCGACAGGAAGAAATGTAAAACAAAG & $\begin{array}{l}\text { LFH-PCR ysbB rev } \\
\text { down-fragment, } \\
\text { Sequenzierprimer }\end{array}$ & Rempeters, 2011 \\
\hline ML251 & TTGATTGGCCAGCGTATTAAACAATACCGTAAAG & fwd; riboprobe $\sin R$ fwd & $\begin{array}{l}\text { Lehnik-Habrink, } \\
2011\end{array}$ \\
\hline ML252 & $\begin{array}{l}\text { CTAATACGACTCACTATAGGGAGACTCCTCTTTTTGG } \\
\text { GATTTTCTCCATTTTTGA }\end{array}$ & $\begin{array}{l}\text { rev; riboprobe } \sin R \text { rev } \\
\text { with T7-Promoter }\end{array}$ & $\begin{array}{l}\text { Lehnik-Habrink, } \\
2011\end{array}$ \\
\hline ML84 & CTAATGGGTGCTTTAGTTGAAGA & $\begin{array}{l}\text { fwd; sequencing of cat- } \\
\text { cassette }\end{array}$ & $\begin{array}{l}\text { Lehnik-Habrink, } \\
2011\end{array}$ \\
\hline ML85 & CTCTATTCAGGAATTGTCAGATAG & $\begin{array}{l}\text { rev; sequencing of cat- } \\
\text { cassette }\end{array}$ & $\begin{array}{l}\text { Lehnik-Habrink, } \\
2011\end{array}$ \\
\hline NC76 & $\begin{array}{l}\text { AAAGGTACCCACTCGTGACGAAGCGAAACAAATCATT } \\
\text { C }\end{array}$ & $\begin{array}{l}\text { fwd; sequencing LFH- } \\
\text { PCR ymdB B. subtilis; } \\
\text { Kpnl }\end{array}$ & $\begin{array}{l}\text { Cascante Estepa, } \\
2016\end{array}$ \\
\hline NP58 & $\begin{array}{l}\text { CCTATCACCTCAAATGGTTCGCTGGCCCGGTGAACCG } \\
\text { ACAACATCTCCG }\end{array}$ & $\begin{array}{l}\text { rev; upstream LFH-PCR } \\
y m d B \text { B. subtilis }\end{array}$ & Pietack, 2010 \\
\hline NP59 & $\begin{array}{l}\text { CCGAGCGCCTACGAGGAATTTGTATCGGACATTGACG } \\
\text { ATCAAACGAAAAAAG }\end{array}$ & $\begin{array}{l}\text { fwd; downstream LFH- } \\
\text { PCR ymdB B. subtilis }\end{array}$ & Pietack, 2010 \\
\hline NP61 & AGTATTGGTACACACATGAGATTTTCCTGTTAG & $\begin{array}{l}\text { rev; downstream LFH- } \\
\text { PCR ymdB B. subtilis / } \\
\text { amplification of } \\
y m d B:: s p c \text { cassette }\end{array}$ & Pietack, 2010 \\
\hline SHU63 & CCGTGCGAAAGAAGAGGCGG & $\begin{array}{l}\text { fwd; upstream LFH-PCR } \\
\text { ymdB B. subtilis / }\end{array}$ & Hübner, 2008 \\
\hline
\end{tabular}


amplification of

ymdB::spc cassette

\begin{tabular}{|c|c|c|c|}
\hline $\begin{array}{l}\text { sinR_up } \\
\text { _fwd }\end{array}$ & GCCAAAAGACCTAGATGGTG & $\begin{array}{l}\text { fwd; amplification of } \\
\Delta \sin R:: s p c \text { from TMB079 }\end{array}$ & Kruse, 2013 \\
\hline $\begin{array}{l}\text { tc-check- } \\
\text { fwd }\end{array}$ & CGGCTACATTGGTGGGATACTTGTTG & $\begin{array}{l}\text { fwd; sequencing of tet- } \\
\text { cassette }\end{array}$ & $\begin{array}{l}\text { Laboratory } \\
\text { collection }\end{array}$ \\
\hline $\begin{array}{l}\text { tc-check- } \\
\text { rev }\end{array}$ & CATCGGTCATAAAATCCGTAATGC & $\begin{array}{l}\text { rev; sequencing of tet- } \\
\text { cassette }\end{array}$ & $\begin{array}{l}\text { Laboratory } \\
\text { collection }\end{array}$ \\
\hline $\begin{array}{l}\text { tc-fwd2 } \\
\text { (kan) }\end{array}$ & $\begin{array}{l}\text { CAGCGAACCATTTGAGGTGATAGGGCTTATCAACGTA } \\
\text { GTAAGCGTGG }\end{array}$ & $\begin{array}{l}\text { fwd; amplification of tet- } \\
\text { resistance cassette }\end{array}$ & $\begin{array}{l}\text { Laboratory } \\
\text { collection }\end{array}$ \\
\hline $\begin{array}{l}\text { tc-rev } \\
\text { (kan) }\end{array}$ & $\begin{array}{l}\text { CGATACAAATTCCTCGTAGGCGCTCGGGAACTCTCTCC } \\
\text { CAAAGTTGATCCC }\end{array}$ & $\begin{array}{l}\text { rev; amplification of tet- } \\
\text { resistance cassette }\end{array}$ & $\begin{array}{l}\text { Laboratory } \\
\text { collection }\end{array}$ \\
\hline
\end{tabular}

Bold, restriction sites

Italic, Kanamycin overhangs for LFH fusion PCR

Underlined, mutated/introduced bases

\subsection{Plasmids}

Plasmids used in this study

\begin{tabular}{|c|c|c|c|}
\hline Plasmid & Description & Construction/ Reference & Remarks \\
\hline pGP1948 & $\begin{array}{l}\text { pET24a/ } \\
\text { Ndel+EcoRI }\end{array}$ & $\begin{array}{l}\text { PCR Prod. } \sin R \text { G253A, G8/G10/ } \\
\text { Ndel+EcoRI }\end{array}$ & $\begin{array}{l}\text { amplified using GP1650 as } \\
\text { template }\end{array}$ \\
\hline pGP1949 & $\begin{array}{l}\text { pET24a/ } \\
\text { Ndel+EcoRI }\end{array}$ & $\begin{array}{l}\text { PCR Prod. } \sin R \text { T127G, G8/G10/ } \\
\text { Ndel+EcoRI }\end{array}$ & $\begin{array}{l}\text { amplified using GP1657 as } \\
\text { template }\end{array}$ \\
\hline pGP1950 & $\begin{array}{l}\text { pET24a/ } \\
\text { Ndel+EcoRI }\end{array}$ & $\begin{array}{l}\text { PCR Prod. } \sin R \text { G310C, G8/G10/ } \\
\text { Ndel+EcoRI }\end{array}$ & $\begin{array}{l}\text { amplified using GP1658 as } \\
\text { template }\end{array}$ \\
\hline pGP2302 & $\begin{array}{l}\text { pET24a/ } \\
\text { Ndel+EcoRI }\end{array}$ & $\begin{array}{l}\text { PCR Prod. } \sin R \text { G311T, G8/G10/ } \\
\text { Ndel+EcoRI }\end{array}$ & $\begin{array}{l}\text { amplified using GP1665 as } \\
\text { template }\end{array}$ \\
\hline pGP2304 & $\begin{array}{l}\text { pET24a/ } \\
\text { Ndel+EcoRI }\end{array}$ & PCR Prod. sinR A83C, G8/G10/ Ndel+EcoRI & $\begin{array}{l}\text { amplified using GP1827 as } \\
\text { template }\end{array}$ \\
\hline pGP2306 & $\begin{array}{l}\mathrm{pAC7} / \\
\text { BamHI+ECORI }\end{array}$ & PCR Prod. sinR, JK125/110/ BamHI+Mfel & $\begin{array}{l}976 \text { bp of upstream region of } \sin R \text {, } \\
\text { and full-length } \sin R \text { without stop } \\
\text { codon fused to lacz }\end{array}$ \\
\hline
\end{tabular}




\begin{tabular}{|c|c|c|c|}
\hline \multirow[t]{2}{*}{ pGP2310 } & pGP382/ & PCR Prod. spoVG JK133/JK134 / & \\
\hline & BamHI+Sall & BamHI+Sall & \\
\hline pGP2325 & $\begin{array}{l}\mathrm{pAC7} / \\
\text { BamHI+ECoRI }\end{array}$ & PCR Prod. sinR JK125/179/ BamHI+Mfel & $\begin{array}{l}976 \mathrm{bp} \text { of upstream region of } \sin R \text {, } \\
\text { start codon and additional } 14 \mathrm{bp} \\
\text { fused to lacZ }\end{array}$ \\
\hline pGP2327 & $\begin{array}{l}\text { pBQ200/ } \\
\text { BamHI+Pstl }\end{array}$ & PCR Prod. trxA, JK235/JK236/ BamHI+PstI & \\
\hline pGP2329 & $\begin{array}{l}\text { pBQ200/ } \\
\text { BamHI+PstI }\end{array}$ & $\begin{array}{l}\text { PCR Prod. S6 RNA, JK295/JK296/ } \\
\text { BamHI+PstI }\end{array}$ & \\
\hline pGP2330 & $\begin{array}{l}\text { pBQ200/ } \\
\text { BamHI+Pstl }\end{array}$ & PCR Prod. sinR, JK297/JK298/ BamHI+PstI & \\
\hline pGP2331 & $\begin{array}{l}\text { pBQ200/ } \\
\text { BamHI+Pstl }\end{array}$ & $\begin{array}{l}\text { PCR Prod. spoVG, JK133/JK299/ } \\
\text { BamHI+PstI }\end{array}$ & \\
\hline
\end{tabular}

Foreign plasmids used in this study

\begin{tabular}{|c|c|c|}
\hline Plasmid & Description & Construction/ Reference \\
\hline pAC7 & $\begin{array}{l}\text { translational lacZ fusions that can be integrated at the } \\
\text { amyE site in B. subtilis }\end{array}$ & Weinrauch et al., 1991 \\
\hline pBQ200 & Constitutive overexpression of proteins in $B$. subtilis & Martin-Verstraete et al., 1994 \\
\hline pC2 & IPTG inducible expression of native Sinl in E. coli & Newman et al., 2013 \\
\hline pC5 & IPTG inducible expression of native SinR in E. coli & Newman et al., 2013 \\
\hline pDG1514 & $\begin{array}{l}\text { Vector for tetracycline resistance cassette for LFH of } B \text {. } \\
\text { subtilis }\end{array}$ & Guérout-Fleury et al., 1995 \\
\hline pET24a & $\begin{array}{l}\text { Vector for in vitro expression via T7 promoter; kanamycin } \\
\text { resistance }\end{array}$ & Novagen \\
\hline pGEM-cat & $\begin{array}{l}\text { Vector for chloramphenicol resistance cassette for LFH of } \\
\text { B. subtilis }\end{array}$ & Youngman, 1990 \\
\hline pGP1039 & Constitutive overexpression of $\mathrm{YmdB}$ in $B$. subtilis & Diethmaier, 2011 \\
\hline pGP1916 & $\begin{array}{l}\text { IPTG inducible expression of N-terminally Strep-tagged } \\
Y_{m \mathrm{mB}^{\mathrm{E} 39 Q}} \text { in } E \text {. coli }\end{array}$ & Diethmaier, 2011 \\
\hline pGP1917 & $\begin{array}{l}\text { IPTG inducible expression of } \mathrm{N} \text {-terminally Strep-tagged } \\
\text { YmdB in E. coli }\end{array}$ & Diethmaier, 2011 \\
\hline
\end{tabular}


Appendix

\begin{tabular}{lll}
\hline pGP1919 & Constitutive overexpression of C-terminally Strep-tagged & Diethmaier, 2011 \\
& YmdB in B. subtilis & \\
\hline pGP1920 & Constitutive overexpression of C-terminally Strep-tagged & Diethmaier, 2011 \\
& YmdB ${ }^{\mathrm{E} 9 Q}$ in B. subtilis & \\
\hline pGP382 & Constitutive overexpression of C-terminally Strep-tagged & Herzberg et al., 2007 \\
& proteins in B. subtilis & \\
& & \\
\hline pGP961 & Constitutive overexpression of C-terminally Strep-tagged & Laboratory collection; kindly provided by \\
& PtsH in B. subtilis & F. M. Commichau
\end{tabular}

7.5. Chemicals, utilities, equipment, antibodies, enzymes, software, and webpages

Chemicals

\begin{tabular}{ll} 
Chemical & Manufacturer \\
\hline$\left(\mathrm{NH}_{4}\right)_{2} \mathrm{SO}_{4}$ & Carl Roth, Karlsruhe \\
\hline Acetic acid & Th.Geyer, Höxter \\
\hline Acrylamide & Carl Roth, Karlsruhe \\
\hline Agar & Carl Roth, Karlsruhe \\
\hline Agarose & Peqlab, Erlangen \\
\hline Amino acids & Sigma-Aldrich, Taufkirchen; Fluka, München; \\
& AppliChem, Darmstadt \\
\hline Ammonium iron(III) citrate & Sigma-Aldrich, Taufkirchen \\
\hline Ammonium persulfate & Sigma-Aldrich, Taufkirchen \\
\hline Antibiotics & Carl Roth, Karlsruhe; Sigma-Aldrich, Taufkirchen \\
\hline APS & Carl Roth, Karlsruhe \\
\hline Bis(p-nitrophenyl) phosphate sodium salt & Sigma-Aldrich, Taufkirchen \\
\hline Blocking reagent & Roche Diagnostics, Mannheim \\
\hline Bromophenol blue & Serva, Heidelberg \\
\hline BSA & AppliChem, Darmstadt \\
\hline CAA & Sigma-Aldrich, Taufkirchen \\
\hline CaCl ${ }_{2}$ & Sigma-Aldrich, Taufkirchen \\
\hline CDP* & Roche Diagnostics, Mannheim \\
\hline
\end{tabular}




\begin{tabular}{|c|c|}
\hline Coomassie Brillant Blue, R350 & Amersham, Freiburg \\
\hline $\mathrm{D}(+)$-Glucose & Merck, Darmstadt \\
\hline D-Desthiobiotin & IBA, Göttingen \\
\hline D-Glucose- ${ }^{13} C_{6}$ & Sigma-Aldrich, Taufkirchen \\
\hline DMSO & Carl Roth, Karlsruhe \\
\hline dNTPs & Roche Diagnostics, Mannheim \\
\hline DTT & Carl Roth, Karlsruhe \\
\hline EDTA & Carl Roth, Karlsruhe \\
\hline Ethanol & VWR, Darmstadt \\
\hline Ethidium bromide & Sigma-Aldrich, Taufkirchen \\
\hline $\mathrm{FeCl}_{3} \times 6 \mathrm{H}_{2} \mathrm{O}$ & Sigma-Aldrich, Taufkirchen \\
\hline Glycerol & Carl Roth, Karlsruhe \\
\hline Glycoblue & Thermo Fisher, Bonn \\
\hline $\mathrm{HCl}$ & VWR, Darmstadt \\
\hline HDGreen $^{\mathrm{TM}}$ DNA-Dye & Intas, Göttingen \\
\hline IPTG & Carl Roth, Karlsruhe \\
\hline $\mathrm{KCl}$ & Carl Roth, Karlsruhe \\
\hline $\mathrm{KH}_{2} \mathrm{PO}_{4}$ & Sigma-Aldrich, Taufkirchen \\
\hline $\mathrm{LiCl}$ & Merck, Darmstadt \\
\hline Luol's solution & Sigma-Aldrich, Taufkirchen \\
\hline Methanol & VWR, Darmstadt \\
\hline $\mathrm{MgSO}_{4} \times 7 \mathrm{H}_{2} \mathrm{O}$ & Carl Roth, Karlsruhe \\
\hline $\mathrm{MnCl}_{2} \times 4 \mathrm{H}_{2} \mathrm{O}$ & Carl Roth, Karlsruhe \\
\hline $\mathrm{MnSO}_{4}$ & Carl Roth, Karlsruhe \\
\hline MOPS & AppliChem, Darmstadt \\
\hline $\mathrm{Na}_{2} \mathrm{CO}_{3}$ & Carl Roth, Karlsruhe \\
\hline $\mathrm{Na}_{2} \mathrm{HPO}_{4} \times 12 \mathrm{H}_{2} \mathrm{O}$ & Carl Roth, Karlsruhe \\
\hline $\mathrm{Na}_{2} \mathrm{~S}_{2} \mathrm{O}_{3} \times 5 \mathrm{H} 2 \mathrm{O}$ & Sigma-Aldrich, Taufkirchen \\
\hline $\mathrm{NAD}^{+}$ & Sigma-Aldrich, Taufkirchen \\
\hline NTPs & Roche Diagnostics, Mannheim, Germany \\
\hline Nutrient broth & Carl Roth, Karlsruhe \\
\hline ONPG & Carl Roth, Karlsruhe \\
\hline
\end{tabular}


Appendix

\begin{tabular}{|c|c|}
\hline Paraformaldehyde & Carl Roth, Karlsruhe \\
\hline PIPES & Serva, Heidelberg \\
\hline RNase inhibitor & Roche Diagnostics, Mannheim, Germany \\
\hline Roti ${ }^{\oplus}$-Aqua-Phenol/C/I & Carl Roth, Karlsruhe \\
\hline Rotiphorese Gel 30 & Carl Roth, Karlsruhe \\
\hline Roti-Quant & Carl Roth, Karlsruhe \\
\hline SDS & Carl Roth, Karlsruhe \\
\hline Silver nitrate & Sigma-Aldrich, Taufkirchen \\
\hline Skim milk powder, fat-free & Carl Roth, Karlsruhe \\
\hline Sodium citrate & AppliChem, Darmstadt \\
\hline Sodium dodecyl sulfate & Serva, Heidelberg \\
\hline Strep-Tactin Sepharose & IBA, Göttingen \\
\hline TEMED & Carl Roth, Karlsruhe \\
\hline Thiamine & Sigma-Aldrich, Taufkirchen \\
\hline Tris free base & Carl Roth, Karlsruhe \\
\hline Tryptone & Oxoid, Heidelberg \\
\hline Tween 20 & Sigma-Aldrich, Taufkirchen \\
\hline U- ${ }^{13} \mathrm{C}_{5}$ Glutamate & Sigma-Aldrich, Taufkirchen \\
\hline X-Gal & Peqlab, Erlangen \\
\hline Xylene cyanol & Carl Roth, Karlsruhe \\
\hline Yeast extract & Oxoid, Heidelberg \\
\hline $\mathrm{ZnCl}_{2}$ & Carl Roth, Karlsruhe \\
\hline$\beta$-mercaptoethanol & Sigma-Aldrich, Taufkirchen \\
\hline
\end{tabular}

Other chemicals were purchased from Merck, Serva, Sigma-Aldrich, and Carl Roth.

Utilities

Utility

24-well plates

Centrifuge cups

Corning 384 well low volume

black round bottom polystyrene NB microplates

Cuvettes (microliter, plastic)
Manufacturer

TPP, Switzerland

Beckmann, München

Sigma-Aldrich, Taufkirchen

Greiner, Nürtingen 


\begin{tabular}{ll}
\hline Falcon tubes $(15 \mathrm{ml}, 50 \mathrm{ml})$ & Sarstedt, Nürmbrecht \\
\hline Gene Amp Reaction Tubes (PCR) & Perkin Elmer, Weiterstadt \\
\hline Glass pipettes & Brand, Wertheim \\
\hline Microlitre pipettes & Eppendorf, Hamburg and Gilson, Düsseldorf \\
$(2 \mu \mathrm{l}, 20 \mu \mathrm{l}, 200 \mu \mathrm{l}, 1000 \mu \mathrm{l}, 5000 \mu \mathrm{l})$ & \\
\hline Petri dishes & Greiner, Nürtingen \\
\hline Phase Lock Gel Heavy Tubes $(2 \mathrm{ml})$ & 5 'Prime, Hamburg \\
\hline Pipette tips & Sarstedt, Nürmbrecht \\
\hline Poly-Prep Chromatography Columns & Bio-Rad Laboratories GmbH, München \\
\hline Polyvinylidene fluoride membrane (PVDF) & Bio-Rad Laboratories GmbH, München \\
\hline PVDF membrane & Roche Diagnostics, Mannheim, Germany \\
\hline Reaction tubes & Greiner, Nürtingen \\
\hline Single-use syringes $(5 \mathrm{ml}, 10 \mathrm{ml})$ & Becton Dickinson Drogheda, Ireland \\
\hline
\end{tabular}

Other utilities were purchased from Bio-Rad, Roche, and VWR.

Equipment

\begin{tabular}{ll} 
Equipment & Manufacturer \\
\hline ÄKTA ${ }^{\text {TM }}$ Pure chromatography workstation & GE, Frankfurt a. M. \\
\hline ANX ion exchange column & GE, Frankfurt a. M. \\
\hline Autoclave & Zirbus technology, Bad Grund \\
\hline Biofuge fresco & Heraeus Christ, Osterode \\
\hline Blotting device VacuGeneTMXI & Amersham, Freiburg \\
\hline ChemoCam Imager & Intas, Göttingen \\
\hline ChemoCam imager & Intas, Göttingen \\
\hline Corning 384 well low volume & GE, Frankfurt a. M. \\
black round bottom polystyrene NB microplates & \\
\hline DAWN HELEOS II MALS detector & Wyatt Technology, Haverhill, UK \\
\hline Electronic scale Sartorius universal & Sartorius, Göttingen \\
\hline Fiberlite F9 / F40 rotors & Thermo Fisher, Bonn \\
\hline Fluorescence microscope Axioskop 40 FL + & Carl Zeiss, Göttingen \\
camera AxioCam MRm & \\
\hline French pressure cell press & G. Heinemann, Schwäbisch Gmünd
\end{tabular}




\begin{tabular}{|c|c|}
\hline Gel electrophoresis apparatus & PeqLab, Erlangen \\
\hline Gel electrophoresis device & Waasetec, Göttingen \\
\hline Heating block Dri Block DB3 & Waasetec, Göttingen \\
\hline Heraeus Pico 21 & Thermo Fisher, Bonn \\
\hline High accuracy scale & Sartorius, Göttingen \\
\hline HiLoad $^{\text {тм} 16 / 600 ~ S u p e r d e x ~} 200$ pg & GE, Frankfurt a. M. \\
\hline Horizontal shaker & GFL, Burgwedel \\
\hline Hydro tech vacuum pump & Bio-Rad, Munich \\
\hline Ice machine & Ziegra, Isernhagen \\
\hline Incubator Innova R44 & New Brunswick, Neu-Isenburg, \\
\hline Incubator shaker Innova 2300 & New Brunswick, Neu-Isenburg \\
\hline LabCycler SensorQuest, Göttingen & LabCycler SensorQuest, Göttingen \\
\hline Magnetic stirrer & JAK Werk, Staufen \\
\hline Mikro-Dismembrator S & Sartorius, Göttingen \\
\hline Mikroprozessor pH-Meter 766 Calimatic & Knick, Berlin \\
\hline Mini-Protean III System & Bio-Rad, Munich \\
\hline Nanodrop ND-1000 & Thermo Fisher, Bonn \\
\hline One Shot Cell Disruptor & Constant Systems Limited, UK \\
\hline Open air shaker Innova 2300 & New Brunswick, Neu-Isenburg \\
\hline Optilab T-rEX differential refractometer & Wyatt Technology, Haverhill, UK \\
\hline $\mathrm{pH}$ meter & Knick, Berlin \\
\hline PHERAstar FS plate reader & Thermo Fisher, Bonn \\
\hline Poly-Prep Chromatography columns & Bio-Rad Laboratories GmbH, München \\
\hline Refrigarated centrifuge PrimoR & Heraeus Christ, Osterode \\
\hline Scale Sartorius universal & Sartorius, Göttingen \\
\hline SDS-PAGE glas plates & Bio-Rad \\
\hline Special accuracy weighing machine & Sartorius, Göttingen \\
\hline Spectral photometer Ultraspec 2000 & Amersham, Freiburg \\
\hline Standard power pack & Bio-Rad Laboratories GmbH, München \\
\hline Steam autoclave & Zirbus, Bad Grund \\
\hline Stereo Lumar V12 stereo microscope & Carl Zeiss, Göttingen \\
\hline Sterile bench Hera Safe & Thermo Fisher, Bonn \\
\hline
\end{tabular}




\begin{tabular}{ll}
\hline StrepTrap HP column & GE, Frankfurt a. M. \\
\hline Thermocycler & Biometra, Göttingen \\
\hline TLA 110 rotor & Beckmann Coulter, Krefeld \\
\hline TS Sorvall WX utraseries centrifuge / RC 6+ & Beckmann Coulter, Krefeld \\
\hline Ultra centrifuge, Sorvall Ultra Pro 80 & Thermo Fisher, Bonn \\
\hline Ultrasonic device & Dr. Hielscher, Teltow \\
\hline UV Transilluminator 2000 & Bio-Rad Laboratories GmbH, München \\
\hline VivaSpin Turbo 15 concentrator & Sartorius, Göttingen \\
\hline Vortex & Bender and Hobein, Bruchsal \\
\hline Water desalination plant & Millipore, Schwalbach \\
\hline
\end{tabular}

Other equipment was purchased from Bio-Rad, Roche, and VWR.

\section{Commercial systems}

Commercial systems

Gene Ruler DNA ladder mix

Nucleospin Plasmid kit

QIAquick PCR-Purification kit

DNeasy Blood and Tissue Kit (250)

RNeasy Plus Mini Kit (50)

Unstained Protein Marker

Prestained Protein Marker

\section{Manufacturer}

Thermo Fisher, Bonn

Macherey-Nagel, Düren

Qiagen, Hilden

Qiagen, Hilden

Qiagen, Hilden

Thermo Fisher, Bonn

Thermo Fisher, Bonn

Other commercial systems were purchased from Qiagen and Thermo Fisher.

Antibodies and enzymes

Antibodies and enzymes

Secondary antibody anti-rabbit IgG-AP coupled

RNase A

DNase I

Lysozyme from chicken egg white

PhusionTM DNA polymerase

Restriction endonucleases

FastAP alkaline phosphatase

\section{Manufacturer}

Promega, Mannheim

Roche Diagnostics, Mannheim

Thermo Fisher, Bonn

Carl Roth, Karlsruhe

Finnzymes, Espoo Finland

Thermo Fisher, Bonn

Thermo Fisher, Bonn 
Appendix

\begin{tabular}{ll}
\hline T4 DNA ligase & Thermo Fisher, Bonn \\
\hline DreamTaq DNA polymerase & Thermo Fisher, Bonn
\end{tabular}

Other antibodies or enzymes were purchased from Thermo Fisher, Finnzymes, and Roche

Software and webpages

Software or Webpage

Manufacturer

\begin{tabular}{ll}
\hline ASTRA 6 software & Wyatt Technology \\
\hline Axio Vision Software Rel. & Carl Zeiss \\
\hline Citavi & Swiss Academic Software \\
\hline ClustalW & Larkin et al., 2007 \\
\hline Geneious & Biomatters \\
\hline http://subtiwiki.uni-goettingen.de/ & Zhu and Stülke, 2018 \\
\hline http://www.ncbi.nlm.nih.gov/ & National Institutes of Health, Bethesda, USA \\
\hline ImageJ & Schindelin et al.,2015 \\
\hline MicrobeJ & Ducret et al., 2016. \\
\hline Microsoft Office & Microsoft \\
\hline RNAstructure & Mathews Lab \\
\hline Zen & Carl Zeiss, Göttingen \\
\hline
\end{tabular}




\subsection{Curriculum vitae}

Personal information

Jan Kampf

Date of birth

27.11.1987, Lübbecke

Contact jan.kampf@web.de

Nationality

German

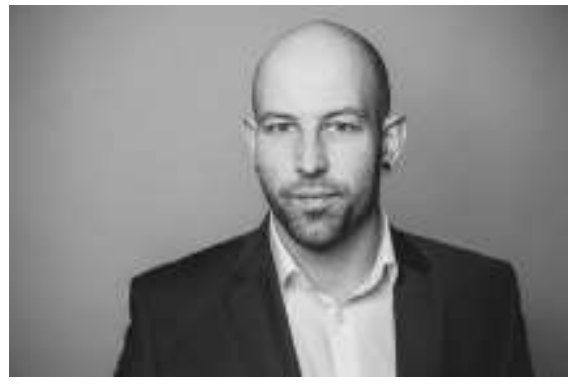

Education

\section{1/2014 - 04/2018}

PhD student at the GGNB program Microbiology and Biochemistry, Göttingen

Project: "Insights into the biofilm formation of B. subtilis" at the Dept. for General Microbiology in the group of Prof. Jörg Stülke

$10 / 2011-03 / 2014$

MSc in Microbiology and Biochemistry, Göttingen

Project: "Insights into cyclic-di-AMP transporters and potential physical interaction partners of the signal nucleotide" at the Dept. for General Microbiology in the group of Prof. Jörg Stülke

$10 / 2008-09 / 2011$

BSc Molecular Biology, Göttingen

Project: "Insights into mammalian Sirt6 function on cellular response" at the Max-Planck Institute for biophysical chemistry Dept. for Genes and Behavior in the group of Prof. Gregor Eichele 
